Guilherme de Queiroz Freire

Madeiras fósseis holocênicas de Ribeirão da Mata: anatomia ecológica, relações florísticas e interpretação paleoambiental da região arqueológica de Lagoa Santa, MG.

Holocene fossil woods from Ribeirão da Mata: ecological wood anatomy, floristic relationships and paleoenvironmental interpretation of the archaeological region of Lagoa Santa, MG, Brazil.

São Paulo 

Guilherme de Queiroz Freire

\section{Madeiras fósseis holocênicas de Ribeirão da Mata: anatomia ecológica, relações florísticas e interpretação paleoambiental da região arqueológica de Lagoa Santa, MG.}

\section{Holocene fossil woods from Ribeirão da Mata: ecological wood anatomy, floristic relationships and paleoenvironmental interpretation of the archaeological region of Lagoa Santa, MG, Brazil.}

Tese apresentada ao Instituto de Biociências da Universidade de São Paulo, para a obtenção de Título de Doutor em Ciências Biológicas, na Área de Botânica.

Orientador Prof. Dr.:

Gregório C. T. Ceccantini

EXEMPLAR CORRIGIDO

(exemplar original depositado na biblioteca do Instituto de Biociências - USP)

São Paulo 



\section{Freire, Guilherme Q.}

Madeiras fósseis holocênicas de Ribeirão da Mata: anatomia ecológica, relações florísticas e interpretação paleoambiental da região arqueológica de Lagoa Santa, MG.

\section{8 páginas}

Tese (Doutorado) - Instituto de Biociências da Universidade de São Paulo. Departamento de botânica

1. madeira fóssil; 2. Lagoa Santa; 3. Anatomia da madeira; 4. Florística; 5. Holoceno.

I. Universidade de São Paulo. Instituto de Biociências. Departamento de Botânica.

\section{Comissão Julgadora:}

Prof. Dr. Ary Teixeira de Oliveira Filho

Prof. Dr. Astolfo Gomes de Mello Araújo

Profa. Dra. Fresia Soledad Ricardi Torres Branco

Profa. Dra. Verônica Angyalossy

Prof. Dr. Gregório C. T. Ceccantini 

DEDICATÓRIA

Aos meus pais e avós 



\section{AGRADECIMENTOS}

Aos lenhos fósseis e ao professor Gregório Ceccantini, por me forçarem o controle da ansiedade para seguir em frente em momentos difíceis.

À minha família, pela simples presença, apoio incondicional às minhas escolhas, e por me resguardar afetiva e financeiramente até que pudesse traçar meus caminhos e segui-los por conta própria.

À minha avó, pelo entusiasmo indestrutível pela minha pesquisa e meu projeto de vida.

À minha irmã Eliza, ao André Miguel, Guilherme de Lucca, Alexandre Mello e Renato Nadal pela paciência, apoio e ajuda nos meses pré-depósito.

Ao Prof. Dr. Gregório Ceccantini, pela orientação, incentivo, amizade e ensinamentos, que tiveram grande influência em minha vida profissional e pessoal.

À Profa. Dra. Verônica Angyalossy, por suas arguições sempre muito construtivas em todas as etapas da minha pós-graduação, e à Profa. Dra. Nanuza de Menezes, pela alegria com que leva a vida e a botânica.

Ao estimado Antônio Carlos F. Barbosa, pela sua ajuda sempre certa no difícil trato com as madeiras fósseis.

Ao prof. Dr. Walter A. Neves por acreditar e apoiar a participação da Botânica na Arqueologia no âmbito do projeto "Origens e Microevolução do homem na América III".

À Celina Nakamura, João C. Melo, Marco Racka e Paulo de Oliveira, pelo interesse comum e trabalho conjunto dentro da paleobotânica de Lagoa Santa.

Ao Geraldo Zenid, Maria José Miranda, Raphael Pigozzo e toda a equipe do Laboratório de Madeira e Produtos Derivados do IPT, pela disponibilização do acervo histológico da xiloteca BCTw e auxílio no processo de identificação dos fósseis.

À Gisele Costa e Tássia dos Santos pelo auxílio no uso das metodologias histológicas e por acompanhar todas as fases do projeto.

Aos amigos que me auxiliaram nas expedições paleontológicas, botânicas e no processamento de materiais: Alan Roque, André Lima, Bruno Balboni, Bianca Brasil, Deusa Abreu, Fernando Andreacci, Giuliano Locosselli, Giovane Siqueira, Gustavo Burin, Luiz Horta, Marilluce Weiers, Magda Bartz, Marcelo Ragazzo, Natalie Britto 
Domingos, Pedro Poli, Ricardo Cardim, Rodrigo D'Angeles, Tiago Mafra, Viviane Jono.

Ao Dr. Ricardo J. F. Garcia e Ms. Matheus F. Santos pela grande parceria no levantamento da flora de Lagoa Santa e à todos os especialistas e profissionais da taxonomia vegetal, pela pronta atenção e auxílio imprescindível nas identificações botânicas: A. Indrinnas, A. Sartori, A.S.F. Vaz, B. Loeuille, B. Wallnöfer, C. Kameyama, C.L. Silva, D.C. Zappi, E.G.A. Martins, E.K.O. Hattori, F. França, F.M. Alves, G. Shimizu, G.A.D.C. Franco, I. Cordeiro, J.A. Pastore, J.A. Lombardi, J.C.F. Melo Jr., J.R. Pirani, J.R. Stehmann, L. Monguilhott, L.C.S. Assis, L.G. Lohmann, L.M. Borges, L.P. de Queiroz, M.C. Duarte, M.C.H. Mamede, M.F. Freitas, P. Fiaschi, P. Guimarães, R. Goldenberg, R. Marquete, R. Mello-Silva, R. Riina, R. Simão-Bianchini, R.F. Almeida, R.M. Harley, R.S. Bianchini, R.S. Pando, S. Honda, S. Vieira, T.B. Cavalcanti.

Aos proprietários ou responsáveis Lydia Brasileira de Britto, José Martins de Freitas, José Hein, Guilherme de Andrade, Dr. João Maria Franco de Camargo, Tonhão Aníbal, Ozanir Camilo da Silveira e Joaquim Alves de Rezende e à Reserva Vale, pela visão científica e autorização para coleta em suas propriedades.

Ao INMET pela disponibilização de dados climáticos.

À CNPq pela bolsa de doutorado e à FAPESP pelo financiamento de atividades de campo e materiais permanentes.

Por fim, à todos que contribuíram para que fosse possível o projeto, o desenvolvimento e o fechamento deste trabalho, 


\section{ÍNDICE}

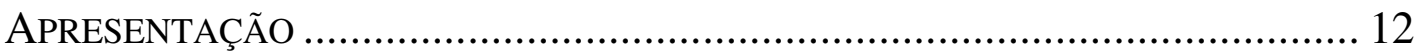

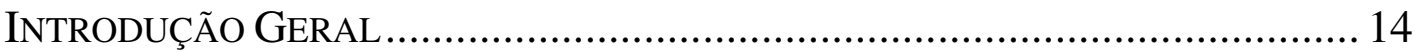

Referências Bibliográficas.................................................................................. 17

CAPÍTULO 1 - FLORÍSTICA E FITOSSOCIOLOGIA PARA INTERPRETAÇÃO PALEOBOtÂNICA DA REGião ARQUEOLÓGICA dE LAGOA SANTA, MG ......... 20

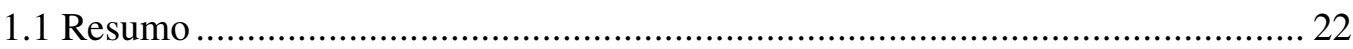

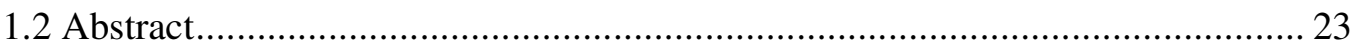

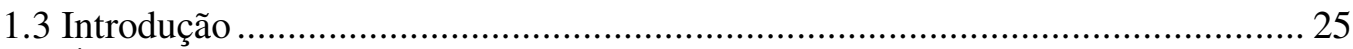

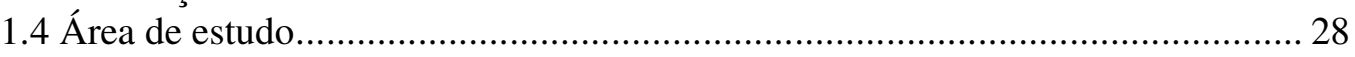

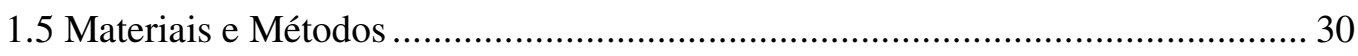

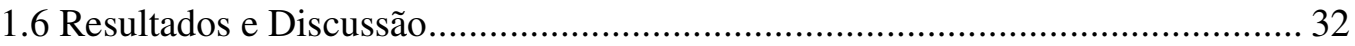

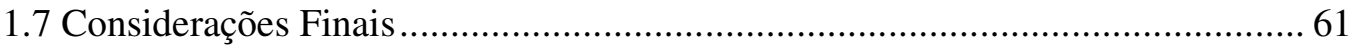

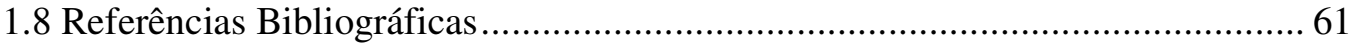

\section{CAPÍTULO 2 - COLEÇÃO DE REFERÊNCIA: MADEIRAS DA APA-CARSTE DE} LAGOA SANTA, DESCRIÇÃO ANATÔMICA E ICONOGRAFIA.............................. 68

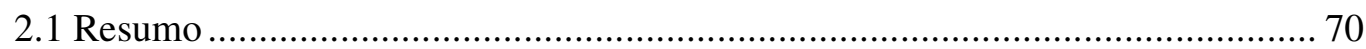

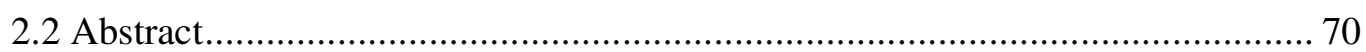

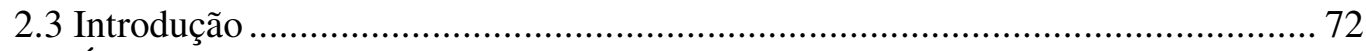

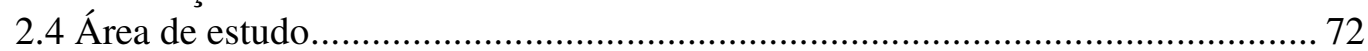

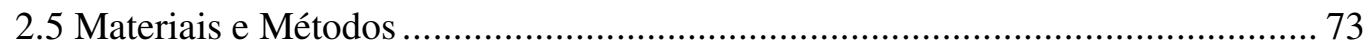

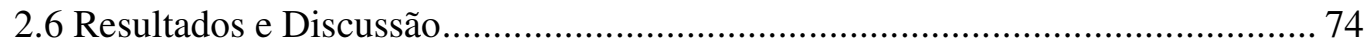

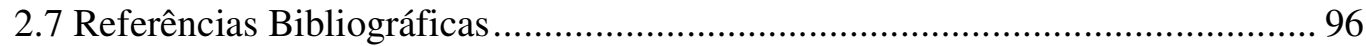

\section{Capítulo 3 - CARACTERIZAÇão da VegetaÇÃo de Lagoa SANTA, MG,} NOS ÚLTIMOS 5000 ANOS POR MEIO DA IDENTIFICAÇÃO TAXONÔMICA DE

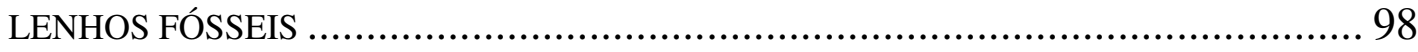

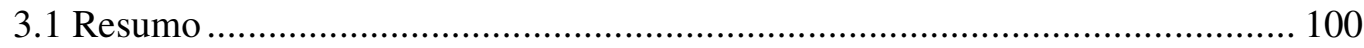

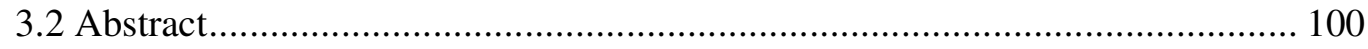

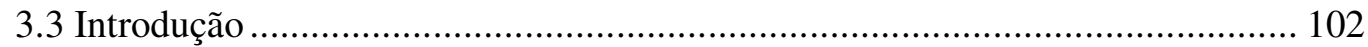

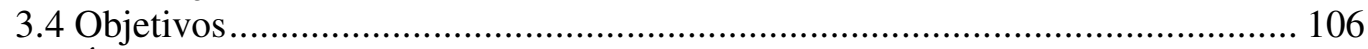

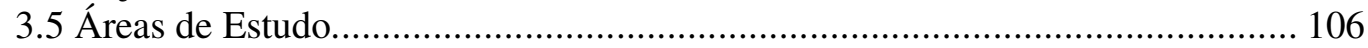

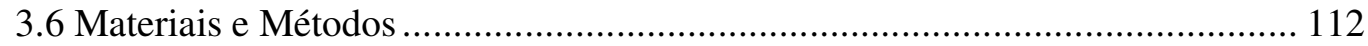

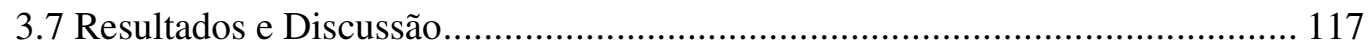

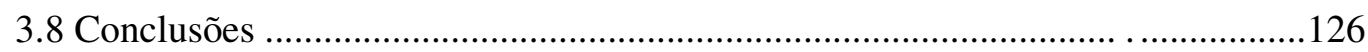

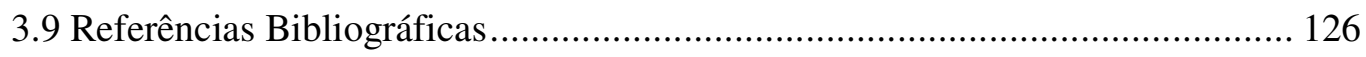


CAPÍtUlo 4 - ANATOMIA ECOLÓGICA MYROXYLON PERUIFERUM L. F. APLICADA A INTERPRETAÇÃO PALEOAMBIENTAL ....................................... 132

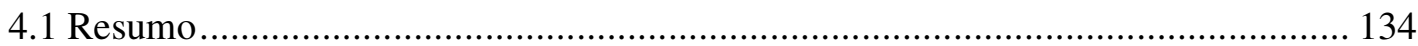

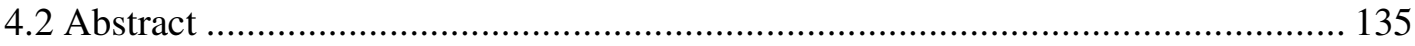

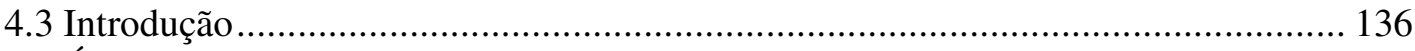

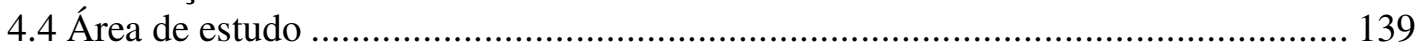

4.5 Materiais e Métodos ....................................................................................... 144

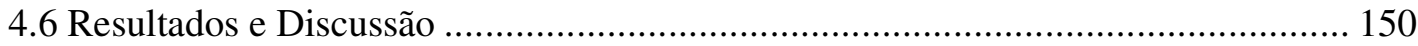

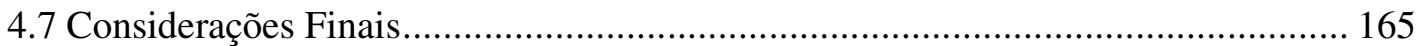

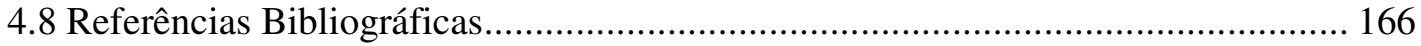

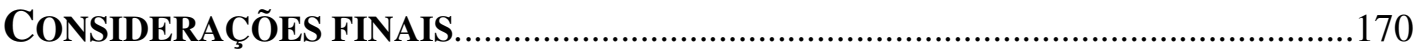

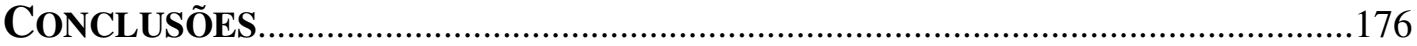

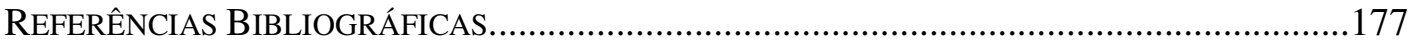

AneXo A - ParÂMETRos FitosSOCIOLÓGICOS UtILIZAdOS ........................ 178

ANEXo B - PROTOCOLO DE MENSURAÇÕES DAS CARACTERÍSTICAS ANATÔMICAS DE M. PERUIFERUM L.F. UTILIZADAS NO CAPÍTULO 4 .............. 182

APÊNDICE 1 - Lista de ESPÉCIES lenhosas da APA - CARSTE DE LagOA

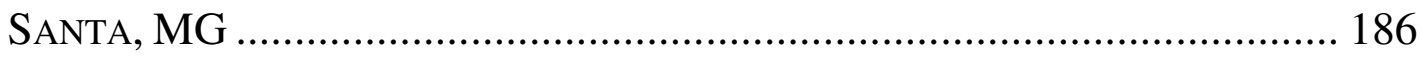

APÊNDICE 2 - DESCRIÇÃO MICROSCÓPICA DA ANATOMIA DOS MORFOTIPOS

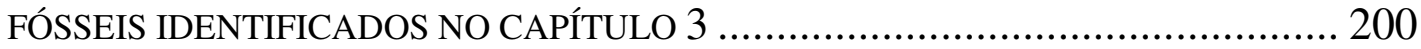

APÊNDICE 3 - ICONOGRAFIA DOS MORFOTIPOS FÓSSEIS IDENTIFICADOS NO

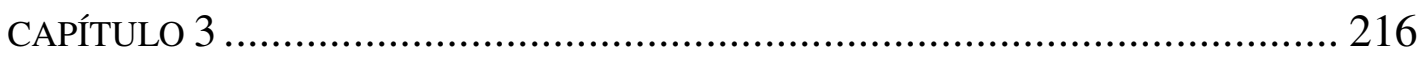

\section{APÊNDICE 4 - CD ROM}

Iconografia das madeiras atuais de Lagoa Santa (Capítulo 2)

Matriz binária para análise de agrupamento (Capítulo 3) 


\section{APRESENTAÇÃO}

Esta tese é apresentada em quatro capítulos. Os dois primeiros contemplam estudos de base, sobre a composição florística e a anatomia das espécies lenhosas que atualmente ocorrem na região de Lagoa Santa (MG), de forma a fundamentar interpretações e discussões paleoclimática realizadas nos capítulos seguintes, que utilizam duas abordagens diferentes na análise de lenhos fósseis.

O capítulo 1 apresenta um levantamento florístico-lenhoso e fitossociológico para diferentes fisionomias vegetais da Área de Proteção Ambiental Carste de Lagoa Santa, caracterizando a vegetação atual da região e permitindo a comparação florística entre a assembleia fóssil, identificada no Capítulo 3, e a vegetação recente. Já o capítulo 2 apresenta uma coleção de referência de lenhos de Lagoa Santa, que auxiliou na identificação taxonômica dos lenhos fósseis escavados e trabalhados também no capítulo 3. Por fim, o Capítulo 4, em outra abordagem de interpretação paleoclimática, aproxima a área da Anatomia Ecológica da Madeira do campo da Paleobotânica. Nele, por meio de correlações encontradas entre variáveis climáticas e anatômicas de indivíduos atuais de Myroxylon peruiferum L.f. (Leguminosae), a anatomia de fósseis da espécie bem identificados no Capítulo 3, é utilizada para interpretar o paleoclima holocênico da região de Lagoa Santa.

Com este formato, pretende-se publicar os resultados dos capítulos 1, 3 e 4 em revistas científicas da área, enquanto que, para o capítulo 2, pretende-se continuar com processamento de todas as espécies coletadas para produzir uma obra com descrição e iconografia de todas as espécies amostradas na APA - Carste de Lagoa Santa 
APRESENTAÇÃO 


\section{INTRODUÇÃO GERAL}

O presente trabalho foi concebido para se integrar ao eixo $\mathrm{n}^{\circ} 5$ ("Paleoclimas e Paleoambientes no final do Pleistoceno e Holoceno na região de Lagoa Santa") da terceira versão do projeto temático "Origens e Microevolução do Homem na América: uma abordagem paleoantropológica III" (FAPESP proc. 04/01321-6), coordenado pelo Dr. Walter Alves Neves no Laboratório de Estudos Evolutivos Humanos. Tal projeto teve como objetivo abordar diretamente as principais problemáticas científicas no campo da arqueologia de Lagoa Santa.

Em seu eixo $\mathrm{n}^{\circ} 5$, o projeto procurou entender a dinâmica vegetacional, faunal e climática da região de Lagoa Santa desde o limite Pleistoceno/Holoceno até os dias atuais, estruturando dissertações e teses que utilizaram diversos indicadores independentes para contextualizar o paleoambiente local. Nesse eixo, a principal questão abordada é a existência de dois picos temporais de esqueletos pré-históricos enterrados na região de Lagoa Santa, MG, separados por um grande período (de 8.000 a 2.000 anos A.P. ${ }^{1}$ ) de drástica redução de sepultamentos e vestígios arqueológicos tanto desta região quanto na região central brasileira delimitada por Araújo et al. (2005), que denominaram este evento de "Hiato do Arcaico".

No início deste período, ocorre também o desaparecimento dos paleoíndios, o primeiro grupo de caçadores coletores que ocupou a América do Sul de, ao menos, 12000 a 7500 anos A.P. Estes primeiros habitantes, segundo Neves, et al. (1999), constituíam uma linhagem genética "negróide" diferente da dos grupos arcaicos que o procederam, de feições “mongolóides”, ou ameríndias.

Estes primeiros povos de Lagoa Santa conviveram com uma megafauna na região (extinta a aproximadamente 9000 anos A.P.), composta por tigres dente-de-sabre, preguiças e tatus gigantes, mastodontes, toxodontes e cavalos (Hubbe, 2008; Neves \& Pilo, 2008). Porém, a falta de indícios de que os paleoíndios se alimentassem destes animais inclina os arqueólogos a propor a exclusão desses na sua dieta. Ao contrário, há evidências de que a principal fonte alimentar desses grupos provinha de coletas vegetais, como araticum (Annona crassiflora Mart.), o pequi (Caryocar brasiliense Cambess.), o licuri (Syagrus coronata Mart. Becc.), o jatobá (Hymenaea sp), a cagaita

\footnotetext{
${ }^{1}$ Antes do presente
} 
(Eugenia dysenterica DC.), guabiroba (Campomanesia $s p$ ) e o araçá (Psidium sp) (Neves \& Pilo, 2008; Prous \& Rodet, 2009). As caças como a anta, os veados, a capivara, a paca, a cotia, o tamanduá, o macaco guariba entre outros, complementavam a dieta proporcionada pelo mosaico vegetacional composto de cerrado, floresta semidecídua e matas secas.

Ampliando para a Região Nordeste brasileira, Prous (2006; 2009) comenta não haver dúvida de que "mudanças importantes aconteceram (...) pois não somente os rituais [dos sepultamentos] mudam (...) mas também as tecnologias. (...) Os arqueólogos debatem para saber se estas transformações seriam adaptativas, tendo a ver com fenômenos climáticos e ambientais, se resultariam de mudanças populacionais (por exemplo, a chegada de imigrantes portadores de inovações) ou se corresponderiam a fenômenos locais de ordem estritamente cultural."

Na região de Lagoa Santa, talvez o único sítio com potencial de trazer luz ao conhecimento do que aconteceu com os povos durante o período arcaico seja o sítio arqueológico Caixa d’Água, localizado em 1987 no centro na cidade mineira de Buritizeiro e deixado intacto até o início das campanhas de escavação em 2005. Nesse sítio foi localizado um cemitério, datado entre 6100 e 5000 anos A.P., e que ainda possui poucos trabalhos publicados. Segundo Prous (2009), um grande uso de artefatos de osso e pedra e grande importância de vegetais na dieta foi detectado, mas não definem estes habitantes como paleoíndios ou ameríndios, muito menos se fazem parte de uma possível "transição" biológica entre eles.

Nesse período, as pesquisas palinológicas no Brasil central, embora existam em número razoável, possuem interpretações paleoambientais contraditórias. Bem caracterizado no Hemisfério Norte, ao redor de 6000 anos A.P., o evento climático conhecido como "Ótimo Climático", período predominantemente mais quente e úmido, se estabeleceu devido a uma maior insolação terrestre, propiciando a expansão de coberturas vegetais de maior porte e umidade em diversos pontos do globo (Wanner et al., 2008). Sustentando esta hipótese no Brasil, Ledru et al. (1998), revisando a literatura palinológica do Brasil central, classifica o período de 7000 a 4000 anos A.P. com uma tendência de aumento de umidade em muitas localidades. $\mathrm{O}$ desenvolvimento de veredas com o aparecimento de Mauritia sp, (Barberi et al., 2000) e a redução de partículas carbonizadas (Salgado-Labouriau et al., 1998) são algumas das características apontadas pelos autores nas localidades hoje ocupadas pelo Cerrado. 
Por outro lado, embora não existam dúvidas de que o nível do mar esteve acima do atual na costa brasileira (Angulo \& Suguio, 1995), é consenso que alterações climáticas do ótimo Climático no HS foram mais amenas e aparentemente mais complexas (Wanner et al., 2008).

Amparados por este raciocínio, para diversas localidades no Hemisfério sul, e particularmente na América do Sul tropical e equatorial, estudos sugerem eventos de seca no período aproximado de 6000 a 4500 anos A.P.. Mesmo Ledru et al. (1998) chama a atenção para um rápido período seco observado em Salitre, MG, no intervalo de 5500 a 4500 anos A.P. (Ledru, 1993). Em região próxima, Behling (1995a; 2003) sugere um período mais seco de 7500 a 5530 anos A.P. e de 7.500 a 6060 anos A.P., e Parizzi (1998), estudando a dinâmica da lagoa Santa, sugere que a lagoa atual deu espaço a um alagadiço intermitente entre 5400 e 4600 anos A.P. Muitos outros trabalhos que corroboram com a hipótese de um Holoceno médio mais seco que atualmente, mostraram que a aridez do Holoceno inicial só acabou a partir dos 4000-3000 anos A.P., ou que houveram rápidos eventos de seca no Holoceno médio. Existem evidências em vários locais do Brasil: em Carajás, PA, e Lago do Caçó, MA (Absy et al., 1991; Sifeddine et al., 1994; Sifeddine et al., 2003); rio São Francisco, BA (De Oliveira et al., 1999); Serra de Salitre, MG (Ledru, 1993); Lagoa Nova, MG (Behling, 2003); Lagoa Santa, MG (Parizzi et al., 1998); Lago do Pires, MG e 3 localidades em SC (Behling, 1995a, b); Serra dos Campos Gerais, PR (Behling, 1997); região metropolitana de São Paulo (Melo et al., 1987).

Tendo em vista esse cenário, o projeto temático concebeu duas hipóteses climáticas para elucidar a questão do "Hiato do Arcaico" (transcritas sem alterações do (proc. FAPESP nº 04/01321-6):

1.“O Pleistoceno Tardio ${ }^{2}$, em Lagoa Santa, foi marcado por um clima mais seco que o atual, tornando a área pouco atrativa para o assentamento humano. O início do Holoceno, por sua vez, foi marcado por um clima mais úmido que o atual. Esse clima teria favorecido a ocupação humana na região, particularmente em função da disponibilidade hídrica nas lagoas cársticas (como nessa região as drenagens são quase todas subterrâneas, as únicas fontes de água superficiais se localizam nas lagoas).

\footnotetext{
${ }^{2}$ Período anterior a 12.000 anos A.P.
} 
No Holoceno Médio um clima mais seco prevaleceu, o que teria ocasionado o deslocamento dos grupos caçadores-coletores para outras áreas. A ausência de sedimentos e esqueletos humanos nos sítios arqueológicos ("Hiato do Arcaico") seria uma resposta a essas condições menos favoráveis ao uso dos abrigos-sob-rocha. No Holoceno Tardio, o aumento da umidade voltaria a proporcionar boas condições para a ocupação humana, como registrado nos abrigos e nos sítios a céu aberto da região, atraindo grupos ceramistas da Tradição Aratu-Sapucaí."

2.“O Pleistoceno Tardio e o Holoceno Inicial, na região de Lagoa Santa, foram marcados por climas mais secos e frios, que teriam sido substituídos paulatinamente por maior umidade, com um pico de umidade ocorrido por volta de 6.000 a 5.000 AP (“Ótimo Climático”), modificandose gradativamente em direção às condições modernas. Nesta hipótese, o "Hiato do Arcaico" seria apenas o produto de uma amostragem tendenciosa, que não privilegiou fácies sedimentares (antropogênicas) intermediárias, mas somente as mais antigas, as mais recentes e aquelas contendo remanescentes ósseos humanos"

Considerando essas hipóteses, a presente tese utiliza a anatomia de lenhos fósseis datados do Holoceno médio (ca. 5000 anos A.P.) e tardio (ca. 2000 anos A.P.), como fonte independente de informações paleoambientais, com a perspectiva de integrar resultados recentes advindos de pesquisas com outros indicadores botânicos (palinomorfos e folhas) para, enfim, elucidar as condições climáticas holocênicas da região Arqueológica de Lagoa Santa, MG.

\section{REFERÊNCIAS BIBLIOGRÁFICAS}

ABSY, M. L. et al. 1991. Occurrence of 4 Episodes of Rain-Forest Regression in Southeastern Amazonia during the Last 60,000 Yrs - 1st Comparison with Other Tropical Regions. Comptes Rendus De L Academie Des Sciences Serie II, v.312, n.6, Mar 14, p.673-678.

ANGULO, R. J. \& K. SUGUIO. 1995. Reevaluation of the Holocene Sea-Level Maxima for the State of Parana, Brazil. Palaeogeography Palaeoclimatology Palaeoecology, v.113, n.2-4, p.385-393.

ARAUJO, A. G. M. et al. 2005. Holocene dryness and human occupation in Brazil during the "Archaic Gap". Quaternary Research, v.64, n.3, Nov, p.298-307. 
BARBERI, M.;M. L. SALGADO-LABOURIAU \& K. SUGUIO. 2000. Paleovegetation and paleoclimate of "Vereda de Aguas Emendadas", central Brazil. Journal of South American Earth Sciences, v.13, n.3, Jul, p.241-254.

BEHLING, H. 1995a. A High-Resolution Holocene Pollen Record from Lago Do Pires, Se Brazil - Vegetation, Climate and Fire History. Journal of Paleolimnology, v.14, n.3, Nov, p.253-268.

BEHLING, H. 1995b. Investigations into the Late Pleistocene and Holocene History of Vegetation and Climate in Santa-Catarina (S Brazil). Vegetation History and Archaeobotany, v.4, n.3, Sep, p.127-152.

BEHLING, H. 1997. Late Quaternary vegetation, climate and fire history of the Araucaria forest and campos region from Serra Campos Gerais, Parana State (South Brazil). Review of Palaeobotany and Palynology, v.97, n.1-2, Jul, p.109-121.

BEHLING, H. 2003. Late glacial and Holocene vegetation, climate and fire history inferred from Lagoa Nova in the southeastern Brazilian lowland. Vegetation History and Archaeobotany, v.12, n.4, Dec, p.263-270.

DE OLIVEIRA, P. E.;A. M. F. BARRETO \& K. SUGUIO. 1999. Late Pleistocene/Holocene climatic and vegetational history of the Brazilian caatinga: the fossil dunes of the middle Sao Francisco River. Palaeogeography Palaeoclimatology Palaeoecology, v.152, n.3-4, Sep 1, p.319-337.

HUBBE, A. 2008. Contextualização taxonômica, tafonômica e morfométrica dos remanescentes ósseos da megamastofauna da gruta Couvieri (MG), um sítio paleontológico do pleistoceno tardio. Dissertação de Mestrado. Depto. Genética e Biologia Evolutiva, Universidade de São Paulo, São Paulo, 141 p.

LEDRU, M. P. 1993. Late Quaternary Environmental and Climatic Changes in Central Brazil. Quaternary Research, v.39, n.1, Jan, p.90-98.

LEDRU, M. P.;M. L. SALGADO-LABOURIAU \& M. L. LORSCHEITTER. 1998. Vegetation dynamics in southern and central Brazil during the last 10,000 yr BP. Review of Palaeobotany and Palynology, v.99, n.2, Jan, p.131-142.

MELO, M. S. et al. 1987. Datações 14C em sedimentos da Grande São Paulo. Anais do $1^{\circ}$ Congresso da Associação Brasileira de Estudos do Quaternário. Porto Alegre: ABEQUA

NEVES, W. A. \& L. B. PILO. 2008. O povo de Luzia: em busca dos primeiros americanos. São Paulo: Globo. 334 p.

NEVES, W. A. et al. 1999. Lapa Vermelha IV Hominid 1: Morphological affinities of the earliest known American. Genetics and Molecular Biology, v.22, n.4, Dec, p.461-469.

PARIZZI, M. G.;M. L. SALGADO-LABOURIAU \& H. C. KOHLER. 1998. Genesis and environmental history of Lagoa Santa, southeastern Brazil. Holocene, v.8, n.3, May, p.311-321.

PROUS, A. 2006. O Brasil antes dos brasileiros : a pré-história do nosso país. Rio de Janeiro: Zahar

PROUS, A. \& M. J. RODET. 2009. Os vivos e seus mortos no Brasil tropical e subtropical pré-histórico (11.000/500 BP). In: W. F. MORALES e P. O. MOI (Ed.). Cenários Regionais em Arqueologia Brasileira. Porto Seguro: Annablume 
SALGADO-LABOURIAU, M. L. et al. 1998. A dry climatic event during the late Quaternary of tropical Brazil. Review of Palaeobotany and Palynology, v.99, n.2, Jan, p.115-129.

SIFEDDINE, A. et al. 1994. Lacustrine Sedimentation Indicator of Paleoenvironments Changes during the Last $30 \mathrm{Ka} \mathrm{Bp}$ (Carajas, Amazonia, Brazil). Comptes Rendus De L Academie Des Sciences Serie Ii, v.318, n.12, Jun 16, p.1645-1652.

SIFEDDINE, A. et al. 2003. A 21000 cal years paleoclimatic record from Caco Lake, northern Brazil: evidence from sedimentary and pollen analyses. Palaeogeography Palaeoclimatology Palaeoecology, v.189, n.1-2, Jan 1, p.25-34.

WANNER, H. et al. 2008. Mid- to Late Holocene climate change: an overview. Quaternary Science Reviews, v.27, n.19-20, Oct, p.1791-1828. 


\section{CAPÍTULO 1}

FLORÍSTICA E FITOSSOCIOLOGIA PARA INTERPRETAÇÃO PALEOBOTÂNICA DA REGIÃO ARQUEOLÓGICA DE LAGOA SANTA, MG 



\subsection{RESUMO}

Os estudos botânicos da região arqueológica de Lagoa Santa, MG, tiveram início em meados de 1860, com a chegada do dinamarquês Eugenius Warming. Durante três anos, ele descreveu 2593 espécies vegetais e seus ecossistemas, tornando a área conhecida como berço da Ecologia Vegetal brasileira. Desde então, a região passou por grandes transformações, principalmente relativas à mudança da capital do estado para Belo Horizonte e sua expansão metropolitana, que atualmente alcança a região. Levando em conta estas transformações, a falta de uma lista florística atual e a importância de estudos florísticos e ecológicos para subsidiar interpretações paleoambientais desta região, o presente trabalho objetivou: 1. listar as espécies lenhosas presentes, hoje, na APA - Carste de Lagoa Santa; 2. conhecer as espécies indicadoras das diferentes fitofisionomias da região e; 3. discutir as diferenças florísticas verificadas entre a florística atual e a publicada por Warming. A lista florística obtida relaciona 347 espécies lenhosas para a região, número expressivamente menor que a listagem de Warming, que listou 854. Nas fisionomias de cerrado, Xylopia aromatica (Lam.) Mart., Qualea parviflora Mart. e Miconia albicans (Sw) figuram entre as mais representativas. Nas transições de floresta estacional semidecidual e cerradão, as espécies diagnósticas foram Ocotea corymbosa (Meisn.) Mez., Machaerium opacum Vogel e Callisthene major Mart \& Zucc.. Na mata ciliar, as espécies mais presentes foram Allophylus sericeus (Cambess.) Radlk., Trichilia elegans A. Juss. e Maytenus ilicifolia Mart. ex Reissek. Os resultados apresentados revelam uma alta riqueza para a APA Carste de Lagoa Santa, mesmo considerando a drástica perda de espécies nos últimos 150 anos. Ainda, a fitossociologia revelou nitidamente diferenças estruturais entre as fitofisionomias analisadas, mostrando maior diversidade, densidade e área basal na área de cerrado stricto sensu do que nas áreas florestais. Resultados estes que são também influenciados pelo diferente grau de conservação das áreas. Por fim, foram encontradas espécies mais representativas e indicadoras de cada fitofisionomia, que fornecerão conhecimento adicionais para subsidiar interpretações paleoambientais nos capítulos seguintes. Dentre elas é possível destacar as espécies Allophylus sericeus (Cambess.) Radlk. e Maytenus ilicifolia Mart. ex Reissek como representativas das matas ciliares, Ocotea corymbosa (Meisn.) Mez, e Machaerium 
opacum Vogel na floresta semidecidual e Xylopia aromática (Lam.) e Qualea parviflora Mart. para a área de cerrado s.s.

\subsection{ABSTRACT}

Botanical studies on Lagoa Santa's archeological region, MG, Brazil, began around the 1860's with the arrival of the Danish researcher Eugenius Warming. For three years, he described 2,593 plant species and their ecosystems, making the region known as the cot of Brazilian Plant Ecology. More over, his studies in this region were supported by Brazilian paleontology pioneer, Peter W. Lund, who understood that studies on these plant ecosystems would help to understand the presence of prehistoric megafauna and human population. Since then, the region has suffered great transformations, especially as a consequence to the change of the state's capital to Belo Horizonte and its urban expansion, wich is currently reaching Lagoa Santa. Considering these transformations, the lack of an updated floristic list of the region and the importance of floristic and ecological studies to help the paleoenvironmental interpretation, the present study aimed to: 1.) list the current woody species in the Environmental Protection Area named Carste de Lagoa Santa; 2.) recognize the species that act as indicators of different phytophysiognomies and; 3.) discuss the differences present in the current flora with that present in Warming's studies, made 150 years ago. The list produced by this study totalized 347 woody species in the region, a number significantly smaller when compared to the 854 species listed by Eugenius Warming. In the cerrado area, Xylopia aromatica (Lam.) Mart., Qualea parviflora Mart. and Miconia albicans $(\mathrm{Sw})$ appear as the most representative species. In transition areas between the semideciduous forest and the cerrado, the diagnostic species were Ocotea corymbosa (Meisn.) Mez., Machaerium opacum Vogel and Callisthene major Mart \& Zucc. In the riparian forest, the prevalent species were Allophylus sericeus (Cambess.) Radlk., Trichilia elegans A. Juss. and Maytenus ilicifolia Mart. ex Reissek. The results revealed an environment rich in species, even if it also points to a drastic loss when compared to the same region 150 years ago. In addition, the phytosociology clearly showed structural differences between the phytophysiognomies analyzed, showing more diversity, density and basal area in the cerrado stricto sensu than in the forested areas. These findings were also determined by different degrees of conservation of the areas. 
Finally, the present study found species that are more representative and act as indicators of each phytophysiognomy, which provide additional information to support paleoenvironmental interpretations presented in the following chapters.

Among them we can highlight the species Allophylus sericeus and Maytenus ilicifolia as representative of the riparian forest, Ocotea corymbosa and Machaerium opacum of semideciduous forest and Xylopia aromatica and Qualea parviflora for the cerrado s.s. 


\subsection{INTRODUÇÃO}

Em Julho de 1863 chegou ao vilarejo de Lagoa Santa, MG, o botânico dinamarquês Eugenius Warming, que se propôs estudar a vegetação tropical da região e a colecionar todas suas plantas. Tamanha foi sua surpresa com ela, que por lá ficou três anos. Voltou sem conseguir coletar todas as espécies mas deixou uma obra que colocou a região de Lagoa Santa, como um dos berços da Ecologia Vegetal brasileira.

Seu livro, "Lagoa Santa - Et Bidrag til den Biologiske Plantegeografi”, publicado em 1892 e traduzido para o português em 1908 (Contribuição para a Geografia Fitobiológica), é a primeira grande obra sobre o cerrado brasileiro. O trabalho traz descrições extremamente fidedignas da vegetação local, identificando as principais formações vegetais da região, relacionando elementos climáticos, pedológicos e biológicos de cada ambiente e ainda identificando a grande variedade de espécies vegetais do cerrado, desde herbáceas a arbóreas, novas, em grande maioria, para a ciência da época. Sendo a primeira lista florística publicada para uma área de cerrado lato sensu, Warming (1908) enúmerou 2593 espécies de todos os grupos vegetais, o que revela sua grande diversidade.

Considerando os trabalhos recentes de Castro et al.(1999) e Ratter et al. (2003), que compilaram 960 espécies lenhosas, e Batalha \& Mantovani (2001), que listaram 2856 espécies herbáceas, o trabalho de Warming amostrou, em Lagoa Santa, MG, 68\% de toda a riqueza vegetal do bioma Cerrado. Os números são muito expressivos, mesmo levando-se em conta que parte da lista de Warming diz respeito a espécies típicas de matas, florestas semidcíduas, típicas do bioma da Mata Atlântica que adentra o Estado de Minas Gerais.

Mas a situação encontrada por Warming (1908) não é a mesma hoje. O autor já chamava atenção para a expansão da atividade antrópica sobre o ambiente natural, por meio de queimadas para dar lugar à lavoura em áreas de mata, e à pecuária em áreas de campos. Lund (1935) também relata a destruição de grutas para a exploração do salitre. Kohler \& Malta (1991) sintetizaram a interferência antrópica sobre o meio biótico da região:

“As formações naturais estão empobrecidas em função de muitos anos de retirada seletiva de madeiras nobres, carvoejamento e desmates extensivos. (...) Antigas fazendas (...) foram transformadas em pólos agropecuários, chácaras de recreação ou 
loteadas no processo de expansão urbana. A exploração de areia e garimpos modificou profundamente a paisagem ao longo do Rio das Velhas e várzeas do Ribeirão da Mata. Muitos fragmentos de matas associados aos afloramentos calcários, preservados (...) em função da dificuldade de acesso, vêm sendo suprimidos com o desmonte do calcário pelas mineradoras. A construção do Aeroporto Internacional Tancredo Neves levou à abertura e à duplicação de rodovias e eixos de circulação (...)"

Considerando essas transformações e atentando, principalmente, para preservação dos sítios espeleológicos e arqueológicos da região, o governo federal criou, em 1990, a Área de Proteção Ambiental - Carste de Lagoa Santa (ACLS), com a função de ordenar e controlar o uso da terra em locais de especial interesse para a conservação dos recursos naturais.

Oito anos depois, Herrmann et al. (1998) estudaram o meio biótico da ACLS, com a finalidade de caracterizar o estado atual de conservação da flora e fauna e propor um zoneamento ambiental para a área. Com esse trabalho, surgiu uma oportunidade única de se comparar as alterações sobre a biodiversidade vegetal da região durante 150 anos de desenvolvimento urbano. Os autores listaram 600 espécies. Mas dois aspectos metodológicos dificultaram a comparação com a obra de Warming (1908). Por um lado, um grande número de espécies (36\% das espécies listadas) não foi identificado ao nível específico, ficando apenas morfotipadas (ex: Myrtaceae sp1). Por outro, os autores amostraram de modo diferente as espécies arbóreo-arbustivas e as herbáceas, o que, se somado à falta de dados sobre o hábito de cada espécie, resulta em uma lista florística de difícil comparação.

A importância biológica da região da ACLS, revelada pela riqueza de espécies encontrada por Warmnig (1908) e Herrmann et al. (1998), divide espaço também com grande importância científica nos campos da Paleontologia e Arqueologia, com os primeiros trabalhos realizados a partir de 1834 pelo zoólogo e paleontólogo dinamarquês Peter Wilhelm Lund. Seus trabalhos tornaram a região conhecida também como o berço da Paleontologia brasileira.

A descoberta de inúmeros sítios paleontológicos e arqueológicos de ocupações humanas antigas, e a proposição da teoria de dois componentes biológicos para explicar a entrada dos povos pré-históricos no continente americano (Neves, et al., 2007; Neves \& Pucciarelli, 1991), acabaram por colocar a região de Lagoa Santa como importante centro de investigações arqueológicas. Por isso, a elucidação de cenários climáticos e 
ambientais para a região nos últimos 12000 anos, durante a ocupação pré-histórica, tornou-se um importante objeto de pesquisas. Grande parte das pesquisas nas áreas paleoambientais utilizaram palinomorfos fósseis para interpretação paleoambiental (Behling, 2003; De Oliveira, 1992; Ledru, 1992, 1993; Raczka, 2009).

Recentemente outras pesquisas paleobotânicas vem sendo conduzidas na região para elucidar questões ainda abertas sobre o clima e o ambiente durante o Holoceno. Elas vêm trabalhando com diversos vestígios vegetais, no intuito de integrar os resultados e construir um cenário sólido sobre o paleoclima e paleovegetação durante a ocupação pré-histórica da região.

Entretanto, qualquer pesquisa paleontológica que remete ao Quaternário, quer utilize fósseis animais ou vegetais, necessita de uma coleção de referência para que se possa realizar uma correta identificação taxonômica dos fósseis. Assim, a existência de uma lista florística completa de espécies de uma localidade e um banco de dados sobre características de determinada estrutura fóssil subsidia a correta identificação do material e propicia uma maior precisão na interpretação paleoambiental (Ceccantini, 2000).

No caso de lenhos fósseis, xilotecas são um excelente banco de dados para subsidiar identificações taxonômicas, mas o acervo atual das instituições brasileiras contempla predominantemente espécies de interesse comercial, como pode ser conferido na base de dados on-line da rede speciesLink (http://splink.cria.org.br/). Espécies arbóreas não comercializadas e, principalmente, de espécies arbustivas e lianas, são pouco representadas nas coleções, o que dificulta a precisa identificação de fósseis.

Neste cenário, este primeiro capítulo objetiva construir uma lista florísticolenhosa das espécies da ACLS, mais detalhada que a de Herrmann et al. (1998), e que possa dialogar não só com a obra de Warming e de outras províncias florísticas, mas também com pesquisas paleontológicas e arqueológicas desenvolvidas na região. Visando subsidiar ainda mais interpretações paleoambientais da região, pretende-se também compreender as assinaturas florísticas específicas das três principais fitofisionomias da ACLS, por meio de estudos fitossociológicos, e construir uma coleção de amostras de lenho das espécies identificadas, para servir de base na identificação anatômica de fósseis. 


\section{4 ÁREA DE ESTUDO}

A área estudada compreende a APA Carste de Lagoa Santa (ACLS), que está situada a norte de Belo Horizonte (aprox. $50 \mathrm{~km}$ ), MG, e abrange os municípios de Lagoa Santa, Matozinhos, Pedro Leopoldo e Funilândia, com área total de 35.900 hectares. Maiores detalhes podem ser encontrados em Herrmann et al. (1998).

Seu clima é classificado como clima tropical quente e semiúmido, com estação seca de 3 a 4 meses de duração, de maio a agosto (Nimer, 1989), sendo o último mês, o mais seco. A precipitação anual média é de $1381 \mathrm{~mm}$. concentrados no período de outubro a abril, sendo janeiro o mês mais chuvoso. A média anual de temperatura varia em torno dos $20,8^{\circ} \mathrm{C}$. A média diária de temperatura não é menor que $15^{\circ} \mathrm{C}$ e as máximas e mínimas absolutas nos últimos 10 anos foram $2^{\circ} \mathrm{C}$ e $35,9^{\circ} \mathrm{C}$ respectivamente (Parizzi et al., 1998).

A ACLS localiza-se em uma área de tensão ecológica entre os biomas de Mata Atlântica e Cerrado (IBGE, 1992) e apresenta sua vegetação natural restrita a remanescentes que misturam as fitofisionomias típicas do bioma Cerrado com as típicas da Mata Atlântica.

O bioma Mata Atlântica é ali representado pela floresta estacional semidecidual e pela mata ciliar, enquanto que o bioma do Cerrado apresenta muitas das variações fitofisionômicas que ocorrem no bioma, como o campo limpo, campo sujo, cerrado s.s. cerradão e mata ciliar. A mata seca, ou floresta estacional decidual, embora tenha muita afinidade florística com fisionomias do bioma da Caatinga, ocorre em Lagoa Santa, restrita aos afloramentos calcários de solo rasos e bem drenados, condicionada não pelo clima (como a Caatinga) mas por fatores edáficos (Ivanauskas \& Rodrigues, 2000). 


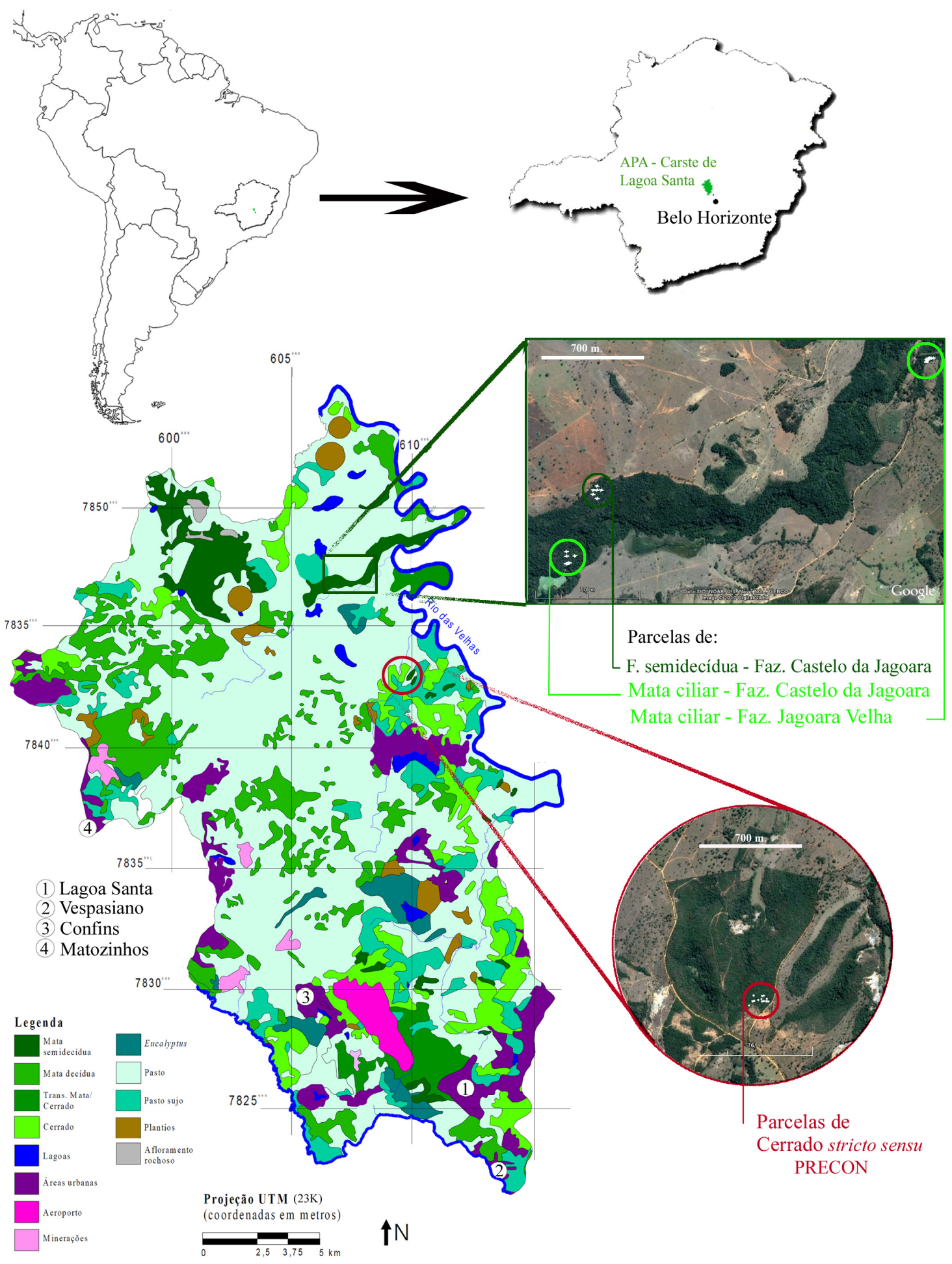

Figura 1: Área de estudo. Localização da APA - Carste de Lagoa Santa, MG e áreas de Cerrado, Floresta Semidecídua e Mata Ciliar estudadas pela fitossociologia. Adaptado de Herrman et al. (1998). 


\subsection{MATERIAIS E MÉTODOS}

\subsubsection{LEVANTAMENTO FLORÍSTICO}

A metodologia utilizada para o levantamento florístico foi a de caminhadas livres e periódicas, utilizando trilhas e estradas vicinais como pontos de referência para a observação e coleta de indivíduos férteis. Entre março de 2006 e outubro de 2007, foram feitas 11 expedições, quase mensais, em todas as estações do ano, com duração de 3 a 7 dias. Embora tenham sido percorridas todas as regiões da APA Carste de Lagoa Santa (ACLS), a coleta concentrou-se na região norte, com expressivas coletas na Fazenda Cauaia, Fazenda Jagoara Velha e Fazenda Castelo da Jagoara. Adicionalmente às caminhadas livres, foram computados os táxons encontrados no levantamento fitossociológico realizado em três remanescentes da região (figura 1).

Foram selecionados indivíduos lenhosos (árvores, arbustos, lianas), com $\mathrm{CAP}^{3} \geq$ $3 \mathrm{~cm}$. Destes, foram coletados ramos férteis para montar exsicatas, amostras de madeira de galho secundário, anotado o hábito, porte e outras observações. As exsicatas foram coletadas em duplicatas e depositadas preferencialmente nos herbários PMSP (Prefeitura de São Paulo) e SPF (IB-USP). As restantes foram encaminhadas para os herbários BHCB (UFMG) e JOI (Univille). As amostras de madeira foram depositadas nas xilotecas SPFw e JOIw.

A identificação do material contou com grande contribuição de profissionais (vide agradecimentos) do herbário da Prefeitura de São Paulo (PMSP), do Laboratório de Sistemática Vegetal do IB-USP (SPF), do Instituto Botânico (SP), do herbário da Esalq (ESA) entre outras instituições brasileiras.

Os nomes de espécies foram atualizados de acordo com Forzza et. al. (2010). Para tanto foram consultados especialistas (Ms. Matheus F. Santos e Dr. Ricardo J.F. Garcia), a base de dados Trópicos (Missouri Botanical Garden), o software Plantminer ${ }^{4}$ (Carvalho, G. H. et al., 2010) e banco TreeAtlan (Oliveira-Filho, 2010).

3 Circunferência do tronco à altura do peito (1,3m do solo)

4 Software que localiza os nomes aceitos na base de dados Tropicos e WCSP e, por último, recorre à base do IPNI 
A lista florística obtida foi comparada com a lista publicada por Warming (1908), para verificar a provável perda de riqueza na região, e com Biodiversitas (2005), com a finalidade de listar as espécies ameaçadas de extinção no Estado que ainda existem na ACLS ou que desapareceram nos últimos 150 anos. Para tal análise, foi necessário digitalizar as listas, atualizar os nomes de acordo com Forzza et. al.(2010) e, no caso de Warming, computar os hábitos das espécies para que uma comparação fosse feita apenas com os hábitos amostrados no levantamento do presente trabalho.

Os hábitos foram computados utilizando a própria obra de Warming (1908), Mendonça et al. (1998) e consulta a especialistas. No caso da listas de Warming, foram excluídos táxons identificados como parasitas, subarbustos, ervas, trepadeiras herbáceas, cactáceas e bambuzóides.

\subsubsection{ESTUdO FITOSSOCIOLÓGICO}

A fitossociologia foi amostrada em 31 parcelas de $10 \times 10 \mathrm{~m}$ em três fitofisionomias diferentes e típicas da região: mata ciliar, floresta semidecídua e cerrado s.s. (Figura 1)

A mata ciliar foi amostrada em duas alturas diferentes ao longo do Córrego da Jagoara, que deságua no rio das Velhas, limite nordeste da ACLS: na Fazenda Jagoara Velha $\left(43^{\circ} 57^{\prime} 42.74^{\prime \prime O}, 1^{\circ} 27^{\prime} 44.08^{\prime \prime} S^{5}\right)$ e na Fazenda Castelo da Jagoara $\left(43^{\circ} 59^{\prime} 10.77^{\prime \prime} \mathrm{O}, 1^{\circ} 28^{\prime} 32.48^{\prime \prime} \mathrm{S}\right)$. Foram estudadas 6 parcelas em cada local.

A área de floresta semidecídua estudada se encontra na borda do mesmo remanescente de mata, distando do corpo d'água em aproximadamente 250 metros. Nesta área foram amostradas apenas 6 parcelas, pois inicialmente se trabalharia em duas áreas diferentes, como na fitossociologia da mata ciliar.

A terceira área é um remanescente de cerrado utilizado como reserva legal da empresa PRECON, inteiramente cercado, onde predomina a fisionomia cerrado s.s.,

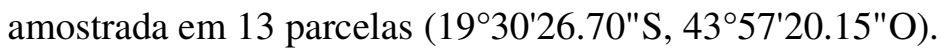

As coletas foram realizadas durante o mês outubro de 2007. Todos os indivíduos vivos lenhosos (árvores, arbustos e lianas) com $\mathrm{DAP}^{6} \geq 3 \mathrm{~cm}$ tiveram sua altura e diâmetro computados e sua espécie identificada em campo. Quando a identificação no

5 Datum WGS-84

6 Diâmetro à altura do peito $(1,3 \mathrm{~m}$.) 
campo não foi possível, ao menos uma exsicata de cada táxon foi coletada para posterior identificação. Indivíduos mortos não foram contados.

Os parâmetros calculados, para cada fisionomia vegetal, foram: a área basal das espécies, o número de parcelas em que ocorreram e o número total de indivíduos. A partir destes dados, foram obtidos os seguintes parâmetros fitossociológicos (MüllerDombois \& Ellenberg, 1974; e Martins, 1991): Frequência absoluta (FA), Frequência relativa (FR), Densidade absoluta (DA), Densidade relativa (DR), Dominância absoluta (DoA), Dominância relativa (DoR), Índice de Valor de Importância (IVI), de diversidade Shannon e de equitabilidade de Pielou (Magurran, 1988; Martins, 1991). As fórmulas estão apresentadas no ANEXO A.

Para analisar a fitossociologia e caracterizar a assinatura florística/fitossociológica dos três ambientes estudados, a interpretação dos dados foi centralizada principalmente no IVI, que leva em consideração não só a densidade relativa das espécies, como também sua área basal; na DR, que hierarquiza as espécies mais frequentes e que podem não estar entre os maiores IVIs; nas espécies indicadoras do ambiente em outros trabalhos na literatura; e nas espécies encontradas com exclusividade em cada ambiente estudado.

\subsection{RESULTADOS E DisCUSSÃO}

\subsubsection{LEVANTAMENTO FLORÍSTICO}

A curva de suficiência amostral (figura 2), embora revele um grande incremento no número de espécies em out/07, data dos trabalhos de fitossociologia, se estabiliza nas últimas coletas, mostrando que os esforços de coleta de 2008 não adicionaram novos táxons, o que evidencia uma boa amostragem. 


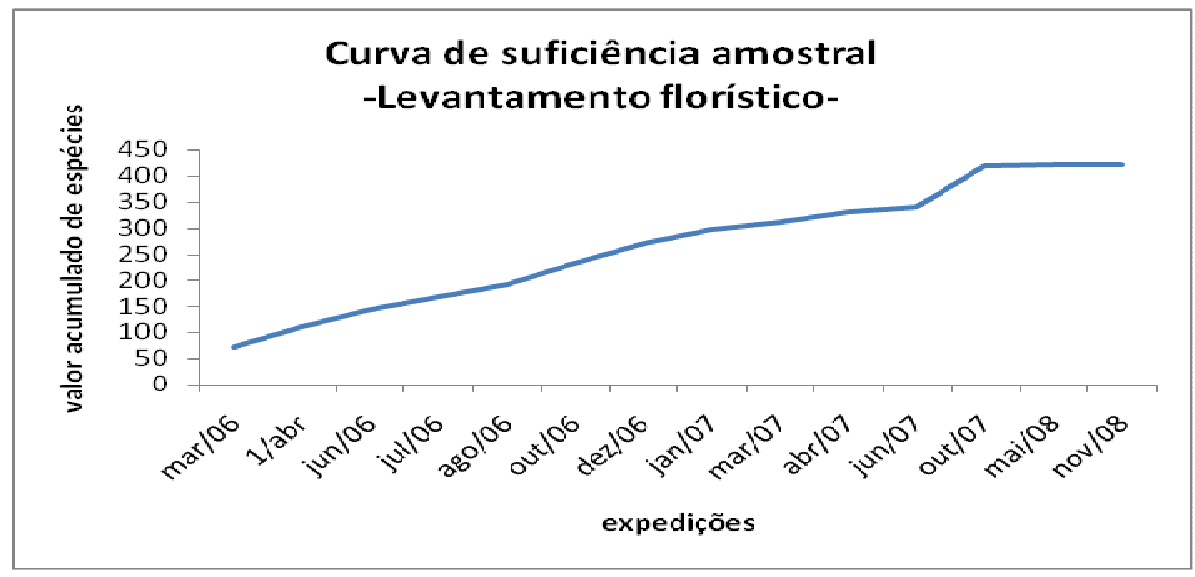

Figura 2: Curva de suficiência amostral do levantamento florístico.

Foram identificadas 347 espécies lenhosas distribuídas em 215 gêneros e 63 famílias (Tabela 1). No APÊNDICE 1 é possível encontrar informações sobre o hábito das espécies e a referência das exsicatas. Foram 229 arbóreas, $93^{7}$ arbustos e 45 lianas. Apenas 11 táxons não foram identificados até o nível específico, ficando sua identificação em nível de gênero.

Se comparada a outros levantamentos florísticos no Estado, esta lista revela alta riqueza na ACLS. Neri et al. (2007) fizeram uma compilação de 28 listas florísticas de fitofisionomias de cerrado no estado de Minas Gerais e chegaram a um total de 402 espécies, somando-se todas as localidades. A riqueza de plantas lenhosas aqui apresentada (347 espécies) corresponde a $88 \%$ das espécies levantadas por Neri et al. (2007) para o cerrado do Estado. No Parque Nacional de Emas (GO), reconhecido como patrimônio natural da humanidade pela UNESCO, Batalha \& Martins (2007) listaram 149 espécies lenhosas. Outros trabalhos no estado mineiro, independentemente da fitofisionomia estudada, raramente amostram mais de 200 espécies lenhosas para uma determinada localidade (Costa \& Araújo, 2001;Ferreira \& Forzza, 2009; Meyer, S. T. et al., 2004; Oliveira-Filho \& Machado, 1993b; Van Den Berg \& Oliveira-Filho, 2000).

A riqueza significativamente maior inventariada neste trabalho pode ser resultante tanto de uma maior área amostrada, integrando metodologia de caminhadas livres e fitossociológica, quanto por se tratar de uma área de tensão ecológica, com uma mistura de fisionomias do bioma Cerrado e Mata Atlântica, que se apresentam em

\footnotetext{
${ }^{7}$ Algumas espécies foram computadas como arbustivo-arbóreas ou arbustivo-lianescentes
} 
mosaicos e contribuem com um maior elenco de espécies. Os levantamentos florísticos e fitossociológicos comumente trabalham apenas com uma formação vegetal.

As famílias e os gêneros de maior riqueza são apresentados na figura 3. Como era de se esperar, as famílias de maior riqueza correspondem a uma mistura de famílias bem representadas nos cerrados e em florestas semidecíduas da Mata Atlântica (Figura 3A). Leguminosae, Myrtaceae, Rubiaceae costumeiramente configuram as mais ricas nos dois ambientes (Botrel et al., 2002; Campos et al., 2006; De Carvalho \& Martins, 2009; Marangon et al., 2003; Silva, A. F. D. et al., 2003; Siqueira et al., 2006; Souza, P. B. D. et al., 2008; Teixeira et al., 2004). Malpighiaceae é mais expressiva em cerrados (Campos et al., 2006; De Carvalho \& Martins, 2009; Neri et al., 2007; Saporetti Jr et al., 2003) enquanto Euphorbiaceae costuma figurar entre as mais ricas em florestas semidecíduas (Marangon et al., 2003; Ribas et al., 2003; Silva, A. F. D. et al., 2003).

Tabela 1: Lista de espécies lenhosas ocorrentes na APA Carste de Lagoa Santa (MG), região metropolitana de Belo Horizonte com suas respectivas famílias

\section{Famílias/Espécies}

\section{ACANTHACEAE}

Ruellia brevifolia (Pohl) C. Ezcurra

Thunbergia convolvulifolia Baker

\section{ANACARDIACEAE}

Astronium graveolens Jacq.

Lithraea molleoides (Vell.) Engl.

Myracrodruon urundeuva Allemão

Tapirira guianensis Aubl.

\section{ANNONACEAE}

Annona crassiflora Mart.

Annona dolabripetala Raddi

Annona sylvatica A.K.Schum.

Guatteria villosissima A.K.Schum.

Xylopia aromatica (Lam.) Mart.

Xylopia brasiliensis Spreng.

Xylopia sericea A. K.Schum.

\section{APOCYNACEAE}

Aspidosperma tomentosum Mart.

Forsteronia cf. thyrsoidea (Vell.) Müll.Arg.

Hancornia $s p$

Himatanthus sucuuba (Spruce ex Müll.Arg.)
Famílias/Espécies

Schubertia grandiflora Mart.

Tabernaemontana catharinensis A.DC.

ARALIACEAE

Dendropanax cuneatus (DC.) Decne. \& Planch.

Schefflera macrocarpa (Cham. \& Schltdl.)

Frodin

Schefflera morototoni (Aubl.) Maguire et al. Schefflera vinosa (Cham. \& Schltdl.) Frodin \& Fiaschi

\section{ARECACEAE}

Acrocomia aculeata (Jacq.) Lodd. ex Mart.

\section{ASTERACEAE}

Baccharis crispa Spreng.

Baccharis dracunculifolia DC.

Chromolaena laevigata (Lam.) R.M.King \&

H.Rob.

Cosmos sulphureus Cav.

Dasyphyllum brasiliense (Spreng.) Cabrera

Eremanthus erythropappus (DC.) MacLeish

Eremanthus glomeratus Less.

Gochnatia paniculata (Less.) Cabrera

Lessingianthus obtusatus (Less.) H. Rob. 
continuação...

Tabela 1: Lista de espécies lenhosas ocorrentes na APA Carste de Lagoa Santa (MG), região metropolitana de Belo Horizonte com suas respectivas famílias

\footnotetext{
Famílias/Espécies

Mikania sp

Piptocarpha rotundifolia (Less.) Baker Vernonanthura membranacea (Gardner) $\mathrm{H}$. Rob.

Vernonanthura phosphorica (Vell.) H. Rob.

Vernonia $s p$

BIGNONIACEAE

Amphilophium crucigerum (L.) L. G.

Lohmann
Amphilophium elongatum (Vahl) L. G Lohmann

Amphilophium paniculatum (L.) Kunth

Cuspidaria pulchra (Cham.) L. Lohmann

Cybistax antisyphilitica (Mart.) Mart

Dolichandra unguis-cati (L.) L. Lohmann

Fridericia chica (Bonpl.) L.G.Lohmann

Fridericia craterophora (DC.) L. Lohmann

Fridericia florida (A. DC.) L. Lohmann

Handroanthus heptaphyllus Mattos

Handroanthus impetiginosus Mattos

Handroanthus serratifolius (A.H.Gentry)

S.Grose

Lundia obliqua Sond.

Pyrostegia venusta (Ker Gawl.) Miers

Stizophyllum riparium (Kunth) Sandwith

Zeyheria montana Mart.

Zeyheria tuberculosa (Vell.) Bureau ex Verl.

BIXACEAE

Bixa orellana $\mathrm{L}$.
}

\section{BORAGINACEAE}

Cordia trichotoma (Vell.) Arráb. ex Steud.

Tournefortia paniculata Cham.

Varronia curassavica Jacq.

\section{BURSERACEAE}

Protium heptaphyllum (Aubl.) Marchand

\section{CANNABACEAE}

Celtis iguanaea (Jacq.) Sarg.

Celtis pubescens (Kunth) Spreng.
Famílias/Espécies

Trema micrantha (L.) Blume

CAPPARACEAE

Cleome viridiflora Schreb.

CARYOCARACEAE

Caryocar brasiliense Cambess.

CELASTRACEAE

Cheiloclinium cognatum (Miers) A.C. Sm.

Hippocratea volubilis $\mathrm{L}$.

Maytenus floribunda Reissek

Maytenus ilicifolia * Mart. ex Reissek

Maytenus robusta Reissek

Peritassa campestris (Cambess.) A.C. Sm.

Plenckia populnea Reissek

CHRYSOBALANACEAE

Couepia grandiflora (Mart. \& Zucc.) Benth.

\section{COMBRETACEAE}

Terminalia argentea Mart.

Terminalia glabrescens Mart.

CONNARACEAE

Connarus L.

Rourea pseudospadicea G.Schellenb.

\section{CONVOLVULACEAE}

Ipomoea tubata Nees

Merremia macrocalyx (Ruiz \& Pav.) O'Donell

\section{DILLENIACEAE}

Doliocarpus dentatus (Aubl.) Standl.

\section{EBENACEAE}

Diospyros hispida A. DC.

Diospyros inconstans Jacq.

\section{ERYTHROXYLACEAE}

Erythroxylum campestre A. K.Schum.

Erythroxylum cuneifolium (Mart.) O.E. Schulz Erythroxylum suberosum A. K.Schum.

Erythroxylum subrotundum A. K.Schum. 
continuação...

Tabela 1: Lista de espécies lenhosas ocorrentes na APA Carste de Lagoa Santa (MG), região metropolitana de Belo Horizonte com suas respectivas famílias

\section{Famílias/Espécies}

Erythroxylum tortuosum Mart.

\section{EUPHORBIACEAE}

Acalypha communis Müll.Arg.

Alchornea glandulosa Poepp. \& Endl.

Astraea lobata (L.) Klotzsch

Croton gracilipes Baill.

Croton urucurana Baill.

Dalechampia stipulacea Müll.Arg.

Euphorbia heterophylla L.

Mabea fistulifera Mart.

Manihot anomala Pohl

Manihot janiphoides Müll.Arg.

Manihot tripartita (Spreng.) Müll.Arg.

Maprounea guianensis Aubl.

Pera glabrata (Schott) Poepp. ex Baill.

Sapium glandulosum (L.) Morong

Sebastiania brasiliensis Spreng.

Sebastiania klotzschiana (Müll.Arg.) Müll.Arg.

\section{LAMIACEAE}

Aegiphila integrifolia (Jacq.) Moldenke

Aegiphila verticillata Vell.

Aegiphila vitelliniflora Walp.

Hyptidendron canum (Pohl ex Benth.) Harley

Vitex polygama Cham.

\section{LAURACEAE}

Nectandra cf. cissiflora Nees

Nectandra lanceolata Nees

Nectandra psammophila Nees

Ocotea corymbosa (Meisn.) Mez

Ocotea velutina (Nees) Rohwer

\section{LECYTHIDACEAE}

Cariniana estrellensis (Raddi) Kuntze

Cariniana legalis (Mart.) Kuntze

\section{LEGUMINOSAE}

Anadenanthera colubrina (Vell.) Brenan

Anadenanthera peregrina (Benth.) Altschul

Bauhinia longifolia (Bong.) Steud.
Famílias/Espécies

Bauhinia ungulata $\mathrm{L}$.

Bowdichia virgilioides Kunth

Cassia ferruginea (Schrad.) Schrad. ex DC.

Chamaecrista apoucouita (Aubl.) H.S. Irwin \& Barneby

Chamaecrista ensiformis (Vell.) H.S. Irwin \& Barneby

Chamaecrista flexuosa (L.) Greene

Clitoria fairchildiana R.A. Howard

Copaifera langsdorffii Desf.

Dalbergia miscolobium Benth.

Dimorphandra mollis Benth.

Enterolobium contortisiliquum (Vell.) Morong

Erythrina falcata Benth.

Harpalyce brasiliana Benth.

Hymenaea courbaril L.

Hymenaea stigonocarpa Mart. ex Hayne

Indigofera suffruticosa Mill.

Inga vera Willd.

Leptolobium dasycarpum Vogel

Lonchocarpus muehlbergianus Hassl.

Lonchocarpus sericeus (Poir.) DC.

Machaerium acutifolium Vogel

Machaerium hirtum (Vell.) Stellfeld

Machaerium opacum Vogel

Mimosa debilis Humb. \& Bonpl. ex Willd.

Mimosa laticifera Rizzini \& A. Mattos

Mucuna pruriens (L.) DC

Peltophorum dubium (Spreng.) Taub.

Plathymenia reticulata Benth.

Platymiscium pubescens Micheli

Platypodium elegans Vogel

Poiretia punctata (Willd.) Desv.

Senegalia martiusiana (Steud.) Seigler \& Ebinger

Senegalia polyphylla (DC.) Britton \& Rose

Senna macranthera (DC. ex Collad.) H.S. Irwin \& Barneby

Senna multijuga (Rich.) H.S. Irwin \& Barneby

Senna pendula (Humb. \& Bonpl. ex Willd.)

H.S. Irwin \& Barneby

Senna silvestris (Vell.) H.S. Irwin \& Barneby

Stryphnodendron adstringens (Mart.) Coville 
continuação...

Tabela 1: Lista de espécies lenhosas ocorrentes na APA Carste de Lagoa Santa (MG), região metropolitana de Belo Horizonte com suas respectivas famílias

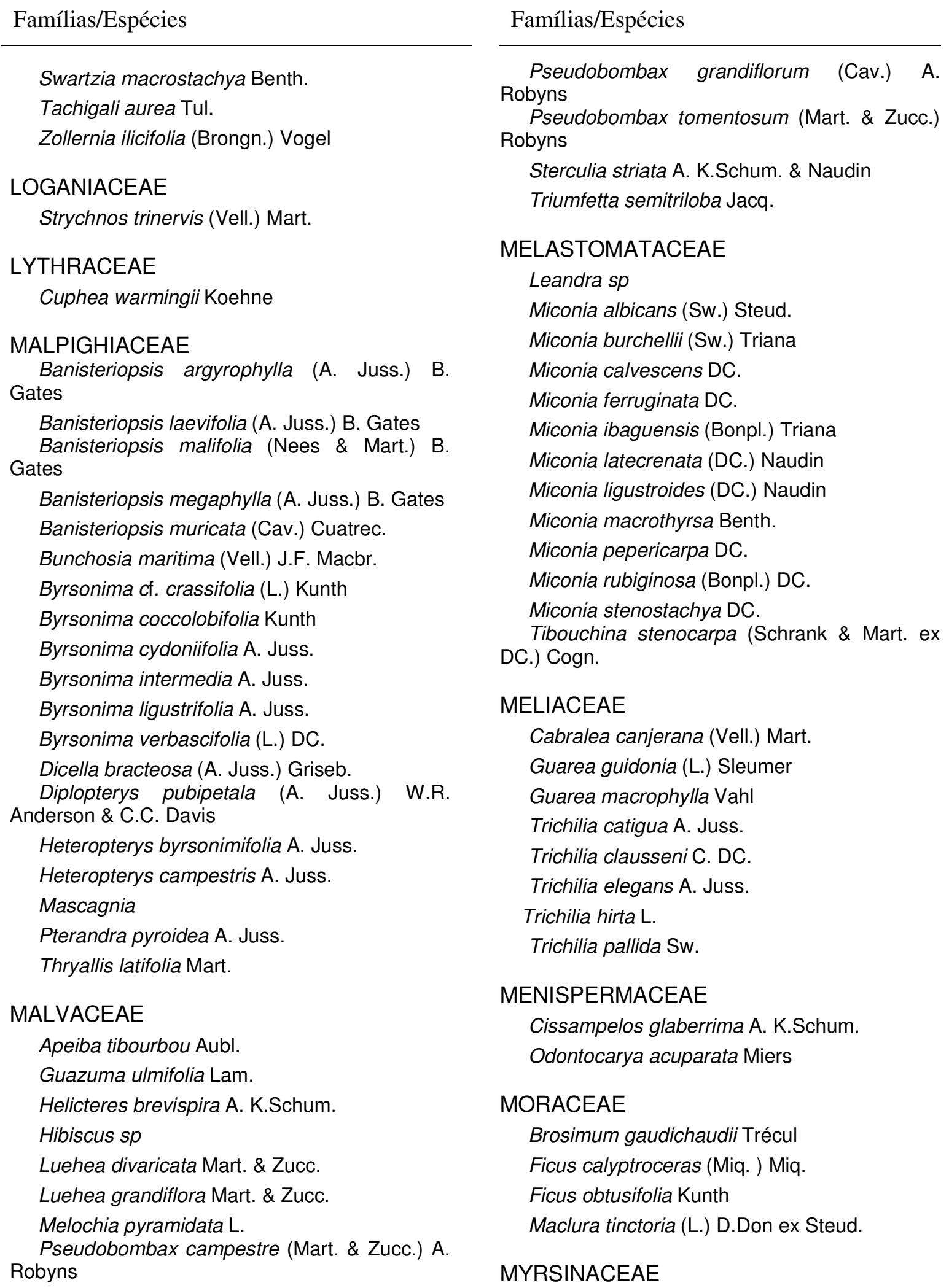


continuação...

Tabela 1: Lista de espécies lenhosas ocorrentes na APA Carste de Lagoa Santa (MG), região metropolitana de Belo Horizonte com suas respectivas famílias

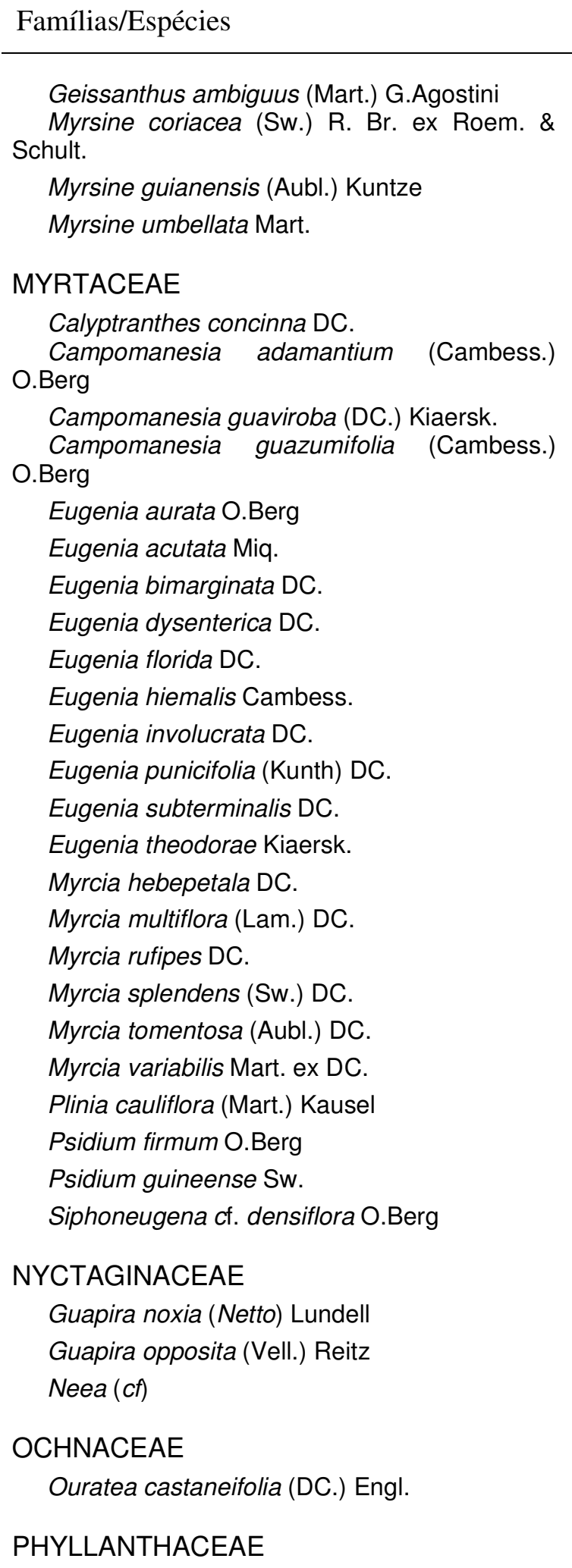

Famílias/Espécies

Margaritaria nobilis L.f.

Phyllanthus acuminatus Vahl

PICRAMNIACEAE

Picramnia sellowii Planch.

PIPERACEAE

Piper amalago L.

POLYGALACEAE

Bredemeyera floribunda Willd.

PROTEACEAE

Roupala montana Aubl.

RHAMNACEAE

Gouania virgata Reissek

ROSACEAE

Prunus myrtifolia (L.) Urb.

RUBIACEAE

Amaioua intermedia Mart. ex Schult. \& Schult.f.

Chiococca alba (L.) Hitchc.

Chomelia obtusa Cham. \& Schltdl.

Chomelia ribesioides Benth. ex A.Gray

Cordiera concolor (Cham.) Kuntze

Cordiera macrophylla (K.Schum.) Kuntze

Coussarea hydrangeifolia (Benth.) Müll.Arg.

Faramea (cf)

Genipa americana L.

Guettarda viburnoides Cham. \& Schltdl.

Hamelia patens Jacq.

Ixora brevifolia Benth.

Palicourea rigida Kunth

Psychotria capitata Ruiz \& Pav.

Psychotria carthagenensis Jacq.

Psychotria vellosiana Benth.

Psychotria warmingii Müll.Arg.

Randia armata (Sw.) DC.

Rudgea corymbulosa Benth.

Rudgea viburnoides (Cham.) Benth.

Tocoyena formosa (Cham. \& Schltdl.) 
continuação...

Tabela 1: Lista de espécies lenhosas ocorrentes na APA Carste de Lagoa Santa (MG), região metropolitana de Belo Horizonte com suas respectivas famílias

\section{Famílias/Espécies}

\section{K.Schum.}

\section{RUTACEAE} Conchocarpus pentandrus (A. K.Schum.) Kallunki \& Pirani

Dictyoloma vandellianum A.H.L. Juss. Galipea jasminiflora (A. K.Schum.) Engl. Zanthoxylum rhoifolium Lam. Zanthoxylum riedelianum Engl.

\section{SALICACEAE}

Azara

Casearia arborea (Rich.) Urb.

Casearia sylvestris Sw.

Prockia crucis $\mathrm{P}$. Browne ex $\mathrm{L}$.

\section{SAPINDACEAE}

Allophylus sericeus (Cambess.) Radlk.

Cupania oblongifolia Mart.

Cupania vernalis Cambess.

Cupania zanthoxyloides Radlk.

Dilodendron bipinnatum Radlk.

Magonia pubescens A. K.Schum.

Matayba elaeagnoides Radlk.

Matayba guianensis Aubl.

Paullinia elegans Cambess.

Paullinia meliifolia Juss.

Paullinia trigonia Vell.

Serjania laruotteana Cambess.

Serjania lethalis A.K.Schum.

Serjania multiflora Cambess.

Serjania reticulata Cambess.

Serjania tristis Radlk.

\section{SAPOTACEAE}

Chrysophyllum gonocarpum (Mart. \& Eichler ex Miq. ) Engl. Radlk.

Chrysophyllum marginatum (Hook. \& Arn.)

Pouteria cf. ramiflora (Mart.) Radlk.

Pouteria torta (Mart.) Radlk.

\section{SCROPHULARIACEAE}

Buddleja stachyoides Cham. \& Schltdl.
Famílias/Espécies

\section{SIMAROUBACEAE}

Simarouba $s p$

SIPARUNACEAE

Siparuna guianensis Aubl.

\section{SMILACACEAE}

cf Smilax

\section{SOLANACEAE}

Brunfelsia uniflora (Pohl) D. Don

Capsicum flexuosum Sendtn.

Cestrum axillare Vell.

Cestrum schlechtendalii G. Don

Cestrum strigilatum Ruiz \& Pav.

Cestrum velutinum Hiern

Solanum alternatopinnatum Steud.

Solanum decompositiflorum Sendtn.

Solanum granulosoleprosum Dunal

Solanum lycocarpum A. K.Schum.

Solanum paniculatum $\mathrm{L}$.

Solanum scuticum M.Nee

Solanum sublentum Hieron.

Solanum variabile Mart.

Solanum viarum Dunal Schrank

STYRACACEAE

Styrax camporum Pohl

Styrax ferrugineus Nees \& Mart.

\section{SYMPLOCACEAE}

Symplocos nitens (Pohl) Benth.

\section{URTICACEAE}

Boehmeria caudata Sw.

Cecropia pachystachya Trécul

Urera baccifera (L.) Gaudich. ex Wedd.

\section{VERBENACEAE}

Lantana camara L.

Lantana trifolia L.

Lippia martiana Schauer

Lippia velutina Schauer 
continuação...

Tabela 1: Lista de espécies lenhosas ocorrentes na APA Carste de Lagoa Santa (MG), região metropolitana de Belo Horizonte com suas respectivas famílias

Famílias/Espécies

VIOLACEAE
Hybanthus atropurpureus (A. K.Schum.)
Taub.

VITACEAE

Cissus sulcicaulis (Baker) Planch.

VOCHYSIACEAE

Callisthene major Mart. \& Zucc.

\section{Famílias/Espécies}

Qualea cordata (Mart.) Spreng.

Qualea grandiflora Mart.

Qualea multiflora Mart.

Qualea parviflora Mart.

Salvertia convallariodora A. K.Schum.

Vochysia rufa Mart.

Vochysia tucanorum Mart.
A

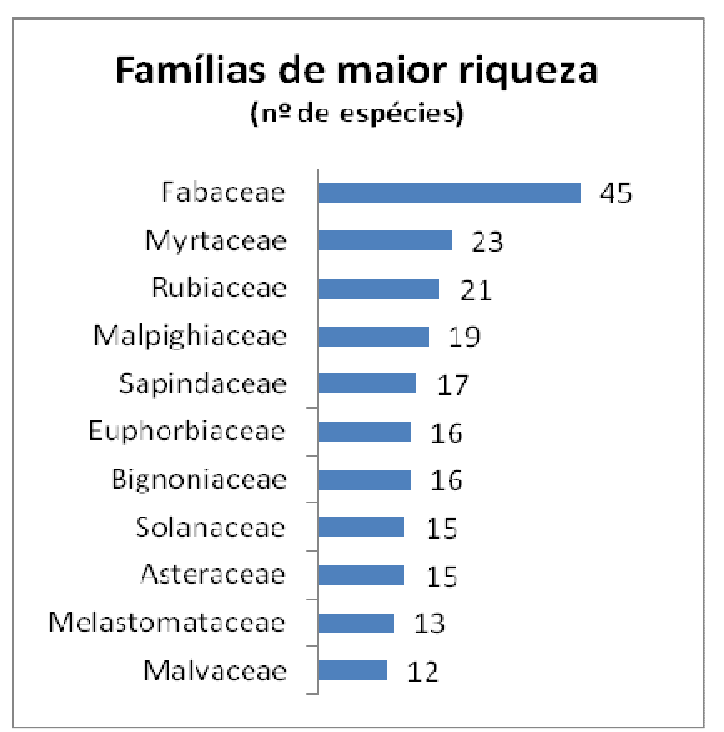

B

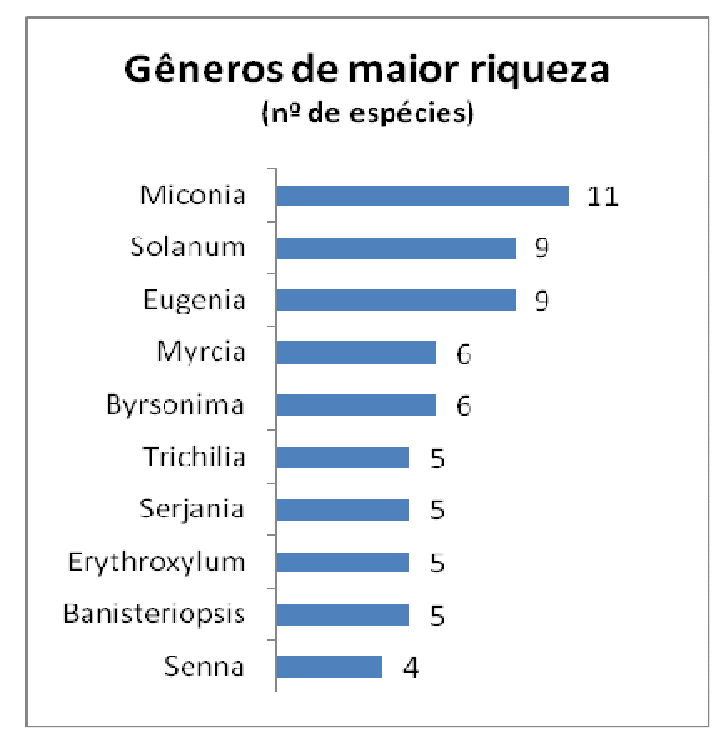

Figura 3: Famílias (A) e gêneros (B) de maior riqueza na APA - Carste de Lagoa Santa, MG.

A mistura florística dos dois biomas também ocorre no nível genérico (Figura 3B). Enquanto Miconia, Byrsonima Erythroxylon e Banisteriopsis são gêneros típicos do cerrado, Myrcia, Trichilia e Senna são mais diversos na mata. Eugenia costuma apresentar significativa riqueza em ambas vegetações (De Carvalho \& Martins, 2009; Marangon et al., 2003; Neri et al., 2007; Rodrigues et al., 2003; Silva, A. F. D. et al., 2003; Werneck et al., 2000). Solanum, contudo, não foi encontrada com grande riqueza na literatura, que comumente trabalha com apenas uma fitofisionomia. Seu aparecimento com o segundo maior número de espécies pode ser interpretada como 
resultante da somatória de sua riqueza nas diferentes fitofisionomias estudadas, representando todo o mosaico de vegetações da ACLS.

\subsubsection{REVISITANDO WARMING (1908)}

A lista de Warming (1908) atualizada resultou em 854 espécies, sendo 473 arbóreas (55\%), $399 \operatorname{arbustivas~}^{8}(47 \%)$ e 54 lianas (6\%). Não foi possível encontrar nomes corretos para 67 espécies listadas na obra.

Em meados de 1860, Warming identificou 588 espécies lenhosas que não foram encontradas no presente levantamento, onde 290 são arbóreas, 311 arbustos $^{8}$ e 31 lianas $^{8}$. Estes números por si só são muito expressivos e levam ao questionamento sobre as causas de tamanha diferença numérica entre os levantamentos florístico-lenhosos produzidos num intervalo de 150 anos.

Como primeira hipótese, pode-se pensar que Warming, morando na região e tendo como principal foco de trabalho a coleta, descrição e identificação das espécies vegetais, dispendeu um esforço muito maior do que o investido no presente trabalho. De fato, isso é bastante plausível e acredita-se que parte destas espécies não apareceu nesta lista por este motivo. Brina (1998), por exemplo, encontrou 11 espécies lenhosas que foram encontradas por Warming (Warming, 1908), mas não neste trabalho.

Entretanto, como já foi dito, os trabalhos atuais de levantamento florístico em uma determinada localidade não costumam listar mais de 200 espécies, seja em ambientes de cerrado ou mata estacional semidecidual. Um dos raros casos é o trabalho de Oliveira-Filho \& Machado (1993b), com 277 espécies identificadas. Desta forma, embora não tenha sido realizado o mesmo esforço de coleta que Warming, a lista por hora apresentada constitui uma das listas mais completas de uma localidade mineira e, portanto, o esforço de coleta não pode ser menosprezado. Por isso, provavelmente o número de 588 espécies é expressivo demais para ser explicado apenas com a diferença dos esforços amostrais.

Uma outra hipótese, que deve coexistir com a anterior, é a possibilidade de ocorrerem extinções locais de espécies vegetais. Nesses quase 150 anos decorridos, muitas foram as interferências antrópicas que ocorreram sobre a paisagem natural da região.

8 Algumas espécies foram computadas como arboreo-arbustivas e arbustivas-lianescentes. 
Em 1894, a mudança da capital do estado de Ouro Preto para Belo Horizonte (outrora denominada "Curral del Rei”) transferiu a estrutura administrativa de Minas Gerais para ainda mais perto da região de Lagoa Santa, trazendo consigo o crescimento econômico e urbano. No ano de sua inauguração como capital do Estado, em 1897, Belo Horizonte contava com 10.000 habitantes. Atualmente, conta com nada menos que 2,4 milhões, um crescimento demográfico de $24400 \%$ que a coloca como a sexta cidade mais populosa do país (IBGE, 2010a, b). Com a recente instalação da Cidade Administrativa quase na margem da ACLS e a duplicação da linha verde na capital, esse processo deve se intensificar ainda mais.

Com tal velocidade de crescimento não é implausível pensar em extinção local de espécies pela interferência antrópica na região. Tanto é que destas espécies não encontradas no presente levantamento, 12 se encontram ameaçadas de extinção no Estado (tabela 2), com Rudgea parvifolia (Cham.) Müll.Arg. sendo categorizada como "criticamente em perigo", uma categoria anterior à "extinta na natureza” (Biodiversitas, 2005).

Tabela 2: Espécies coletadas por Warming em 1860 não encontradas atualmente na região e listadas como espécies ameaçadas de extinção no estado de Minas Gerais. Categorias de risco de extinção: VU, vulnerável; EM, em perigo; CR, criticamente em perigo (Mendonça, P. M. \& Vanucci, 2005)

\begin{tabular}{lll}
\hline \multicolumn{1}{c}{ Família } & \multicolumn{1}{c}{ Espécie } & Categoria \\
\hline Arecaceae & Butia capitata (Mart.) Becc. & VU \\
Burseraceae & Protium icicariba (DC.) Marchand & EM \\
Leguminosae & Dalbergia nigra (Vell.) Allemao ex Benth. & VU \\
Leguminosae & Melanoxylon brauna Schott & VU \\
Melastomataceae & Leandra adenothrix Cogn. & VU \\
Melastomataceae & Ossaea warmingiana Cogn. & VU \\
Monimiaceae & Siparuna brasiliensis (Spreng.) A. DC. & VU \\
Oleaceae & Chionanthus subsessilis (Eichler) P.S.Green & EN \\
Piperaceae & Piper bennettianum C. DC. & VU \\
Rubiaceae & Rudgea parvifolia (Cham.) Müll.Arg. & CR \\
Rubiaceae & Rudgea sessilis (Vell.) Müll.Arg. & VU \\
Simaroubaceae & Simaba warmingiana Engl. & VU \\
\hline
\end{tabular}

Por outro lado, o levantamento florístico atual aponta 82 espécies não encontradas por Warming há 150 anos (APÊNDICE 1). São 47 arbóreas, $15 \operatorname{arbustos}^{9}$ e

\footnotetext{
${ }^{9}$ Algumas espécies foram consideradas tanto arbustos como arbóreas
} 
19 lianas, um número também bastante expressivo. Por que Warming, dedicando-se três anos integralmente à coleta e identificação das plantas da região não teria amostrado 82 espécies que o presente levantamento listou para a região?

Possivelmente as espécies apareceram na região depois dos trabalhos de Warming, favorecidas pelo ao aumento da interferência humana e pelas alterações ecológicas associadas a isso, ou as espécies ainda não haviam sido descritas em meados do século XIX e acabaram recebendo outra identificação, que na época provávelmente circunscrevia mais de uma espécie das quais hoje conhecemos.

Quanto à primeira hipótese, é muito difícil colher evidências ou possíveis exemplos. A lista de espécies não identificadas no final do séc. XIX não relaciona espécies atípicas da região, por exemplo. Já no caso da segunda explicação, se observa que Warming não listou a presença nem de Myracrodruon urundeuva Allemao, nem de seu sinônimo Astronium urundeuva Allemão, a aroeira, árvore típica da região, de muito interesse econômico e há muitos anos utilizada como estrutura de sustentação de construções, como a Capela Nossa Senhora de Jagoara, que data do século XVIII (comunicação pessoal de G. Ceccantinni). É possível que tal espécie tenha sido considerada como Astronium graveolens Jacq. ou A. fraxinifolium Schott. Esta hipótese pode ter grande significância nesta questão, pois muito da identificação botânica se desenvolveu desde 1860 e grande parte destas 82 espécies podem não ter sido listada por esta causa. Cabe contudo, uma análise mais minuciosa acerca da história de classificação de cada espécie.

Do levantamento florístico atual, três espécies são listadas por Biodiverstias (2005) como ameaçadas de extinção: Myracrodruon urundeuva Allemão, Protium heptaphyllum (Aubl.) Marchand e Rourea pseudospadicea G.Schellenb, mostrando que a região ainda abriga espécies ameaçadas de extinção no Estado de Minas Gerais.

\subsubsection{COLEÇÃO DE REFERÊNCIA PARA IDENTIFICAÇÃO DE LENHOS FÓSSEIS}

Foi realizada a coleta de lenho de 270 espécies, sendo 182 espécies arbóreas, 73 arbustivas e 32 lianas.

Embora não se tenha atingido o objetivo de amostrar todas as espécies lenhosas, devido a particularidades do momento de cada coleta, como o clima, a falta de material ou mesmo a necessidade de coleta destrutiva em alguns casos, a coleção amostrou $73 \%$ 
da flora identificada, o que já é uma significativa contribuição para a identificação de lenhos fósseis da ACLS.

A coleção de referência é detalhada no Capítulo 2.

\subsubsection{FitOSSOCIOLOGIA}

O estudo fitossociológico foi inicialmente pensado para que, por meio de uma ferramenta objetiva que distinguisse as fitofisionomias do cerrado s.s, a mata estacional semidecidual e a mata ciliar, fosse possível embasar discussões paleobotânicas mais detalhadas sobre a ocorrência de determinados táxons nas assembleias fósseis estudadas no capítulo 2. Trabalhos fitossociológicos já foram realizados em remanescentes da ACLS (Herrmann et al., 1998), mas foi utilizada uma classificação pouco precisa das fisionomias vegetais da região, dividindo-as apenas em cerrado e mata.

Nesta discussão, os resultados fitossociológicos serão comentados em duas etapas distintas. A primeira focará a discussão na comparação da estrutura horizontal das três fitofisionomias estudadas, enquanto que, num segundo momento, serão discutidas as assinaturas florísticas das áreas, focando a discussão nas espécies mais representativas e diagnósticas de cada fitofisionomia.

\subsubsection{ESTRUTURA HORIZONTAL}

A amostragem fitossociológica realizada revelou uma tendência à estabilização da curva de suficiência amostral para as áreas de cerrado s.s. e mata ciliar (figura 4A). Enquanto no cerrado ela é nítida, na mata ciliar a curva se estabiliza a partir da parcela 8 , embora tenha um leve incremento na última parcela.

A área de floresta semidecídua, entretanto, não apresentou suficiência amostral devido ao menor número de parcelas amostradas (Figura 4A). Numa amostragem reduzida, os dados que são perdidos dizem respeito a espécies raras e/ou muito esparsas, e como o objetivo deste estudo é encontrar "assinaturas" de cada fitofisionomia, o interesse maior é conhecer os táxons de maior importância fitossociológica, mais frequentes e as associações mais características de cada área, e não espécies raras, difíceis de serem encontradas atualmente, e muito mais em registros fósseis. 
A

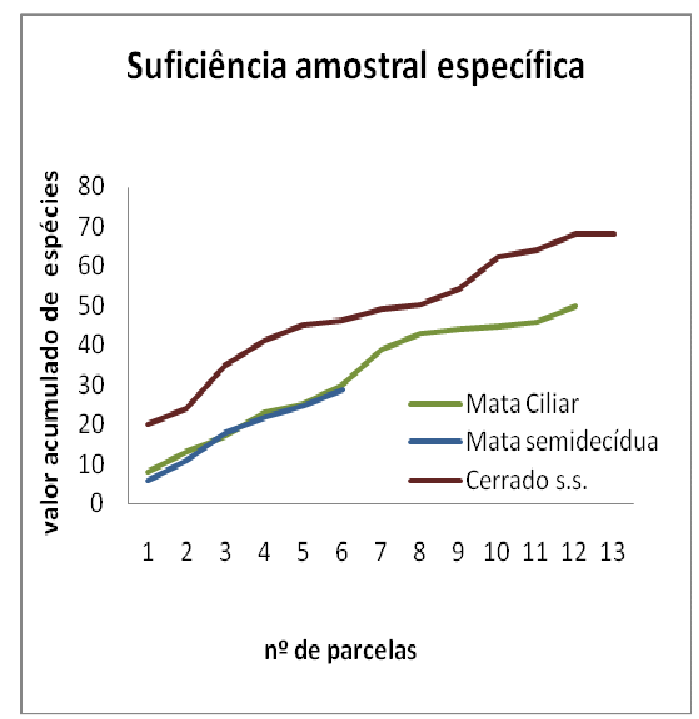

B

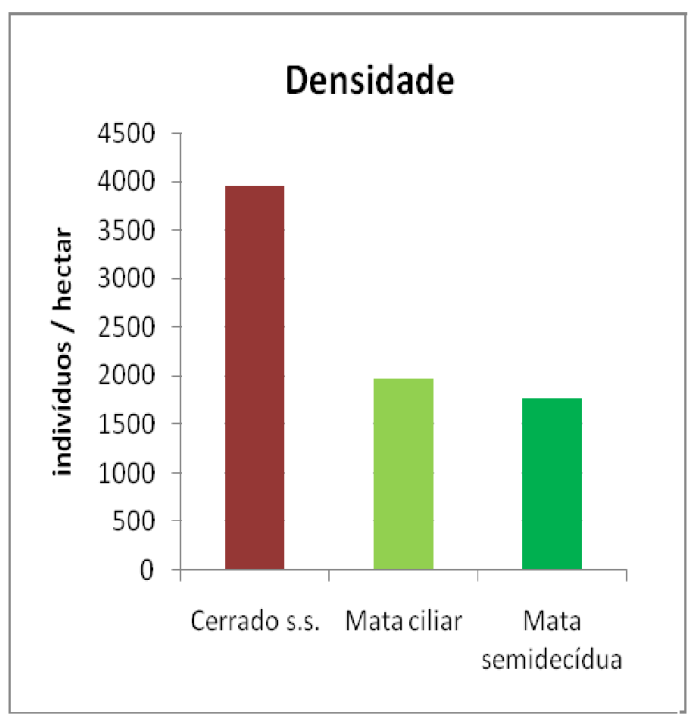

Figura 4: A. Curva de suficiência amostral geral e para cada fisionomia estudada; B. Densidade de indivíduos por área nas três fitofisionomias estudadas.

O cerrado s.s. foi a área que apresentou maior densidade de indivíduos, com $3960 \mathrm{ind} / \mathrm{ha}$, seguido da mata ciliar, com $1968 \mathrm{ind} / \mathrm{ha}$, e da floresta semidecídua, com $1767 \mathrm{ind} /$ ha (figura 4B).

A densidade nitidamente maior no cerrado s.s. do que nas fitofisionomias florestais traz estranhamento à primeira vista. Entretanto, Herrmann et al. (1998) também obtiveram este resultado estudando a fitossociologia de 4 áreas de cerrado, 4 de floresta semidecídua e 2 de mata seca na ACLS e Carvalho (1987) encontrou uma densidade ainda maior para cerrados s.s. do sudoeste de MG, com 5207ind./ha. Os autores explicam a diferença pelo maior ou menor grau de preservação dos remanescentes.

Para entender melhor a integridade e preservação das áreas amostradas, pode-se observar o gráfico de classes diamétricas (figura 5B) que diz como os indivíduos estão distribuídos em termos da espessura de seu tronco (Meyer et al., 1961). Teoricamente é de se esperar que um remanescente bem preservado tenha muitos indivíduos delgados, que ficam cada vez menos frequentes conforme seu diâmetro aumenta. Segundo Lopes et al.(2002) este padrão mostra que o remanescente está em amplo desenvolvimento, com muitos indivíduos jovens que irão alcançar porte maior.

Os resultados obtidos na análise de classes diamétricas (figura 5B) sustentam a interpretação de maior preservação da área de cerrado s.s. ao exibir o padrão mais 
próximo do considerado para áreas bem preservadas. Mais pronunciado na floresta semidecídua do que na mata ciliar, verifica-se que nem sempre uma classe diamétrica tem maior número de indivíduos que as classes seguintes. É o caso da classe diamétrica de 13 a $18 \mathrm{~cm}$ da área de semidecídua, onde se verifica um menor número de indivíduos. Olhando para as espécies das duas classes vizinhas (8-13 e 18-23), vemos um maior número de indivíduos de Myracrodruon urundeuva Allemao (aroeira-dosertão), muito empregada pelo Homem para diversos usos. O mesmo acontece na mata ciliar, no diâmetro entre 28 e 33, embora o pequeno número de indivíduos prejudique uma análise bem sustentada. Possivelmente estes dados revelem uma exploração seletiva desta espécie, podendo ter ocorrido há algum tempo ou recentemente.

Quanto aos índices de diversidade de Shannon e de equitabilidade de Pielou (figura 5A,C), nota-se que apresentam padrões inversos. A área de cerrado s.s. tem maior diversidade e sua riqueza (figura 5E) é o principal fator para tal índice. Nas outras áreas, o índice de Shannon também é considerado alto, mas recebe maior influência da uniformidade da frequência de suas espécies. É importante comentar que a diferença do tamanho amostral praticado nas áreas influência na riqueza de espécies, principalmente na área de floresta semidecídua onde a amostragem foi reduzida. Considerando a riqueza de espécies por unidade de área amostrada, a floresta semidecídua se torna intermediária, com riqueza/hectare maior que a mata ciliar, mas ainda menor que no cerrado. Sendo assim, se torna mais prudente considerar as diversidades entre a área de mata ciliar e semidecídua similares.

Portanto, os resultados até então discutidos apontam a área de cerrado s.s., que é utilizada como reserva legal, como a área amostrada melhor preservada, com os melhores parâmetros fitossociológicos, sejam eles maior densidade de indivíduos, riqueza, diversidade e padrão de distribuição de classes diamétricas típico de vegetações saudáveis.

A área de mata ciliar, embora com significativa diversidade, não alcançou índices tão altos quanto a área de cerrado s.s. A distribuição de classes diamétricas revelaram algumas perturbações propiciadas possivelmente pela interferência antrópica existente hoje ou no passado, quer seja pela entrada de gado ou pelo trânsito de carros, caminhões e de pessoas por suas estradas e trilhas.

Quanto à área de floresta semidecídua, sua distribuição de classes diamétricas mostrou maiores perturbações do que na mata ciliar, possíveis causas da baixa 
densidade e riqueza. De fato, era de se esperar uma maior interferência externa nesta área, pois se localizava na borda do remanescente onde foram amostradas parte das parcelas da mata ciliar, mais sujeita a interferências externas.

A

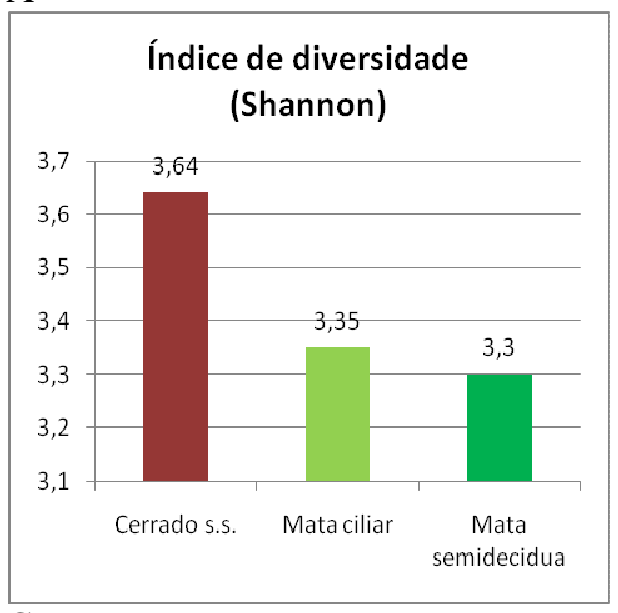

C

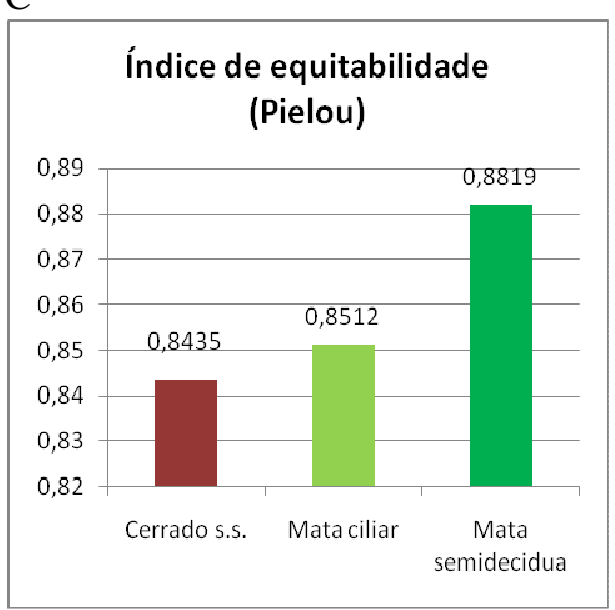

$\mathrm{E}$

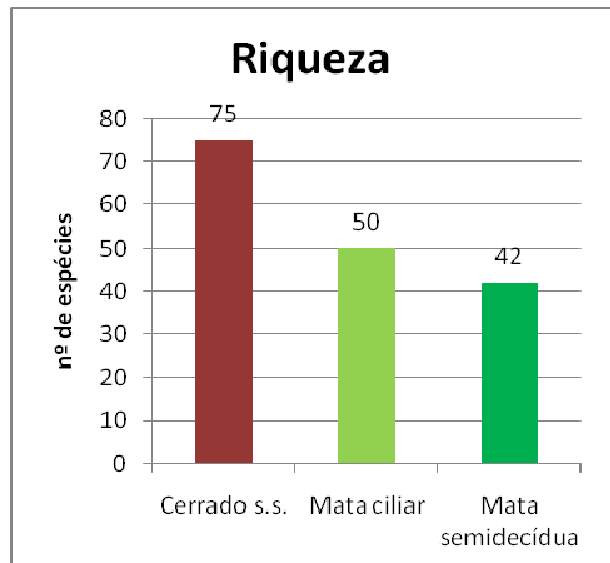

B

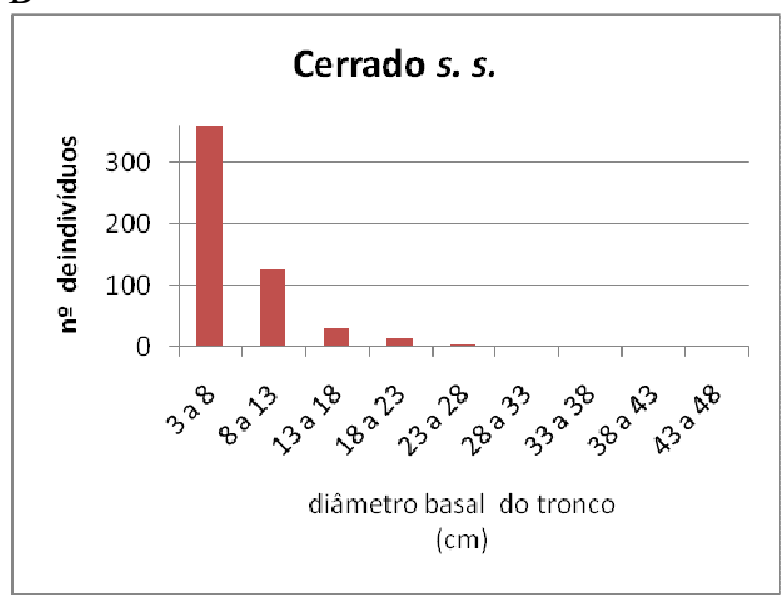

$\mathrm{D}$

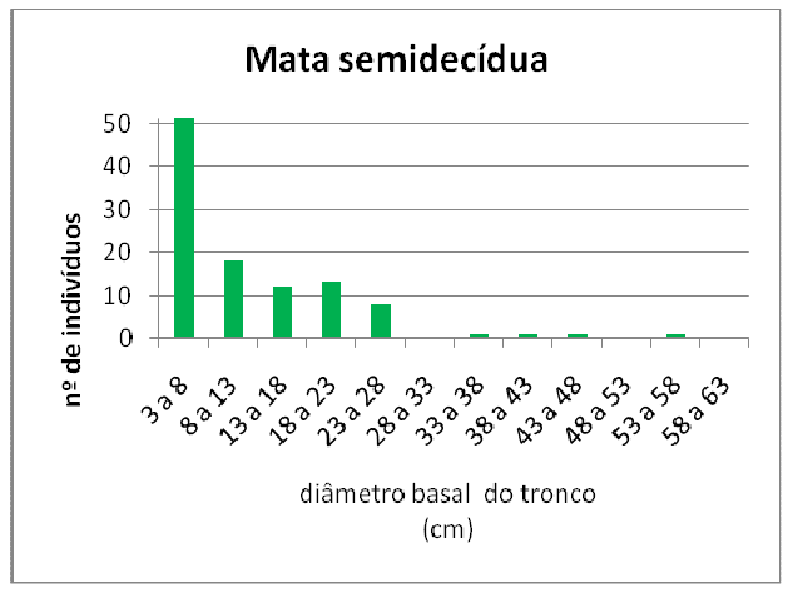

$\mathrm{F}$

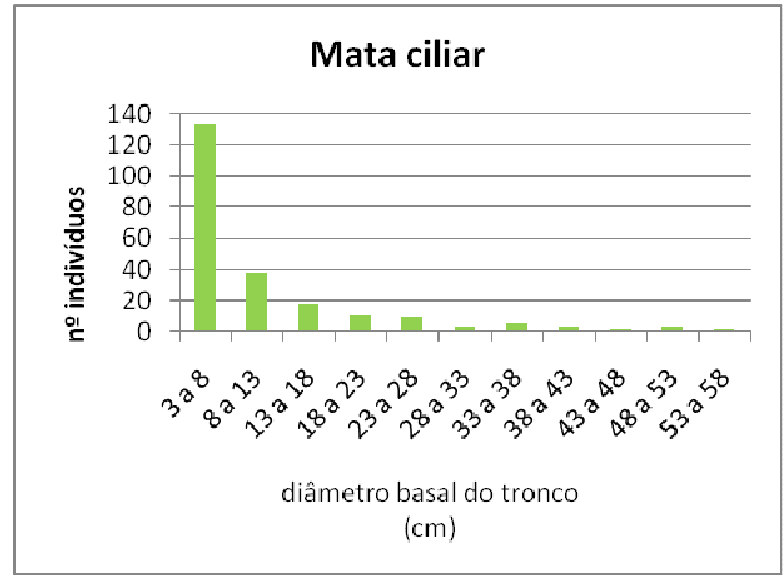

Figura 5: Gráficos obtidos com dados dos levantamentos fitossociológicos nas fitofisionomias cerrado s.s., floresta semidecídua e mata cilar: A. Índice de diversidade de Shannon; B,D,F. $\mathrm{n}^{\circ}$ de indivíduos em cada classe de diâmetro (DAP) de tronco; C. Índice de equabilidade de Pielou; E. Riqueza de espécies encontradas. 


\subsubsection{ESPÉCIES REPRESENTATIVAS E DIAGNÓSTICAS (ASSINATURA FLORÍSTICA)}

Os resultados da fitossociologia nas áreas estudadas na ACLS foram eficientes ao revelar as diferenças estruturais das fitofisionomias cerrado s.s., floresta semidecídua e mata ciliar.

A seguir, serão discutidos os parâmetros fitossociológicos FA, FR, DA, DR, DoA, DoR e IVI, relacionados à representatividade de cada espécie em cada uma das três áreas estudadas (tabelas 3, 4 e 5). Espécies generalistas, que ocorrem nas diversas fitofisionomias, mesmo se ocorrerem com elevado índice de valor de importância, como o caso das espécies Copaifera langsdorffii, Myracrodruon urundeuva e Aspidosperma $s p$, não serão discutidas.

\subsection{CERRADO STRICTO SENSO}

A área de cerrado s.s. (Tabela 3) mostrou ser a fisionomia mais distinta em termos florísticos, com as espécies Pera glabrata e Xylopia aromática ocupando papel de destaque em IVI, seguidas de Miconia albicans (Sw.) Steud. e Qualea grandiflora Mart. Analisando a densidade relativa, podemos citar também Eugenia dysenterica DC. e Stryphnodendron adstringens (Mart.) Coville.

A espécie de maior importância foi Pera glabrata, com alta densidade e área basal. Foi encontrada também em cerrado s.s. por Balduino et al. (2005) e em cerradão por Gomes et al. (2004) e Pereira-Silva et al. (2004), com expressivo IVI. Segundo a bibliografia consultada, a espécie ocorre também em matas semideciduais e de galeria, mas sempre pouco expressiva (Botrel et al., 2002; Rodrigues et al., 2003).

Xylopia aromatica, Qualea parviflora e Miconia albicans são espécies ainda mais características do cerrado. Herrmann et al. (1998) também encontraram essas espécies apenas nos fragmentos de cerrado e com destacado IVI, estando ausentes em remanescentes de matas da ACLS.

Q. parviflora foi denominada por Ratter et al. (2003) como a espécie mais ocorrente no cerrado brasileiro. Os autores a encontraram-na em 274 das 315 localidades compiladas para o cerrado brasileiro e diversos estudos fitossociológicos apontam-na com alto índice de importância em áreas de cerrado (Costa \& Araújo, 2001; 
Gomes et al., 2004; Herrmann et al., 1998; Pereira-Silva et al., 2004; Saporetti Jr et al., 2003; Teixeira et al., 2004).

Carvalho (1987) encontrou X. aromatica tanto em área de cerrado quanto em área de floresta semidecídua na região sudoeste de Minas Gerais. Mas, enquanto que na primeira área a espécie possuía um dos maiores IVIs, na segunda era a espécie menos representativa, sugerindo que sua presença seja uma influência da área de cerrado vizinha. M. albicans foi encontrada com expressivo IVI também nos trabalhos em cerrados de Costa \& Araújo (2001), Pereira-Silva et al. (2004), Saporetti Jr. et al. (2003), Gomes et al. (2004), entre outros. Embora não se descarte a ocorrência desta espécie em áreas de florestas semidecíduas e matas ciliares, tanto os resultados aqui apresentados quanto os de Herrmann et al. (1998) para áreas de mata da ACLS não apontam para a ocorrência desta espécie.

As espécies Eugenia dysenterica e Stryphnodendron adstringens, embora não apresentem alto IVI, são espécies importantes no cerrado s.s. por suas densidades. No estudo de Hermann et al. (1998) estas espécies também ocorreram exclusivamente em áreas de cerrado, com valores de IVI e DR muito variáveis. Carvalho (1987) encontrou S. adstringens com alto valor de importância. Por outro lado, a espécie foi vista em matas semidecíduas de Luminárias e Ingaí (MG) mas não possuiam nenhum valor de importância e poderiam ser influência das áreas de cerrados que existem nas adjacências dos fragmentos, como colocam os autores (Botrel et al., 2002; Rodrigues et al., 2003).

Ainda, se fazem importantes certas espécies que, embora neste estudo não tenham se destacado quanto aos IVIs e DRs, não foram encontradas nas outras fitofisionomias, e, na literatura, são comumente citadas como espécies importantes e características de cerrado s.s., como Erythroxylum suberosum, Schefflera vinosa e Campomanesia adamantium (Castro et al., 1999; Herrmann et al., 1998; Meira Neto, 1991; Ratter et al., 2003).

Desta forma, é possível identificar uma assinatura do cerrado s.s. na ACLS onde Xylopia aromatica, Qualea parviflora, Miconia albicans, Eugenia dysenterica e Stryphnodendron adstringens figuram entre as espécies fitossociológicamente mais importantes, enquanto Erythroxylum suberosum, Schefflera vinosa e Campomanesia adamantium, apesar de baixos índices, também devem ser considerados para o diagnóstico de cerrado s.s. da ACLS, por sua exclusividade. 


\subsection{FLORESTA SEMIDECÍDUA}

Aparecem como principais IVIs para a área de floresta semidecídua (Tabela 4): Myracrodruon urundeuva, Aspidosperma sp, Callisthene major, Machaerium opacum e Ocotea corymbosa. Contudo, apenas C. major, M. opacum e O. corymbosa se mostraram mais representativos nesta área do que nas outras, enquanto os outros táxons também aparecem bem representados ou na mata ciliar ou no cerrado s.s.. Mas essas três espécies não costumam ser classificadas como típicas da floresta semidecídua pelos trabalhos analisados da literatura fitossociológica.

Callisthene majo também ocorreu na área de cerrado s.s., mas com pequena representatividade. Nos trabalhos de cerrado em que é citada (Ratter et al., 2003), ou a espécie é considerada rara (Dos Santos, 2000), ou está presente em áreas florestais, como cerradão e mesmo mata semidecídua (Carvalho, D. A. \& Martins, 2009; Siqueira et al., 2006) ou, ainda, é classificada como espécie típica de florestas (Dos Santos, 2000; Oliveira, P. S. \& Marquis, 2002). Por outro lado, a espécie não é muito comum também na literatura para florestas semidecíduas, ocorrendo apenas em poucos estudos (Botrel et al., 2002; Rodrigues et al., 2003). Esta conjuntura de ocorrências parece indicar que $C$. major é, na verdade, uma espécie mais ocorrente em fitofisionomias florestais muito relacionadas com cerrado, sendo portanto, típica de florestas transicionais entre cerrado e semidecíduas ou, principalmente, de áreas de cerradões.

A ocorrência de Ocotea corymbosa também parece ser típica de áreas transicionais. Costa \& Araújo (2001) mostram que a espécie, embora possa ocorrer em cerrados s.s., possui IVIs significativamente mais altos em vegetações florestais. De fato, os maiores IVIs encontrados para a espécie estão em fitossociologias de cerradões (Costa \& Araújo, 2001; Meira Neto, 1991; Pereira-Silva et al., 2004), embora estudos em matas ciliares e semidecíduas mostrem uma representatividade de mediana a alta (Lopes \& Schiavini, 2007; Meyer, et al., 2004; Oliveira-Filho \& Machado, 1993a; Rodrigues et al., 2003; Van Den Berg \& Oliveira-Filho, 2000).

Já Machaerium opacum foi encontrado por Herrmann et al. (1998) em duas áreas de cerrado e em uma área de transição com mata, onde alcançou o $3^{\circ}$ maior IVI, resultado similar ao deste trabalho. Apenas fitossociologias de áreas de cerrado citam a ocorrência da espécie com representatividade de mediana a alta (Balduino et al., 2005; Costa \& Araújo, 2001; Saporetti Jr et al., 2003), sugerindo que sua presença resulta da influência do cerrado que circunda a área. 
Somente duas espécies, Eugenia involucrata e Annona sylvatica, com valores medianos e baixos de IVI e DR, foram exclusivas desta área. Elas costumam ocorrer em matas ciliares (Botrel et al., 2002; Ferreira Júnior et al., 2007; Lombardi \& Gonçalves, 2000; Mendonça, R. C. et al., 1998; Meyer, S. T. et al., 2004; Oliveira, R. J., 2006; Rodrigues et al., 2003; Santos, 2003; Van Den Berg \& Oliveira-Filho, 2000) e mostram que, além da influência do cerrado, a área também recebe influência da vegetação ripária.

Ficou evidente, por fim, a composição mista de espécies tanto de cerrado s.s. quanto de matas ciliares na área considerada como floresta semidecídua. Tal padrão reflete a dificuldade de classificação de determinadas fitofisionomias numa região de transição ecológica. A área não mostrou ter uma mata estacional semidecidual típica, e a grande influência de espécies comuns no cerrado bem representadas na áreas, traz o questionamento se a melhor classificação para a área não seria a denominação de “Cerradão”, em solo mesotrófico, rico em cálcio.

De qualquer forma, a assinatura dessa mata tem Ocotea corymbosa, Machaerium opacum e Callisthene major como espécies de muita importância e que não são bem representados nas outras fitofisionomias. As duas primeiras espécies ocorrem em diversos outros cerrados s.s., e, portanto, devem ser utilizados como indicadores de floresta semidecídua apenas localmente, assim como as espécies encontradas exclusivamente nesta fitofisionomia, como Eugenia involucrata e Annona sylvatica.

\subsection{MATA CILIAR}

A fitossociologia da mata ciliar foi estudada por meio de parcelas distribuídas em dois locais distantes, mas do mesmo remanescente (figura 1). Os resultados foram semelhantes para os dois locais e, assim, sua análise será feita utilizando todas as parcelas conjuntamente. As pequenas diferenças que surgiram serão pontuadas.

A mata ciliar mostrou altíssimos IVIs para Copaifera langsdorffii $(65,29)$ e Aspidosperma sp $(19,04)$. Contudo, são táxons presentes também nas demais fitofisionomias e com altos valores, não sendo diagnósticos da área.

Já as espécies Allophylus sericeus, na Fazenda Castelo de Jagoara e Trichilia elegans e Maytenus ilicifolia, na Fazenda Jagoara Velha, tiveram grande 
representatividade e são bons indicadores da fitofisionomia, por não ocorrerem nas outras áreas estudadas.

A. sericeus só é listado, em MG, em levantamentos florísticos de florestas semidecíduas e ciliares (Ferreira Júnior et al., 2007; Lombardi \& Gonçalves, 2000; Marangon et al., 2003; Ribas et al., 2003; Soares et al., 2006). Quando presente em trabalhos de cerrado, aparece associada às áreas de mata (Castro et al., 1999; Mendonça, et al., 1998).

T. elegans ocorre tipicamente em florestas úmidas, como as ombrófilas, matas ciliares e semidecíduas. Ribeiro \& Tabarelli (2002) também a encontraram no cerradão, mas os altos índices de importância da espécie nos estudos fitossociológicos de Oliveira (2006), de Santos (2003) e de Sciamarelli (2005) indicam que a espécie é bastante importante em áreas de floresta semidecidual. Hermann et al. (1998) não encontraram tal espécie na mesma ACLS, contudo deixaram não identificadas duas espécies de Trichilia $s p$, ocorrentes na mata semidecídua. Segundo os autores, todas as 5 espécies encontradas do gênero ocorreram em fisionomias florestais, exceto T. pallida, que foi encontrada também em um remanescente de cerrado. O gênero Trichilia $s p$, parece estar relacionado a ambientes florestais pois, de um total de 35 listas, aparece em 18, sendo todas florestais.

O mesmo foi constatado para Maytenus ilicifolia e para as espécies exclusivamente encontradas na mata ciliar do presente trabalho: Eugenia acutata, Cariniana legalis, Cupania oblongifolia, Cupania vernalis, Eugenia florida, Faramea sp, Inga vera, Ixora brevifolia, Nectandra cf. cissiflora, Ocotea velutina e Platymiscium aff pubescens. Estas espécies, mesmo quando em ambiente de cerrado $1 . s^{10}$., sempre estão associadas às matas de galeria, coerente com o que foi verificado em campo (Botrel et al., 2002; Peixoto et al., 2004; Rodrigues et al., 2003; Silva \& Scariot, 2003; Silva \& Soares, 2003; Souza, et al., 2003).

Assim, a assinatura florística e fitossociológica da mata ciliar estudada tem grande influência de táxons mais representativos de floresta semidecídua, com alta importância fitossociológica e diagnóstica de Allophylus sericeus, Trichilia elegans entre outras espécies do gênero, e Maytenus ilicifolia. Ainda, muitas são as espécies típicas de ambiente florestal que não foram encontradas nas outras áreas amostradas:

\footnotetext{
${ }^{10}$ lato sensu: delimitação mais genérica do cerrado, que inclui as diversas fitofisionomias presentes no bioma Cerrado
} 
Eugenia acutata, Cariniana legalis, Cupania oblongifolia, Cupania vernalis, Eugenia florida, Faramea sp, Inga vera, Ixora brevifolia, Nectandra cf. cissiflora, Ocotea velutina e Platymiscium aff pubescens. 
Tabela 3: Parâmetros fitossociológicos das espécies arbóreas, arbustivas e lianas do cerrado stricto sensu da ACLS Carste de Lagoa Santa, MG, Brasil. $\mathrm{N}_{\mathrm{p}}=\mathrm{n}^{\circ}$ de parcelas em que ocorre; $\mathrm{N}_{\mathrm{i}}=\mathrm{n}^{\circ}$ de indivíduos; $\mathrm{A} . \mathrm{B} .=$ área basal $\left(\mathrm{m}^{2}\right) ; \mathrm{FA}=$ Frequência absoluta; $\mathrm{FR}=$ Frequência relativa; DA = densidade absoluta; DR = Densidade relativa;

DoA = Dominância absoluta; DoR = dominância relativa; IVI = Índice do Valor de Importância; * = espécies levantadas apenas nesta fitofisionomia.

\section{FITOSSOCIOLOGIA - CERRADO}

\begin{tabular}{cl}
$\mathbf{n}^{\mathbf{o}}$ & \multicolumn{1}{c}{ NOME CIENTÍFICO } \\
1 & *Pera glabrata (Schott) Poepp. ex Baill. \\
2 & Xylopia aromatica (Lam.) Mart. \\
3 & *Miconia albicans (Sw.) Triana \\
4 & *Qualea grandiflora Mart. \\
5 & Terminalia argentea Mart. \\
6 & Copaifera langsdorffii Desf. \\
7 & *Eugenia dysenterica DC. \\
8 & *Stryphnodendron adstringens (Mart.) Coville \\
9 & *Rudgea viburnoides (Cham.) Benth. \\
10 & Cordiera macrophylla (K.Schum.) Kuntze \\
11 & *Caryocar brasiliense Cambess. \\
12 & Eupatorium sp \\
13 & *Plathymenia reticulata Benth. \\
14 & Protium heptaphyllum (Aubl.) Marchand \\
15 & *Zanthoxylum rhoifolium Lam. \\
16 & *Zeyheria montana Mart. \\
17 & *Leptolobium dasycarpum Vogel \\
18 & Myrcia splendens (Sw.) DC. \\
19 & *Heteropterys byrsonimiifolia A.Juss. \\
20 & *Siparuna guianensis Aubl. \\
21 & *Guapira noxia (Netto) Lundell \\
22 & Machaerium acutifolium Vogel \\
23 & *Myrsine umbellata Mart. \\
&
\end{tabular}

$\begin{array}{ccccccccccc}\text { FAMÍLIA } & \text { Np } & \text { Ni } & \text { Á.B. } & \text { FA } & \text { FR } & \text { DA } & \text { DR } & \text { DoA } & \text { DoR } & \text { IVI } \\ \text { EUPHORB. } & 12 & 49 & 0,96 & 0,92 & 4,84 & 376,92 & 9,51 & 7,40 & 21,85 & 36,21 \\ \text { ANNONAC. } & 12 & 56 & 0,24 & 0,92 & 4,84 & 430,77 & 10,87 & 1,87 & 5,51 & 21,23 \\ \text { MELAST. } & 11 & 49 & 0,14 & 0,85 & 4,44 & 376,92 & 9,51 & 1,14 & 3,36 & 17,31 \\ \text { VOCHYS. } & 11 & 26 & 0,26 & 0,85 & 4,44 & 200,00 & 5,05 & 2,04 & 6,03 & 15,52 \\ \text { COMBRET. } & 1 & 1 & 0,53 & 0,08 & 0,40 & 7,69 & 0,19 & 4,11 & 12,14 & 12,74 \\ \text { LEG. } & 5 & 13 & 0,29 & 0,38 & 2,02 & 100,00 & 2,52 & 2,28 & 6,73 & 11,27 \\ \text { MYRTAC. } & 7 & 18 & 0,15 & 0,54 & 2,82 & 138,46 & 3,50 & 1,19 & 3,51 & 9,83 \\ \text { LEG. } & 6 & 17 & 0,17 & 0,46 & 2,42 & 130,77 & 3,30 & 1,31 & 3,87 & 9,59 \\ \text { RUBIAC. } & 6 & 15 & 0,12 & 0,46 & 2,42 & 115,38 & 2,91 & 0,96 & 2,83 & 8,16 \\ \text { RUBIAC. } & 7 & 16 & 0,08 & 0,54 & 2,82 & 123,08 & 3,11 & 0,62 & 1,82 & 7,75 \\ \text { CARYOC. } & 4 & 4 & 0,20 & 0,31 & 1,61 & 30,77 & 0,78 & 1,55 & 4,59 & 6,98 \\ \text { ASTERAC. } & 5 & 16 & 0,04 & 0,38 & 2,02 & 123,08 & 3,11 & 0,37 & 1,08 & 6,21 \\ \text { LEG. } & 6 & 10 & 0,07 & 0,46 & 2,42 & 76,92 & 1,94 & 0,58 & 1,71 & 6,07 \\ \text { BURSERAC. } & 3 & 13 & 0,10 & 0,23 & 1,21 & 100,00 & 2,52 & 0,78 & 2,31 & 6,04 \\ \text { RUTAC. } & 7 & 12 & 0,03 & 0,54 & 2,82 & 92,31 & 2,33 & 0,24 & 0,70 & 5,86 \\ \text { BIG. } & 7 & 9 & 0,03 & 0,54 & 2,82 & 69,23 & 1,75 & 0,30 & 0,88 & 5,45 \\ \text { LEG. } & 5 & 8 & 0,06 & 0,38 & 2,02 & 61,54 & 1,55 & 0,53 & 1,57 & 5,14 \\ \text { MYRTAC. } & 5 & 11 & 0,03 & 0,38 & 2,02 & 84,62 & 2,14 & 0,25 & 0,74 & 4,89 \\ \text { MALPIGHI. } & 5 & 8 & 0,03 & 0,38 & 2,02 & 61,54 & 1,55 & 0,28 & 0,82 & 4,39 \\ \text { SIPARUN. } & 4 & 10 & 0,01 & 0,31 & 1,61 & 76,92 & 1,94 & 0,14 & 0,42 & 3,97 \\ \text { NYCTAG. } & 5 & 5 & 0,04 & 0,38 & 2,02 & 38,46 & 0,97 & 0,32 & 0,95 & 3,94 \\ \text { LEG. } & 4 & 7 & 0,03 & 0,31 & 1,61 & 53,85 & 1,36 & 0,25 & 0,73 & 3,70 \\ \text { MYRSIN. } & 4 & 8 & 0,02 & 0,31 & 1,61 & 61,54 & 1,55 & 0,15 & 0,46 & 3,62\end{array}$


24 Aspidosperma tomentosum Mart.

$25 *$ Schefflera macrocarpa (Cham. \& Schltdl.) Frodin

$26 *$ Myrsine guianensis (Aubl.) Kuntze

27 Magonia pubescens A.St.-Hil.

28 *Hymenaea stigonocarpa Mart. ex Hayne

29 Myrtaceae spl

30 Ouratea spl

31 Cordiera concolor (Cham.) Kuntze

32 *Schefflera vinosa (Cham. \& Schltdl.) Frodin \& Fiaschi

33 *Roupala montana Aubl.

34 *Schefflera morototoni (Aubl.) Maguire et al.

$35 *$ Xylopia brasiliensis Spreng.

36 Myrcia tomentosa (Aubl.) DC.

37 Myrcia hebepetala DC.

38 Machaerium opacum Vogel

$39 *$ Myrcia variabilis Mart. ex DC.

40 *Styrax camporum Pohl

41 Styrax sp1

42 Matayba guianensis Aubl.

43 Platypodium elegans Vogel

44 Terminalia sp1

45 Lippia sp1

46 Aspidosperma SP

47 *Tachigali aurea Tul.

48 *Plenckia populnea Reissek

$49 *$ Astronium graveolens Jacq.

50 *Vernonia $s p$

51 Callisthene major Mart. \& Zucc.

52 Tibouchina stenocarpa (Schrank \& Mart. ex DC.) Cogn.

$\begin{array}{cllllllllll}\text { APOCYN. } & 5 & 7 & 0,00 & 0,38 & 2,02 & 53,85 & 1,36 & 0,07 & 0,20 & 3,58 \\ \text { ARALIAC. } & 5 & 6 & 0,01 & 0,38 & 2,02 & 46,15 & 1,17 & 0,11 & 0,32 & 3,51 \\ \text { MYRSIN. } & 4 & 5 & 0,03 & 0,31 & 1,61 & 38,46 & 0,97 & 0,27 & 0,79 & 3,37 \\ \text { SAPIND. } & 3 & 6 & 0,04 & 0,23 & 1,21 & 46,15 & 1,17 & 0,31 & 0,93 & 3,30 \\ \text { LEG. } & 1 & 1 & 0,11 & 0,08 & 0,40 & 7,69 & 0,19 & 0,91 & 2,69 & 3,29 \\ \text { MYRTAC. } & 5 & 5 & 0,00 & 0,38 & 2,02 & 38,46 & 0,97 & 0,05 & 0,14 & 3,12 \\ \text { OCHNAC. } & 3 & 5 & 0,03 & 0,23 & 1,21 & 38,46 & 0,97 & 0,24 & 0,72 & 2,90 \\ \text { RUBIAC. } & 3 & 4 & 0,03 & 0,23 & 1,21 & 30,77 & 0,78 & 0,30 & 0,89 & 2,87 \\ \text { ARALIAC. } & 3 & 6 & 0,02 & 0,23 & 1,21 & 46,15 & 1,17 & 0,16 & 0,47 & 2,85 \\ \text { PROTEAC. } & 4 & 4 & 0,01 & 0,31 & 1,61 & 30,77 & 0,78 & 0,09 & 0,27 & 2,66 \\ \text { ARALIAC. } & 3 & 3 & 0,02 & 0,23 & 1,21 & 23,08 & 0,58 & 0,16 & 0,46 & 2,26 \\ \text { ANNONAC. } & 2 & 6 & 0,01 & 0,15 & 0,81 & 46,15 & 1,17 & 0,09 & 0,28 & 2,25 \\ \text { MYRTAC. } & 3 & 4 & 0,00 & 0,23 & 1,21 & 30,77 & 0,78 & 0,04 & 0,12 & 2,11 \\ \text { MYRTAC. } & 3 & 3 & 0,01 & 0,23 & 1,21 & 23,08 & 0,58 & 0,09 & 0,27 & 2,06 \\ \text { LEG. } & 3 & 3 & 0,00 & 0,23 & 1,21 & 23,08 & 0,58 & 0,07 & 0,21 & 2,00 \\ \text { MYRTAC. } & 3 & 3 & 0,00 & 0,23 & 1,21 & 23,08 & 0,58 & 0,05 & 0,14 & 1,93 \\ \text { STYRAC. } & 3 & 3 & 0,00 & 0,23 & 1,21 & 23,08 & 0,58 & 0,04 & 0,11 & 1,90 \\ \text { STYRAC. } & 3 & 3 & 0,00 & 0,23 & 1,21 & 23,08 & 0,58 & 0,04 & 0,11 & 1,90 \\ \text { SAPIND. } & 3 & 3 & 0,00 & 0,23 & 1,21 & 23,08 & 0,58 & 0,03 & 0,07 & 1,87 \\ \text { LEG. } & 2 & 2 & 0,02 & 0,15 & 0,81 & 15,38 & 0,39 & 0,20 & 0,60 & 1,80 \\ \text { COMBRET. } & 1 & 2 & 0,04 & 0,08 & 0,40 & 15,38 & 0,39 & 0,33 & 0,96 & 1,76 \\ \text { VERBEN. } & 2 & 3 & 0,01 & 0,15 & 0,81 & 23,08 & 0,58 & 0,08 & 0,24 & 1,63 \\ \text { APOCYN. } & 2 & 2 & 0,01 & 0,15 & 0,81 & 15,38 & 0,39 & 0,12 & 0,36 & 1,56 \\ \text { LEG. } & 2 & 2 & 0,01 & 0,15 & 0,81 & 15,38 & 0,39 & 0,09 & 0,28 & 1,47 \\ \text { CELAST. } & 2 & 2 & 0,01 & 0,15 & 0,81 & 15,38 & 0,39 & 0,08 & 0,24 & 1,43 \\ \text { ANACARD. } & 2 & 2 & 0,00 & 0,15 & 0,81 & 15,38 & 0,39 & 0,06 & 0,17 & 1,36 \\ \text { ASTERAC. } & 1 & 4 & 0,00 & 0,08 & 0,40 & 30,77 & 0,78 & 0,06 & 0,18 & 1,36 \\ \text { VOCHYS. } & 2 & 2 & 0,00 & 0,15 & 0,81 & 15,38 & 0,39 & 0,04 & 0,11 & 1,31 \\ \text { MELAST. } & 2 & 2 & 0,00 & 0,15 & 0,81 & 15,38 & 0,39 & 0,03 & 0,09 & 1,29\end{array}$




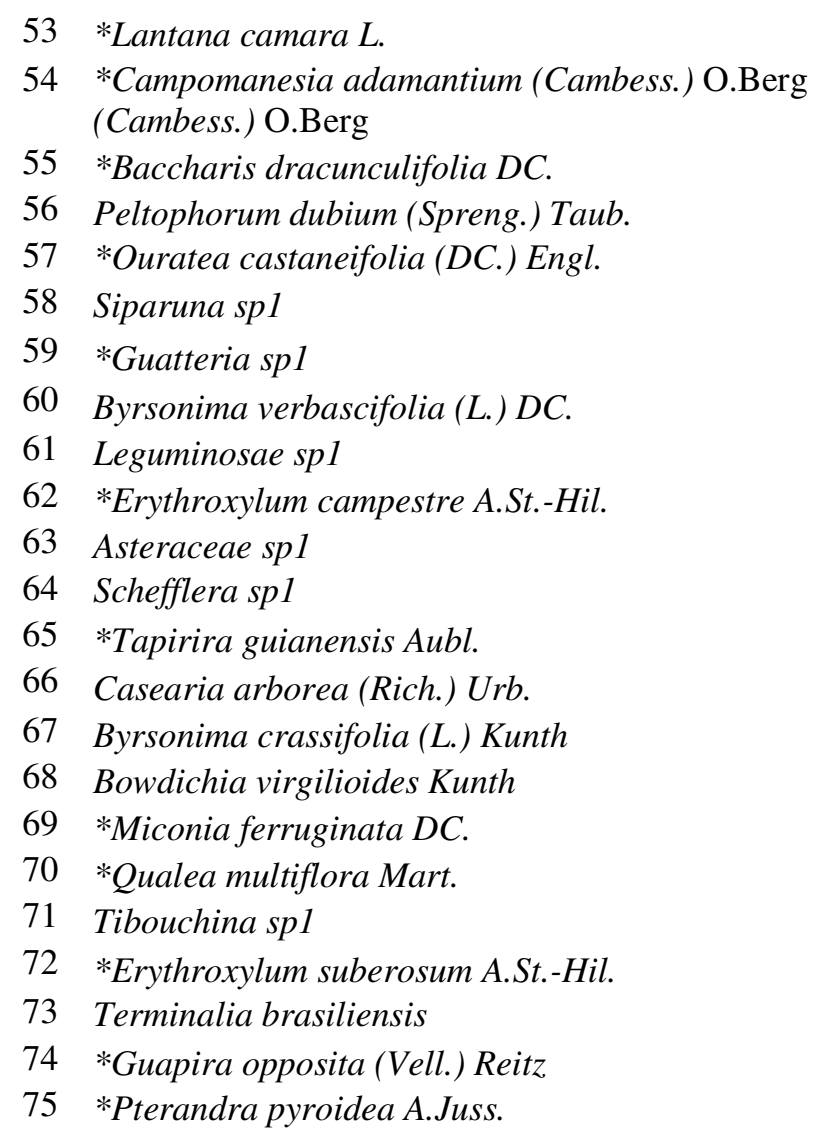

\begin{tabular}{ccccccccccc} 
Labiat. & 2 & 2 & 0,00 & 0,15 & 0,81 & 15,38 & 0,39 & 0,03 & 0,09 & 1,29 \\
MYRTAC. & 2 & 2 & 0,00 & 0,15 & 0,81 & 15,38 & 0,39 & 0,02 & 0,06 & 1,26 \\
ASTERAC. & 2 & 2 & 0,00 & 0,15 & 0,81 & 15,38 & 0,39 & 0,01 & 0,04 & 1,24 \\
LEG. & 1 & 1 & 0,02 & 0,08 & 0,40 & 7,69 & 0,19 & 0,21 & 0,61 & 1,21 \\
OCHNAC. & 1 & 2 & 0,01 & 0,08 & 0,40 & 15,38 & 0,39 & 0,14 & 0,40 & 1,19 \\
SIPARUN. & 1 & 3 & 0,00 & 0,08 & 0,40 & 23,08 & 0,58 & 0,06 & 0,18 & 1,17 \\
ANNONAC. & 1 & 2 & 0,00 & 0,08 & 0,40 & 15,38 & 0,39 & 0,06 & 0,17 & 0,96 \\
MALPIGHI. & 1 & 2 & 0,00 & 0,08 & 0,40 & 15,38 & 0,39 & 0,05 & 0,15 & 0,94 \\
LEG. & 1 & 1 & 0,00 & 0,08 & 0,40 & 7,69 & 0,19 & 0,07 & 0,21 & 0,81 \\
Erythr. & 1 & 1 & 0,00 & 0,08 & 0,40 & 7,69 & 0,19 & 0,06 & 0,17 & 0,77 \\
ASTERAC. & 1 & 1 & 0,00 & 0,08 & 0,40 & 7,69 & 0,19 & 0,04 & 0,13 & 0,73 \\
ARALIAC. & 1 & 1 & 0,00 & 0,08 & 0,40 & 7,69 & 0,19 & 0,04 & 0,11 & 0,71 \\
ANACARD. & 1 & 1 & 0,00 & 0,08 & 0,40 & 7,69 & 0,19 & 0,04 & 0,10 & 0,70 \\
FLACOURT. & 1 & 1 & 0,00 & 0,08 & 0,40 & 7,69 & 0,19 & 0,03 & 0,10 & 0,69 \\
MALPIGHI. & 1 & 1 & 0,00 & 0,08 & 0,40 & 7,69 & 0,19 & 0,03 & 0,08 & 0,68 \\
MALPIGHI. & 1 & 1 & 0,00 & 0,08 & 0,40 & 7,69 & 0,19 & 0,02 & 0,07 & 0,67 \\
MELAST. & 1 & 1 & 0,00 & 0,08 & 0,40 & 7,69 & 0,19 & 0,02 & 0,06 & 0,66 \\
VOCHYS. & 1 & 1 & 0,00 & 0,08 & 0,40 & 7,69 & 0,19 & 0,02 & 0,05 & 0,64 \\
MELAST. & 1 & 1 & 0,00 & 0,08 & 0,40 & 7,69 & 0,19 & 0,02 & 0,05 & 0,64 \\
Erythr. & 1 & 1 & 0,00 & 0,08 & 0,40 & 7,69 & 0,19 & 0,01 & 0,03 & 0,63 \\
COMBRET. & 1 & 1 & 0,00 & 0,08 & 0,40 & 7,69 & 0,19 & 0,01 & 0,03 & 0,63 \\
NYCTAG. & 1 & 1 & 0,00 & 0,08 & 0,40 & 7,69 & 0,19 & 0,01 & 0,02 & 0,61 \\
MALPIGHI. & 1 & 1 & 0,00 & 0,08 & 0,40 & 7,69 & 0,19 & 0,01 & 0,02 & 0,61 \\
\hline & & & & & & & & & &
\end{tabular}


Tabela 4: Parâmetros fitossociológicos das espécies arbóreas, arbustivas e lianescentes da área de floresta semidecídua da ACLS Carste de Lagoa Santa, MG, Brasil. $\mathrm{N}_{\mathrm{p}}$ $=\mathrm{n}^{\mathrm{o}}$ de parcelas em que ocorre; $\mathrm{N}_{\mathrm{i}}=\mathrm{n}^{\mathrm{o}}$ de indivíduos; $\mathrm{A} . \mathrm{B} .=$ área basal $\left(\mathrm{m}^{2}\right) ; \mathrm{FA}=$ Frequência absoluta; FR $=$ Frequência relativa; $\mathrm{DA}=$ densidade absoluta; $\mathrm{DR}=$

Densidade relativa; DoA = Dominância absoluta; DoR = dominância relativa; IVI = Índice do Valor de Importância; * = espécies levantadas apenas nesta fitofisionomia.

\section{FITOSSOCIOLOGIA - FLORESTA SEMIDECÍIDUA}

$\mathbf{n}^{\mathbf{o}}$

1 Myracrodruon urundeuva Allemão

2 Aspidosperma SP

3 Callisthene major Mart. \& Zucc.

4 Machaerium opacum Vogel

5 Ocotea corymbosa (Meisn.) Mez

6 Protium heptaphyllum (Aubl.) Marchand

7 Casearia sylvestris $S w$.

8 Swartzia macrostachya Benth.

9 Myrcia rufipes DC.

10 Platypodium elegans Vogel

11 Terminalia $s p$

12 Peltophorum dubium (Spreng.) Taub.

13 Xylopia aromatica (Lam.) Mart.

14 Alibertia sp

15 Magonia pubescens A.St.-Hil.

16 Chrysophyllum/Pouteria sp

17 Lonchocarpus sp

18 Cordiera macrophylla (K.Schum.) Kuntze

19 Magonia sp1

20 Mystaceae sp7

21 Senna macranthera (DC. ex Collad.) H.S.Irwin \& Barneby

22 Eugenia aurata O.Berg

$\begin{array}{ccccccccccc}\text { FAMÍLIA } & \text { Np } & \text { Ni } & \text { A.B. } & \text { FA } & \text { FR } & \text { DA } & \text { DR } & \text { DoA } & \text { DoR } & \text { IVI } \\ \text { ANACARD. } & 5 & 15 & 0,59 & 0,83 & 8,20 & 250,00 & 16,67 & 9,84 & 32,98 & 57,85 \\ \text { APOCYN. } & 4 & 7 & 0,15 & 0,67 & 6,56 & 116,67 & 7,78 & 2,45 & 8,20 & 22,53 \\ \text { VOCHYS. } & 3 & 9 & 0,04 & 0,50 & 4,92 & 150,00 & 10,00 & 0,69 & 2,33 & 17,24 \\ \text { LEG. } & 1 & 1 & 0,25 & 0,17 & 1,64 & 16,67 & 1,11 & 4,11 & 13,78 & 16,53 \\ \text { LAURAC. } & 2 & 2 & 0,17 & 0,33 & 3,28 & 33,33 & 2,22 & 2,87 & 9,62 & 15,12 \\ \text { BURSERAC. } & 2 & 3 & 0,08 & 0,33 & 3,28 & 50,00 & 3,33 & 1,30 & 4,36 & 10,98 \\ \text { FLACOURT. } & 3 & 4 & 0,01 & 0,50 & 4,92 & 66,67 & 4,44 & 0,23 & 0,77 & 10,14 \\ \text { LEG. } & 2 & 3 & 0,06 & 0,33 & 3,28 & 50,00 & 3,33 & 1,04 & 3,49 & 10,10 \\ \text { MYRTAC. } & 3 & 4 & 0,01 & 0,50 & 4,92 & 66,67 & 4,44 & 0,10 & 0,35 & 9,71 \\ \text { LEG. } & 1 & 1 & 0,12 & 0,17 & 1,64 & 16,67 & 1,11 & 2,04 & 6,84 & 9,59 \\ \text { COMBRET. } & 2 & 4 & 0,03 & 0,33 & 3,28 & 66,67 & 4,44 & 0,54 & 1,81 & 9,53 \\ \text { LEG. } & 1 & 4 & 0,03 & 0,17 & 1,64 & 66,67 & 4,44 & 0,49 & 1,65 & 7,73 \\ \text { ANNONAC. } & 2 & 2 & 0,02 & 0,33 & 3,28 & 33,33 & 2,22 & 0,33 & 1,10 & 6,60 \\ \text { RUBIAC. } & 2 & 2 & 0,01 & 0,33 & 3,28 & 33,33 & 2,22 & 0,11 & 0,38 & 5,88 \\ \text { SAPIND. } & 1 & 1 & 0,04 & 0,17 & 1,64 & 16,67 & 1,11 & 0,60 & 2,00 & 4,75 \\ \text { SAPOTAC. } & 1 & 1 & 0,03 & 0,17 & 1,64 & 16,67 & 1,11 & 0,50 & 1,66 & 4,41 \\ \text { LEG. } & 1 & 1 & 0,03 & 0,17 & 1,64 & 16,67 & 1,11 & 0,48 & 1,60 & 4,35 \\ \text { RUBIAC. } & 1 & 2 & 0,00 & 0,17 & 1,64 & 33,33 & 2,22 & 0,07 & 0,25 & 4,11 \\ \text { SAPIND. } & 1 & 1 & 0,02 & 0,17 & 1,64 & 16,67 & 1,11 & 0,33 & 1,11 & 3,86 \\ \text { MYRTAC. } & 1 & 1 & 0,02 & 0,17 & 1,64 & 16,67 & 1,11 & 0,33 & 1,11 & 3,86 \\ \text { LEG. } & 1 & 1 & 0,02 & 0,17 & 1,64 & 16,67 & 1,11 & 0,29 & 0,98 & 3,73 \\ \text { MYRTAC. } & 1 & 1 & 0,01 & 0,17 & 1,64 & 16,67 & 1,11 & 0,20 & 0,68 & 3,43\end{array}$




\begin{tabular}{|c|c|c|c|c|c|c|c|c|c|c|c|c|}
\hline \multicolumn{13}{|c|}{ Continuação... } \\
\hline 23 & Byrsonima sp & MALPIGHI. & 1 & 1 & 0,01 & 0,17 & 1,64 & 16,67 & 1,11 & 0,17 & 0,58 & 3,33 \\
\hline 24 & Myrtaceae sp4 & MYRTAC. & 1 & 1 & 0,01 & 0,17 & 1,64 & 16,67 & 1,11 & 0,10 & 0,32 & 3,07 \\
\hline 25 & Myrtaceae sp8 & MYRTAC. & 1 & 1 & 0,01 & 0,17 & 1,64 & 16,67 & 1,11 & 0,09 & 0,30 & 3,05 \\
\hline 26 & Myrtaceae sp9 & MYRTAC. & 1 & 1 & 0,00 & 0,17 & 1,64 & 16,67 & 1,11 & 0,06 & 0,20 & 2,95 \\
\hline 27 & Copaifera langsdorffii Desf. & LEG. & 1 & 1 & 0,00 & 0,17 & 1,64 & 16,67 & 1,11 & 0,05 & 0,18 & 2,93 \\
\hline 28 & *Annona sylvatica A.St.-Hil. & ANNONAC. & 1 & 1 & 0,00 & 0,17 & 1,64 & 16,67 & 1,11 & 0,05 & 0,18 & 2,93 \\
\hline 29 & Zeyheria tuberculosa (Vell.) Bureau ex Verl. & BIG. & 1 & 1 & 0,00 & 0,17 & 1,64 & 16,67 & 1,11 & 0,05 & 0,18 & 2,93 \\
\hline 30 & Myrtaceae sp6 & MYRTAC. & 1 & 1 & 0,00 & 0,17 & 1,64 & 16,67 & 1,11 & 0,04 & 0,14 & 2,89 \\
\hline 31 & Myrtaceae sp3 & MYRTAC. & 1 & 1 & 0,00 & 0,17 & 1,64 & 16,67 & 1,11 & 0,04 & 0,13 & 2,88 \\
\hline 32 & Handroanthus sp & BIG. & 1 & 1 & 0,00 & 0,17 & 1,64 & 16,67 & 1,11 & 0,03 & 0,11 & 2,86 \\
\hline 33 & Myrtaceae sp2 & MYRTAC. & 1 & 1 & 0,00 & 0,17 & 1,64 & 16,67 & 1,11 & 0,03 & 0,10 & 2,85 \\
\hline 34 & Myrtaceae sp1 & MYRTAC. & 1 & 1 & 0,00 & 0,17 & 1,64 & 16,67 & 1,11 & 0,03 & 0,09 & 2,84 \\
\hline 35 & Myrcia splendens (Sw.) DC. & MYRTAC. & 1 & 1 & 0,00 & 0,17 & 1,64 & 16,67 & 1,11 & 0,02 & 0,08 & 2,83 \\
\hline 36 & Annonaceae sp1 & ANNONAC. & 1 & 1 & 0,00 & 0,17 & 1,64 & 16,67 & 1,11 & 0,02 & 0,06 & 2,81 \\
\hline 37 & Myrcia tomentosa (Aubl.) DC. & MYRTAC. & 1 & 1 & 0,00 & 0,17 & 1,64 & 16,67 & 1,11 & 0,02 & 0,06 & 2,81 \\
\hline 38 & Myrtaceae sp5 & MYRTAC. & 1 & 1 & 0,00 & 0,17 & 1,64 & 16,67 & 1,11 & 0,02 & 0,06 & 2,81 \\
\hline 39 & Chamaecrista apoucouita (Aubl.) H.S.Irwin \& Barneby & LEG. & 1 & 1 & 0,00 & 0,17 & 1,64 & 16,67 & 1,11 & 0,02 & 0,05 & 2,80 \\
\hline 40 & Vochysiaceae. sp1 & VOCHYS. & 1 & 1 & 0,00 & 0,17 & 1,64 & 16,67 & 1,11 & 0,02 & 0,05 & 2,80 \\
\hline 41 & *Eugenia involucrata DC. & MYRTAC. & 1 & 1 & 0,00 & 0,17 & 1,64 & 16,67 & 1,11 & 0,01 & 0,04 & 2,79 \\
\hline 42 & Xylopia sp1 & ANNONAC. & 1 & 1 & 0,00 & 0,17 & 1,64 & 16,67 & 1,11 & 0,01 & 0,04 & 2,79 \\
\hline
\end{tabular}


Tabela 5: Parâmetros fitossociológicos das espécies arbóreas, arbustivas e lianas da área de mata ciliar da ACLS Carste de Lagoa Santa, $\mathrm{MG}$, Brasil. $\mathrm{N}_{\mathrm{p}}=\mathrm{n}^{\circ}$ de parcelas em que ocorre; $\mathrm{N}_{\mathrm{i}}=\mathrm{n}^{\circ}$ de indivíduos; A.B. = área basal $\left(\mathrm{m}^{2}\right) ; \mathrm{FA}=$ Frequência absoluta; FR $=$ Frequência relativa; $\mathrm{DA}=$ densidade absoluta; DR = Densidade relativa; DoA = Dominância absoluta; DoR = dominância relativa; IVI = Índice do Valor de Importância; * = espécies levantadas apenas nesta

fitofisionomia.

\section{FITOSSOCIOLOGIA - MATA CILIAR}

$\mathbf{n}^{\mathbf{0}}$

1 Copaifera langsdorffii Desf.

\section{Aspidosperma sp}

*Allophylus sericeus (Cambess.) Radlk.

Myracrodruon urundeuva Allemão

*Trichilia elegans A.Juss.

*Maytenus ilicifolia Mart. ex Reissek

\section{Trichilia sp}

Cordiera macrophylla (K.Schum.) Kuntze n.i.

10 *Eugenia acutata Miq.

11 Protium heptaphyllum (Aubl.) Marchand

12 Casearia sylvestris $S w$.

13 Leguminosae sp

14 Swartzia macrostachya Benth.

$15 *$ Trichilia pallida $S w$.

16 Eugenia aurata O.Berg

17 Alibertia sp

18 *Acrocomia aculeata (Jacq.) Lodd. ex Mart.

19 Myrcia rufipes DC.

20 Terminalia sp

21 *Cupania oblongifolia Mart.

22 Myrtaceae sp

\section{FAMÍLIA}

LEG.

APOCYN.

SAPIND.

ANACARD.

MELIAC.

CELAST.

MELIAC.

RUBIAC.

n.i.

MYRTAC.

BURSERAC.

FLACOURT.

LEG.

LEG.

MELIAC.

MYRTAC.

RUBIAC.

AREC.

MYRTAC.

COMBRET.

SAPIND.

MYRTAC.

\section{Np Ni. Á.B. FA FR DA DR DoA DoR IVI}

$\begin{array}{llllllllll}11 & 19 & 3,86 & 0,92 & 8,73 & 158,33 & 8,09 & 32,13 & 48,47 & 65,29\end{array}$

$\begin{array}{llllllllll}5 & 5 & 1,03 & 0,42 & 3,97 & 41,67 & 2,13 & 8,58 & 12,94 & 19,04\end{array}$

$\begin{array}{llllllllll}5 & 22 & 0,17 & 0,42 & 3,97 & 183,33 & 9,36 & 1,38 & 2,08 & 15,41\end{array}$

$\begin{array}{llllllllll}5 & 6 & 0,58 & 0,42 & 3,97 & 50,00 & 2,55 & 4,82 & 7,27 & 13,79\end{array}$

$\begin{array}{llllllllll}8 & 15 & 0,08 & 0,67 & 6,35 & 125,00 & 6,38 & 0,67 & 1,02 & 13,75\end{array}$

$\begin{array}{lllllllllll}6 & 18 & 0,05 & 0,50 & 4,76 & 150,00 & 7,66 & 0,44 & 0,66 & 13,08\end{array}$

$\begin{array}{lllllllllll}5 & 19 & 0,07 & 0,42 & 3,97 & 158,33 & 8,09 & 0,59 & 0,90 & 12,95\end{array}$

$\begin{array}{lllllllllll}6 & 16 & 0,03 & 0,50 & 4,76 & 133,33 & 6,81 & 0,29 & 0,44 & 12,01\end{array}$

$\begin{array}{lllllllllll}6 & 10 & 0,14 & 0,50 & 4,76 & 83,33 & 4,26 & 1,13 & 1,70 & 10,72\end{array}$

$\begin{array}{lllllllllll}4 & 14 & 0,09 & 0,33 & 3,17 & 116,67 & 5,96 & 0,77 & 1,16 & 10,29\end{array}$

$\begin{array}{llllllllll}5 & 10 & 0,08 & 0,42 & 3,97 & 83,33 & 4,26 & 0,65 & 0,98 & 9,21\end{array}$

$\begin{array}{lllllllllll}5 & 8 & 0,05 & 0,42 & 3,97 & 66,67 & 3,40 & 0,40 & 0,60 & 7,97\end{array}$

$\begin{array}{llllllllll}2 & 3 & 0,36 & 0,17 & 1,59 & 25,00 & 1,28 & 3,03 & 4,57 & 7,43\end{array}$

$\begin{array}{llllllllll}3 & 4 & 0,22 & 0,25 & 2,38 & 33,33 & 1,70 & 1,83 & 2,76 & 6,85\end{array}$

$\begin{array}{llllllllll}4 & 4 & 0,02 & 0,33 & 3,17 & 33,33 & 1,70 & 0,14 & 0,21 & 5,08\end{array}$

$\begin{array}{llllllllll}3 & 4 & 0,07 & 0,25 & 2,38 & 33,33 & 1,70 & 0,57 & 0,86 & 4,95\end{array}$

$\begin{array}{llllllllll}1 & 7 & 0,02 & 0,08 & 0,79 & 58,33 & 2,98 & 0,16 & 0,24 & 4,01\end{array}$

$\begin{array}{llllllllll}2 & 2 & 0,12 & 0,17 & 1,59 & 16,67 & 0,85 & 0,97 & 1,46 & 3,90\end{array}$

$\begin{array}{llllllllll}3 & 3 & 0,00 & 0,25 & 2,38 & 25,00 & 1,28 & 0,03 & 0,05 & 3,70\end{array}$

$\begin{array}{lllllllllll}1 & 1 & 0,18 & 0,08 & 0,79 & 8,33 & 0,43 & 1,49 & 2,25 & 3,47\end{array}$

$\begin{array}{lllllllllll}1 & 1 & 5 & 0,02 & 0,08 & 0,79 & 41,67 & 2,13 & 0,18 & 0,27 & 3,19\end{array}$

$\begin{array}{llllllllll}1 & 5 & 0,02 & 0,08 & 0,79 & 41,67 & 2,13 & 0,18 & 0,27 & 3,19 \\ 2 & 3 & 0,02 & 0,17 & 1,59 & 25,00 & 1,28 & 0,19 & 0,29 & 3,16\end{array}$ 
CAPÍtUlO 01

\begin{tabular}{|c|c|c|c|c|c|c|c|c|c|c|c|c|}
\hline \multicolumn{13}{|c|}{ Continuação... } \\
\hline 23 & *Cupania vernalis Cambess. & SAPIND. & 2 & 2 & 0,03 & 0,17 & 1,59 & 16,67 & 0,85 & 0,22 & 0,34 & 2,78 \\
\hline 24 & *Ixora brevifolia Benth. & RUBIAC. & 2 & 2 & 0,02 & 0,17 & 1,59 & 16,67 & 0,85 & 0,18 & 0,28 & 2,72 \\
\hline 25 & *Nectandra cf cissiflora Nees & LAURAC. & 1 & 1 & 0,12 & 0,08 & 0,79 & 8,33 & 0,43 & 0,99 & 1,49 & 2,71 \\
\hline 26 & *Eugenia florida DC. & MYRTAC. & 2 & 2 & 0,02 & 0,17 & 1,59 & 16,67 & 0,85 & 0,14 & 0,21 & 2,65 \\
\hline 27 & Lonchocarpus muehlbergianus Hassl. & LEG. & 2 & 2 & 0,01 & 0,17 & 1,59 & 16,67 & 0,85 & 0,09 & 0,14 & 2,58 \\
\hline 28 & *Platymiscium aff pubescens Micheli & LEG. & 1 & 1 & 0,09 & 0,08 & 0,79 & 8,33 & 0,43 & 0,75 & 1,12 & 2,34 \\
\hline 29 & *Trichilia clausseni C. DC. & MELIAC. & 1 & 3 & 0,02 & 0,08 & 0,79 & 25,00 & 1,28 & 0,17 & 0,26 & 2,33 \\
\hline 30 & Machaerium acutifolium Vogel & LEG. & 1 & 1 & 0,08 & 0,08 & 0,79 & 8,33 & 0,43 & 0,68 & 1,02 & 2,24 \\
\hline 31 & *Faramea sp & RUBIAC. & 1 & 2 & 0,03 & 0,08 & 0,79 & 16,67 & 0,85 & 0,27 & 0,41 & 2,06 \\
\hline 32 & Alibertiac cf Macrophylla & RUBIAC. & 1 & 2 & 0,03 & 0,08 & 0,79 & 16,67 & 0,85 & 0,21 & 0,32 & 1,97 \\
\hline 33 & Annonaceae sp & ANNONAC. & 1 & 1 & 0,05 & 0,08 & 0,79 & 8,33 & 0,43 & 0,39 & 0,59 & 1,81 \\
\hline 34 & *Cariniana legalis (Mart.) Kuntze & LECYTHID. & 1 & 1 & 0,04 & 0,08 & 0,79 & 8,33 & 0,43 & 0,36 & 0,55 & 1,77 \\
\hline 35 & cf Chamaecrista ensiformis (Vell.) H.S.Irwin \& Barneby & LEG. & 1 & 1 & 0,04 & 0,08 & 0,79 & 8,33 & 0,43 & 0,31 & 0,46 & 1,68 \\
\hline 36 & ANACARD./BURSERAC. & ANAC./BURSER. & 1 & 1 & 0,03 & 0,08 & 0,79 & 8,33 & 0,43 & 0,22 & 0,34 & 1,56 \\
\hline 37 & *Inga vera Willd. & LEG. & 1 & 1 & 0,02 & 0,08 & 0,79 & 8,33 & 0,43 & 0,21 & 0,31 & 1,53 \\
\hline 38 & Nyctaginaceae $s p$ & NYCTAG. & 1 & 1 & 0,02 & 0,08 & 0,79 & 8,33 & 0,43 & 0,19 & 0,28 & 1,50 \\
\hline 39 & Matayba sp & SAPIND. & 1 & 1 & 0,02 & 0,08 & 0,79 & 8,33 & 0,43 & 0,14 & 0,21 & 1,43 \\
\hline 40 & Handroanthus serratifolius (A.H.Gentry) S.Grose & BIG. & 1 & 1 & 0,01 & 0,08 & 0,79 & 8,33 & 0,43 & 0,07 & 0,11 & 1,33 \\
\hline 41 & *Ocotea velutina (Nees) Rohwer & LAURAC. & 1 & 1 & 0,01 & 0,08 & 0,79 & 8,33 & 0,43 & 0,06 & 0,09 & 1,31 \\
\hline 42 & Matayba guianensis Aubl. & SAPIND. & 1 & 1 & 0,00 & 0,08 & 0,79 & 8,33 & 0,43 & 0,04 & 0,06 & 1,28 \\
\hline 43 & Myrcia tomentosa (Aubl.) DC. & MYRTAC. & 1 & 1 & 0,00 & 0,08 & 0,79 & 8,33 & 0,43 & 0,03 & 0,05 & 1,27 \\
\hline 44 & Casearia $S P$ & FLACOURT. & 1 & 1 & 0,00 & 0,08 & 0,79 & 8,33 & 0,43 & 0,03 & 0,04 & 1,26 \\
\hline 45 & *Trichilia catigua A.Juss. & MELIAC. & 1 & 1 & 0,00 & 0,08 & 0,79 & 8,33 & 0,43 & 0,02 & 0,04 & 1,26 \\
\hline 46 & Ocotea cf corymbosa & LAURAC. & 1 & 1 & 0,00 & 0,08 & 0,79 & 8,33 & 0,43 & 0,02 & 0,03 & 1,25 \\
\hline 47 & Myrcia hebepetala DC. & MYRTAC. & 1 & 1 & 0,00 & 0,08 & 0,79 & 8,33 & 0,43 & 0,01 & 0,02 & 1,24 \\
\hline 48 & Senna sp & LEG. & 1 & 1 & 0,00 & 0,08 & 0,79 & 8,33 & 0,43 & 0,01 & 0,02 & 1,24 \\
\hline 49 & Cupania sp & SAPIND. & 1 & 1 & 0,00 & 0,08 & 0,79 & 8,33 & 0,43 & 0,01 & 0,01 & 1,23 \\
\hline 50 & Zeyheria tuberculosa (Vell.) Bureau ex Verl. & BIG. & 1 & 1 & 0,00 & 0,08 & 0,79 & 8,33 & 0,43 & 0,01 & 0,01 & 1,23 \\
\hline 51 & Siphoneugena cf. densiflora O.Berg & MYRTAC. & 1 & 1 & 0,00 & 0,08 & 0,79 & 8,33 & 0,43 & 0,01 & 0,01 & 1,23 \\
\hline
\end{tabular}




\subsection{CONSIDERAÇÕES FINAIS}

O levantamento florístico-lenhoso da APA Carste de Lagoa Santa apresentado revelou um cenário aparente de grandes mudanças florísticas nos últimos 150 anos da região de Lagoa Santa, com significativa perda de espécies que, embora não se possa precisar devido às diferenças metodológicas, é discutida como consequência do crescimento da interferência antrópica. Entretanto, muitas espécies não identificadas por Warming (1908) foram encontradas e contribuiram para revelar uma expressiva riqueza de espécies lenhosas na região, mesmo quando comparada com a riqueza de parques com biomas similares reconhecidos como patrimônio natural mundial, como o Parque Nacional de Emas.

Tal riqueza é influenciada principalmente pelo mosaico de vegetações existente na área, com o contato do bioma do Cerrado com a Mata Atlântica. Tal importância sugere que as estratégias de conservação da biodiversidade vegetal da ACLS devem considerar a preservação do mosaico de remanescentes, e não apenas determinados remanescentes. A presença de 12 espécies ameaçadas, sendo três na categoria de vulneráveis à extinção no Estado de Minas Gerais, também é um importante indicador para estas estratégias.

Já os estudos fitossociológicos mostraram diferenças estruturais e florísticas de algumas fitofisionomias da ACLS. A análise das espécies representativas e diagnósticas das áreas amostradas teve sucesso ao indicar táxons típicos ou exclusivos de determinadas fisionomias vegetais da região e, juntamente com o significativo acervo de referência de lenhos coletados e com o levantamento florístico bastante completo, será de muita utilidade na interpretação paleoambiental das pesquisas paleobotânicas desenvolvidas na Região Arqueológica de Lagoa Santa.

\subsection{REFERÊNCIAS BIBLIOGRÁFICAS}

BALDUINO, A. P. D. C. et al. 2005. Fitossociologia e análise comparativa da composição florística do cerrado da flora de Paraopeba-MG. Revista Árvore, v.29, p.25-34.

BATALHA, M. A. \& W. MANTOVANI. 2001. Floristic composition of the cerrado in the Pé-de-Gigante Reserve (Santa Rita do Passa Quatro, southeastern Brazil). Acta Botanica Brasilica, v.15, p.289-304. 
BATALHA, M. A. \& F. R. MARTINS. 2007. The vascular flora of the Cerrado in Emas National Park (Central Brazil): A savanna flora summarized. Brazilian Archives of Biology and Technology, v.50, n.2, p.269-277.

BEHLING, H. 2003. Late glacial and Holocene vegetation, climate and fire history inferred from Lagoa Nova in the southeastern Brazilian lowland. Vegetation History and Archaeobotany, v.12, n.4, Dec, p.263-270.

BIODIVERSITAS. 2005. Lista vermelha das espécies ameaçadas de extinção da flora do estado de Minas Gerais. Belo Horizonte: Fundação Biodiversitas, Fundação Zoobotânica de Belo Horizonte.

BOTREL, R. T. et al. 2002. Influência do solo e topografia sobre as variações da composição florística e estrutura da comunidade arbóreo-arbustiva de uma floresta estacional semidecidual em Ingaí, MG. Revista Brasileira de Botânica, v.25, p.195213.

BRINA, A. E. 1998. Aspecto da dinâmica da vegetação associada a afloramentos calcários da APA Carste de Lagoa Santa, MG. Dissertação de Mestrado. Universidade Federal de Minas Gerais.

CAMPOS, É. P. D. et al. 2006. Composição florística de um trecho de cerradão e cerrado sensu stricto e sua relação com o solo na floresta nacional (FLONA) de Paraopeba, MG, Brasil. Revista Árvore, v.30, p.471-479.

CARVALHO, D. A. 1987. Composição florística e estrutura de cerrados do sudoeste de Minas Gerais. Tese de Doutorado. Instituto de Biologia, Universidade Estadual de Campinas, Campinas, 201p.

CARVALHO, D. A. \& F. R. MARTINS. 2009. Shrub and tree species composition in the cerrados of southwest Minas Gerais. Cerne, v.15, n.2, p.142-154.

CARVALHO, G. H.;M. V. CIANCIARUSO \& M. A. BATALHA. 2010. Plantminer: A web tool for checking and gathering plant species taxonomic information. Environmental Modelling \& Software, v.25, n.6, Jun, p.815-816.

CASTRO, A. A. J. F. et al. 1999. How rich is the flora of Brazilian cerrados. Annals of the Missouri Botanical Garden, v.86, n.1, p.192-224.

CECCANTINI, G. C. T. 2000. O uso da anatomia da madeira na arqueologia. In: T. B. CAVALCANTI e B. M. T. WALTER (Ed.). Tópicos atuais em Botânica. Brasília: Embrapa Recursos Genéticose Biotecnologia/ Sociedade Botânica do Brasil. p.p.383-389.

COSTA, A. A. \& G. M. D. ARAÚJO. 2001. Comparação da vegetação arbórea de cerradão e de cerrado na Reserva do Panga, Uberlândia, Minas Gerais. Acta Botanica Brasilica, v.15, p.63-72.

DE CARVAlHO, D. A. \& F. R. MARTINS. 2009. Shrub and Tree Species Composition in the Cerrados of Southwest Minas Gerais. Cerne, v.15, n.2, Apr-Jun, p.142-154.

DE OLIVEIRA, P. E. 1992. A palynological record of Late Quaternary vegetation and climatic change in southern Brazil. Tese de Doutorado. The Ohio State University, Columbus, Ohio, 238 p. 
Capítulo 01

DOS SANTOS, E. R. 2000. Análise florística e estrutura fitosociológica da vegetação lenhosa de um trecho de cerrado stricto sensu do Parque Estadual do Lajeado, Palmas - TO. Dissertação de Mestrado. Universidade de Viçosa, Viçosa, 64 p.

FERREIRA, F. M. \& R. C. FORZZA. 2009. Florística e caracterização da vegetação da Toca dos Urubus, Baependi, Minas Gerais, Brasil. Biota Neotropica, v.9, p.131148.

FERREIRA JÚNIOR, W. G. et al. 2007. Composição florística da vegetação arbórea de um trecho de floresta estacional semidecídua em Viçosa, Minas Gerais, e espécies de maior ocorrência na região. Revista Árvore, v.31, p.1121-1130.

FORZZA, R. C. O. et al. 2010. Catálogo das Plantas e Fungos do Brasil. Rio de Janeiro: Andrea Jakobsson Estúdio \& Jardim Botânico do Rio de Janeiro 2.1699 p.

GOMES, B. Z.;F. R. MARTINS \& J. Y. TAMASHIRO. 2004. Estrutura do cerradão e da transição entre cerradão e floresta paludícola num fragmento da International Paper do Brasil Ltda., em Brotas, SP. Revista Brasileira de Botânica, v.27, p.249262.

HERRMANN, G. et al. 1998. Estudo do meio biótico da APA Carste de Lagoa Santa. Belo Horizonte: Ibama, Companhia de Pesquisa de Recursos Minerais: 92p.

IBGE. 1992. Manual Técnico da Vegetação Brasileira. Brasília. 81p.

IBGE. 2010a. Documentação territorial do Brasil. In: acervo digital da biblioteca IBGE. Brasília. 2010:< http://biblioteca.IBGE.gov.br/>. Acessado em 10/10/2010.

IBGE. 2010b. IBGE Cidades@. Brasília: Instituto Brasileiro de Geografia e Estatística. 2010: <http://www.IBGE.gov.br/cidadesat/default2.php>. Acessado em $10 / 10 / 2010$.

IVANAUSKAS, N. M. \& R. R. RODRIGUES. 2000. Florística e fitossociologia de remanescentes de floresta estacional decidual em Piracicaba, São Paulo, Brasil. Revista Brasileira de Botânica, v.23, p.291-304.

KOHLER, H. C. \& I. M. C. MALTA. 1991. Região de Lagoa Santa: O cenário cárstico: guardião da fauna extinta aos legados bandeirantes. In: $3^{\circ}$ Congresso da Associação Brasileira de Estudos do Quaternário. Belo Horizonte.

LEDRU, M. P. 1992. Vegetation Changes in Central Brazil between the Late Glacial and the Present Interglacial. Comptes Rendus De L Academie Des Sciences Serie Ii, v.314, n.1, Jan 2, p.117-123.

LEDRU, M. P. 1993. Late Quaternary Environmental and Climatic Changes in Central Brazil. Quaternary Research, v.39, n.1, Jan, p.90-98.

LOMBARDI, J. A. \& M. GONÇALVES. 2000. Composição florística de dois remanescentes de Mata Atlântica do sudeste de Minas Gerais, Brasil. Revista Brasileira de Botânica, v.23, p.255-282.

LOPES, S. D. F. \& I. SCHIAVINI. 2007. Dinâmica da comunidade arbórea de mata de galeria da Estação Ecológica do Panga, Minas Gerais, Brasil. Acta Botanica Brasilica, v.21, p.249-261.

LOPES, W. D. P. et al. 2002. Estrutura fitossociológia de um trecho de vegetação arbórea no Parque Estadual do Rio Doce - Minas Gerais, Brasil. Acta Botanica Brasilica, v.16, p.443-456. 
Capítulo 01

LUND, P. W. 1935. Memorias scientificas. Belo Horizonte: Biblioteca Mineira de Cultura.

MAGURRAN, A. E. 1988. Ecological diversity and its measurement. Princeton: Princeton University Press.

MARANGON, L. C.;J. J. SOARES \& A. L. P. FELICIANO. 2003. Florística arbórea da Mata da Pedreira, município de Viçosa, Minas Gerais. Revista Árvore, v.27, p.207-215.

MARTINS, F. R. 1991. Estrutura de uma floresta mesófila. Campinas: Edunicamp.

MEIRA NETO, J. A. A. 1991. Composição florístico e fitossociológia de fisionomias de vegetaçlão de cerrado sensu lato da Estação Ecológico Santa Bárbara (E.E.S.S.), municíspio de àguas de Santa Bárbara, estado de São Paulo.Dissertação de Mestrado, Universidade Estadual de Campinas, Campinas, 105p.

MENDONÇA, P. M. \& L. L. O. VANUCCI. 2005. Lista vermelha das espécies ameaçadas de extinção da flora do estado de Minas Gerais. Belo Horizonte: Fundação Biodiversitas, Fundação Zoobotânica de Belo Horizonte.

MENDONÇA, R. C. et al. 1998. Flora Vascular do Bioma Cerrado. In: SANO, S. M.; ALMEIDA, S. P.. (Eds.). Cerrado: Ambiente e Flora: Planaltina: Embrapa - CPAC p.287-556.

MEYER, H. A. et al. 1961. Forest management. New York: Ronald.

MEYER, S. T. et al. 2004. Composição florística da vegetação arbórea de um trecho de floresta de galeria do Parque Estadual do Rola-Moça na Região Metropolitana de Belo Horizonte, MG, Brasil. Acta Botanica Brasilica, v.18, p.701-709.

MÜLLER-DOMBOIS, H. \& D. ELLENBERG. 1974. Aims and methods of vegetation ecology. New York: Wiley.

NERI, A. V. et al. 2007. Composição florísitca de uma área de cerrado sensu stricto no município de Senador Modestino Gonçalves, Vale do Jequitinhonha (MG) e análise de similaridade florística de algumas áreas de cerrado em Minas Gerais. Revista Árvore, v.31, p.1109-1119.

NEVES, W. A.;D. V. BERNARDO \& M. M. M. OKUMURA. 2007. A origem do homem americano vista a partir da América do Sul: uma ou duas migrações? Revista de Antropologia, v.50, p.9-44.

NEVES, W. A. \& H. M. PUCCIARELLI. 1991. Morphological Affinities of the 1st Americans - an Exploratory Analysis Based on Early South-American Human Remains. Journal of Human Evolution, v.21, n.4, Oct, p.261-273.

NIMER, E. 1989. Climatologia do Brasil. Rio de Janeiro: Publicações do IBGE. 421 p.

OLIVEIRA-FILHO, A. T. 2010. TreeAtlan 2.0, Flora arbórea da América do Sul cisandina tropical e subtropical: Um banco de dados envolvendo biogeografia, diversidade e conservação.: Universidade Federal de Minas Gerais $<$ http://www.icb.ufmg.br/treeatlan/>. Acessado em 1/09/2010.

OLIVEIRA-FILHO, A. T. \& J. N. M. MACHADO. 1993a. Composição florística de uma floresta semidecídua montana, na Serra de São José, Tiradentes, MG. Acta Botanica Brasilica, v.7, p.71-88. 
OLIVEIRA-FILHO, A. T. \& J. N. M. MACHADO. 1993b. Composição florística de uma floresta semidecídua montana, na Serra de São José, Tiradentes, MG. Acta Botanica Brasilica, v.7, p.71-88.

OLIVEIRA, P. S. \& R. J. MARQUIS. 2002. The cerrados of brazil. New York: Columbia University Press. 367 p.

OLIVEIRA, R. J. 2006. Variação da composição florística e da diversidade alfa das florestas atlânticas no estado de São Paulo. Tese de Doutorado. Instituto de Biologia, Universidade Estadual de Campinas, Campinas, 144 p.

PARIZZI, M. G.;M. L. SALGADO-LABOURIAU \& H. C. KOHLER. 1998. Genesis and environmental history of Lagoa Santa, southeastern Brazil. Holocene, v.8, n.3, p.311-321.

PEIXOTO, G. L. et al. 2004. Composição florística do componente arbóreo de um trecho de Floresta Atlântica na Área de Proteção Ambiental da Serra da Capoeira Grande, Rio de Janeiro, RJ, Brasil. Acta Botanica Brasilica, v.18, p.151-160.

PEREIRA-SILVA, E. F. L. et al. 2004. Florística e fitossociologia dos estratos arbustivo e arbóreo de um remanescente de cerradão em uma Unidade de Conservação do Estado de São Paulo. Revista Brasileira de Botânica, v.27, p.533544.

RACZKA, M. F. 2009. Mudanças aleoambientais quaternárias na região de Lagoa Santa, Mg, Brasil: a palinologia como subsídeo para o entendimento do padrão de ocupação humana. Dissertação de Mestrado. Universidade de Guarulhos, Guarulhos, $119 \mathrm{p}$.

RATTER, J. A.;S. BRIDGEWATER \& J. F. RIBEIRO. 2003. Analysis of the floristic composition of the brazilian cerrado vegetation III: comparison of the woody vegetation of 376 areas. Edinburgh Journal of Botany, v.60, n.01, p.57-109.

RIBAS, R. F. et al. 2003. Composição florística de dois trechos em diferentes etapas serais de uma floresta estacional semidecidual em Viçosa, Minas Gerais. Revista Árvore, v.27, p.821-830.

RIBEIRO, L. F. \& M. TABARELLI. 2002. A structural gradient in cerrado vegetation of Brazil: changes in woody plant density, species richness, life history and plant composition. Journal of Tropical Ecology, v.18, Sep, p.775-794.

RODRIGUES, L. A. et al. 2003. Florística e estrutura da comunidade arbórea de um fragmento florestal em Luminárias, MG. Acta Botanica Brasilica, v.17, p.71-87.

SANTOS, K. 2003. Caracterização florística e estrutural de onze fragmentos de mata estacional semidecidual da área de proteção ambiental do município de Campinas - SP. Dissertação de Mestrado. Instituto de Biologia, Universidade Estadual de Campinas, Campinas, 225p p.

SAPORETTI JR, A. W.;J. A. A. MEIRA NETO \& R. D. P. ALMADO. 2003. Fitossociologia de cerrado sensu stricto no município de Abaeté-MG. Revista Árvore, v.27, p.413-419.

SCIAMARELLI, A. 2005. Estudo florístico e fitossociológico da "Mata de Dourados", Fazenda Paradouro, Dourados, Mato Grosso do Sul, Brasil. Tese de Doutorado. Instituto de Biologia, Universidade Estadual de Campinas, Campinas, 120 p. 
SILVA, A. F. D. et al. 2003. Composição florística e grupos ecológicos das espécies de um trecho de floresta semidecídua submontana da Fazenda São Geraldo, ViçosaMG. Revista Árrvore, v.27, p.311-319.

SILVA, L. Á. D. \& A. SCARIOT. 2003. Composição florística e estrutura da comunidade arbórea em uma floresta estacional decidual em afloramento calcário (Fazenda São José, São Domingos, GO, bacia do rio Paraná). Acta Botanica Brasilica, v.17, p.305-313.

SILVA, L. Á. D. \& J. J. SOARES. 2003. Composição florística de um fragmento de floresta estacional semidecídua no município de São Carlos-SP. Revista Árvore, v.27, p.647-656.

SIQUEIRA, A. D. S.;G. M. D. ARAÚJO \& I. SCHIAVINI. 2006. Caracterização florística da Reserva Particular do Patrimônio Natural (RPPN) Fazenda Carneiro, Lagamar, MG, Brasil. Biota Neotropica, v.6.

SOARES, M. P. et al. 2006. Composição florística do estrato arbóreo de floresta Atlântica Interiorana em Araponga - Minas Gerais. Revista Árvore, v.30, p.859-870.

SOUZA, J. S. et al. 2003. Análise das variações florísticas e estruturais da comunidade arbórea de um fragmento de floresta semidecídua às margens do rio Capivari, Lavras-MG. Revista Árvore, v.27, p.185-206.

SOUZA, P. B. D. et al. 2008. Composição florística da vegetação arbórea de um remanescente de cerradão, paraopeba, MG. Revista Árvore, v.32, p.781-790.

TEIXEIRA, M. I. J. G. et al. 2004. Florística e fitossociologia de área de cerrado S.S. no município de Patrocínio Paulista, nordeste do Estado de São Paulo. Bragantia, v.63, p.1-11.

TRÓPICOS. 2010. Botanical information system at the Missouri Botanical Garden. Base de dados. Saint Louis.Disponível em <http://www.tropicos.org/Home.aspx>. Acessado em 5/09/2010.

VAN DEN BERG, E. \& A. T. OLIVEIRA-FILHO. 2000. Composição florística e estrutura fitossociológica de uma floresta ripária em Itutinga, MG, e comparação com outras áreas. Revista Brasileira de Botânica, v.23, p.231-253.

WARMING, E. 1908. Lagoa Santa, contribuição para a geographia phytobiológica. Belo Horizonte: Imprensa Oficial do Estado de Minas Gerais. II+282p.

WERNECK, M. D. E. S. et al. 2000. Florística e estrutura de três trechos de uma floresta semidecídua na Estação Ecológica do Tripuí, Ouro Preto, MG. Revista Brasileira de Botânica, v.23, p.97-106. 


\section{CAPÍTULO 2}

\section{COLEÇÃO DE REFERÊNCIA:}

\section{MADEIRAS DA APA-CARSTE DE LAGOA SANTA, DESCRIÇÃO ANATÔMICA E ICONOGRAFIA}





\subsection{RESUMO}

No processo de identificação taxonômica de amostras de madeira, a comparação anatômica visual com coleções de referência, bem identificadas taxonomicamente é um procedimento imprescindível. Consequentemente, as publicações iconográficas sobre a anatomia de lenho das espécies brasileiras tornam-se de grande valia. Entretanto, apesar do expressivo acervo de amostras de lenho e lâminas histológicas das diversas xilotecas brasileiras, publicações descritivas e iconográficas da anatomia da madeiras se concentram em espécies amazônicas e, principalmente, de interesse comercial. Com o objetivo de diminuir esta lacuna e produzir descrições e iconografias de espécies sem valor econômico de uma zona de contato entre os biomas Mata Atlântica e Cerrado, este capítulo apresenta um acervo de amostras de lenho de 270 espécies, com lâminas histológicas para 156 delas e iconografia para 89. Embora estes números já sejam expressivos e não existam iconografias para muitas das espécies aqui trabalhadas, há a perspectiva de ampliar as iconografias para a totalidade das espécies amostradas, com intuito de comporem uma publicação iconográfica e descritiva final para e espécies da APA Carste de Lagoa Santa, MG, Brasil.

\subsection{ABSTRACT}

The visual comparison between anatomy of wood of collected samples with that of samples present in reference collections is a key procedure in the process of wood identification. Therefore, Consequently, iconographic publications of the wood anatomy of Brazilian species are of great use. However, despite the expressive collection of wood samples and histological slides of many Brazilian Xylariums, descriptive and iconographic publications of wood anatomy are concentrated mainly on species from Amazonia or with commercial value. With the purpose of reducing this gap and presenting descriptions and iconographies of species that occur in the area within the Atlantic Forest and Cerrado biomes, this chapter presents a collection of wood samples of 270 species, with 156 histological and 89 iconography slides. Although these numbers are already expressive and there is no iconography for many of these species, there is a perspective of expanding the iconography for all species, aiming to compose a final descriptive and iconographic publication on the anatomy of species from APA Carste de Lagoa Santa, MG, Brazil. 
CAPÍtulo 02 


\subsection{INTRODUÇÃO}

O processo de identificação taxonômica da madeira baseia-se principalmente na comparação direta com coleções de referência de madeiras (Xilotecas). Para tanto, a descrição das características macro e microscópicas da madeira, embora de fundamental importância, não bastam. A comparação visual e precisa com a anatomia de amostras bem identificadas, com vouchers em herbários é imprescindível. No Brasil, existem ao menos 17 xilotecas institucionais, que possuem, conjuntamente, um acervo aproximado 69.326 amostras e com 56547 lâminas histológicas (Barros \& Coradin, 2005).

Com todo este material, existe uma vasta bibliografia para a identificação anatômica de madeiras. Contudo, a grande maioria destas publicações se referem à identificação de espécies e gêneros de interesse comercial (Fedalto et al., 1989; Mainieri \& Chimelo, 1989). São poucos os exemplos da literatura para identificações de espécies não comerciais (Détienne \& Jacquet, 1983; Luchi, A.E., 1998; Marchiori, 2007; Marchiori et al., 2010). Quando encontradas, tais publicações geralmente se referem à região Amazônica, de forma que as espécies não comerciais do Cerrado brasileiro e das florestas semidecíduas do sul e sudeste ainda menos representadas.

Contudo, conforme (Barros \& Coradin, 2005), a anatomia da madeira, além de proporcionar bases para o entendimento e a solução de problemas na legislação, controle e fiscalização do comércio madeireiro, tecnologia da madeira, também vêm sendo muito utilizados em outras áreas, como na taxonomia, arqueologia e antropologia.

Neste contexto, o presente capítulo objetiva, primeiramente, construir uma coleção de amostras de lenho das espécies ocorrentes na APA Carste de Lagoa Santa, sem privilegiar espécies de valor comercial. Em um segundo momento, foi se proposto produzir um acervo de lâminas histológicas e uma iconografia da anatomia da madeira destas espécies, para servirem de esteio a identificações anatômicas precisas e embasadas em coleções locais, bem identificadas (especialistas das famílias) e rastreadas (vouchers).

\section{4 ÁREA DE ESTUDO}

Os materiais do presente trabalho foram coletados na Área de Proteção Ambiental Carste de Lagoa Santa, somando 35.900 hectares localizados nos municípios de Lagoa Santa, Matozinhos, Pedro Leopoldo e Funilândia, distantes cerca de $50 \mathrm{Km}$ ao norte de Belo Horizonte (MG). 
Por ser uma região bastante antropizada e de tensão ecológica entre os biomas Cerrado e Mata Atlântica (IBGE, 1992), sua vegetação natural está bastante fragmentada e se apresenta como um mosaico de fisionomias dentre as quais podemos citar os cerrados, cerradões, matas de galeria, florestas semidecíduas e matas secas (sobre calcário), entre outras. Informações mais detalhadas podem ser encontradas em Herrmann et. al. (1998).

\subsection{MATERIAIS E MÉTODOS}

As coletas botânicas foram realizadas por meio de caminhadas livres na APA Carste de Lagoa Santa (ACLS) durante 14 expedições entre Março de 2006 e Outubro de 2007 e levantamento sistemáticos em parcelas, para um inventário fitossociológico.

Para cada indivíduo amostrado no levantamento florístico (capítulo 1), foram coletadas exsicatas e amostras de lenho predominantemente de galhos e ramos secundários, o mais espessos possível, mas não a ponto de comprometer a sobrevivência do indivíduo. A coleta foi realizada com martelo e formão e com serrote de poda. As exsicatas foram identificadas por especialistas ou profissionais da área (relacionadas na página de agradecimentos) e depositadas no herbário SPF. Das amostras de lenho, foi retirado um pequeno corpo de prova (ca. $2 \mathrm{~cm}$ de aresta) para a confecção de lâminas histológicas. Após a retirada, as amostras foram secas à sombra e depositadas na xiloteca SFPw (IBUSP ${ }^{11}$ ).

Com o corpo de prova, foram feitos cortes dos três planos fundamentais da madeira, com auxílio de micrótomo de deslize, e prosseguiu-se com a confecção de lâminas histológicas, segundo a metodologia tradicional reproduzida por Kraus \& Arduin (1997), com o uso de dupla coloração (safranina e azul de astra) e montagem em lâminas permanentes em resina Entelan. A ordem de processamento das espécies seguiu o critério da necessidade de material de referência para a identificação dos fósseis apresentadas no Capítulo 3. Conforme surgia a necessidade de verificar determinados gêneros, as amostras foram sendo processadas.

Seguiu-se então, a documentação iconográfica, por meio do Sistema de Digitalização de Imagem (IM50) acoplado ao microscópio Leica DMLB, concomitantemente com a descrição das características microscópicas das amostras, listadas pela IAWA Committee (1989).

\footnotetext{
${ }^{11}$ Instituto de Biociências da Universidade de São Paulo
} 


\subsection{RESUltAdOS E DisCUSSÃO}

Foram coletadas amostras da madeira de 610 indivíduos, perfazendo um total de 270 espécies. Destas espécies, 183 são arbóreas, 73 arbustivas e 32 lianas (a soma maior que 270 está relacionada a táxons que receberam mais de uma classificação de hábito). A relação das espécies amostradas é apresentada na tabela 1.

Esta coleção de amostras de lenho de alta qualidade, com voucher depositado em herbário e identificação taxonômica precisa e confiável, feita por especialistas e profissionais da taxonomia é, por si só, um resultado de grande relevância, uma vez que pesquisas científicas em Botânica necessitam confiabilidade na identificação dos materiais, principalmente em táxons de grupos de filogenia ainda incertas. Soma-se ainda, a presença de espécies arbustivas e lianas, pouco frequentes, até mesmo raras, na maior xiloteca brasileira. Além disso, as amostras rastreadas em herbário podem ter a identificação corrigida e atualizada posteriormente, conforme a evolução dos trabalhos de sistemática. Contudo, deve-se atentar para o fato das amostras serem provenientes de galhos e ramos secundários, diferentemente das amostras de tronco que são usualmente fazem parte das coleções das xilotecas. Assim, as características anatômicas destas amostras devem ser analisadas levando-se em conta que fazem parte de outra estrutura que não o tronco. A característica anatômica de obstrução de vasos, por exemplo, ocorrerá muito raramente em galhos (nos mais espessos), ao contrário das amostras de tronco da mesma espécie.

Quanto ao processamento histológico, produção iconográfica e à descrição anatômica das amostras, a tabela 1 sintetiza os resultados alcançados. Do material coletado, foi construído um laminário que contava, na data da conclusão deste trabalho, com 156 espécies, distribuídas em 109 gêneros de 37 famílias.

A iconografia anatômica produzida apresenta pranchas da anatomia geral dos três planos da madeira para 89 espécies, referentes a 73 gêneros e 31 famílias. As figuras 1 e 2 exemplificam o formato a iconografia produzida, que pode ser consultada integralmente no CD-ROM, anexado ao final desta tese (APÊNDICE 4). Esta iconografia deve, no futuro próximo, crescer em número de espécies, e ser complementada com descrições anatômicas que, por hora, perfazem 56 espécies e são apresentadas nas tabelas 2 e 3.

Espera-se, portanto, que estes materiais auxiliem, como auxiliou nesta tese, pesquisadores e técnicos ou mesmo interessados pela identificação anatômica da madeira e na diversidade estrutural do xilema secundário. 
Família. Asteraceae

Espécie. Dasyphyllum brasiliense (Spreng.) Cabrera Amostra. SPFw 2409

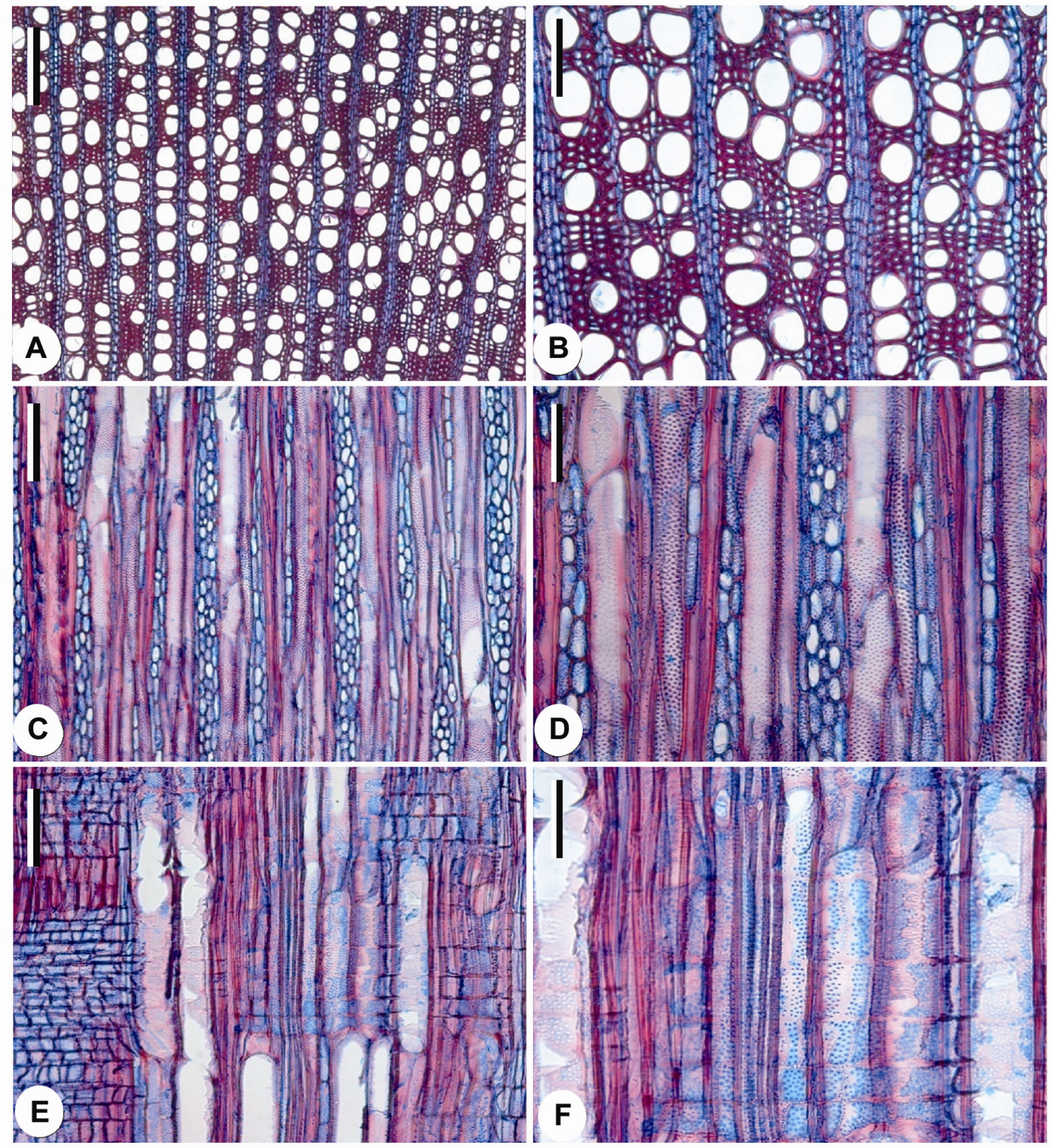

Figura: Fotomicrografias do plano transversal ( $A$ e $B$ ), tangencial ( $C$ e $D)$ e radial ( $E$ e $F$ ).

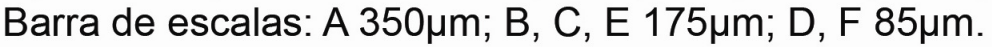

Figura 1: Formato das pranchas iconográficas produzidas, evidenciando o aspecto geral da anatomia da madeira de espécies da APA Carste de Lago Santa, MG. 
Família. Combretaceae

Espécie. Terminalia argentea Mart. Amostra. SPFw 2415
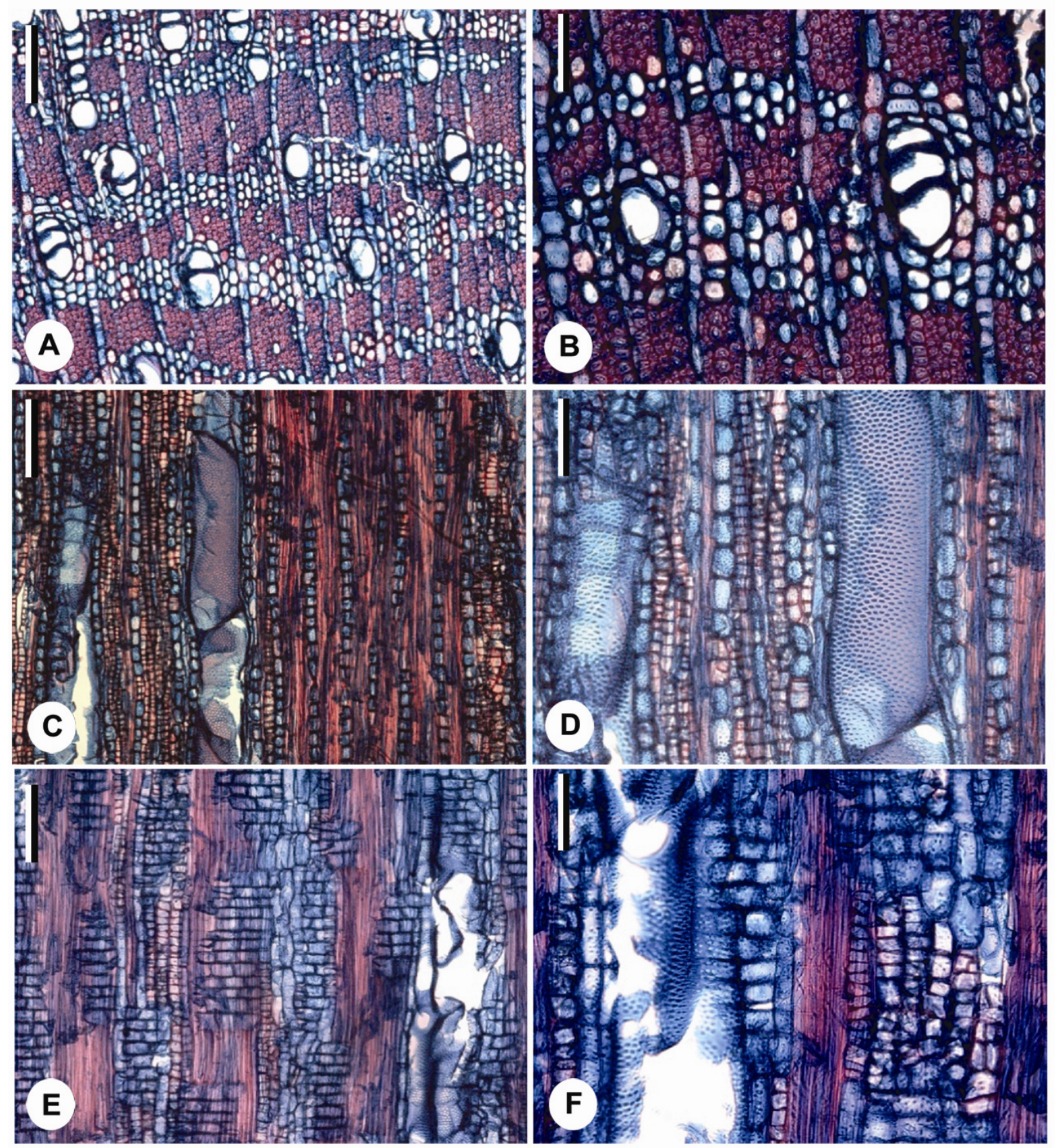

Fotomicrografias do plano transversal $(A$ e $B)$, tangencial $(C$ e $D)$ e radial (E e $F)$. Barra de escalas: A, C e E, $175 \mu \mathrm{m}$; B, D e F $85 \mu \mathrm{m}$.

Figura 2: Formato das pranchas iconográficas produzidas, evidenciando o aspecto geral da anatomia da madeira de espécies da APA Carste de Lago Santa, MG. 
Capítulo 03

Tabela 1:Relação das espécies cujas amostras de lenho foram depositadas na xiloteca SPFw e as exsicatas, no herbário SPF. O processamento realizado para cada espécie é também apresentado.

FAMÍLIA E Nome científico

ACANTHACEAE

Ruellia brevifolia (Pohl) C. Ezcurra

ANACARDIACEAE

Astronium graveolens Jacq.

Lithrea molleoides (Vell.) Engl.

Myracrodruon urundeuva Allemão

Tapirira guianensis Aubl.

ANNONACEAE

Annona crassiflora Mart.

Annona dolabripetala Raddi

Annona sylvatica A.St.-Hil.

Guatteria villosissima A.St.-Hil.

Xylopia aromatica (Lam.) Mart.

Xylopia sericea A. St.-Hil.

\section{APOCYNACEAE}

Aspidosperma tomentosum Mart.

Forsteronia cf. thyrsoidea (Vell.) Müll.Arg.

Hancornia SP

Himatanthus sucuuba (Spruce ex Müll.Arg.)

Woodson

Tabernaemontana catharinensis A.DC.

ARALIACEAE

$\begin{array}{llllll}\text { Dendropanax cuneatus (DC.) Decne. \& Planch. } & \text { X } & \text { X } & \text { X } & 2358\end{array}$

Schefflera macrocarpa (Cham. \& Schltdl.)

Frodin

Schefflera morototoni (Aubl.) Maguire et al.

ARECACEAE

Acrocomia aculeata (Jacq.) Lodd. ex Mart.

ASTERACEAE

Baccharis crispa Spreng.

Chromolaena laevigata (Lam.) R.M.King \&

H.Rob.

Cosmos sulphureus Cav.

Dasyphyllum brasiliense (Spreng.) Cabrera

Eremanthus erythropappus (DC.) MacLeish

Eremanthus glomeratus Less.

Gochnatia paniculata (Less.) Cabrera

Piptocarpha rotundifolia (Less.) Baker

Vernonanthura membranacea (Gardner) H.

Rob.

Vernonanthura phosphorica (Vell.) H. Rob.
$X \times X$

2275

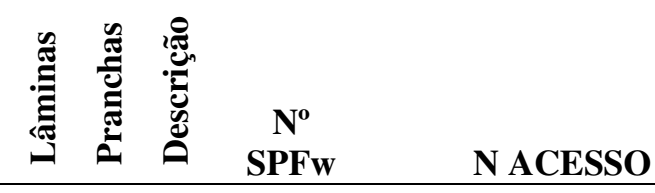

$X \quad-\quad-2407$

$\begin{array}{llll}X & X & 2586\end{array}$

$X \quad X \quad 2371$

$X \quad X-2375$

$\begin{array}{llll}X & X & 2720\end{array}$

$x \quad-\quad x \quad 2602$

X X X 2346

- $\quad$ - $\quad 2591$

X X - 2251

- $\quad-\quad 2483$

$x \quad-\quad-2756$

X - X 2726

- $\quad$ - 2859

$\mathrm{x} \times \mathrm{x}$

2673

2503

G.Q.Freire, 230

J.C.F.Melo Jr., 544

G.C.T.Ceccantini, 2841

G.C.T.Ceccantini, 2707

G.C.T.Ceccantini, 2778

G.C.T.Ceccantini, 3136

$\begin{array}{llll}X & X \quad 2306\end{array}$

G.C.T.Ceccantini, 2739

2334

G.C.T.Ceccantini, 2809

- $\quad$ - 2691

J.C.F.Melo Jr., 607

X X - 2409

G.C.T.Ceccantini, 2904

- $\quad$ - 2286

X X - 2299

G.C.T.Ceccantini, 2718

G.C.T.Ceccantini, 2731

- $-\quad$ - 2493

J.C.F.Melo Jr., 532

- - - 2662

G.Q.Freire, 219

$\begin{array}{lll}- & - & \\ X & & \end{array}$

G.C.T.Ceccantini, 2810

$\begin{array}{llll}X & X \quad 2298\end{array}$

G.C.T.Ceccantini, 2730 
Capítulo 02

continuação...

Tabela 1:Relação das espécies cujas amostras de lenho foram depositadas na xiloteca SPFw e as exsicatas, no herbário SPF. O processamento realizado para cada espécie é também apresentado.

FAMÍLIA E Nome científico BIGNONIACEAE

Amphilophium crucigerum (L.) L. G. Lohmann Amphilophium elongatum (Vahl) L. G.

Lohmann

Amphilophium paniculatum (L.) Kunth

Cuspidaria pulchra (Cham.) L. Lohmann

Cuspidaria sp (puchra?)

Cybistax antisyphilitica (Mart.) Mart

Dolichandra unguis-cati (L.) L. Lohmann

Fridericia chica (Bonpl.) L.G.Lohmann

Fridericia craterophora (DC.) L. Lohmann

Fridericia florida (A. DC.) L. Lohmann

Handroanthus heptaphyllus Mattos

Handroanthus impetiginosus Mattos

Handroanthus serratifolius (A.H.Gentry)

S.Grose

Lundia obliqua Sond.

Pyrostegia venusta (Ker Gawl.) Miers

Zeyheria montana Mart.

Zeyheria tuberculosa (Vell.) Bureau ex Verl.

\section{BIXACEAE}

Bixa orellana L.

\section{BORAGINACEAE}

Cordia trichotoma (Vell.) Arráb. ex Steud.

Tournefortia paniculata Cham.

Varronia curassavica Jacq.

\section{CANNABACEAE}

Celtis pubescens (Kunth) Spreng.

Trema micrantha (L.) Blume

\section{CAPPARACEAE}

Cleome viridiflora Schreb.

\section{CARYOCARACEAE}

Caryocar brasiliense Cambess.

\section{CELASTRACEAE}

Cheiloclinium cognatum (Miers) A.C. Sm.

Maytenus floribunda Reissek

Peritassa campestris (Cambess.) A.C. Sm.

\section{CHRYSOBALANACEAE}

Couepia grandiflora (Mart. \& Zucc.) Benth.

COMBRETACEAE

Terminalia argentea Mart.

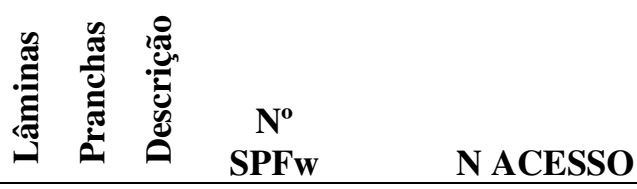

G.C.T.Ceccantini, 3030

G.C.T.Ceccantini, 2788

G.Q.Freire, 181

G.C.T.Ceccantini, 2861

G.C.T.Ceccantini, 2671

J.C.F.Melo Jr., 597

G.C.T.Ceccantini, 2687

G.C.T.Ceccantini, 2954

G.C.T.Ceccantini, 2689

G.C.T.Ceccantini, 2823

G.Q.Freire, 266

G.C.T.Ceccantini, 2855

G.Q.Freire, 314

G.Q.Freire, 200

G.C.T.Ceccantini, 2892

G.C.T.Ceccantini, 2719

G.C.T.Ceccantini, 2980

G.Q.Freire, 271

G.C.T.Ceccantini, 2897

G.Q.Freire, 204

G.Q.Freire, 249

X X - 2222

G.C.T.Ceccantini, 2650

G.C.T.Ceccantini, 3025

G.C.T.Ceccantini, 2808

G.C.T.Ceccantini, 2829

- $\quad$ - $\quad-2682 \quad$ G.Q.Freire, 241

X - $\quad$ - $2787 \quad$ G.Q.Freire, 328

X - - 2419

G.C.T.Ceccantini, 2914

G.Q.Freire, 163

X X X $2415 \quad$ G.C.T.Ceccantini, 2910 
Capítulo 02

continuação...

Tabela 1:Relação das espécies cujas amostras de lenho foram depositadas na xiloteca SPFw e as exsicatas, no herbário SPF. O processamento realizado para cada espécie é também apresentado.

\begin{tabular}{|c|c|c|c|c|c|}
\hline FAMÍLIA E Nome científico & 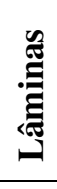 & 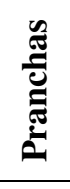 & 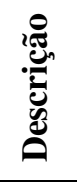 & $\begin{array}{c}\mathbf{N}^{\mathbf{o}} \\
\text { SPFw }\end{array}$ & N ACESSO \\
\hline Terminalia glabrescens Mart. & $x$ & - & $x$ & 2470 & J.C.F.Melo Jr., 507 \\
\hline \multicolumn{6}{|l|}{ CONNARACEAE } \\
\hline Rourea pseudospadicea G.Schellenb. & - & - & - & 2476 & J.C.F.Melo Jr., 514 \\
\hline \multicolumn{6}{|l|}{ CONVOLVULACEAE } \\
\hline Ipomoea tubata Nees & - & - & - & 2737 & G.Q.Freire, 269 \\
\hline \multicolumn{6}{|l|}{ DILLENIACEAE } \\
\hline Doliocarpus dentatus (Aubl.) Standl. & $x$ & $x$ & - & 2640 & G.Q.Freire, 196 \\
\hline \multicolumn{6}{|l|}{ EBENACEAE } \\
\hline Diospyros hispida A. DC. & $x$ & $\mathrm{x}$ & $x$ & 2303 & G.C.T.Ceccantini, 2735 \\
\hline \multicolumn{6}{|l|}{ ERYTHROXYLACEAE } \\
\hline Erythroxylum campestre A. St.-Hil. & - & - & - & 2558 & J.C.F.Melo Jr., 600 \\
\hline Erythroxylum cuneifolium (Mart.) O.E. Schulz & $x$ & $\mathrm{x}$ & - & 2225 & G.C.T.Ceccantini, 2654 \\
\hline Erythroxylum suberosum A. St.-Hil. & $x$ & $x$ & - & 2604 & G.C.T.Ceccantini, 2999 \\
\hline Erythroxylum subrotundum A. St.-Hil. & $x$ & $\mathrm{x}$ & $x$ & $2255 / 2584$ & G.C.T.Ceccantini, 2685 \\
\hline Erythroxylum tortuosum Mart. & $x$ & $\mathrm{x}$ & $\mathrm{X}$ & 2491 & J.C.F.Melo Jr., 530 \\
\hline \multicolumn{6}{|l|}{ EUPHORBIACEAE } \\
\hline Acalypha communis Müll.Arg. & $\mathrm{x}$ & - & $\mathrm{x}$ & 2655 & G.Q.Freire, 211 \\
\hline Alchornea glandulosa Poepp. \& Endl. & - & - & - & 2367 & G.C.T.Ceccantini, 2853 \\
\hline Astraea lobata (L.) Klotzsch & - & - & - & 2521 & J.C.F.Melo Jr., 563 \\
\hline Croton gracilipes Baill. & $\mathrm{x}$ & - & $\mathrm{x}$ & 2592 & G.C.T.Ceccantini, 2985 \\
\hline Croton urucurana Baill. & - & - & - & 2649 & G.Q.Freire, 205 \\
\hline Dalechampia stipulacea Müll.Arg. & - & - & - & 2381 & G.C.T.Ceccantini, 2870 \\
\hline Mabea fistulifera Mart. & - & - & - & 2729 & G.Q.Freire, 261 \\
\hline Manihot anomala Pohl & - & - & - & 2708 & J.C.F.Melo Jr., 625 \\
\hline Manihot janiphoides Müll.Arg. & - & - & - & 2736 & G.Q.Freire, 268 \\
\hline Manihot tripartita (Spreng.) Müll.Arg. & - & - & - & 2553 & J.C.F.Melo Jr., 595 \\
\hline Maprounea guianensis Aubl. & - & - & - & 2751 & G.Q.Freire, 287 \\
\hline Pera glabrata (Schott) Poepp. ex Baill. & $\mathrm{x}$ & $\mathrm{x}$ & $\mathrm{x}$ & 2313 & G.C.T.Ceccantini, 2785 \\
\hline Sapium glandulosum (L.) Morong & - & - & - & 2783 & G.Q.Freire, 324 \\
\hline Sebastiania brasiliensis Spreng. & - & - & - & 2650 & G.Q.Freire, 206 \\
\hline Sebastiania klotzschiana (Müll.Arg.) Müll.Arg. & - & - & - & 2733 & G.Q.Freire, 265 \\
\hline \multicolumn{6}{|l|}{ LAMIACEAE } \\
\hline Aegiphila integrifolia (Jacq.) Moldenke & - & - & - & 2237 & G.C.T.Ceccantini, 2776 \\
\hline Aegiphila verticillata Vell. & - & - & - & 2549 & J.C.F.Melo Jr., 591 \\
\hline Hyptidendron canum (Pohl ex Benth.) Harley & - & - & - & 2537 & J.C.F.Melo Jr., 579 \\
\hline Vitex polygama Cham. & - & - & - & 2631 & G.C.T.Ceccantini, 3040 \\
\hline \multicolumn{6}{|l|}{ LAURACEAE } \\
\hline Nectandra lanceolata Nees & $\mathrm{X}$ & - & $\mathrm{x}$ & 2446 & G.Q.Freire, 177 \\
\hline Nectandra psammophila Nees & $\mathrm{x}$ & - & $\mathrm{x}$ & 2402 & G.C.T.Ceccantini, 2896 \\
\hline Ocotea corymbosa (Meisn.) Mez & $x$ & $x$ & $x$ & 2599 & G.C.T.Ceccantini, 2994 \\
\hline
\end{tabular}


Capítulo 02

continuação...

Tabela 1:Relação das espécies cujas amostras de lenho foram depositadas na xiloteca SPFw e as exsicatas, no herbário SPF. O processamento realizado para cada espécie é também apresentado.

\begin{tabular}{|c|c|c|c|c|c|}
\hline FAMÍLIA E Nome científico & 苞 & 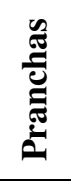 & 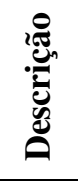 & $\begin{array}{c}\mathbf{N}^{\circ} \\
\text { SPFw }\end{array}$ & N ACESSO \\
\hline Ocotea velutina (Nees) Rohwer & $x$ & $\mathrm{X}$ & $\mathrm{X}$ & 2786 & G.Q.Freire, 327 \\
\hline \multicolumn{6}{|l|}{ LECYTHIDACEAE } \\
\hline Cariniana estrellensis (Raddi) Kuntze & $\mathrm{x}$ & $\mathrm{x}$ & $x$ & 2747 & G.Q.Freire, 282 \\
\hline Cariniana legalis (Mart.) Kuntze & $\mathrm{x}$ & $\mathrm{x}$ & $x$ & 2511 & J.C.F.Melo Jr., 552 \\
\hline \multicolumn{6}{|l|}{ LEGUMINOSAE } \\
\hline Bauhinia longifolia (Bong.) Steud. & $\mathrm{x}$ & - & - & 2352 & G.C.T.Ceccantini, 2834 \\
\hline Bauhinia ungulata $\mathrm{L}$. & $\mathrm{x}$ & - & - & 2542 & J.C.F.Melo Jr., 584 \\
\hline Bowdichia virgilioides Kunth & $\mathrm{x}$ & $\mathrm{x}$ & - & 2301 & G.C.T.Ceccantini, 2733 \\
\hline Cassia ferruginea (Schrad.) Schrad. ex DC. & $\mathrm{x}$ & $\mathrm{x}$ & - & 2601 & G.C.T.Ceccantini, 2996 \\
\hline $\begin{array}{l}\text { Chamaecrista apoucouita (Aubl.) H.S. Irwin \& } \\
\text { Barneby }\end{array}$ & $\mathrm{x}$ & - & - & 2647 & G.Q.Freire, 203 \\
\hline Clitoria fairchildiana R.A. Howard & - & - & - & 2746 & G.Q.Freire, 281 \\
\hline Copaifera langsdorffii Desf. & - & - & - & 2771 & G.Q.Freire, 312 \\
\hline Dalbergia miscolobium Benth. & $\mathrm{x}$ & $\mathrm{x}$ & - & 2305 & G.C.T.Ceccantini, 2738 \\
\hline Dimorphandra mollis Benth. & $\mathrm{x}$ & - & - & 2435 & G.Q.Freire, 164 \\
\hline Enterolobium contortisiliquum (Vell.) Morong & $\mathrm{x}$ & $\mathrm{x}$ & - & 2637 & G.C.T.Ceccantini, 3047 \\
\hline Erythrina falcata Benth. & $\mathrm{x}$ & $\mathrm{x}$ & $x$ & 2447 & G.Q.Freire, 178 \\
\hline Harpalyce brasiliana Benth. & $\mathrm{x}$ & - & $x$ & 2292 & G.C.T.Ceccantini, 2724 \\
\hline Hymenaea courbaril $\mathrm{L}$. & - & - & - & 2974 & G.Q.Freire, 336 \\
\hline Hymenaea stigonocarpa Mart. ex Hayne & $\mathrm{x}$ & $\mathrm{x}$ & $x$ & 2674 & G.Q.Freire, 231 \\
\hline Inga sp & $\mathrm{x}$ & $\mathrm{x}$ & $\mathrm{x}$ & 2440 & G.Q.Freire, 169 \\
\hline Inga vera Willd. & $\mathrm{x}$ & - & - & 2680 & G.Q.Freire, 239 \\
\hline Leptolobium dasycarpum Vogel & - & - & - & 2278 & G.C.T.Ceccantini, 2710 \\
\hline Lonchocarpus sericeus (Poir.) DC. & $\mathrm{x}$ & - & $x$ & 2437 & G.Q.Freire, 166 \\
\hline Machaerium hirtum (Vell.) Stellfeld & $\mathrm{x}$ & $\mathrm{x}$ & $x$ & 2247 & G.C.T.Ceccantini, 2677 \\
\hline Machaerium opacum Vogel & $\mathrm{x}$ & $\mathrm{x}$ & $x$ & 2283 & G.C.T.Ceccantini, 2715 \\
\hline Mimosa debilis Humb. \& Bonpl. ex Willd. & $\mathrm{x}$ & - & $x$ & 2709 & J.C.F.Melo Jr., 627 \\
\hline Mimosa laticifera Rizzini \& A. Mattos & $\mathrm{x}$ & - & $x$ & 2703 & J.C.F.Melo Jr., 620 \\
\hline Mucuna pruriens (L.) DC & - & - & - & 2677 & G.Q.Freire, 235 \\
\hline Peltophorum dubium (Spreng.) Taub. & $\mathrm{x}$ & $\mathrm{x}$ & - & 2597 & G.C.T.Ceccantini, 2992 \\
\hline Plathymenia reticulata Benth. & $\mathrm{x}$ & $\mathrm{x}$ & - & 2719 & J.C.F.Melo Jr., 638 \\
\hline Platymiscium pubescens Micheli & $\mathrm{x}$ & $\mathrm{x}$ & $x$ & 2638 & G.C.T.Ceccantini, 3048 \\
\hline Platypodium elegans Vogel & - & - & - & 2748 & G.Q.Freire, 284 \\
\hline $\begin{array}{l}\text { Poiretia punctata (Willd.) Desv. } \\
\text { Senegalia martiusiana (Steud.) Seigler \& }\end{array}$ & - & - & - & 2878 & G.C.T.Ceccantini, 3196 \\
\hline Ebinger & - & & - & 2580 & G.C.T.Ceccantini, 2972 \\
\hline Senegalia polyphylla (DC.) Britton \& Rose & $\mathrm{x}$ & $\mathrm{x}$ & - & 2234 & G.C.T.Ceccantini, 2664 \\
\hline $\begin{array}{l}\text { Senna macranthera (DC. ex Collad.) H.S. Irwin } \\
\& \text { Barneby }\end{array}$ & $\mathrm{x}$ & $\mathrm{X}$ & - & 2297 & G.C.T.Ceccantini, 2729 \\
\hline Senna multijuga (Rich.) H.S. Irwin \& Barneby & $\mathrm{x}$ & $\mathrm{X}$ & $\mathrm{x}$ & 2233 & G.C.T.Ceccantini, 2662 \\
\hline $\begin{array}{l}\text { Senna pendula (Humb. \& Bonpl. ex Willd.) } \\
\text { H.S. Irwin \& Barneby }\end{array}$ & $\mathrm{X}$ & & $\mathrm{x}$ & 2341 & G.C.T.Ceccantini, 2817 \\
\hline
\end{tabular}


Capítulo 02

continuação...

Tabela 1:Relação das espécies cujas amostras de lenho foram depositadas na xiloteca SPFw e as exsicatas, no herbário SPF. O processamento realizado para cada espécie é também apresentado.

\begin{tabular}{|c|c|c|c|c|c|}
\hline FAMÍLIA E Nome científico & : & 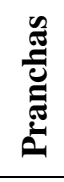 & 胥 & $\begin{array}{c}\mathbf{N}^{\mathbf{o}} \\
\text { SPFw }\end{array}$ & N ACESSO \\
\hline Senna silvestris (Vell.) H.S.Irwin \& Barneby & $\mathrm{x}$ & - & $\mathrm{x}$ & 2643 & J.C.F.Melo Jr., 640 \\
\hline Stryphnodendron adstringens (Mart.) Coville & $\mathrm{x}$ & $\mathrm{x}$ & - & 2659 & G.Q.Freire, 216 \\
\hline Swartzia macrostachya Benth. & $\mathrm{x}$ & $\mathrm{x}$ & - & 2328 & G.C.T.Ceccantini, 2803 \\
\hline $\begin{array}{l}\text { Zollernia ilicifolia (Brongn.) Vogel } \\
\text { LOGANIACEAE }\end{array}$ & - & - & - & 2879 & G.C.T.Ceccantini, 3197 \\
\hline $\begin{array}{l}\text { Strychnos trinervis (Vell.) Mart. } \\
\text { LYTHRACEAE }\end{array}$ & - & - & - & 2386 & G.C.T.Ceccantini, 2877 \\
\hline $\begin{array}{l}\text { Cuphea warmingii Koehne } \\
\text { MALPIGHIACEAE }\end{array}$ & - & - & - & 2614 & G.C.T.Ceccantini, 3020 \\
\hline $\begin{array}{l}\text { Banisteriopsis argyrophylla (A. Juss.) B. Gates } \\
\text { Banisteriopsis malifolia (Nees \& Mart.) B. } \\
\text { Gates }\end{array}$ & $\mathrm{x}$ & $\mathrm{x}$ & - & 2240 & G.C.T.Ceccantini, 2678 \\
\hline Banisteriopsis megaphylla (A. Juss.) B. Gates & $\mathrm{x}$ & - & - & 2412 & G.C.T.Ceccantini, 2907 \\
\hline Banisteriopsis muricata (Cav.) Cuatrec. & $\mathrm{x}$ & - & - & 2235 & G.C.T.Ceccantini, 2665 \\
\hline Bunchosia maritima (Vell.) J.F. Macbr. & $x$ & - & - & 2784 & G.Q.Freire, 325 \\
\hline Byrsonima coccolobifolia Kunth & $x$ & $\mathrm{x}$ & - & 2671 & G.Q.Freire, 228 \\
\hline Byrsonima cydoniifolia A. Juss. & - & - & - & 2668 & G.Q.Freire, 225 \\
\hline Byrsonima intermedia A. Juss. & $x$ & - & - & 2562 & J.C.F.Melo Jr., 604 \\
\hline Byrsonima ligustrifolia A. Juss. & $\mathrm{x}$ & - & - & 2338 & G.C.T.Ceccantini, 2813 \\
\hline Byrsonima verbascifolia (L.) DC. & $\mathrm{x}$ & $\mathrm{x}$ & - & 2296 & G.C.T.Ceccantini, 2728 \\
\hline $\begin{array}{l}\text { Dicella bracteosa (A. Juss.) Griseb. } \\
\text { Diplopterys pubipetala (A. Juss.) W.R. } \\
\text { Anderson \& C.C. Davis }\end{array}$ & $x$ & $x$ & - & 2727 & G.C.T.Ceccantini, 2656 \\
\hline Heteropterys byrsonimifolia A. Juss. & $\mathrm{x}$ & - & - & 2600 & G.C.T.Ceccantini, 2995 \\
\hline Heteropterys campestris A. Juss. & $\mathrm{x}$ & $x$ & - & 2254 & G.C.T.Ceccantini, 2684 \\
\hline $\begin{array}{l}\text { Pterandra pyroidea A. Juss. } \\
\text { MALVACEAE }\end{array}$ & $x$ & - & - & 2492 & J.C.F.Melo Jr., 531 \\
\hline Apeiba tibourbou Aubl. & - & - & - & 2695 & J.C.F.Melo Jr., 611 \\
\hline Guazuma ulmifolia Lam. & $x$ & - & - & 2400 & G.C.T.Ceccantini, 2894 \\
\hline Helicteres brevispira A. St.-Hil. & - & - & - & 2687 & G.Q.Freire, 246 \\
\hline Luehea divaricata Mart. \& Zucc. & - & - & - & 2728 & G.Q.Freire, 259 \\
\hline Luehea grandiflora Mart. \& Zucc. & - & - & - & 2757 & G.Q.Freire, 298 \\
\hline $\begin{array}{l}\text { Pseudobombax grandiflorum (Cav.) A. Robyns } \\
\text { Pseudobombax tomentosum (Mart. \& Zucc.) } \\
\text { Robyns }\end{array}$ & $\mathrm{x}$ & $x$ & - & 2372 & G.C.T.Ceccantini, 2858 \\
\hline $\begin{array}{l}\text { Triumfetta semitriloba Jacq. } \\
\text { MELASTOMATACEAE }\end{array}$ & $\mathrm{x}$ & $x$ & - & 2243 & G.C.T.Ceccantini, 2673 \\
\hline Miconia albicans (Sw.) Steud. & $\mathrm{x}$ & $x$ & - & 2431 & G.Q.Freire, 160 \\
\hline Miconia burchellii (Sw.) Triana & - & - & - & 2722 & J.C.F.Melo Jr., 641 \\
\hline Miconia calvescens DC. & - & - & - & 2715 & J.C.F.Melo Jr., 634 \\
\hline Miconia ferruginata DC. & - & - & - & 2765 & G.Q.Freire, 306 \\
\hline Miconia ibaguensis (Bonpl.) Triana & - & - & - & 2593 & G.C.T.Ceccantini, 2988 \\
\hline
\end{tabular}


Capítulo 02

continuação...

Tabela 1:Relação das espécies cujas amostras de lenho foram depositadas na xiloteca SPFw e as exsicatas, no herbário SPF. O processamento realizado para cada espécie é também apresentado.

\begin{tabular}{|c|c|c|c|c|c|}
\hline FAMÍLIA E Nome científico & 芯 & $\frac{\mathscr{E}}{\mathscr{E}}$ & 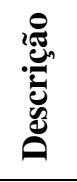 & $\begin{array}{c}\mathbf{N}^{\circ} \\
\text { SPFw }\end{array}$ & N ACESSO \\
\hline Miconia latecrenata (DC.) Naudin & - & - & - & 2633 & $\begin{array}{l}\text { G.C.T.Ceccantini, } 3042 \\
-\mathrm{B}\end{array}$ \\
\hline Miconia ligustroides (DC.) Naudin & - & - & - & 2656 & G.Q.Freire, 213 \\
\hline Miconia macrothyrsa Benth. & $x$ & - & - & 2664 & G.Q.Freire, 221 \\
\hline Miconia pepericarpa DC. & - & - & - & 2693 & J.C.F.Melo Jr., 609 \\
\hline Miconia rubiginosa (Bonpl.) DC. & $\mathrm{x}$ & $\mathrm{x}$ & - & 2308 & G.C.T.Ceccantini, 2741 \\
\hline $\begin{array}{l}\text { Miconia stenostachya DC. } \\
\text { Tibouchina stenocarpa (Schrank \& Mart. ex } \\
\text { DC.) Cogn. }\end{array}$ & $x$ & - & - & 2307 & G.C.T.Ceccantini, 2740 \\
\hline \multicolumn{6}{|l|}{ MELIACEAE } \\
\hline Guarea guidonia (L.) Sleumer & $\mathrm{x}$ & - & - & 2566 & G.C.T.Ceccantini, 2951 \\
\hline Guarea macrophylla Vahl & $x$ & $x$ & - & 2323 & G.C.T.Ceccantini, 2796 \\
\hline Trichilia clausseni C. DC. & $x$ & $x$ & - & 2524 & J.C.F.Melo Jr., 566 \\
\hline Trichilia hirta $\mathrm{L}$. & $x$ & $\mathrm{x}$ & - & 2229 & G.C.T.Ceccantini, 2658 \\
\hline \multicolumn{6}{|l|}{ MORACEAE } \\
\hline Brosimum gaudichaudii Trécul & $x$ & $x$ & - & 2636 & G.C.T.Ceccantini, 3046 \\
\hline Ficus obtusifolia Kunth & $x$ & $\mathrm{x}$ & - & 2258 & G.C.T.Ceccantini, 2688 \\
\hline $\begin{array}{l}\text { Maclura tinctoria (L.) D.Don ex Steud. } \\
\text { MYRSINACEAE }\end{array}$ & $x$ & - & - & 2504 & J.C.F.Melo Jr., 545 \\
\hline $\begin{array}{l}\text { Geissanthus ambiguus (Mart.) G.Agostini } \\
\text { Myrsine coriacea (Sw.) R. Br. ex Roem. \& } \\
\text { Schult. }\end{array}$ & - & - & - & 2354 & G.C.T.Ceccantini, 2836 \\
\hline \multicolumn{6}{|l|}{ MYRTACEAE } \\
\hline $\begin{array}{l}\text { Calyptranthes concinna DC. } \\
\text { Campomanesia adamantium (Cambess.) } \\
\text { O.Berg }\end{array}$ & - & - & - & 2564 & $\begin{array}{l}\text { G.C.T.Ceccantini, } 2952 \\
\text { J.C.F.Melo Jr., } 606\end{array}$ \\
\hline $\begin{array}{l}\text { Campomanesia guaviroba (DC.) Kiaersk. } \\
\text { Campomanesia guazumifolia (Cambess.) } \\
\text { O.Berg }\end{array}$ & $x$ & - & - & 2530 & G.C.T.Ceccantini, 3037 \\
\hline Eugenia aurata O.Berg & $x$ & - & $x$ & 2252 & G.C.T.Ceccantini, 2682 \\
\hline Eugenia bimarginata DC. & $x$ & - & - & 2560 & J.C.F.Melo Jr., 602 \\
\hline Eugenia dysenterica DC. & $x$ & - & - & 2791 & G.Q.Freire, 154 \\
\hline Eugenia involucrata DC. & $x$ & - & - & 2629 & G.C.T.Ceccantini, 3038 \\
\hline Eugenia punicifolia (Kunth) DC. & - & - & - & 2413 & G.C.T.Ceccantini, 2908 \\
\hline Eugenia subterminalis DC. & - & - & - & 2725 & G.Q.Freire, 256 \\
\hline Eugenia theodorae Kiaersk. & $x$ & - & - & 2543 & J.C.F.Melo Jr., 585 \\
\hline Myrcia multiflora (Lam.) DC. & $x$ & - & - & 2632 & G.C.T.Ceccantini, 3041 \\
\hline Myrcia rufipes DC. & $x$ & - & - & 2590 & G.C.T.Ceccantini, 2983 \\
\hline Myrcia splendens (Sw.) DC. & $x$ & - & - & 2578 & J.C.F.Melo Jr., 529 \\
\hline Myrcia tomentosa (Aubl.) DC. & $x$ & - & - & 2499 & J.C.F.Melo Jr., 538 \\
\hline Myrcia variabilis Mart. ex DC. & $x$ & - & - & 2496 & J.C.F.Melo Jr., 535 \\
\hline
\end{tabular}


Capítulo 02

continuação...

Tabela 1:Relação das espécies cujas amostras de lenho foram depositadas na xiloteca SPFw e as exsicatas, no herbário SPF. O processamento realizado para cada espécie é também apresentado.

\begin{tabular}{|c|c|c|c|c|c|}
\hline FAMÍLIA E Nome científico & 駡 & 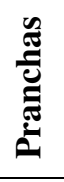 & 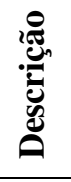 & $\begin{array}{c}\mathbf{N}^{\mathbf{o}} \\
\text { SPFw }\end{array}$ & N ACESSO \\
\hline Plinia cauliflora (Mart.) Kausel & $x$ & - & - & 2468 & J.C.F.Melo Jr., 505 \\
\hline Psidium guineense $\mathrm{Sw}$. & $x$ & - & - & 2689 & G.Q.Freire, 248 \\
\hline \multicolumn{6}{|l|}{ NYCTAGINACEAE } \\
\hline Neea $(c f)$ & - & - & - & 2498 & J.C.F.Melo Jr., 537 \\
\hline \multicolumn{6}{|l|}{ OCHNACEAE } \\
\hline Ouratea castaneifolia (DC.) Engl. & - & - & - & 2541 & J.C.F.Melo Jr., 583 \\
\hline \multicolumn{6}{|l|}{ PHYLLANTHACEAE } \\
\hline Margaritaria nobilis L.f. & $x$ & - & - & 2264 & G.C.T.Ceccantini, 2694 \\
\hline Phyllanthus acuminatus Vahl & - & - & - & 2627 & G.C.T.Ceccantini, 3036 \\
\hline \multicolumn{6}{|l|}{ PICRAMNIACEAE } \\
\hline Picramnia sellowii Planch. & $x$ & - & - & 2378 & G.C.T.Ceccantini, 2866 \\
\hline \multicolumn{6}{|l|}{ PIPERACEAE } \\
\hline Piper amalago L. & - & - & - & 2714 & J.C.F.Melo Jr., 633 \\
\hline \multicolumn{6}{|l|}{ POLYGALACEAE } \\
\hline Bredemeyera floribunda Willd. & - & - & - & 2698 & J.C.F.Melo Jr., 614 \\
\hline \multicolumn{6}{|l|}{ PROTEACEAE } \\
\hline Roupala montana Aubl. & - & - & - & 2880 & G.C.T.Ceccantini, 3198 \\
\hline \multicolumn{6}{|l|}{ RHAMNACEAE } \\
\hline Gouania virgata Reissek & $\mathrm{x}$ & $\mathrm{x}$ & - & 2228 & G.C.T.Ceccantini, 2657 \\
\hline \multicolumn{6}{|l|}{ RUBIACEAE } \\
\hline Chiococca alba (L.) Hitchc. & $x$ & $x$ & - & 2620 & G.C.T.Ceccantini, 3029 \\
\hline Faramea $(c f)$ & - & - & - & 2820 & G.C.T.Ceccantini, 3159 \\
\hline Genipa americana $\mathrm{L}$. & $x$ & - & - & 2376 & G.C.T.Ceccantini, 2864 \\
\hline Guettarda viburnoides Cham. \& Schltdl. & - & - & - & 2571 & G.C.T.Ceccantini, 2961 \\
\hline Hamelia patens Jacq. & $\mathrm{x}$ & $\mathrm{x}$ & - & 2609 & G.C.T.Ceccantini, 3004 \\
\hline Ixora brevifolia Benth. & - & - & - & 2711 & J.C.F.Melo Jr., 630 \\
\hline Palicourea rigida Kunth & - & - & - & 2486 & J.C.F.Melo Jr., 525 \\
\hline Psychotria capitata Ruiz \& Pav. & - & - & - & 2667 & G.Q.Freire, 224 \\
\hline Psychotria carthagenensis Jacq. & $\mathrm{x}$ & $\mathrm{x}$ & - & 2606 & G.C.T.Ceccantini, 3001 \\
\hline Psychotria vellosiana Benth. & - & - & - & 2716 & J.C.F.Melo Jr., 635 \\
\hline Randia armata $(\mathrm{Sw}.) \mathrm{DC}$. & - & - & - & 2731 & G.Q.Freire, 263 \\
\hline $\begin{array}{l}\text { Rudgea viburnoides (Cham.) Benth. } \\
\text { Tocoyena formosa (Cham. \& Schltdl.) }\end{array}$ & $x$ & $\mathrm{x}$ & - & 2480 & J.C.F.Melo Jr., 519 \\
\hline K.Schum. & - & - & - & 2767 & G.Q.Freire, 308 \\
\hline \multicolumn{6}{|l|}{ RUTACEAE } \\
\hline Dictyoloma vandellianum A.H.L. Juss. & - & - & - & 2635 & G.C.T.Ceccantini, 3044 \\
\hline Galipea jasminiflora (A. St.-Hil.) Engl. & $x$ & - & - & 2525 & J.C.F.Melo Jr., 567 \\
\hline Zanthoxylum rhoifolium Lam. & $x$ & $x$ & - & 2612 & G.C.T.Ceccantini, 3007 \\
\hline Zanthoxylum riedelianum Engl. & - & - & - & 2869 & G.C.T.Ceccantini, 3177 \\
\hline \multicolumn{6}{|l|}{ SALICACEAE } \\
\hline Casearia arborea (Rich.) Urb. & - & - & - & 2538 & J.C.F.Melo Jr., 580 \\
\hline
\end{tabular}


Capítulo 02

continuação...

Tabela 1:Relação das espécies cujas amostras de lenho foram depositadas na xiloteca SPFw e as exsicatas, no herbário SPF. O processamento realizado para cada espécie é também apresentado.

\begin{tabular}{|c|c|c|c|c|c|}
\hline FAMÍLIA E Nome científico & 駡 & 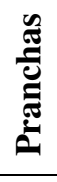 & 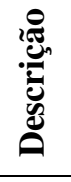 & $\begin{array}{c}\mathbf{N}^{\mathbf{o}} \\
\text { SPFw }\end{array}$ & N ACESSO \\
\hline Casearia sylvestris $\mathrm{Sw}$. & $x$ & - & - & 2396 & G.C.T.Ceccantini, 2890 \\
\hline Prockia crucis P. Browne ex L. & - & - & - & 2579 & G.C.T.Ceccantini, 2971 \\
\hline \multicolumn{6}{|l|}{ SAPINDACEAE } \\
\hline Allophylus sericeus (Cambess.) Radlk. & $\mathrm{x}$ & $x$ & $\mathrm{x}$ & 2510 & J.C.F.Melo Jr., 551 \\
\hline Cupania cf. vernalis Cambess. & $x$ & $x$ & $x$ & 2613 & G.C.T.Ceccantini, 3008 \\
\hline Cupania zanthoxyloides Radlk. & $x$ & - & - & 2520 & J.C.F.Melo Jr., 562 \\
\hline Dilodendron bipinnatum Radlk. & $x$ & $x$ & - & 2392 & G.C.T.Ceccantini, 2885 \\
\hline Magonia pubescens A. St.-Hil. & $x$ & $x$ & - & 2253 & G.C.T.Ceccantini, 2683 \\
\hline Matayba elaeagnoides Radlk. & $x$ & - & - & 2500 & J.C.F.Melo Jr., 541 \\
\hline Matayba guianensis Aubl. & $\mathrm{x}$ & $\mathrm{x}$ & - & 2594 & G.C.T.Ceccantini, 2989 \\
\hline Paullinia meliifolia Juss. & $x$ & - & - & 2516 & J.C.F.Melo Jr., 558 \\
\hline Paullinia trigonia Vell. & $x$ & $x$ & - & 2374 & G.C.T.Ceccantini, 2862 \\
\hline Serjania laruotteana Cambess. & $x$ & $x$ & $x$ & 2406 & G.C.T.Ceccantini, 2901 \\
\hline Serjania lethalis A.St.-Hil. & $x$ & - & - & 2792 & G.Q.Freire, 155 \\
\hline Serjania multiflora Cambess. & - & - & - & 2619 & G.C.T.Ceccantini, 3028 \\
\hline Serjania reticulata Cambess. & - & - & - & 2741 & G.Q.Freire, 274 \\
\hline Serjania tristis Radlk. & - & - & - & 2724 & G.Q.Freire, 255 \\
\hline $\begin{array}{l}\text { SAPOTACEAE } \\
\text { Chrysophyllum marginatum (Hook. \& Arn.) } \\
\text { Radlk. }\end{array}$ & $x$ & 2 & $x$ & $2223 / 2608$ & G.C.T.Ceccantini, 2651 \\
\hline Pouteria torta (Mart.) Radlk. & - & - & - & 2424 & G.C.T.Ceccantini, 2919 \\
\hline \multicolumn{6}{|l|}{ SIPARUNACEAE } \\
\hline Siparuna guianensis Aubl. & $x$ & $x$ & - & 2246 & G.C.T.Ceccantini, 2676 \\
\hline \multicolumn{6}{|l|}{ SMILACACEAE } \\
\hline Smilax $(c f)$ & - & - & - & 2533 & J.C.F.Melo Jr., 575 \\
\hline \multicolumn{6}{|l|}{ SOLANACEAE } \\
\hline Brunfelsia uniflora (Pohl) D. Don & - & - & - & 2528 & J.C.F.Melo Jr., 570 \\
\hline Cestrum axillare Vell. & - & - & - & 2467 & J.C.F.Melo Jr., 504 \\
\hline Cestrum schlechtendalii G. Don & - & - & - & 2363 & G.C.T.Ceccantini, 2847 \\
\hline Cestrum strigilatum Ruiz \& Pav. & $x$ & $x$ & - & 2242 & G.C.T.Ceccantini, 2672 \\
\hline Solanum decompositiflorum Sendtn. & $x$ & $\mathrm{x}$ & - & 2230 & G.C.T.Ceccantini, 2659 \\
\hline Solanum lycocarpum A. St.-Hil. & $x$ & $x$ & - & 2423 & G.C.T.Ceccantini, 2918 \\
\hline Solanum paniculatum $\mathrm{L}$. & - & - & - & 2678 & G.Q.Freire, 236 \\
\hline Solanum scuticum M.Nee & - & - & - & 2449 & G.Q.Freire, 180 \\
\hline Solanum sublentum Hieron. & - & - & - & 2337 & G.C.T.Ceccantini, 2812 \\
\hline Solanum variabile Mart. & - & - & - & 2573 & G.C.T.Ceccantini, 2963 \\
\hline \multicolumn{6}{|l|}{ STYRACACEAE } \\
\hline Styrax camporum Pohl & $x$ & $x$ & - & 2250 & G.C.T.Ceccantini, 2680 \\
\hline Styrax ferrugineus Nees \& Mart. & - & - & - & 2764 & G.Q.Freire, 305 \\
\hline \multicolumn{6}{|l|}{ SYMPLOCACEAE } \\
\hline Symplocos nitens (Pohl) Benth. & - & - & - & 2494 & J.C.F.Melo Jr., 533 \\
\hline
\end{tabular}


Capítulo 02

continuação...

Tabela 1:Relação das espécies cujas amostras de lenho foram depositadas na xiloteca SPFw e as exsicatas, no herbário SPF. O processamento realizado para cada espécie é também apresentado.

\begin{tabular}{|c|c|c|c|c|c|}
\hline FAMÍLIA E Nome científico & 苞 & 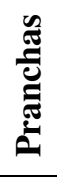 & 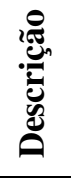 & $\begin{array}{c}\mathbf{N}^{\mathbf{o}} \\
\text { SPFw }\end{array}$ & N ACESSO \\
\hline \multicolumn{6}{|l|}{ URTICACEAE } \\
\hline Boehmeria caudata $\mathrm{Sw}$. & $\mathrm{x}$ & - & - & 2226 & G.C.T.Ceccantini, 2655 \\
\hline Cecropia pachystachya Trécul & - & - & - & 2506 & J.C.F.Melo Jr., 547 \\
\hline Urera baccifera (L.) Gaudich. ex Wedd. & $\mathrm{x}$ & $\mathrm{x}$ & - & 2622 & G.C.T.Ceccantini, 3031 \\
\hline \multicolumn{6}{|l|}{ VERBENACEAE } \\
\hline Lantana camara $\mathrm{L}$. & $x$ & $\mathrm{x}$ & - & 2260 & G.C.T.Ceccantini, 2690 \\
\hline Lippia martiana Schauer & - & - & - & 2651 & G.Q.Freire, 207 \\
\hline Lippia velutina Schauer & $x$ & - & - & 2345 & G.C.T.Ceccantini, 2821 \\
\hline \multicolumn{6}{|l|}{ VIOLACEAE } \\
\hline Hybanthus atropurpureus (A. St.-Hil.) Taub. & - & - & - & 2505 & J.C.F.Melo Jr., 546 \\
\hline Cissus sulcicaulis (Baker) Planch. & - & - & - & 2707 & J.C.F.Melo Jr., 624 \\
\hline \multicolumn{6}{|l|}{ VOCHYSIACEAE } \\
\hline Callisthene major Mart. \& Zucc. & $x$ & $x$ & $x$ & 2304 & G.C.T.Ceccantini, 2736 \\
\hline Qualea grandiflora Mart. & $x$ & $x$ & - & 2282 & G.C.T.Ceccantini, 2714 \\
\hline Qualea multiflora Mart. & $x$ & - & $x$ & 2279 & G.C.T.Ceccantini, 2711 \\
\hline Qualea parviflora Mart. & $x$ & - & $x$ & 2760 & G.Q.Freire, 301 \\
\hline Salvertia convallariodora A. St.-Hil. & $x$ & - & - & 2759 & G.Q.Freire, 300 \\
\hline Vochysia rufa Mart. & - & - & - & 2701 & J.C.F.Melo Jr., 618 \\
\hline Vochysia tucanorum Mart. & $\mathrm{x}$ & $x$ & - & 2311 & G.C.T.Ceccantini, 2783 \\
\hline
\end{tabular}


Tabela 2: $1^{\text {a }}$ parte da descrição microscópica da anatomia de 56 espécies de plantas coletadas na APA Carste de Lagoa Santa, MG, segundo características propostas pela IAWA Committee (1989).

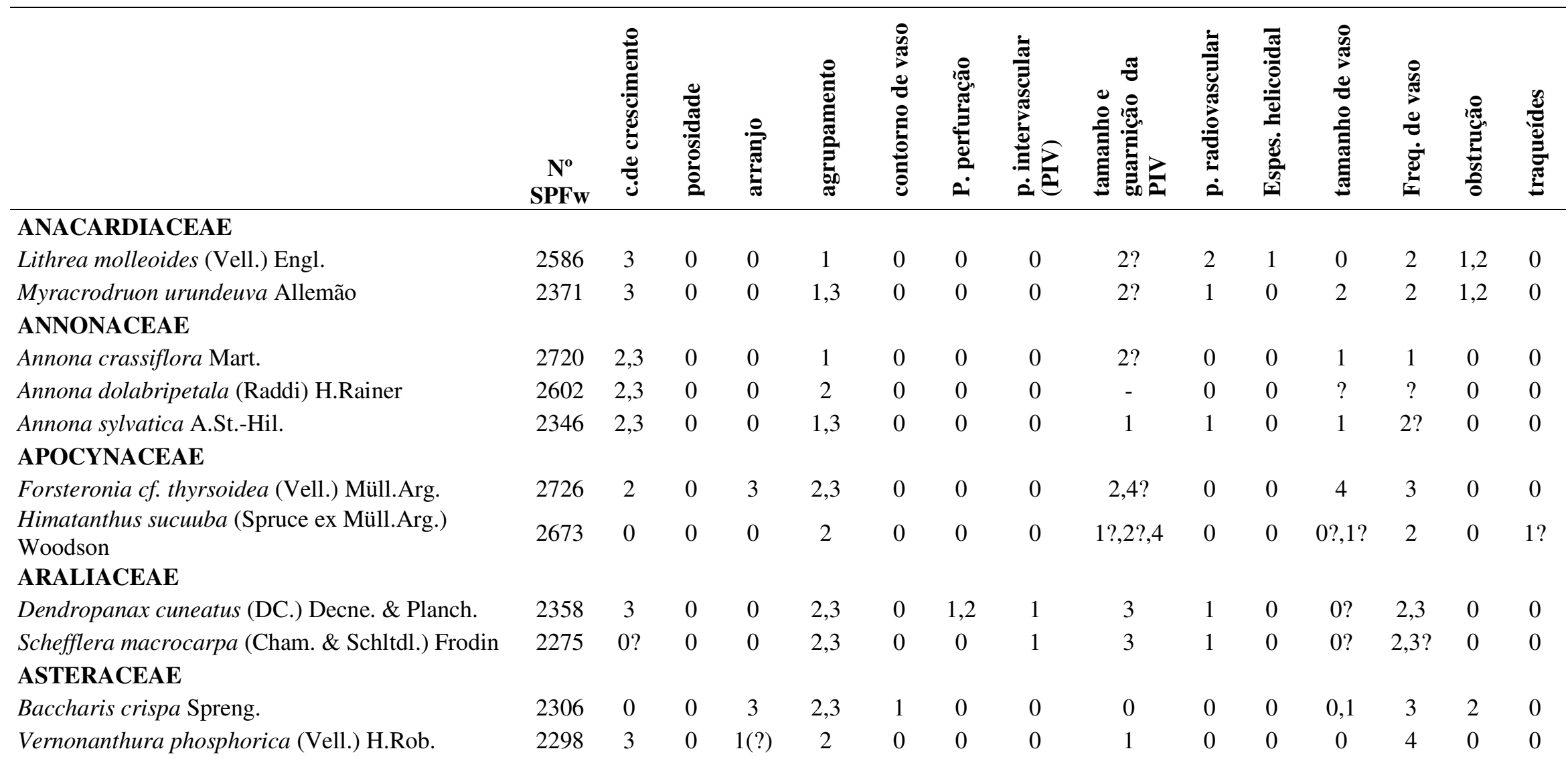

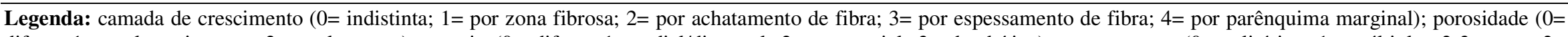
difusa; $1=$ anel semiporoso; $2=$ anel poroso $)$; arranjo $(0=$ difuso; $1=$ radial $/$ diagonal; $2=$ tangencial; $3=$ dendrítico $)$; agrupamento $(0=$ solitários; $1=$ múltiplos $2-3$ vasos; $2=$ múltiplos radias com mais de 4 vasos; $3=$ múltiplos em cachos comuns); contorno angular de vaso ( $0=$ ausente; $1=$ presente); placa de perfuração ( $0=$ simples; $1=$ escalariforme de

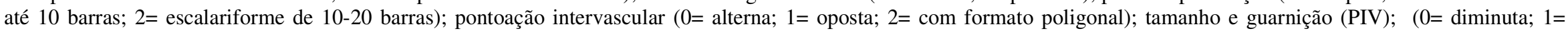
pequena; $2=$ média; $3=$ grande; $4=$ guarnecida); pontoação radiovascular $(0=$ igual a intervascular em tamanho e forma; $1=$ circular a angular; $2=$ escalariforme a vertical);

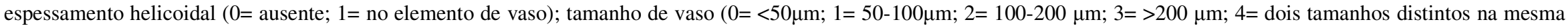

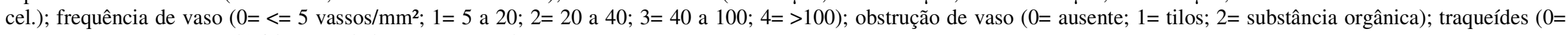
ausente; $1=$ presente); ?= dúvida; "“-“= dado não computado. 
continuação...

Tabela 2: $1^{\mathrm{a}}$ parte da descrição microscópica da anatomia de 56 espécies de plantas coletadas na APA Carste de Lagoa Santa, MG, segundo características propostas pela IAWA Committee (1989)..

\begin{tabular}{|c|c|c|c|c|c|c|c|c|c|c|c|c|c|c|}
\hline $\begin{array}{c}\mathbf{N}^{\mathbf{0}} \\
\text { SPF }\end{array}$ & 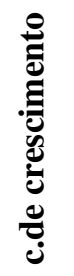 & 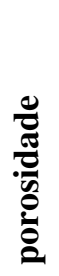 & 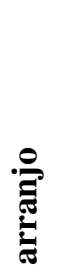 & 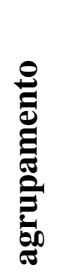 & 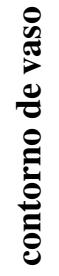 & 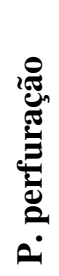 & 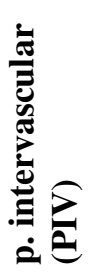 & 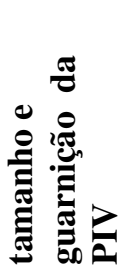 & 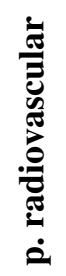 & 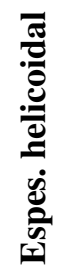 & 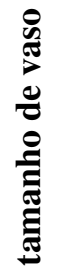 & 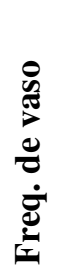 & 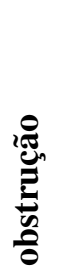 & 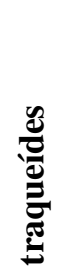 \\
\hline
\end{tabular}

\section{BIGNONIACEAE}

Cuspidaria sp

Handroanthus heptaphyllus Mattos

$\begin{array}{cccccccc}2241 & 2,3 & 0 & 0 & 1,3 & 0 & 0 & 0 \\ 2734 & 4 & 0 & 0 & 1 & 0 & 0 & 0 \\ 2369 & 3,4 & 0 & 0 & 1 & 0 & 0 & 0 \\ 2773 & 3,4 & 0 & 0 & 1 & 0 & 0 & 0 \\ 2644 & 3 & 0 & 1,2 & 2 & 0 & 0 & 0 \\ 2398 & 0 & 0 & 0 & 1,2,3 & 0 & 0 & 0 \\ 2287 & 4 & 0 & 0 & 0,1 & 0 & 0 & 0 \\ 2587 & ? & 0 & 1,2 & 3 & 0 & 0 & 0\end{array}$

3
3
3
3
3
3
0
1

$\begin{array}{cccccc}0 & 0 & 3,4 & 1 & 0 & 0 \\ 0 & 0 & 1 & 2 & 0 & 0 \\ 0 & 0 & 2 & 3 & 0 & 0 \\ 0 & 0 & 2 & 2 & 0 & 0 \\ 0 & 0 & 4 & 2 & 1 & 0 \\ 0 & 0 & 0,1,2 & 3 & 0 & 0 \\ 0(?) & 0 & 0 ?, 1 ? & 1 & 0 & 0 \\ 0 & 0 & 1 & 2,3 ? & 0 & 0\end{array}$

\section{BORAGINACEAE}

Cordia trichotoma (Vell.) Arráb. ex Steud.

\section{COMBRETACEAE}

Terminalia argentea Mart.

Terminalia glabrescens Mart.

2403

0

$\begin{array}{cccc}2415 & 3 & 0 & 0 \\ 2470 & 3,4 & 0 & 0\end{array}$

\section{EBENACEAE}

\section{Diospyros hispida A.DC.}

$\begin{array}{llllllll}2303 & 0 & 0 & 0 & 1 & 0 & 0 & 0,2\end{array}$

$\begin{array}{lllllll}1 ? & 0 & 0 & 1 ? & 2 & 0 & 0 \\ 2,4 & 0 & 0 & 0 & 3 & 0 & 1 \\ 2,4 & 0 & 0 & 1 & 2 & 0 & 0 \\ 1,4 ? & 0 & 0 & 1 & 2 & 0 & 0\end{array}$

\section{ERYTHROXYLACEAE}

Legenda: camada de crescimento $(0=$ indistinta; $1=$ por zona fibrosa; $2=$ por achatamento de fibra; $3=$ por espessamento de fibra; $4=$ por parênquima marginal); porosidade $(0=$ difusa; $1=$ anel semiporoso; $2=$ anel poroso); arranjo $(0=$ difuso; $1=$ radial $/$ diagonal; $2=$ tangencial; $3=$ dendrítico); agrupamento $(0=$ solitários; $1=$ múltiplos $2-3$ vasos; $2=$ múltiplos radias com mais de 4 vasos; $3=$ múltiplos em cachos comuns); contorno angular de vaso ( $0=$ ausente; $1=$ presente); placa de perfuração ( $0=$ simples; $1=$ escalariforme de

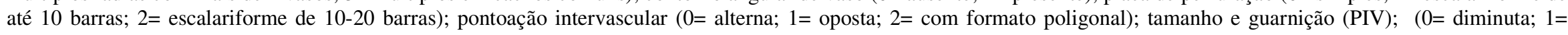
pequena; $2=$ média; $3=$ grande; $4=$ guarnecida); pontoação radiovascular $(0=$ igual a intervascular em tamanho e forma; $1=$ circular a angular; $2=$ escalariforme a vertical); espessamento helicoidal ( $0=$ ausente; $1=$ no elemento de vaso); tamanho de vaso $(0=<50 \mu \mathrm{m} ; 1=50-100 \mu \mathrm{m} ; 2=100-200 \mu \mathrm{m} ; 3=>200 \mu \mathrm{m} ; 4=$ dois tamanhos distintos na mesma

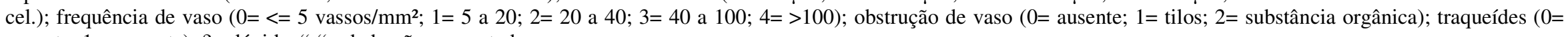
ausente; $1=$ presente); ?= dúvida; "“_"= dado não computado. 
continuação...

Tabela 2: $1^{\mathrm{a}}$ parte da descrição microscópica da anatomia de 56 espécies de plantas coletadas na APA Carste de Lagoa Santa, MG, segundo características propostas pela IAWA Committee (1989)..

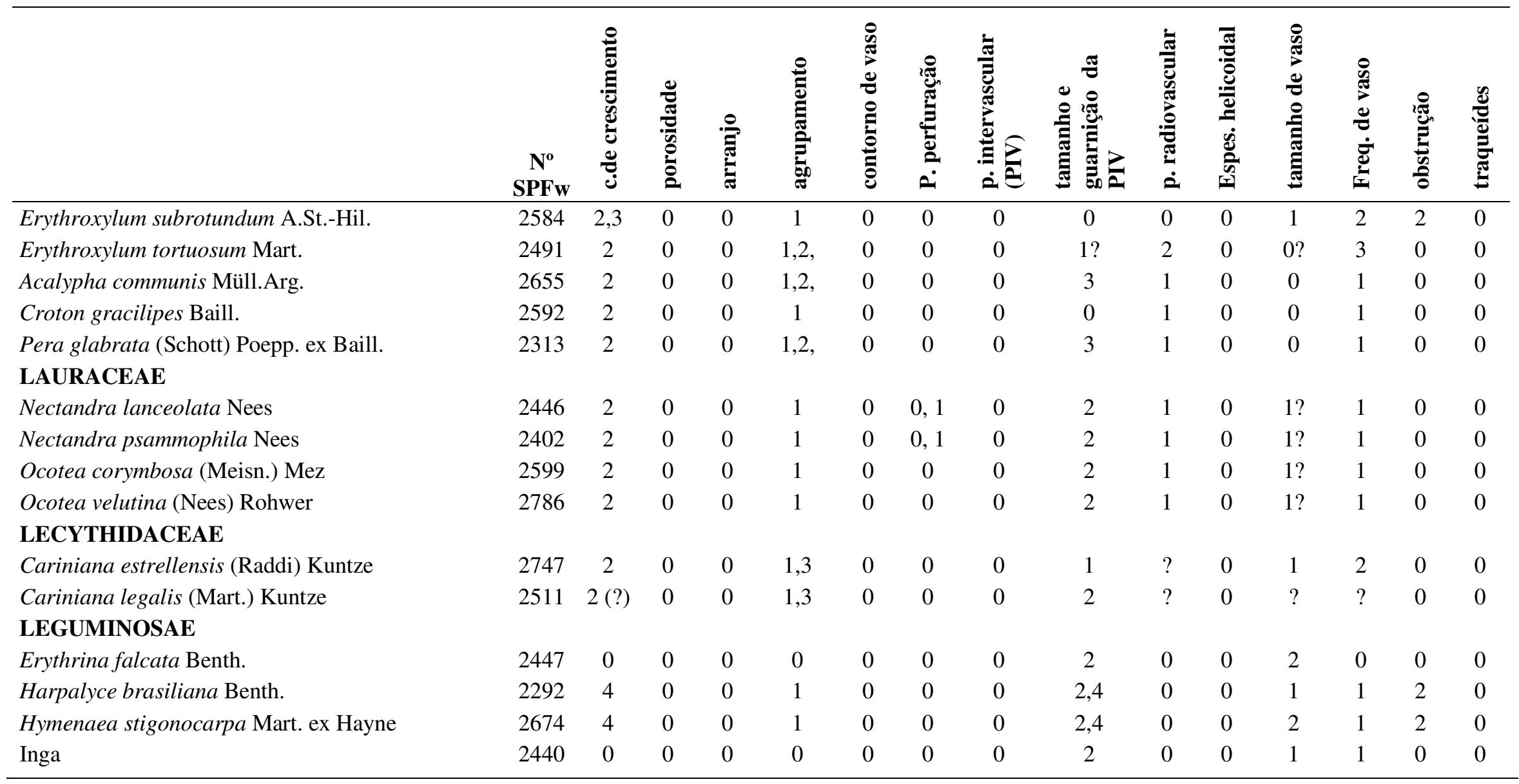

Legenda: camada de crescimento $(0=$ indistinta; $1=$ por zona fibrosa; $2=$ por achatamento de fibra; $3=$ por espessamento de fibra; $4=$ por parênquima marginal $)$; porosidade $(0=$ difusa; $1=$ anel semiporoso; $2=$ anel poroso); arranjo $(0=$ difuso; $1=$ radial $/$ diagonal; $2=$ tangencial; $3=$ dendrítico); agrupamento $(0=$ solitários; $1=$ múltiplos $2-3$ vasos; $2=$

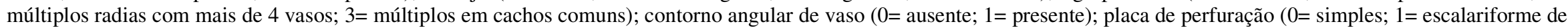

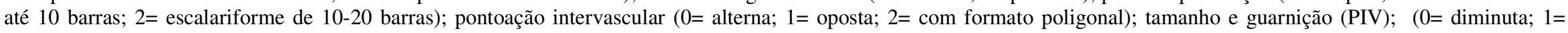
pequena; $2=$ média; $3=$ grande; $4=$ guarnecida); pontoação radiovascular $(0=$ igual a intervascular em tamanho e forma; $1=$ circular a angular; $2=$ escalariforme a vertical);

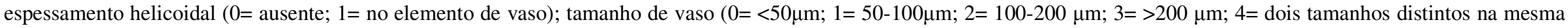

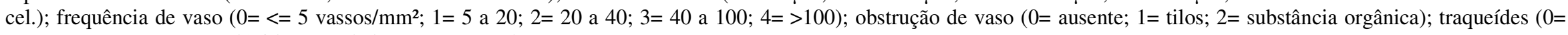
ausente; $1=$ presente); ?= dúvida; "“-"= dado não computado. 
continuação...

Tabela 2: $1^{\mathrm{a}}$ parte da descrição microscópica da anatomia de 56 espécies de plantas coletadas na APA Carste de Lagoa Santa, MG, segundo características propostas pela IAWA Committee (1989)..

\begin{tabular}{|c|c|c|c|c|c|c|c|c|c|c|c|c|c|c|c|}
\hline & $\begin{array}{c}\mathbf{N}^{\circ} \\
\text { SPFw }\end{array}$ & 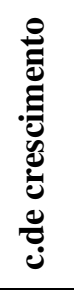 & 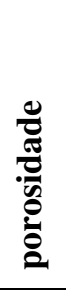 & 异 & 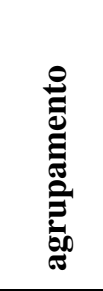 & 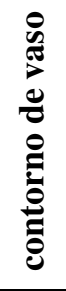 & م: & 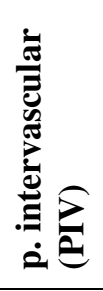 & 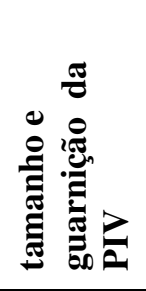 & 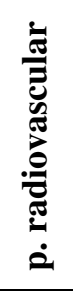 & 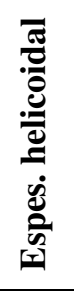 & 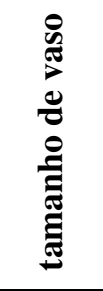 & 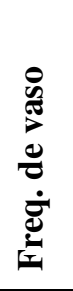 & 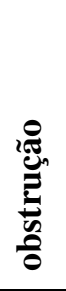 & 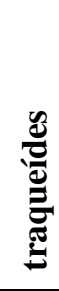 \\
\hline Lonchocarpus sericeus (Poir.) Kunth ex DC. & 2437 & 0 & 0 & 0 & 0 & 0 & 0 & 0 & 2 & 0 & 0 & 3 & 0 & 0 & 0 \\
\hline Machaerium hirtum (Vell.) Stellfeld & 2417 & 2 & 0 & 0 & 0 & 0 & 0 & 0 & 2 & 0 & 0 & 2 & 1 & 0 & 0 \\
\hline Mimosa laticifera Rizzini \& A. Mattos & 2703 & 4 & 0 & 0 & 0 & 0 & 0 & 0 & 2 & 0 & 0 & 1 & 1 & 0 & 0 \\
\hline Platymiscium pubescens Micheli & 2638 & 2 & 0 & 0 & 0 & 0 & 0 & 0 & 2,4 & 0 & 0 & 2 & 1 & 0 & 0 \\
\hline Senna multijuga (Rich.) H.S.Irwin \& Barneby & 2233 & 0 & 0 & 0 & $1,2,3$ & 1 & 0 & 0 & 2 & 0 & 0 & 1 & 1 & 0 & 0 \\
\hline $\begin{array}{l}\text { Senna pendula (Humb.\& Bonpl. ex Willd.) } \\
\text { H.S.Irwin \& Barneby }\end{array}$ & 2341 & - & 0 & 0 & 0 & 0 & 0 & 0 & 2 & 0 & 0 & 1 & 1 & 0 & 0 \\
\hline $\begin{array}{l}\text { Senna silvestris (Vell.) H.S.Irwin \& Barneby } \\
\text { MYRTACEAE }\end{array}$ & 2643 & 2 & 0 & 0 & 0 & 0 & 0 & 0 & 2 & 0 & 0 & 1 & 1 & 0 & 0 \\
\hline Cupania cf. vernalis Cambess. & 2613 & 1 & 0 & 0 & 1 & 0 & 0 & 0 & $0 ?, 4 ?$ & 0 & 0 & $0 ?, 1 ?$ & 3 & 2 & 0 \\
\hline $\begin{array}{l}\text { Serjania laruotteana } \text { Cambess. } \\
\text { SAPOTACEAE }\end{array}$ & 2406 & 0 & 0 & 0 & 2 & 0 & 0 & 0 & $2,4 ?$ & 0 & 0 & 4 & 3 & 0 & 0 \\
\hline Chrysophyllum marginatum (Hook. \& Arn.) Radlk. & 2608 & 0 & 0 & 0 & 2 & 0 & 0 & 0 & $1 ?$ & 0 & 0 & 2,4 & 2 & 0 & 0 \\
\hline
\end{tabular}

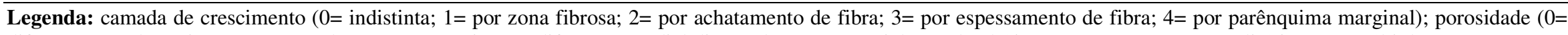
difusa; $1=$ anel semiporoso; $2=$ anel poroso); arranjo $(0=$ difuso; $1=$ radial/diagonal; $2=$ tangencial; $3=$ dendrítico $)$; agrupamento $(0=$ solitários; $1=$ múltiplos $2-3$ vasos; $2=$ múltiplos radias com mais de 4 vasos; $3=$ múltiplos em cachos comuns); contorno angular de vaso ( $0=$ ausente; $1=$ presente); placa de perfuração ( $0=$ simples; $1=$ escalariforme de

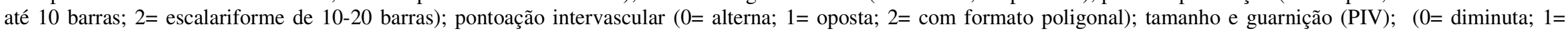
pequena; $2=$ média; $3=$ grande; $4=$ guarnecida); pontoação radiovascular $(0=$ igual a intervascular em tamanho e forma; $1=$ circular a angular; $2=$ escalariforme a vertical);

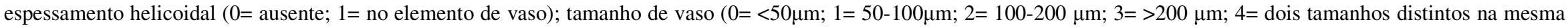

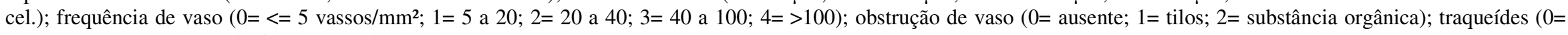
ausente; $1=$ presente); ?= dúvida; "“-“= dado não computado. 
continuação...

Tabela 2: $1^{\mathrm{a}}$ parte da descrição microscópica da anatomia de 56 espécies de plantas coletadas na APA Carste de Lagoa Santa, MG, segundo características propostas pela IAWA Committee (1989)..

\begin{tabular}{|c|c|c|c|c|c|c|c|c|c|c|c|c|c|c|c|}
\hline & $\begin{array}{c}\mathbf{N}^{\mathbf{0}} \\
\text { SPFw }\end{array}$ & 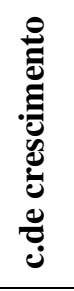 & 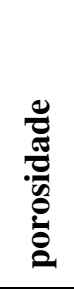 & & 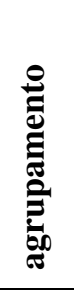 & 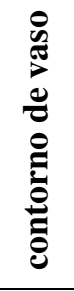 & a: & 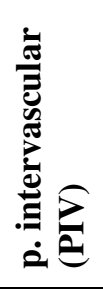 & 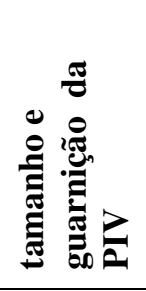 & 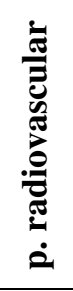 & 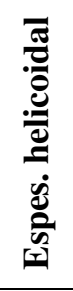 & 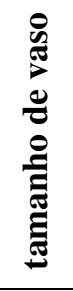 & 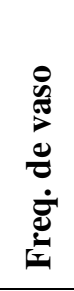 & 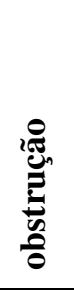 & $\frac{\mathscr{E}}{\tilde{E}}$ \\
\hline \multicolumn{16}{|l|}{ VOCHYSIACEAE } \\
\hline Callisthene major Mart. \& Zucc. & 2304 & 0 & 0 & 0 & 1 & 0 & 0 & 0 & $1,4 ?$ & 0 & 0 & 0 & 3 & 0 & 0 \\
\hline
\end{tabular}

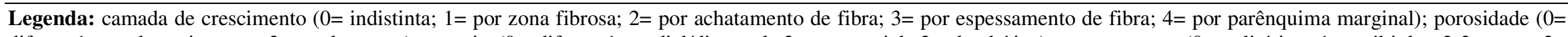

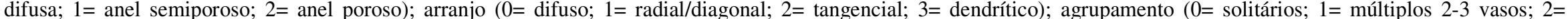

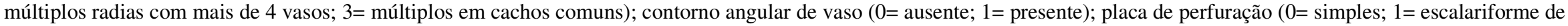

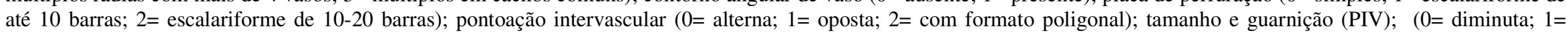
pequena; $2=$ média; $3=$ grande; $4=$ guarnecida); pontoação radiovascular $(0=$ igual a intervascular em tamanho e forma; $1=$ circular a angular; $2=$ escalariforme a vertical);

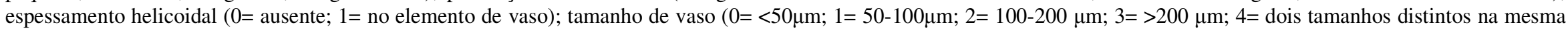

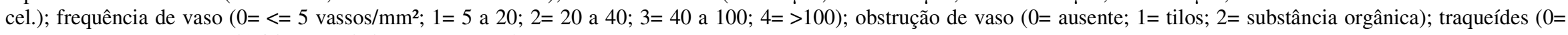
ausente; $1=$ presente); ?= dúvida; "“"“= dado não computado. 
Tabela 3: $2^{\mathrm{a}}$ parte da descrição microscópica da anatomia de 56 espécies de plantas coletadas na APA Carste de Lagoa Santa, MG, segundo características propostas pela IAWA Committee (1989).

\section{ANACARDIACEAE}

Lithrea molleoides (Vell.) Engl.

Myracrodruon urundeuva Allemão

\section{ANNONACEAE}

Annona crassiflora Mart.

Annona dolabripetala (Raddi) H.Rainer

Annona sylvatica A.St.-Hil.

\section{APOCYNACEAE}

Forsteronia cf. thyrsoidea (Vell.) Müll.Arg.

Himatanthus sucuuba (Spruce ex Müll.Arg.)

Woodson

\section{ARALIACEAE}

Dendropanax cuneatus (DC.) Decne. \& Planch.

Schefflera macrocarpa (Cham. \& Schltdl.) Frodin

\section{ASTERACEAE}

Baccharis crispa Spreng.

Vernonanthura phosphorica (Vell.) H.Rob.

\section{BIGNONIACEAE}

\section{Cuspidaria $s p$}

Handroanthus heptaphyllus Mattos

Handroanthus impetiginosus Mattos

Handroanthus serratifolius (A.H.Gentry) S.Grose

Lundia obliqua Sond.

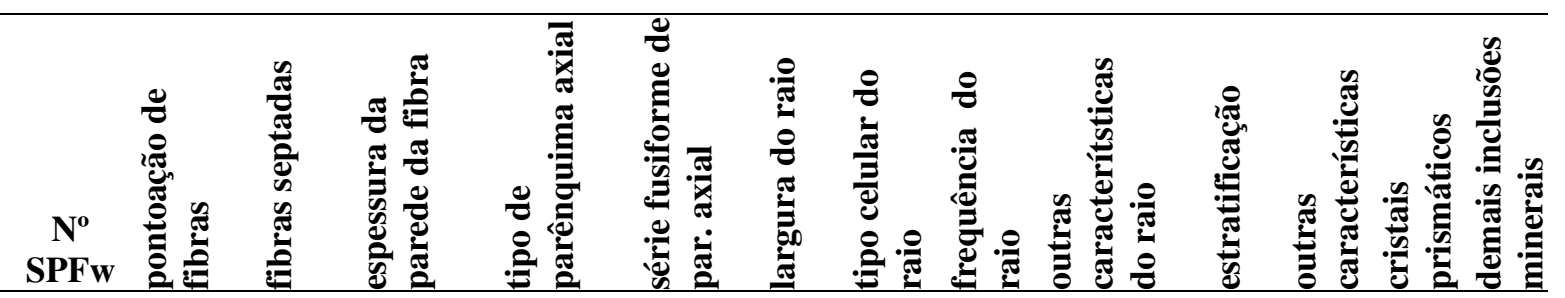

$\begin{array}{cccccccccccccc}2586 & 0 & 0 & 1 & 0 & - & 2 & 3 & 1 & 0 & 0 & - & 1 & 0 \\ 2371 & 0 & 1 & 1 & 3 & 3 & 2 & 3 & 1 & 0 & 0 & 2 & 1 & 0 \\ 2720 & 0,2 & 0 & 0 & 9,11 & 3 ? & 3 & 2 & 1 & 2 & 0 & - & 0 & 0 \\ 2602 & 2 ? & 0 & 1 & - & - & 3 & - & - & 0 & 0 & - & - & 0 \\ 2346 & 0,2 & 0 & 0 & 9,11 & 3 & 2 & 0 & 1 & 0 & 0 & - & 0 & 0 \\ & & & & & & & & & & & & & \\ 2726 & 1 & 0,2 ? & 1 & 0 ?, 1 ?, 12 ? & - & 2 & 2,3,4 & 2 & 3 ?, 4,7 & 0 & 4 & 4,6 & 0 \\ 2673 & 1 ? & 0 & 1 & 2 & 3 & 2 & 0 & 1,2 & 0 & 0 & - & 0 & 0 \\ & & & & & & & & & & & & & \\ 2358 & 0 & 1 & 0 & 3 & 5 & 2 & 2,3 & 0,1 & 0 & 0 & - & 0 & 0 \\ 2275 & 0 & 0 & 2 & 3 & 8 & 2,3 ? & 2,3 & 1 ? & 0 & 0 & - & 0 & 0 \\ & & & & & & & & & & & & & \\ 2306 & 0,2 & 0 & 1 & 0,3 ?, & 2 ? & 1,2,5 & 2,3,5 & 1 & 0 & 0 & - & 0 & 0 \\ 2298 & 0,2 & 0 & 1 & 0 & - & 2 & 1 & 0 & 0,7 & 0 & - & 1 & 0 \\ & & & & & & & & & & & & & \\ 2241 & 0 & 1 & 1 & 8 & 2,3 & 3 & 0 & 1 & 0 & 0 & - & 0 & 1 \\ 2734 & 0 & 0 & 2 & 6,7,12 & 2 & 2 & 0 & 1 & 0 & 1 & - & 0 & 2 \\ 2369 & 0,2 ? & 0 & 2 & 6,7,12 & 1,2 & 2 & 0 & 1 & 0 & 0,2 & - & 0 & 0 \\ 2773 & 0 & 0 & 2 & 7,12 & 2,3 & 2 & 0 & 1 & 0 & 1 & - & 0 & 0 \\ 2644 & 0 & 1 & 0,1 & 0 ?, 7 ?, 12 ? & 2 & 2 & 5 & 2 & 0,6 & 0 & - & 0 & 0\end{array}$


Tabela 3: $2^{\mathrm{a}}$ parte da descrição microscópica da anatomia de 56 espécies de plantas coletadas na APA Carste de Lagoa Santa, MG, segundo características propostas pela IAWA Committee (1989).

\begin{tabular}{|c|c|c|c|c|c|c|c|c|c|c|c|c|c|c|}
\hline & $\begin{array}{c}\mathbf{N}^{\circ} \\
\text { SPFw }\end{array}$ & 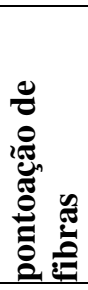 & 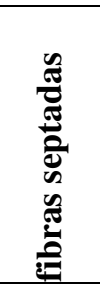 & 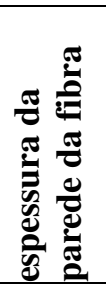 & 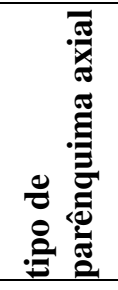 & 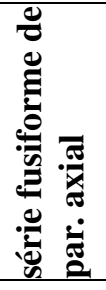 & 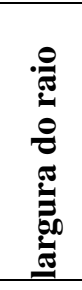 & 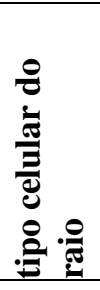 & 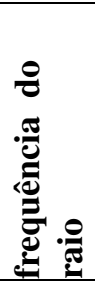 & 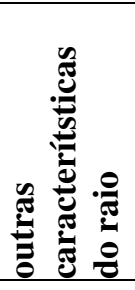 & 氖: & : & 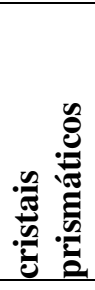 & 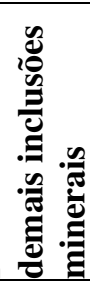 \\
\hline Pyrostegia venusta (Ker Gawl.) Miers & 2398 & 0,2 & 0 & 1 & 0 & - & 3 & 0 & - & 3 & 0 & - & 0 & 0 \\
\hline Zeyheria montana Mart. & 2287 & 0,2 & 0 & 2 & 4,12 & 2 & 4 & $1,5 ?$ & $0,1 ?$ & 3 & 2 & - & 0 & 0 \\
\hline $\begin{array}{l}\text { Zeyheria tuberculosa (Vell.) Bureau ex Verl. } \\
\text { BORAGINACEAE }\end{array}$ & 2587 & 0 & 0 & 2 & 3,7 & 2 & 2 & 0 & 1 & 0 & $1 ?, 2,4$ & - & 0 & 0 \\
\hline $\begin{array}{l}\text { Cordia trichotoma (Vell.) Arráb. ex Steud. } \\
\text { COMBRETACEAE }\end{array}$ & 2403 & 0 & 0 & 1 & 12 & 2 & 3 & 5 & $1 ?$ & 5 & 0 & - & 1 & 0 \\
\hline Terminalia argentea Mart. & 2415 & 0 & 0,1 & 2 & 5,7 & 3 & 1 & $0,5 ?$ & 2 & 0 & 0 & 3 & 4,6 & 3 \\
\hline $\begin{array}{l}\text { Terminalia glabrescens Mart. } \\
\text { EBENACEAE }\end{array}$ & 2470 & 0 & 0,1 & $1,2 ?$ & $5,7,12$ & 3 & 1 & $5 ?$ & 2 & 0 & 0 & - & 0 & 0 \\
\hline $\begin{array}{l}\text { Diospyros hispida A.DC. } \\
\text { ERYTHROXYLACEAE }\end{array}$ & 2303 & 0 & 0 & $1 ?, 2 ?$ & $4 ?, 11$ & 3 & 2 & $2,3,5$ & 2 & 0 & 0 & - & 4,6 & 0 \\
\hline Erythroxylum subrotundum A.St.-Hil. & 2584 & 0 & $0,1,2 ?$ & 2 & 0 & 3,5 & $1,2 ?$ & 0 & 2 & 0 & 0 & - & 7 & 0 \\
\hline Erythroxylum tortuosum Mart. & 2491 & 0 & 0 & 1 & 3 & 5 & 2 & 3 & $1 ?$ & 0 & 0 & - & 0 & 0 \\
\hline Acalypha communis Müll.Arg. & 2655 & 0 & 1 & 1 & 1 & 5 & 2 & 5 & 1 & 0 & 0 & - & 0 & 0 \\
\hline
\end{tabular}

Legenda: pontoação de fibras $(0=$ simples ou com aréola diminuta; $1=$ areolada; $2=$ nas paredes tangencial e radial $)$; fibras septadas $(0=$ ausentes; $1=$ presentes; $2=$ fibras parecidas com parênquima); espessura da parede da fibra $(0=$ fina; $1=$ fina a espessa; $2=$ muito espessa $)$; tipo de parênquima axial $(0=$ ausente ou extremamente raro; $1=$ difuso; $2=$ difuso em agregados; $3=$ paratraqueal escasso; $4=$ vasicêntrico; $5=$ aliforme losangular; $6=$ aliforme linear; $7=$ confluente; $8=$ em faixas com mais de 3 cels de espessura; $9=$ em linhas de até 3 cels de espessura; $10=$ reticulado; $11=$ escalariforme; $12=$ marginal ou quase marginal ); série fusiforme de parênquima axial $(1=$ uma; $2=$ duas; $3=3$ a $4 ; 5=5$ a $8 ; 8=>8)$; largura dos raios $(1=$ unisseriados; $2=$ de 1 a 3 cels; $3=$ os mais largos de 4 a $10 ; 4=$ mais de 10$)$; frequência do raio $(0=<4$ raios $/ \mathrm{mm} ; 2=4$ a 12 raios $/ \mathrm{mm} ; 3=>12$ raios $/ \mathrm{mm})$; tipo celular do raio $(0=$ apenas com cels. procumbentes; $1=$ apenas com cels. eretas/quadradas; $2=$ com 1 fileira marginal de cels. eretas $/$ quadradas; $3=$ com 2 a 4 fileiras marginais de cels. eretas/quadradas; $4=$ com mais de 4 fileiras marginais de cels. eretas/quadradas; $5=$ com cels. eretas/quadradas misturadas); outras características do raio $(0=$ ausentes; $1=$ porção uni igual porção multisseriada; $2=$ agregados; $3=$ mais altos que $1 \mathrm{~mm} ; 4=$ dois tamanhos distintos; $5=$ cels. envolventes; $6=$ cel. perfurada de raio presente; $7=$ Raios com cels. de parede disjuntiva); estratificação $(0=$ estratificação ausente; $1=$ de todos os raios; $2=$ do parênquima axial/elemento de vaso; $3=$ de fibras; $4=$ raios ou elementos axiais irregularmente estratificados); outras características $(1=$ cels. oleíferas e/ou mucilaginosas associadas com raio; $2=$ canais radiais; $3=$ canais intercelulares de origem traumática; $4=$ túbulos laticíferos ou taniníferos $)$; cristais prismáticos $(0=$ ausente; $1=$ em cels. de raio eretas/quadradas; $2=$ em cels. procumbentes; $3=$ em alinhamento radial nas cels. procumbentes; $4=$ em cel. de raio ereta/quadrada subdividida; $5=$ em cels. não subdivididas de parênquima axial; $6=$ em cels. subdivididas de parênquima axial; $7=$ em fibras $)$; demais inclusões minerais $(0=$ ausentes; $1=$ cristais estilóides e alongados; $2=$ cristais de outros formatos; $3=$ mais de um cristal de mesmo tamanho por cel. ou subdivisão; 4= cristais de dois tamanhos distintos por cel. ou subdivisão; 5= corpos silicosos); ?= dúvida; " “" = dado não computado. 
continuação...

Tabela 3: $2^{\text {a }}$ parte da descrição microscópica da anatomia de 56 espécies de plantas coletadas na APA Carste de Lagoa Santa, MG, segundo características propostas pela IAWA Committee (1989).

\begin{tabular}{|c|c|c|c|c|c|c|c|c|c|c|c|c|c|c|}
\hline & $\begin{array}{c}\mathbf{N}^{\mathbf{o}} \\
\text { SPFw } \\
\end{array}$ & 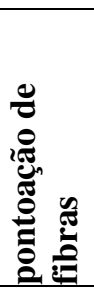 & 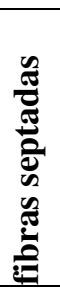 & 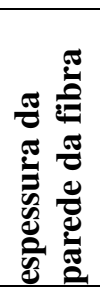 & 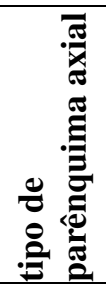 & 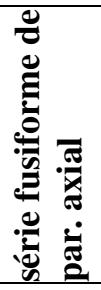 & 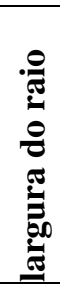 & 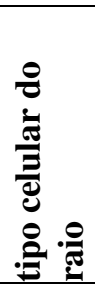 & 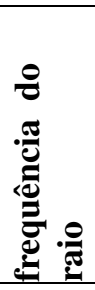 & 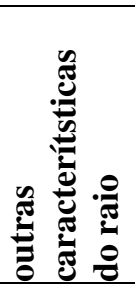 & 氖 & 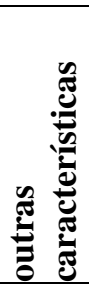 & 葛 & 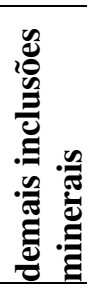 \\
\hline Croton gracilipes Baill. & 2592 & 0 & 0 & 0 & 1 & 5 & 1 & $1 ?$ & 1 & 0 & 0 & - & 0 & 0 \\
\hline Pera glabrata (Schott) Poepp. ex Baill. & 2313 & 0 & 0 & 1 & 9,1 & 5 & 1 & 5 & 1 & 0 & 0 & - & 0 & 0 \\
\hline \multicolumn{15}{|l|}{ LAURACEAE } \\
\hline Nectandra lanceolata Nees & 2446 & 0 & 1 & 1 & 3 & 8 & 2 & 2 & 1 & 0 & 0 & - & 0 & 0 \\
\hline Nectandra psammophila Nees & 2402 & 0 & 1 & 1 & 3 & 8 & 2 & 2 & 1 & 0 & 0 & - & 0 & 0 \\
\hline Ocotea corymbosa (Meisn.) Mez & 2599 & 0 & 1 & 1 & 3 & 8 & 2 & 2 & 1 & 0 & 0 & 1 & 0 & 5 \\
\hline Ocotea velutina (Nees) Rohwer & 2786 & 0 & 1 & 1 & 3 & 8 & 2 & 2 & 1 & 0 & 0 & 1 & 2 & 5 \\
\hline \multicolumn{15}{|l|}{ LECYTHIDACEAE } \\
\hline Cariniana estrellensis (Raddi) Kuntze & 2747 & 0 & 0 & 1 & 9,1 & 3,5 & 1,2 & 0 & 1 & 0 & 0 & - & 6 & 0 \\
\hline Cariniana legalis (Mart.) Kuntze & 2511 & 0 & 0 & 1 & 9,1 & 3,5 & 2 & $2,3 ?$ & 1 & 0 & 0 & - & 6 & 0 \\
\hline \multicolumn{15}{|l|}{ LEGUMINOSAE } \\
\hline Erythrina falcata Benth. & 2447 & 0 & 0 & 1 & 8 & 2 & 3 & 3 & 1 & 2 & 2 & - & 6 & 0 \\
\hline Harpalyce brasiliana Benth. & 2292 & 0 & 0 & 1 & $5,7,12$ & 2 & 1 & 3 & 1 & 0 & 2,3 & - & 0 & 0 \\
\hline Hymenaea stigonocarpa Mart. ex Hayne & 2674 & 0 & 0 & 2 & $5,7,12$ & 3 & 2 & 0 & 1 & 0 & 0 & - & 6 & 0 \\
\hline
\end{tabular}

Legenda: pontoação de fibras $(0=$ simples ou com aréola diminuta; $1=$ areolada; $2=$ nas paredes tangencial e radial $)$; fibras septadas $(0=$ ausentes; $1=$ presentes; $2=$ fibras parecidas com parênquima); espessura da parede da fibra $(0=$ fina; $1=$ fina a espessa; $2=$ muito espessa $)$; tipo de parênquima axial $(0=$ ausente ou extremamente raro; $1=$ difuso; $2=$ difuso em agregados; $3=$ paratraqueal escasso; $4=$ vasicêntrico; $5=$ aliforme losangular; $6=$ aliforme linear; $7=$ confluente; $8=$ em faixas com mais de 3 cels de espessura; $9=$ em linhas de até 3 cels de espessura; $10=$ reticulado; $11=$ escalariforme; $12=$ marginal ou quase marginal ); série fusiforme de parênquima axial $(1=$ uma; $2=$ duas; $3=3$ a $4 ; 5=5$ a $8 ; 8=>8)$; largura dos raios ( $1=$ unisseriados; $2=$ de 1 a 3 cels; $3=$ os mais largos de 4 a $10 ; 4=$ mais de 10$) ;$ frequência do raio $(0=<4$ raios $/ \mathrm{mm} ; 2=4$ a 12 raios $/ \mathrm{mm} ; 3=>12$ raios $/ \mathrm{mm})$;tipo celular do raio $(0=$ apenas com cels. procumbentes; $1=$ apenas com cels. eretas/quadradas; $2=$ com 1 fileira marginal de cels. eretas/quadradas; $3=$ com 2 a 4 fileiras marginais de cels. eretas/quadradas; $4=$ com mais de 4 fileiras marginais de cels. eretas/quadradas; $5=$ com cels. eretas/quadradas misturadas); outras características do raio $(0=$ ausentes; $1=$ porção uni igual porção multisseriada; $2=$ agregados; $3=$ mais altos que $1 \mathrm{~mm} ; 4=$ dois tamanhos distintos; $5=$ cels. envolventes; $6=$ cel. perfurada de raio presente; $7=$ Raios com cels. de parede disjuntiva); estratificação $(0=$ estratificação ausente; $1=$ de todos os raios; $2=$ do parênquima axial/elemento de vaso; $3=$ de fibras; $4=$ raios ou elementos axiais irregularmente estratificados); outras características $(1=$ cels. oleíferas e/ou mucilaginosas associadas com raio; $2=$ canais radiais; $3=$ canais intercelulares de origem traumática; $4=$ túbulos laticíferos ou taniníferos $)$; cristais prismáticos $(0=$ ausente; $1=$ em cels. de raio eretas/quadradas; $2=$ em cels. procumbentes; $3=$ em alinhamento radial nas cels. procumbentes; $4=$ em cel. de raio ereta/quadrada subdividida; $5=$ em cels. não subdivididas de parênquima axial; $6=$ em cels. subdivididas de parênquima axial; $7=$ em fibras $)$; demais inclusões minerais $(0=$ ausentes; $1=$ cristais estilóides e alongados; $2=$ cristais de outros formatos; $3=$ mais de um cristal de mesmo tamanho por cel. ou subdivisão; 4= cristais de dois tamanhos distintos por cel. ou subdivisão; 5= corpos silicosos); ?= dúvida; " “" = dado não computado. 
Tabela 3: $2^{\text {a }}$ parte da descrição microscópica da anatomia de 56 espécies de plantas coletadas na APA Carste de Lagoa Santa, MG, segundo características propostas pela IAWA Committee (1989).

\begin{tabular}{|c|c|c|c|c|c|c|c|c|c|c|c|c|c|c|}
\hline & $\begin{array}{c}\mathbf{N}^{\circ} \\
\text { SPFw }\end{array}$ & 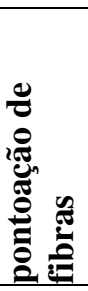 & 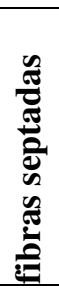 & 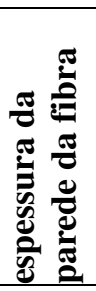 & 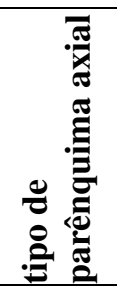 & 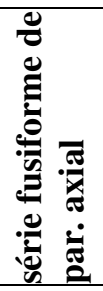 & 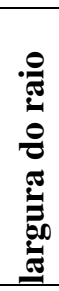 & 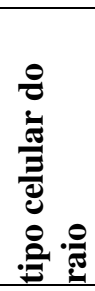 & 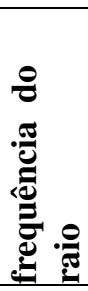 & 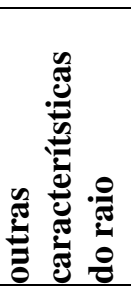 & 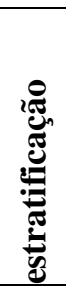 & $\begin{array}{l} \\
0 \\
0\end{array}$ & 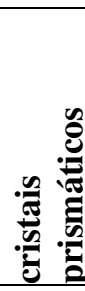 & 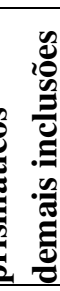 \\
\hline Inga $S P$ & 2440 & 0 & 0 & 1 & 5,7 & 3 & 1 & 0 & 1 & 0 & 2 & - & 6 & \\
\hline Lonchocarpus sericeus (Poir.) Kunth ex DC. & 2437 & 0 & 0 & 2 & 6,8 & 2 & 2 & 0 & 1 & 2,4 & 2,3 & - & 6 & \\
\hline Machaerium hirtum (Vell.) Stellfeld & 2417 & 0 & 0 & 0 & $5,7,12$ & 2 & 1 & 2 & 1 & 0 & 1,2 & - & 6 & \\
\hline Machaerium opacum Vogel & 2283 & 0 & 0 & 1 & 7,12 & 2 & 1 & 2 & 1 & 0 & 1,2 & - & 6 & \\
\hline Mimosa debilis Humb. \& Bonpl. ex Willd. & 2709 & 0 & 0 & 1 & 1 & 2 & 1 & 3 & 1 & 0 & 0 & - & 0 & \\
\hline Mimosa laticifera Rizzini \& A. Mattos & 2703 & 0 & 0 & 1 & 5,12 & 2 & 2 & 0 & 1 & 0 & 2 & - & 0 & \\
\hline Platymiscium pubescens Micheli & 2638 & 0 & 0 & 1 & 5,8 & 2 & 2 & 0 & 1 & 0 & 0 & - & 6 & \\
\hline Senna multijuga (Rich.) H.S.Irwin \& Barneby & 2233 & 0 & 0 & 0 & 3 & 2 & 2 & 5 & 1 & 0 & 0 & - & 2 & \\
\hline $\begin{array}{l}\text { Senna pendula (Humb.\& Bonpl. ex Willd.) } \\
\text { H.S.Irwin \& Barneby }\end{array}$ & 2341 & 0 & 0 & 1 & 3 & 5 & 2 & 5 & 1 & 0 & 0 & - & $1,2,6$ & \\
\hline $\begin{array}{l}\text { Senna silvestris (Vell.) H.S.Irwin \& Barneby } \\
\text { MYRTACEAE }\end{array}$ & 2643 & 0 & 0 & 1 & 5,7 & 2 & 1 & 0 & - & 0 & 0 & - & 0 & \\
\hline $\begin{array}{l}\text { Eugenia aurata O.Berg } \\
\text { SAPINDACEAE }\end{array}$ & 2252 & 1,2 & 0 & 1 & 9 & 5 & 2 & 3 & 1 & 0,7 & 0 & - & 6 & \\
\hline Allophylus sericeus (Cambess.) Radlk. & 2510 & 0 & 0 & 2 & 7 & 3 & 2 & 0 & 1 & 0 & 0 & - & 6 & \\
\hline
\end{tabular}

Legenda: pontoação de fibras $(0=$ simples ou com aréola diminuta; $1=$ areolada; $2=$ nas paredes tangencial e radial); fibras septadas $(0=$ ausentes; $1=$ presentes; $2=$ fibras parecidas com parênquima); espessura da parede da fibra ( $0=$ fina; $1=$ fina a espessa; $2=$ muito espessa); tipo de parênquima axial $(0=$ ausente ou extremamente raro; $1=$ difuso; $2=$ difuso em agregados; $3=$ paratraqueal escasso; $4=$ vasicêntrico; $5=$ aliforme losangular; $6=$ aliforme linear; $7=$ confluente; $8=$ em faixas com mais de 3 cels de espessura; $9=$ em linhas de até 3 cels de espessura; $10=$ reticulado; $11=$ escalariforme; $12=$ marginal ou quase marginal $)$; série fusiforme de parênquima axial $(1=$ uma; $2=$ duas; $3=3$ a $4 ; 5=5$ a $8 ; 8=>8)$; largura dos raios ( $1=$ unisseriados; $2=$ de 1 a 3 cels; $3=$ os mais largos de 4 a $10 ; 4=$ mais de 10$)$; frequência do raio $(0=<4$ raios $/ \mathrm{mm} ; 2=4$ a 12 raios $/ \mathrm{mm} ; 3=>12$ raios $/ \mathrm{mm})$;tipo celular do raio $(0=$ apenas com cels. procumbentes; $1=$ apenas com cels. eretas/quadradas; $2=$ com 1 fileira marginal de cels. eretas/quadradas; $3=$ com 2 a 4 fileiras marginais de cels. eretas/quadradas; $4=$ com mais de 4 fileiras marginais de cels. eretas/quadradas; $5=$ com cels. eretas/quadradas misturadas); outras características do raio $(0=$ ausentes; $1=$ porção uni igual porção multisseriada; $2=$ agregados; $3=$ mais altos que $1 \mathrm{~mm} ; 4=$ dois tamanhos distintos; $5=$ cels. envolventes; $6=$ cel. perfurada de raio presente; $7=$ Raios com cels. de parede disjuntiva); estratificação ( $0=$ estratificação ausente; $1=$ de todos os raios; $2=$ do parênquima axial/elemento de vaso; $3=$ de fibras; $4=$ raios ou elementos axiais irregularmente estratificados); outras características $(1=$ cels. oleíferas e/ou mucilaginosas associadas com raio; $2=$ canais radiais; $3=$ canais intercelulares de origem traumática; $4=$ túbulos laticíferos ou taniníferos); cristais prismáticos $(0=$ ausente; $1=$ em cels. de raio eretas/quadradas; $2=$ em cels. procumbentes; $3=$ em alinhamento radial nas cels. procumbentes; $4=\mathrm{em}$ cel. de raio ereta/quadrada subdividida; $5=\mathrm{em}$ cels. não subdivididas de parênquima axial; $6=\mathrm{em}$ cels. subdivididas de parênquima axial; $7=\mathrm{em}$ fibras); demais inclusões minerais ( $0=$ ausentes; $1=$ cristais estilóides e alongados; $2=$ cristais de outros formatos; $3=$ mais de um cristal de mesmo tamanho por cel. ou subdivisão; 4= cristais de dois tamanhos distintos por cel. ou subdivisão; $5=$ corpos silicosos); ?= dúvida; "-“= dado não computado. 
continuação...

Tabela 3: $2^{\text {a }}$ parte da descrição microscópica da anatomia de 56 espécies de plantas coletadas na APA Carste de Lagoa Santa, MG, segundo características propostas pela IAWA Committee (1989).

\begin{tabular}{|c|c|c|c|c|c|c|c|c|c|c|c|c|c|c|}
\hline & $\begin{array}{c}\mathbf{N}^{\mathbf{0}} \\
\text { SPFw } \\
\end{array}$ & 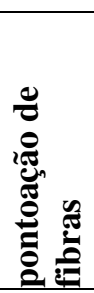 & 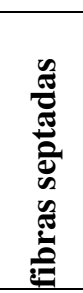 & 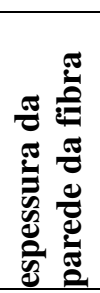 & 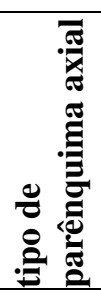 & 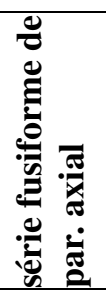 & 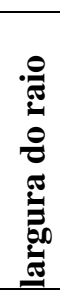 & 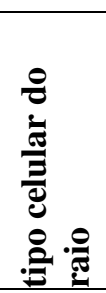 & 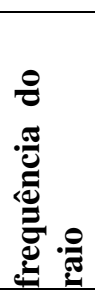 & 窇 & & 总 & : & 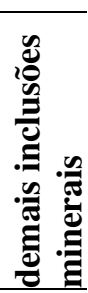 \\
\hline Cupania cf. vernalis Cambess. & 2613 & 0 & $0,2 ?$ & 1 & 0 & - & 1 & 0 & 1 & 0 & 0 & - & 7 & 0 \\
\hline $\begin{array}{l}\text { Serjania laruotteana Cambess. } \\
\text { SAPOTACEAE }\end{array}$ & 2406 & 0,2 & 0 & 2 & 9 & 2,3 & 3 & $5 ?$ & 1 & $2,3,4,6$ & 0 & - & 4,5 & 0 \\
\hline $\begin{array}{l}\text { Chrysophyllum marginatum (Hook. \& Arn.) Radlk. } \\
\text { VOCHYSIACEAE }\end{array}$ & 2608 & 0 & $0,2 ?$ & 1 & 3 & 3 & 3 & 5 & 1 & $2,3,4$ & 0 & - & 1,7 & 0 \\
\hline Callisthene major Mart. \& Zucc. & 2304 & 0 & 1 & 2 & 8 & 2,3 & 3 & 2,3 & 1 & 2 & 0 & - & $3,4,6$ & 0 \\
\hline Qualea multiflora Mart. & 2279 & 0,2 & 0 & 2 & 7 & 3 & 2 & 3 & 0 & 3,7 & 0 & - & 7 & 0 \\
\hline Qualea parviflora Mart. & 2760 & 0 & 0,1 & 2 & 7 & 2,3 & 3 & 0 & 2 & 1,2 & 0 & - & 2,6 & 3,4 \\
\hline
\end{tabular}

\footnotetext{
Legenda: pontoação de fibras $(0=$ simples ou com aréola diminuta; $1=$ areolada; $2=$ nas paredes tangencial e radial $)$; fibras septadas $(0=$ ausentes; $1=$ presentes; $2=$ fibras parecidas com parênquima); espessura da parede da fibra $(0=$ fina; $1=$ fina a espessa; $2=$ muito espessa); tipo de parênquima axial $(0=$ ausente ou extremamente raro; $1=$ difuso; $2=$ difuso em agregados; $3=$ paratraqueal escasso; $4=$ vasicêntrico; $5=$ aliforme losangular; $6=$ aliforme linear; $7=$ confluente; $8=$ em faixas com mais de 3 cels de espessura; $9=$ em linhas de até 3 cels de espessura; $10=$ reticulado; $11=$ escalariforme; $12=$ marginal ou quase marginal ); série fusiforme de parênquima axial $(1=$ uma; $2=$ duas; $3=3$ a $4 ; 5=5$ a $8 ; 8=>8)$; largura dos raios $(1=$ unisseriados; $2=$ de 1 a 3 cels; $3=$ os mais largos de 4 a $10 ; 4=$ mais de 10$)$; frequência do raio $(0=<4$ raios $/ \mathrm{mm} ; 2=4$ a 12 raios $/ \mathrm{mm} ; 3=>12$ raios $/ \mathrm{mm})$;tipo celular do raio $(0=$ apenas com cels. procumbentes; $1=$ apenas com cels. eretas/quadradas; $2=$ com 1 fileira marginal de cels. eretas/quadradas; $3=$ com 2 a 4 fileiras marginais de cels. eretas/quadradas; $4=$ com mais de 4 fileiras marginais de cels. eretas/quadradas; $5=$ com cels. eretas/quadradas misturadas); outras características do raio $(0=$ ausentes; $1=$ porção uni igual porção multisseriada; $2=$ agregados; $3=$ mais altos que $1 \mathrm{~mm} ; 4=$ dois tamanhos distintos; $5=$ cels. envolventes; $6=$ cel. perfurada de raio presente; $7=$ Raios com cels. de parede disjuntiva); estratificação ( $0=$ estratificação ausente; $1=$ de todos os raios; $2=$ do parênquima axial/elemento de vaso; $3=$ de fibras; $4=$ raios ou elementos axiais irregularmente estratificados); outras características $(1=$ cels. oleíferas e/ou mucilaginosas associadas com raio; $2=$ canais radiais; $3=$ canais intercelulares de origem traumática; $4=$ túbulos laticíferos ou taniníferos $)$; cristais prismáticos $(0=$ ausente; $1=$ em cels. de raio eretas/quadradas; $2=$ em cels. procumbentes; $3=$ em alinhamento radial nas cels. procumbentes; $4=$ em cel. de raio ereta/quadrada subdividida; $5=$ em cels. não subdivididas de parênquima axial; $6=$ em cels. subdivididas de parênquima axial; $7=$ em fibras $)$; demais inclusões minerais $(0=$ ausentes; $1=$ cristais estilóides e alongados; $2=$ cristais de outros formatos; $3=$ mais de um cristal de mesmo tamanho por cel. ou subdivisão; 4= cristais de dois tamanhos distintos por cel. ou subdivisão; 5= corpos silicosos); ?= dúvida; "“" = dado não computado. 


\subsection{REFERÊNCIAS BIBLIOGRÁFICAS}

BARROS, C. F. \& V. R. CORADIN. 2005. Xilotecas Brasileiras, o Estado da Arte: Centro de Referência em Informação Ambiental (CRIA). Documento digital disponível em <http://www.cria.org.br/cgee/col/>. Acessado em 26/01/2011.

DÉTIENNE, P. \& P. JACQUET. 1983. Atlas d'identifi cation des bois de l'Amazonie et des régions voisines. Norgent-sur-Marne.: Centre Téchnique Forestier Tropical.

FEDALTO, L. C.;I. C. A. MENDES \& V. R. CORADIN. 1989. Madeiras da Amazônia: descrição do lenho de 40 espécies ocorrentes na Floresta Nacional do Tapajós. Brasília: IBAMA.

HERRMANN, G. et al. 1998. Estudo do meio biótico da APA Carste de Lagoa Santa. Belo Horizonte: Ibama, Companhia de Pesquisa de Recursos Minerais: 92p.

IAWA-COMMITTEE. 1989. List of microscopic features for hardwood identification. IAWA Bulletin, v.10, p.220-332.

IBGE. 1992. Manual Técnico da Vegetação Brasileira. Brasília. 81p.

KRAUS, J. E. \& M. ARDUIN. 1997. Manual Básico de Métodos em Morfologia Vegetal. Seropédia, RJ, Brasil: EDUR.

LUCHI, A. E. 1998. Periodicidade de crescimento em Hymenaea courbaril L. e Anatomia ecológica do lenho de espécies de mata ciliar. Tese de doutorado. Depto. Botânica, Universidade de São Paulo, São Paulo,

MAINIERI, C. \& J. P. CHIMELO. 1989. Ficha de características das Madeiras Brasileiras. São Paulo: Instituto de Pesquisas Tecnológicas

MARCHIORI, J. N. C. 2007. Dendrologia das angiospermas: Leguminosas. Santa Maria: UFSM. 199 p.

MARCHIORI, J. N. C.;G. I. B. MUNIZ \& S. R. SANTOS. 2010. Madeiras do Rio Grande do Sul. 2 - Descrição microscópica de 35 espécies nativas. Santa Maria: Anaterra, 2010. v. 1.80 p. : Anaterra, v.1. 80 p. 



\section{Capítulo 3}

\section{CARACTERIZAÇÃO DA VEGETAÇÃO DE LAGOA SANTA, MG, NOS ÚLTIMOS 5000 ANOS POR MEIO DA IDENTIFICAÇÃO TAXONÔMICA DE LENHOS FÓSSEIS}





\subsection{RESUMO}

Pesquisas paleoambientais na região do Brasil central interpretam de forma diferente a dinâmica climática durante o Holoceno médio. Enquanto alguns autores sugerem o retorno de condições úmidas para o período, outros encontram instabilidade e mesmo um drástico evento de seca, com expressiva expansão de gramíneas e retração de arbóreas. Soma-se a este cenário uma grande redução de sepultamentos de povos préhistóricos na região de Lagoa Santa, MG, que poderia ter suas causas na migração para locais mais favoráveis em momentos de climas desfavoráveis. Desse modo, o presente estudo utilizou a identificação taxonômica de lenhos fósseis para caracterizar a vegetação pretérita de Lagoa Santa e avaliar possíveis alterações potencialmente causadas por mudanças climáticas. Foram identificados 15 táxons para o Holoceno médio e 13 para o Holoceno tardio, que evidenciaram uma vegetação muito similar entre os dois períodos, não sugerindo uma grande alteração climática ou vegetacional. Ao mesmo tempo, o conjunto de táxons indica fortemente a presença de floresta estacional semidecidual, mas também se relaciona com as outras fitofisionomias que fazem parte do mosaico vegetacional presente atualmente na região, como o cerrado, a mata ciliar e mata seca, sugerindo um ambiente de clima sazonal como o atual, sem grandes alterações nos últimos 6.000 anos.

\subsection{ABSTRACT}

Paleoenvironmental researches in central Brazil interpret in different ways the climate dynamics during the mid Holocene. While some authors suggest the return of humidity in that period, others find instability and even a drastic dry event, with an expressive expansion of gramineous and a decrease of woody plants. In support to the last last hypothesis, there is a drastic decrease of prehistoric burials in the Lagoa Santa region, which may have been due to population migration to more favorable climates. As so, the present study has used the taxonomic identification of wood fossils to characterize the past vegetation of Lagoa Santa and evaluate possible modifications caused by climate changes. Fifteen taxa were identified for the mid Holocene and thirteen for the late Holocene, indicating very similar vegetation between the two periods and no significant climate change. At the same time, the fossils taxa assemblage strongly indicates the presence of semideciduous forest, but also the relation with other 
phytophysiognomies that compose the current vegetational mosaic of the region as the Brazilian (cerrado, riparian, and the deciduous forest), suggesting an environment with seasonal climate very similar to the present one, with no great changes during the past 6,000 years. 


\subsection{INTRODUÇÃO}

O período denominado Holoceno compreende os últimos 10.000 anos A.P. ${ }^{12}$, e tem como marco temporal o final da última glaciação, "quando as condições ambientais e os processos geológicos superficiais ainda não tinham sido substancialmente alterados pelas ações do homem" (De Oliveira et al., 2005). De forma geral, o final da última glaciação proporcionou um gradativo aumento da temperatura global até o período atual.

O início do Holoceno é caracterizado pela saída de um clima seco, com o retorno gradativo da pluviosidade, mas ainda com valores abaixo do atual (Martin et al., 1997). A expansão da vegetação florestal em Carajás, PA, Lagoa do Caçó, MA, Lago Calado e Lagoa da Pata, AM (Absy et al., 1991; Behling, 2002; Colinvaux et al., 1996; Ledru et al., 2006; Sifeddine et al., 2003), segundo Martin et al. (1997), pode ser explicada por meio das evidências de que, durante o Holoceno inicial, a Zona de Convergência Intertropical esteve limitada mais ao norte do que no presente, fazendo com que a umidade se concentrasse mais nessa região. Ainda, a maior presença de táxons como Podocarpus sp durante este período é interpretada como consequência de uma temperatura mais amena que a atual para a região norte brasileira (Colinvaux et al., 1996).

Já para a região central e sul brasileira, Ledru et al. (1998) sintetizam a dinâmica climática holocênica dividida em três períodos climáticos distintos: 1. Holoceno inicial (10.000-7.000 anos A.P.); 2. Holoceno médio (7.000-4.000 anos A.P.); 3. Holoceno tardio (4.000 anos A.P.- hoje).

Assim, o Holoceno inicial no centro-sul brasileiro, ao contrário da região norte, se caracterizou por um clima mais seco, com hiatos de deposição sedimentar em muitas localidades e, nas demais, uma maior porcentagem polínica de vegetações mais secas que atualmente. A única exceção foi a Serra de Salitre (Ledru, 1992), a 200 km de distância de Lagoa Santa, que evidenciou um clima úmido e frio, deduzido pela aparição de pólens de Araucaria angustifolia (Bertol.) Kuntze. Para as outras localidades, os autores não estimam a temperatura no período.

\footnotetext{
${ }^{12}$ Antes do presente
} 
Ao redor de 6.000 anos, é muito bem conhecido no Hemisfério Norte o evento climático conhecido como "Ótimo Climático", influenciado por uma maior insolação global durante o meio do ano, ocasionando um período predominantemente mais quente e úmido, propício à expansão de coberturas vegetais mais úmidas, de maior porte.

No Brasil, o segundo período climático holocênico sugerido na revisão de Ledru et al. (1998), que abrange de 7.000 a 4.000 anos A.P., se caracteriza por uma tendência ao aumento de umidade em todas as localidades. $\mathrm{O}$ desenvolvimento de veredas com o aparecimento de buritis (Mauritia), a redução de partículas carbonizadas, o aumento de táxons arbóreos de cerrado, o estabelecimento de lagoas e até o aparecimento de táxons de matas de galeria, são algumas das características apontadas pelos autores nas localidades que hoje são Cerrados. Nos locais mais próximos à costa, onde hoje ocorre Floresta Estacional Semidecídual, o principal indicador de umidade foi o aparecimento e aumento dos polens de táxons como Melastomataceae/Combretaceae, Arecaceae, Alchornea, Tabebuia, Tecoma e Lithraea/Tapirira em detrimento de pólens de herbáceas, principalmente de gramíneas. Na região sul, as herbáceas cederam espaço para Araucaria angustifolia nas terras altas do Paraná, enquanto que na região costeira a Mata Atlântica se expandiu com a presença de Weinmannia, Alchornea, Urticales, Myrtaceae, Celtis, Rapanea e Arecaceae.

Embora não haja dúvida de que o nível do oceano na costa brasileira esteve em media cinco metros acima do atual, a influência "ótimo climático" no Hemisfério Sul (HS) foi mais amena e, aparentemente, mais complexa que no Hemisfério Norte (HN) (Martin et al., 1997). Invernos mais quentes e verões mais amenos no HS teriam como consequência a redução da sazonalidade térmica e, consequentemente, da precipitação. Apoiando este raciocínio, estudos em diversas localidades na América do Sul tropical e equatorial sugerem eventos de seca no período aproximado de 6.000 a 4500 anos A.P.

Indo de encontro com a tendência observada para as localidades do centro-sul brasileiras, Ledru et al. (1998) chama a atenção para um rápido período árido observado em Salitre, MG, no intervalo de 5.500 a 4.500 anos A.P. (Ledru, 1993). Em região próxima, Behling (1995a; 2003) sugere um período mais seco entre 7.500 e 5.530 anos A.P. e de 7.500 a 6060 anos A.P., respectivamente. Já Parizzi (1998), estudando a dinâmica da lagoa Santa, sugere que a lagoa atual deu espaço a um alagadiço intermitente entre 5.400 e 4.600 anos A.P. Muitos outros trabalhos corroboram com a hipótese de um Holoceno médio mais seco que o atual, mostrando rápidos eventos de seca ou mostrando que o ressecamento do Holoceno inicial se estendeu até 4000-3000 
anos A.P., interrompendo a tendência holocênica geral de incremento de umidade no hemisfério sul (Absy et al., 1991; Baker et al., 2001; Behling, 1995a, b, 1997, 2003; De Oliveira et al., 1999; Grosjean et al., 2001; Ledru, 1993; MELO et al., 1987; Parizzi et al., 1998; Sifeddine et al., 2003; Sifeddine et al., 1994).

Ainda está muito longe uma conclusão sobre se os eventos de secas mostrados nos trabalhos foram relacionados ao "Ótimo Climático" do Hemisfério Norte, ou se foram eventos regionais. O que é evidente na literatura atual, é que a América do Sul teve particularidades climáticas onde, embora possa ser identificada uma tendência geral de incremento de umidade, deve-se levar em conta diferenças locais na interpretação do clima e da cobertura vegetal durante o Holoceno médio.

Entretanto, há consenso de que o aumento de temperatura e, principalmente o da umidade, nos últimos 4.000-3.000 anos A.P., moldou a distribuição das fitofisionomias que temos hoje. Alterações significativas na cobertura vegetal durante este período são comumente referidas como interferências humanas, pré e pós-colonização, e não de causas climáticas (Behling et al., 2004; Ledru et al., 1998).

A região da APA - Carste de Lagoa Santa, MG, é uma área de grande interesse arqueológico desde 1835, quando o dinamarquês Peter Wilhmen Lund encontrou e estudou inúmeros sítios arqueológicos ocupados desde os últimos 12.000 anos (Neves \& Pucciarelli, 1991).

Recentemente, o trabalho de Araújo et al. (2005) chama a atenção para a existência de dois picos temporais de esqueletos pré-históricos enterrados, separados por um grande período de drástica redução de sepultamentos pré-históricos na região de Lagoa Santa, MG (Araújo et al., 2005). O primeiro pico estende-se entre 10.000 e 8.000 anos A.P. (11.380 a 8.970 anos A.P. Cal. ${ }^{13}$ ) enquanto o segundo, entre 2.000 e 1.000 anos A.P. (1940 a 940 anos A.P. Cal.). No intervalo dos picos, de 6.000 anos de duração e que abrange o Holoceno médio, o enterro de humanos pré-históricos é praticamente ausente nas áreas de sepultamento (figura 1). Os autores apontam também que "não há, até o estágio atual das pesquisas, nenhum esqueleto humano ou sítio arqueológico datado do Holoceno Médio na região de Lagoa Santa" (Araújo et al., 2005). Tais evidências, ou a falta delas, levaram os autores a denominarem o período de "Hiato do Arcaico. Entretanto, quando se procura por outros vestígios de ocupação, em área mais

\footnotetext{
${ }^{13}$ Idade calibrada: correção mais fina da datação radiocarbônica convencional
} 
ampliada que apenas a região de Lagoa Santa, este hiato não é verificado com tamanha intensidade. Mas ainda sim, a concentração destes vestígios acompanha a redução de esqueletos durante o Holoceno médio, onde possuem seus valores mínimos, que voltam a crescer no Holoceno tardio.

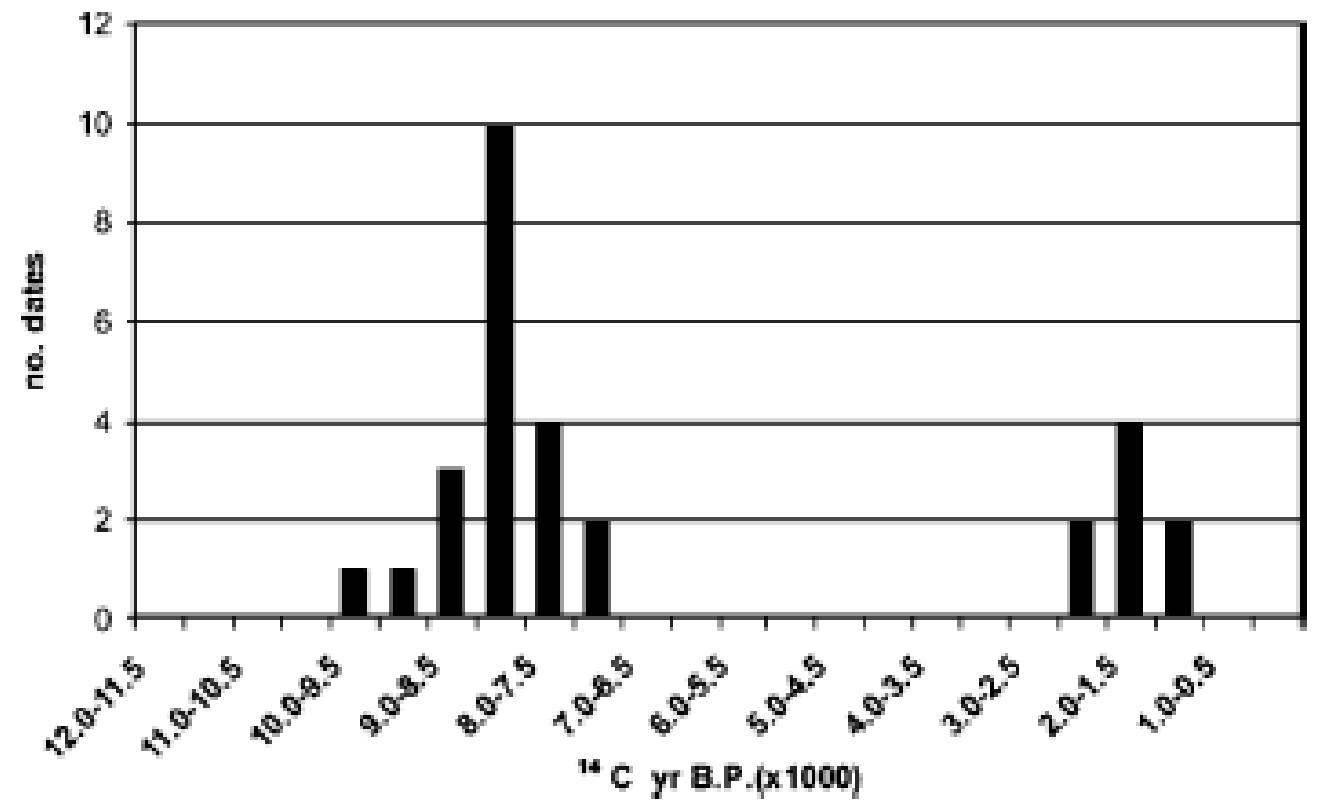

Figura 1: Frequência das idades radiocarbonicas de esqueletos humanos pré-históricos escavados na região de Lagoa Santa nos últimos 12000 anos A.P. Fonte: Araújo et al., 2005).

As razões para tal hiato não são conhecidas. Mudanças culturais relacionadas aos sepultamentos, mudanças climáticas, ou mesmo problemas na metodologia das escavações são algumas das possíveis causas.

Tendo em vista a razoável, porém contraditória, bibliografia que sugere períodos mais secos que os atuais na região durante o Holoceno médio, e a redescoberta do afloramento Ribeirão da Mata (RMT), com lenhos e folhas depositados desde os últimos 5.000 anos, surgiu a oportunidade de adicionar à discussão interpretações baseadas em vestígios botânicos independentes dos palinomorfos, comumente utilizados. Freire \& Ceccantini (2004) trabalharam com alguns fragmentos de lenhos fósseis do afloramento e verificaram a possibilidade de identificação taxonômica de significativa parte deles.

No Brasil, os estudos de lenhos fósseis até 1990 eram muito escassos e se concentravam apenas na identificação taxonômica do fóssil, sem sequer entrar em considerações climáticas, salvo raras exceções onde uma breve interpretação foi feita (Suguio, 1971; Suguio \& Coimbra, 1972; Suguio \& Mussa, 1978). 
O crescimento no estudo de lenhos fósseis no país se deu principalmente com a parceria entre a anatomia da madeira e a arqueologia, que começou a se interessar pelos demais vestígios botânicos não utilizados para alimentação. A partir de então, avanços têm sido feitos principalmente no campo da antracologia (Scheel-Ybert, 2000; ScheelYbert et al., 2003) e com madeiras de sítios arqueológicos (Ceccantini, 2002; Ceccantini \& Fernandez, 2005).

Segundo Ceccantini (2000), a possibilidade de relacionar uma determinada espécie de madeira a uma condição ambiental torna a Anatomia da Madeira atraente em diversas áreas da Ciência, como a Arqueologia e Paleontologia, uma vez que os lenhos fósseis fornecem uma fonte independente que incrementa o conhecimento sobre o ambiente e a biodiversidade pretérita de determinado local. E, diferentemente de palinomorfos, sementes ou frutos, o lenho não constitui um órgão com função de dispersão e sua ocorrência em uma flora fóssil é, em princípio, mais representativa da paleoflora do local de escavação do que estruturas reprodutoras, que têm maior possibilidade e capacidade de deslocamento (Poole, 2000). Segundo Wheeler \& Baas (1993), ainda há muito espaço para o crescimento do uso de lenhos fósseis, principalmente de eudicotiledôneas (sic.:“dicotiledôneas”), em reconstruções climáticas pretéritas.

\subsection{OBJETIVOS}

O objetivo principal desse capítulo é responder à seguinte pergunta:

A assembléia de lenhos fósseis do afloramento paleontológico RMT evidencia mudanças florísticas significativas durante o Holoceno médio e tardio da região arqueológica de Lagoa Santa, MG, que podem ser atribuídas às mudanças climáticas?

\section{5 ÁREAS DE ESTUDO}

\subsubsection{O CARSTE DE LAGOA SANTA}

O trabalho foi desenvolvido com material fóssil retirado da Área de Proteção Ambiental - Carste de Lagoa Santa (ACLS), região que abriga, além de diversos sítios 
arqueológicos, fragmentos relativamente preservados das diferentes fisionomias vegetais que ocorrem na região, estudadas no capítulo 1.

A ACLS se localiza na região centro-sul do Estado de Minas Gerais, cerca de 40 $\mathrm{Km}$ ao norte da capital Belo Horizonte e se estende por $356 \mathrm{Km}^{2}$, compreendendo os municípios de Pedro Leopoldo, Matozinhos, Prudente de Moraes, Confins, São José da Lapa, Lagoa Santa e Vespasiano. Limita-se a leste pelo Rio das Velhas, a oeste pelo Ribeirão da Mata, ao sul pelo contato do embasamento calcário do Grupo Bambuí com o embasamento gnáissico Pré-Cambriano, próximo à Vespasiano e, ao norte, pela vizinhança de Fildalgo-Matozinhos (Piló, 1998).

A região possui um clima tipicamente tropical, enquadrado como Aw na classificação de Köppen, com altas temperaturas e alta pluviosidade anual concentrada no verão, e inverno seco (Patrus, 1998). No município de Sete Lagoas, vizinho à região, a temperatura média anual histórica foi de $20,9^{\circ} \mathrm{C}$ e pluviosidade média anual de 1328 mm (Agritempo, 2002-2009). Embora a temperatura oscile pouco durante o ano, com temperaturas médias mensais podendo ficar em 17,5 graus no inverno e $23^{\circ} \mathrm{C}$ no verão, a pluviosidade sofre uma grande variação, oscilando de $289 \mathrm{~mm}$ mensais no verão, à apenas $10 \mathrm{~mm}$ mensais na estiagem, que se estende por até seis meses, de Abril a Setembro.

Sob este clima, fisionomias vegetais de Mata Atlântica, como as matas de Galeria e Florestas Estacionais Semideciduais, disputam espaço com as fisionomias de Cerrado que variam desde cerrados stricto sensu até cerradões. Nos afloramentos calcários é possível encontrar Floresta Decídua, conhecida também como Mata Seca e, nas lagoas, vegetação higrófila. Tal mosaico de vegetações propicia uma grande riqueza de espécies lenhosas, como constatado na tabela 1 do Capítulo 1.

\subsubsection{AFLORAMENTO PALEONTOLÓGICO RIBEIRÃO DA MATA}

Delimitando a APA - Carste de Lagoa Santa, no sudoeste, corre o Ribeirão da Mata, atravessando diversos municípios mineiros como Matozinhos, Pedro Leopoldo e Vespasiano. Precisamente no município de Pedro Leopoldo, Km 15 da rodovia MG 424, no distrito Dr. Lund às margens do ribeirão, está situado o afloramento paleontológico Ribeirão da Mata (RMT), de coordenadas 19³8'56.40"S e $44^{\circ}$ 0'20.31"O (figura 2). 


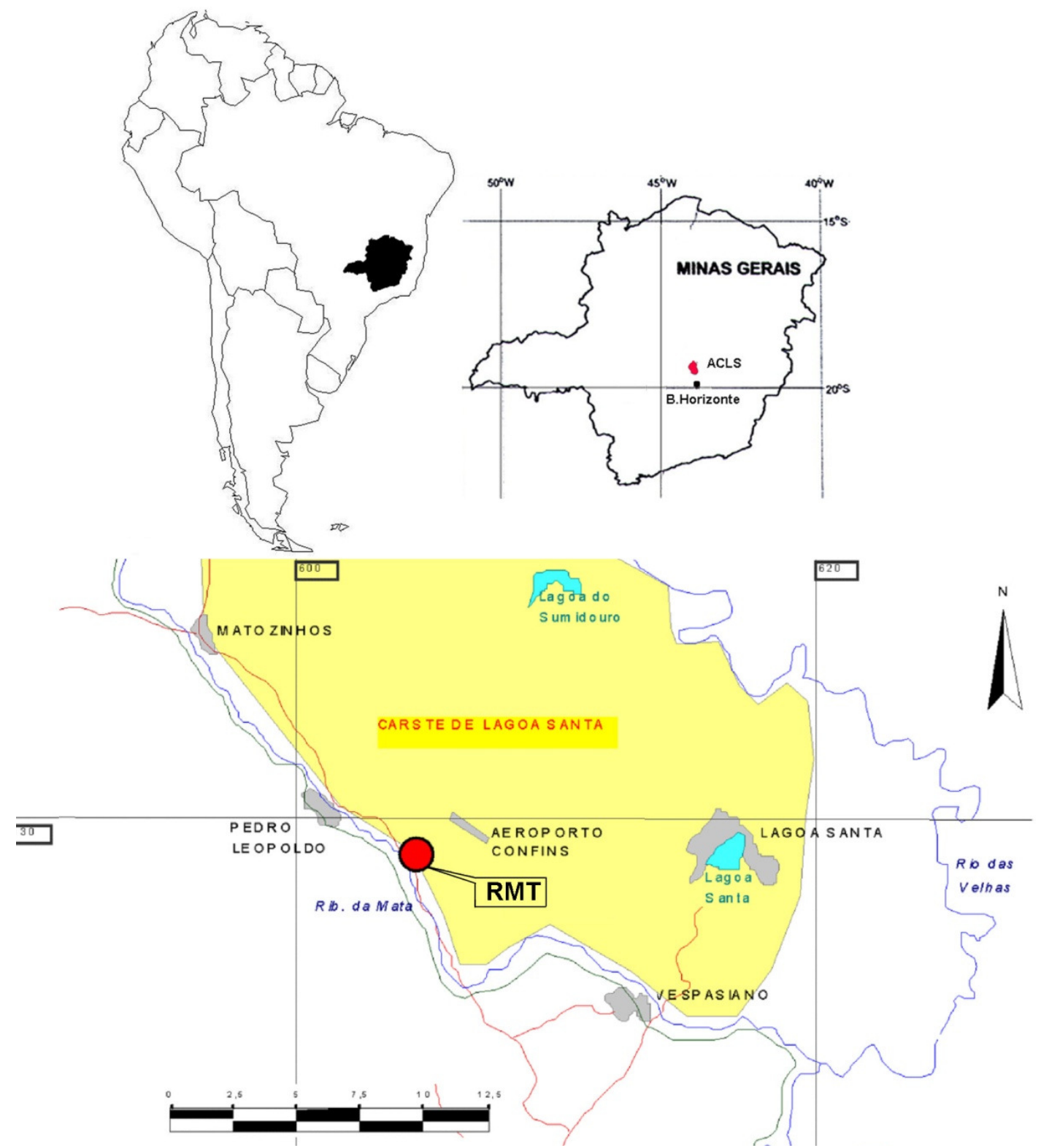

Figura 2: Localização do afloramento paleontológico Ribeirão da Mata, no limite sudoeste da APA Carste de Lagoa Sana, em Pedro Leopoldo, MG. Adaptado de (Piló, 1998). Base cartográfica: FIBGE, 1979. Carta topográfica de Belo Horizonte, Folha SE-23-2-C - 1:250.000.

Embora a ACLS seja drenada, em sua maior parte, diretamente para o rio das Velhas, a bacia de drenajem do ribeirão da Mata, à montante do afloramento RMT, compreende uma área contígua e aproximadamente de mesma dimensão e tipos vegetacionais que a ACLS (figura 3). 


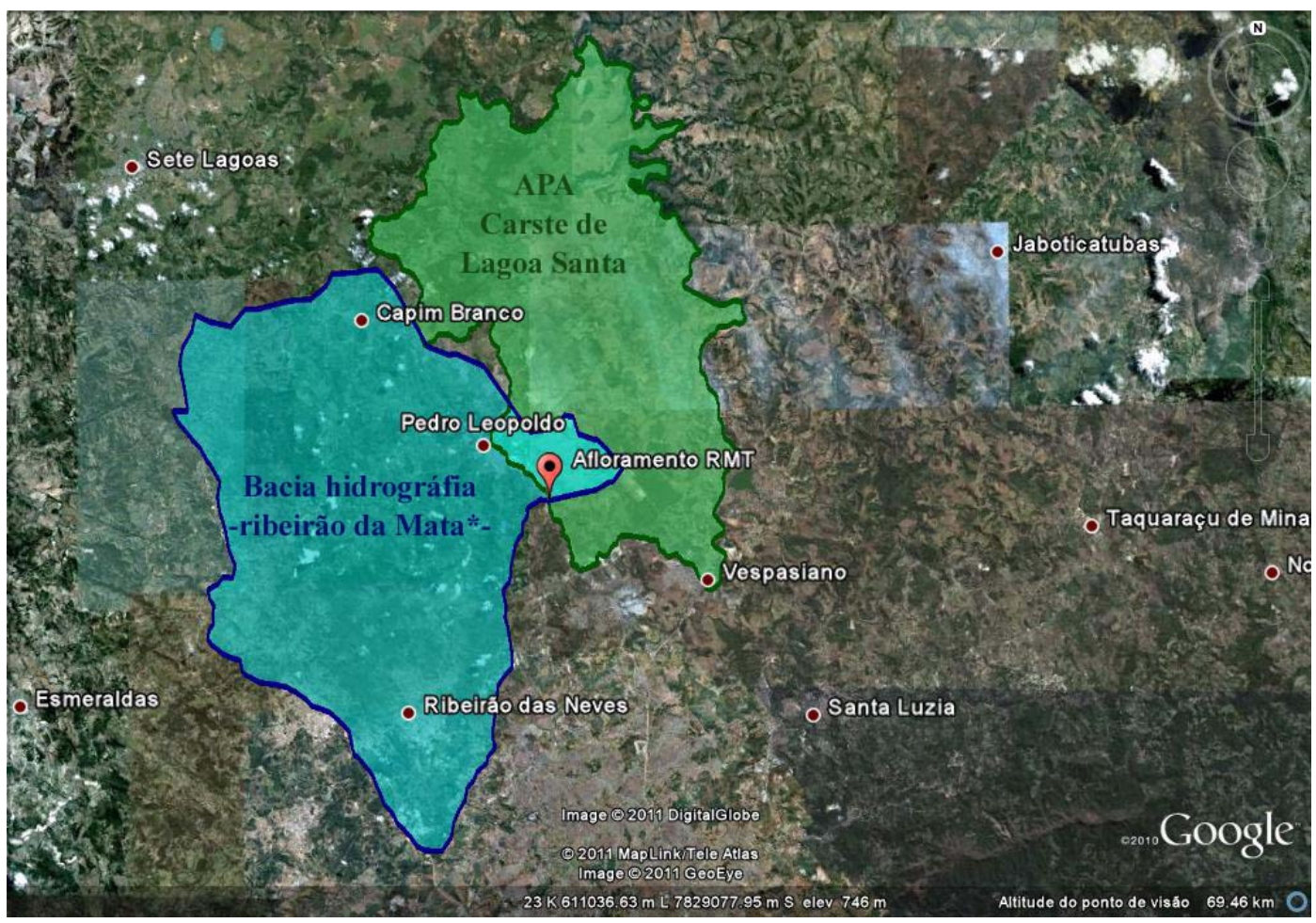

Figura 3: Localização do afloramento Ribeirão da Mata em relação à sua bacia de drenagem e à APA Carste de Lagoa Santa. *foi excluída a área de drenagem do ribeirão da Mata à jusante do afloramento.

O afloramento RMT (figura 4) é do tipo vertical, escavado naturalmente por meio da erosão promovida pelo ribeirão da Mata na época chuvosa. Possui aproximadamente $9 \mathrm{~m}$ de altura e $23 \mathrm{~m}$ de comprimento. É delimitado por uma área de forte intervenção antrópica à montante do rio e por um duto de escoamento de água da rodovia MG-424 à jusante.

Piló ${ }^{14}$ identificou no afloramento 5 fácies, de acordo com a cor, estratigrafia, textura e estrutura. Abaixo são colocadas as descrições dos fácies feitas pelo autor e a nomenclatura utilizada neste trabalho: Fácies A: Areia grossa estratificada; cor 10YR 8/2 (branca); textura arenosa; estrutura maciça; presença de estratificação cruzada; a areia é constituída principalmente por quarzto, com presença de alguns poucos fragmentos de lenho. Fácies B: lama arenosa orgânica; cor 2.5Y 4/0 (preto); textura silto-argilo-arenoso; ligeira laminação localizada, constituída por areias; presença de mica; foram localizados restos de folhas dentro da massa lamosa, assim como restos de troncos. Fácies C: lama arenosa; cor 2.5Y 6/6 (amarelo oliva); textura silto-argilo-

\footnotetext{
${ }^{14}$ Comunicação pessoal. Análise preliminar.
} 
arenoso; estrutura em blocos grandes subangulares de consistência extremamente dura; muitas gretas de contração. A equipe do presente trabalho encontrou restos de lenho e folhas. Fácies D: Areia grossa com estratificação cruzada; cor 10YR 7/2 (cinzento claro); textura arenosa; estrutura maciça; estratificação cruzada (tabular) resultante de transporte de sedimentos arenosos de carga de fundo; localmente, as sequências estratificadas estão interrompidas por superfícies inclinadas que separam lâminas aparentemente concordantes, indicando interrupção momentânea da forma do leito em processo de migração; troncos de árvores e macrovestígios orgânicos foram localizados no interior dessa fácies. Fácies E: Areia lamosa; cor 10YR 6/6 (amarelo brunado); textura areno-silte-argiloso; estrutura em blocos subangulares de consistência extremamente dura; porosidade alta (bioporos); gretas de contração. A equipe do presente trabalho acredita ser sedimento recente, coluvionar e provavelmente alterado pelas obras da rodovia MG424, que passa sobre o fácies.

\subsubsection{CRONOESTRATIGRAFIA}

A cronoestratigrafia do afloramento RMT foi construída por meio das datações de 19 amostras de lenho fóssil e outras amostras de matéria orgânica utilizadas por Raczka (Raczka, 2009) depositadas no fácies A, B, C e D. As datações radiocarbônicas dos lenhos fósseis são apresentadas na tabela 1, e foram realizadas por método convencional e por acelerador (Aceleration Mass Spectrometry - AMS), no Beta Analytic Radiocarbon Laboratory, em Miami, EUA.

A nítida e brusca alteração sedimentar observada entre o fácies D e C se revelou também na cronologia deposicional, onde as datações mostraram um hiato deposicional de 2.240 anos entre os dois fácies.

Elas revelaram uma cronologia coesa, sem nenhuma inversão estratigráfica, que distinguiu nitidamente dois períodos deposicionais: o fácies D foi datado do Holoceno tardio, com datas que vão desde 1.560 a 2.740 anos A.P. Cal., enquanto que o fácies A, B e C apresentaram datações que variam de 4.980 e 5.920 anos A.P. Cal., sem hiatos temporais significativos. Devido à difícil delimitação dos fácies $\mathrm{C}$ e $\mathrm{B}$ em determinadas regiões do afloramento, preferiu-se classificar as amostras destes sedimentos como provenientes dos fácies $\mathrm{C}, \mathrm{B}$. 


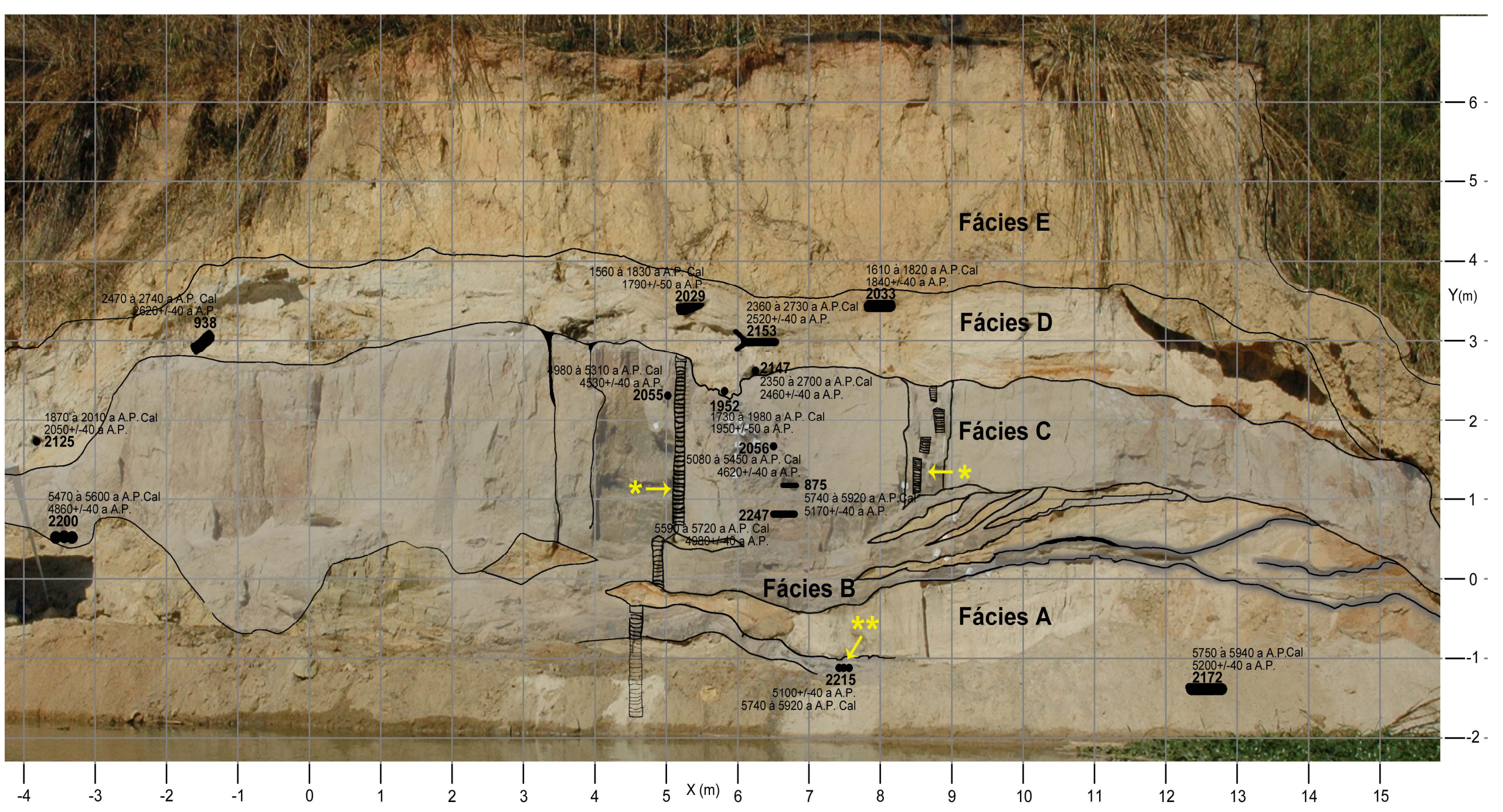

Figura 4: Afloramento paleontológico Ribeirão da Mata (RMT), com a identificação dos fácies e a posição de algumas das amostras de lenhos datadas. *indicam perfil polínico estudado por Raczka (2009). ** representam a localização de folhas estudadas por Nakaumra (2011). 
Tabela 1: Relação das amostras datadas pelo Beta Analytic Radiocarbon Laboratory e sua localização no afloramento RMT. * folhas $\mathrm{f}$

\begin{tabular}{|c|c|c|c|c|c|c|}
\hline $\begin{array}{l}N^{0} \text { de } \\
\text { coleta }\end{array}$ & fácies & $\begin{array}{c}\text { Idade } \\
\text { radiocarbônica } \\
\text { convencional } \\
(\text { anos A.P. })\end{array}$ & $\begin{array}{c}\text { Calibração } 2 \\
\text { sigma (anos } \\
\text { A.P. Cal.) }\end{array}$ & $\underset{(\mathbf{m})}{\mathbf{X}}$ & $\begin{array}{c}\mathbf{Y} \\
(\mathbf{m})\end{array}$ & $\begin{array}{c}\mathbf{N}^{\circ} \text { de } \\
\text { registro } \\
\text { laboratorial }\end{array}$ \\
\hline RMT-2143 & $\mathrm{D}$ & $1630+/-40$ & 1600 a 1420 & 12,7 & 1,82 & Beta - 222595 \\
\hline RMT-2205 & $\mathrm{D}$ & $1750+/-40$ & 1740 a 1550 & 7,35 & 0,22 & Beta - 222601 \\
\hline RMT-2029 & $\mathrm{D}$ & $1780+/-50$ & 1830 a 1560 & $5,1 / 5,6$ & 3,2 & Beta - 222583 \\
\hline RMT-2033 & $\mathrm{D}$ & $1790+/-40$ & 1820 a 1610 & $7,6 / 8$ & 3,2 & Beta - 222584 \\
\hline RMT-1952 & $\mathrm{D}$ & $1920+/-50$ & 1980 a 1730 & 5,9 & 2,20 & Beta - 222582 \\
\hline RMT-2125 & $\mathrm{D}$ & $1990+/-40$ & 2010 a 1870 & $-5,6$ & 2,15 & Beta - 222594 \\
\hline RMT-1310 & $\mathrm{D}$ & $2190+/-50$ & 2340 a 2050 & 13,5 & 2,5 & Beta - 242566 \\
\hline RMT-2147 & $\mathrm{D}$ & $2420+/-40$ & $\begin{array}{c}2700 \text { a } 2630 \text { ou } \\
2620 \text { a } 2560\end{array}$ & 6,3 & 2,35 & Beta - 222596 \\
\hline RMT-2153 & $\mathrm{D}$ & $2480+/-40$ & 2730 a 2360 & $6,0 / 6,6$ & $2,65 / 2,8$ & Beta - 222597 \\
\hline RMT-938 & $\mathrm{D}$ & $2520+/-40$ & 2740 a 2470 & $-3 /-2,5$ & 2,8 & Beta - 222579 \\
\hline RMT-2055 & $\mathrm{B}, \mathrm{C}$ & $4500+/-40$ & $\begin{array}{c}5310 \text { a } 5030 \text { ou } \\
5010 \text { a } 4980\end{array}$ & 5,1 & 1,95 & Beta - 222585 \\
\hline RMT-2056 & $\mathrm{B}, \mathrm{C}$ & $4590+/-40$ & $\begin{array}{c}5450 \text { a } 5390 \text { ou } \\
5330 \text { a } 5280\end{array}$ & 6,25 & 1,75 & Beta - 222586 \\
\hline RMT-2185 & $\mathrm{B}, \mathrm{C}$ & $4770+/-40$ & $\begin{array}{c}5600 \text { a } 5460 \text { ou } \\
5380 \text { a } 5340\end{array}$ & $-3 /-3,15$ & 0,25 & Beta - 222599 \\
\hline RMT-2200 & $\mathrm{B}, \mathrm{C}$ & $4800+/-40$ & 5600 a 5470 & $-3,4 /-3,6$ & $-0,27 / 0,5$ & Beta - 222600 \\
\hline RMT-2247 & $\mathrm{B}, \mathrm{C}$ & $4910+/-40$ & 5720 a 5590 & $6,6 / 6,77$ & 0,67 & Beta - 222603 \\
\hline RMT-2098 & $\mathrm{B}, \mathrm{C}$ & $4910+/-50$ & 5740 a 5590 & $-6,8 /-5,2$ & $-025 /-0,81$ & Beta - 222593 \\
\hline RMT-875 & $\mathrm{B}, \mathrm{C}$ & $5090+/-40$ & 5920 a 5740 & $6,7 / 7,0$ & 1,00 & Beta - 222578 \\
\hline RMT-2215* & $\mathrm{B}, \mathrm{C}$ & $5100+/-40$ & 5920 a 5740 & 7,5 & $-1,1$ & Beta - 222602 \\
\hline RMT-2172 & A & $5130+/-40$ & $\begin{array}{c}5940 \text { a } 5860 \text { ou } \\
5830 \text { a } 5750 \\
\end{array}$ & $12,3 / 12,9$ & $-1,48$ & Beta - 222598 \\
\hline
\end{tabular}

\subsection{MATERIAIS E MÉTODOS}

\subsubsection{PROCESSAMENTO DOS MATERIAIS}

Esta abordagem no estudo da vegetação pretérita de Lagoa Santa, MG utilizou 118 fragmentos de lenhos fósseis escavados dos fácies A, B, C e D (figura 5). Devido à cronologia bem estabelecida pelas datações radiocarbônicas, as amostras fósseis referentes aos fáceis $\mathrm{A}, \mathrm{B}$ e $\mathrm{C}$ foram analisadas conjuntamente, e serão referidas como amostras do Holoceno médio, enquanto que as amostras escavadas no fácies D serão tratadas separadamente, referidas como amostras do Holoceno tardio. 
A

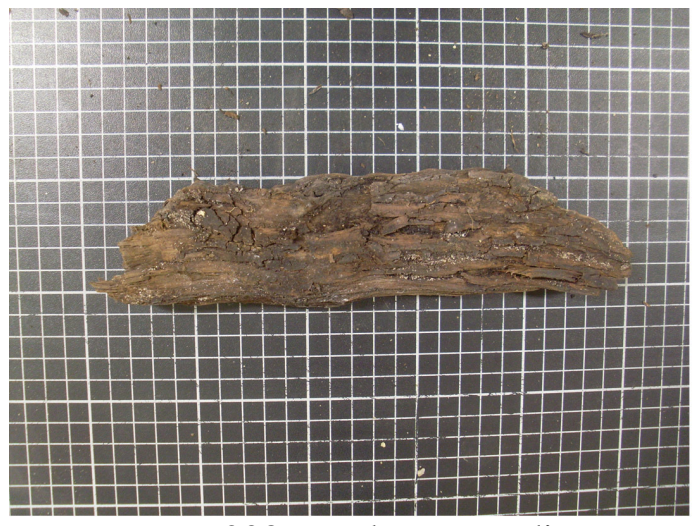

RMT 938 - Holoceno tardio

C

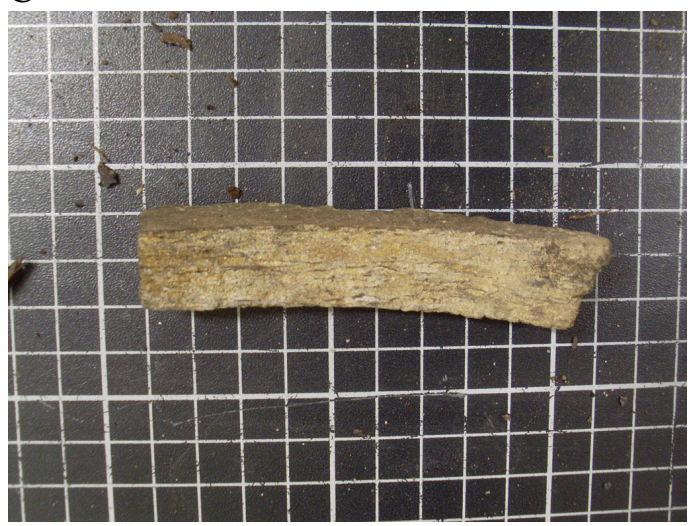

RMT 1310 - Holoceno tardio

E

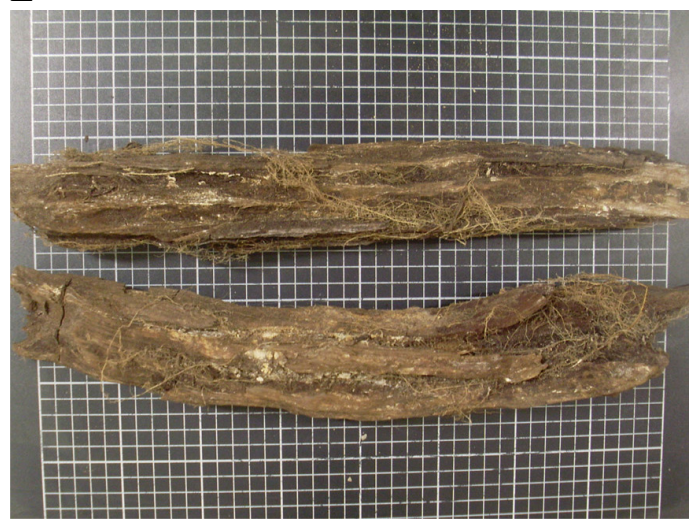

RMT 2039 - Holoceno tardio
B

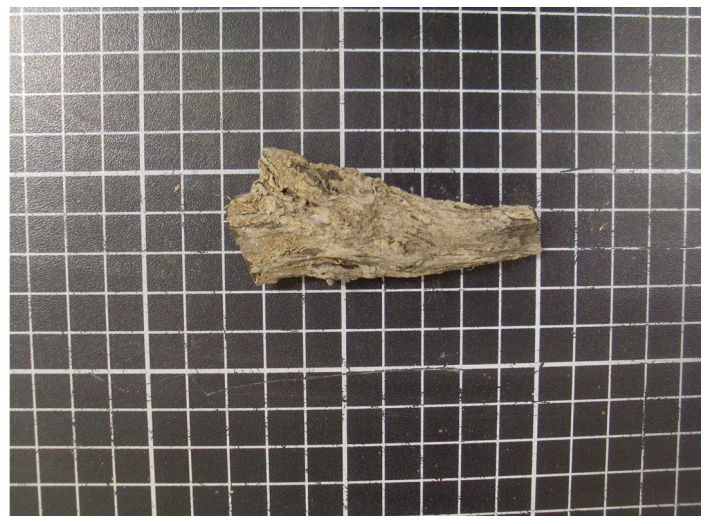

RMT 879 - Holoceno médio

D

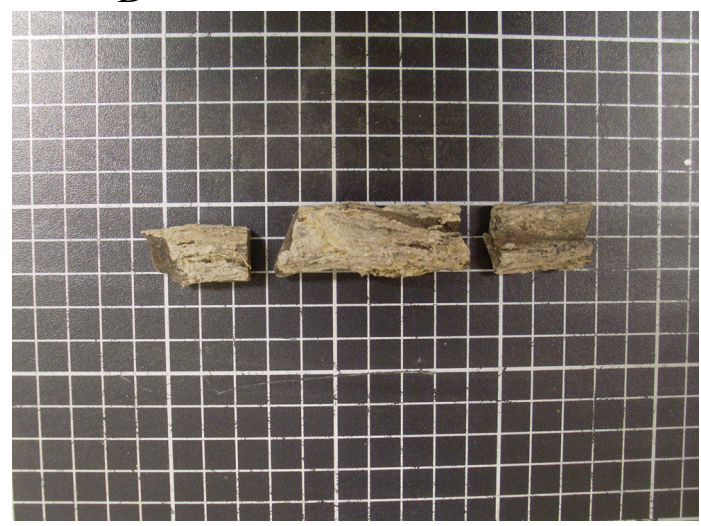

RMT 882 - Holoceno médio

F

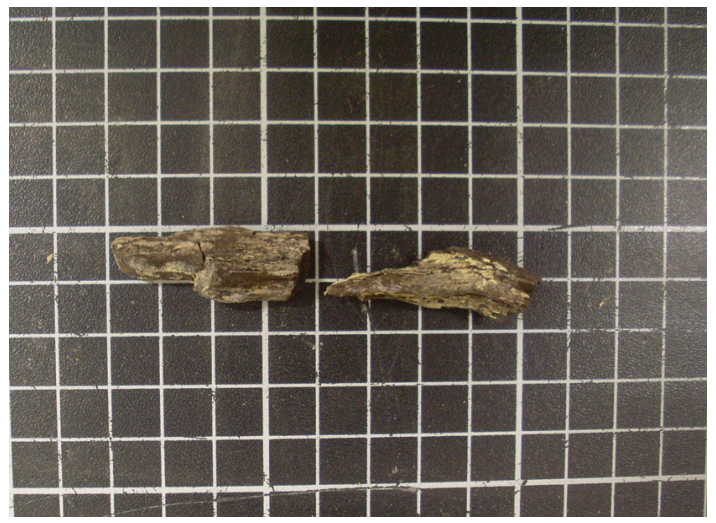

RMT 1965 - Holoceno médio

Figura 5: Alguma das amostras fósseis estudadas.Rede de $1 \mathrm{~cm}$ de aresta.

As amostras de lenhos são neste trabalho consideradas fósseis, e não apenas madeiras holocênicas, por apresentarem alterações físicas e químicas características do processo tafonômico de carbonificação. São elas: a coloração bastante escura, a 
fragilidade, a textura, por vezes, parecida a de um carvão, quebradiça e, principalmente, a baixa quantidade de celulose encontrada nas amostras enviadas para a datação de ${ }^{14} \mathrm{C}$. Embora o termos "fóssil" ainda seja bastante discutido entre especialistas, como foi possível constatar em minha aula de qualificação e a respectiva arguição, preferiu-se utilizar o termo "lenhos fósseis" para remeter à existência de um processo tafonômico que estava ocorrendo com as amostras no momento de retirada do afloramento.

A escavação dos lenhos fósseis envolveu a localização de cada um perante dois eixos estipulados (X, Y) (figura 4), representação em croquis, caracterização quanto ao fácies deposicional, identificação com numeração própria e transporte ao Laboratório de Anatomia Vegetal do Instituto de Biociências - USP (IBUSP). Então, seguiu-se a lavagem em água corrente para a remoção de sedimento e a retirada do corpo de prova para a montagem de lâminas histológicas permanentes dos três planos principais da madeira, sem a necessidade de amolecimento prévio para a maioria das amostras, segundo a metodologia reproduzida por Krauss \& Arduim (1997). Para amostras em estado de degradação mais avançado, a metodologia utilizada foi a descrita por Barbosa et al. (2010). Os corantes utilizados foram azul de astra e safranina.

Uma vez preparadas as lâminas, foi feita, por meio da microscopia de luz e de luz polarizada, a descrição microscópica da anatomia das amostras utilizando como referência IAWA Committee (1989). Devido ao grande número de amostras, a descrição foi feita apenas de forma qualitativa. Características quantitativas, como diâmetro e frequência de vasos, frequência e altura de raios e tamanho de pontoações intervasculares, foram determinadas por meio da impressão visual. Embora aparentemente subjetiva, esta determinação foi possível depois de 7 anos de experiência com descrição de madeiras, iniciada ainda na graduação, e depois de observar centenas lâminas histológicas dos acervos BCTw e SPFw. As categorias aqui discriminadas seguiram, aproximadamente, as categorias propostas pela IAWA. Embora possa haver imprecisões na classificação de amostras com características quantitativas no limiar entre duas categorias, estas classificações foram úteis ao descartar categorias extremas para as características anatômicas. Por exemplo: quando o diâmetro de vasos foi classificado como "grande", embora se tenha imprecisão sobre a presença de vasos médios, ficou-se com a certeza da inexistência de vasos pequenos, o que auxiliou na identificação ao se excluir táxons com vasos deste tamanho.

As descrições anatômicas obtidas serviram então como documento básico para o procedimento de identificação taxonômica dos fósseis, realizada por meio de:1.) 
consulta de listas florísticas atuais da região (incluída a lista apresentada na tabela 1 do capítulo 1); 2.) bibliografia específica para identificação de madeira (Brunner et al., 1994; Détienne \& Jacquet, 1983; Evans et al., 2006; Fedalto et al., 1989; Klaasesen, 1999; Mainieri \& Chimelo, 1989; Record \& Hess, 1943; Wheeler, E.A. et al., 1986); 3.) banco de dados online Inside Wood (2004-onwards); 4.) comparação direta com laminários das xilotecas BCTw (IPT) e SPFw(IB-USP), incluindo neste último, as lâminas histológicas referentes ao material de referência coletado em Lagoa Santa e trabalhados no capítulo 2; 5.) Para toda a documentação microfotográfica foi utilizado Sistema de Digitalização de Imagem (IM50) acoplado ao microscópio Leica DMLB.

\subsubsection{ANÁLISE DOS RESULTADOS}

A análise dos resultados foi realizada utilizando duas abordagens diferentes comumente usadas nos estudos paleobotânicos (Poole, 2000). Em ambas as abordagens, foram utilizadas para comparação florística 45 listas florístico-lenhosas publicadas e mais 4 listas florísticas resultantes da separação em fitofisionomias (floresta semidecídua, cerrado, mata ciliar e mata seca) da listagem de espécies apresentada no Capítulo 1 (tabela 1 do Capítulo 1). A relação das listas florísticas, as siglas utilizadas e as respectivas citações são apresentadas na tabela 2. Para verificar a matriz binária e as referências bibliográficas completas, vide CD-ROM anexo (APÊNDICE 4).

$\mathrm{Na}$ primeira abordagem, denominada por Poole (2000) de "Nearest Living Relative", cada táxon identificado foi analisado individualmente, verificando-se sua ocorrência atual dentro das listas florístico-lenhosas selecionadas e suas restrições ecológicas. Nesta abordagem, além de listas florísticas, as informações fitossociológicas dos táxons, nos diversos habitats em que ocorrem, são levadas em consideração na interpretação ambiental, utilizando, além da bibliografia publicada, os resultados fitossociológicos apresentados nas tabelas 3, 4 e 5 do Capítulo 1.

Na segunda abordagem, denominada "Coexistence Appproach" (Poole, 2000), foi analisada a ocorrência conjunta de todos os táxons identificados para cada período de sedimentação do afloramento RMT. Para tanto, optou-se por utilizar a metodologia de análise multivariada de agrupamento (índice de similaridade de Jaccard e algoritmo de aglomeração da distância média), por meio da elaboração de uma matriz binária de presença/ausência de cada táxon nas diferentes listas florístico-lenhosas selecionadas e nas listas taxonômicas para o Holoceno médio e tardio, obtidas após as identificações.

Tabela 2: Relação das listas florísticas utilizadas nas comparações com as assembléias fósseis 


\begin{tabular}{|c|c|}
\hline SIGLA UTILIZADA & REFERÊNCIA \\
\hline Caatinga (Areia/Remígio, PE) & (Pereira et al., 2002) \\
\hline Caatinga (Caruaru, PE) & (Alcoforado-Filho et al., 2003) \\
\hline Caatinga (Itaparica, PE) & (Rodal \& Nascimento, 2002) \\
\hline Caatinga (Serra da Capivara, PI & (Lemos \& Rodal, 2002) \\
\hline Cerradão (Brotas, SP) & (Gomes et al., 2004) \\
\hline Cerradão (Luis Antônio, SP) & (Pereira-Silva et al., 2004) \\
\hline Cerrado (Abaeté, MG) & (Saporetti Jr et al., 2003) \\
\hline Cerrado (Água Boa,MT) & (Felfili et al., 2002) \\
\hline Cerrado (Chapada do Araripe,CE) & (Costa et al., 2004) \\
\hline Cerrado (Itirapina SP) & (Tannus \& Assis, 2004) \\
\hline Cerrado (Lagoa Santa) & Tabela 1, Capitulo 1, (Editada) \\
\hline Cerrado (Paraopeba,MG) & (Balduino et al., 2005) \\
\hline Cerrado (Patrocínio Paulista, SP) & (Teixeira et al., 2004) \\
\hline Cerrado (Poconé, MT) & (Silveira et al., 2000) \\
\hline Cerrado sensu stricto (Caldas Novas, GO) & (Silva, L.O. et al., 2002) \\
\hline Cerrado/Cerradão (Goiás, DF) & (Andrade et al., 2002) \\
\hline Cerrado/Semidecídua (Pedregulho, SP) & (Sasaki \& Mello-Silva, 2008) \\
\hline Fl. E. Semidecidual - alto montana (Viçosa, MG) & (Ribas et al., 2003) \\
\hline Fl. E. Semidecidual - montana (Viçosa, MG) & (Meira-Neto \& Martins, 2002) \\
\hline Fl. E. Semidecidual - submontana (Viçosa, MG) & (Paula et al., 2002) \\
\hline Fl. E. Semidecidual (Campinas, SP) & Guaratini et al., 2008 \\
\hline Fl. E. Semidecidual (Ingaí, MG) & (Botrel et al., 2002) \\
\hline Fl. E. Semidecidual (Marilea/Timóteo/Dionísio, MG) & (Lopes et al., 2002) \\
\hline Fl. E. Semidecidual (Ouro Preto, MG) & (Werneck et al., 2000) \\
\hline Fl. E. Semidecidual (São Carlos, SP) & (Silva \& Soares, 2003) \\
\hline Fl. E. Semidecidual (Timóteo/Dionísio, MG) & (Lombardi \& Gonçalves, 2000) \\
\hline Fl. E. Semidecidual (Viçosa, MG) & (Marangon et al., 2003) \\
\hline Fl. E.Semidecidual - submontana (Viçosa, MG) & (Silva et al., 2003) \\
\hline Fl. Ombrófila Densa - submontana (Imbé, RJ) & (Moreno et al., 2003) \\
\hline Fl. Ombrófila Densa (Camanducaia, MG) & (França \& Stehmann, 2004) \\
\hline Fl. Ombrófila Densa (Rio de Janeiro, RJ) & (Kurtz \& Araújo, 2000) \\
\hline Floresta decídua (Piracicaba, SP) & (Ivanauskas \& Rodrigues, 2000) \\
\hline Floresta Ombrófila (Capoeira Grande, RJ) & (Peixoto et al., 2004) \\
\hline Floresta Ombrofila (Intervales, SP) & (Ziparro et al., 2005) \\
\hline Mata Ciliar (Lagoa Santa) & Tabela 1, Capitulo 1, (Editada) \\
\hline Mata de Galeria (Belo Horizonte, MG) & (Meyer et al., 2004) \\
\hline Mata de Galeria (Ipeúna, SP) & (Bertani et al., 2001) \\
\hline Mata de Galeria (Itutinga, MG) & (Van Den Berg \& Oliveira-Filho, 2000) \\
\hline Mata Seca (Lagoa Santa) & Tabela 1, Capitulo 1, (Editada) \\
\hline Mata Seca (São Domingos, GO) & (Silva \& Scariot, 2003) \\
\hline Mosaico (Baependi, MG) & (Ferreira \& Forzza, 2009) \\
\hline Mosaico (Montes Claros, MG) & (Brandão, M. et al., 1993) \\
\hline Mosaico (Pedro Leopoldo, MG) & (Brandão, M. et al., 1996) \\
\hline Mosaico (Prudente de Morais, MG) & (Brandão, M. et al., 1996) \\
\hline Mosaico (Uberaba, MG) & (Brandão, M et al., 1995) \\
\hline Restinga (Guarapari, ES) & (Assis et al., 2004) \\
\hline Restinga (S.J. da Barra, RJ) & (Assumpção \& Nascimento, 2000) \\
\hline Semidecídua (Lagoa Santa) & Tabela 1, Capitulo 1, (Editada) \\
\hline Vereda (Uberlândia, MG) & (Araújo et al., 2002) \\
\hline
\end{tabular}


Para a confecção da matriz binária, não se trabalhou com o nível específico, visto que a maioria das identificações dos fósseis alcançou o nível de gênero. Quando alguma identificação chegou em nível de espécie, utilizou-se este nível. Quando a identificação ficou entre dois gêneros, as ocorrências destes gêneros foram agrupadas em apenas uma coluna. Para reduzir o número total de táxons (colunas), optou-se também por excluir táxons herbáceos, parasitas e bambuzóides (APÊNDICE 4 - CD ROM). Por fim, computaram-se a presença e ausência dos táxons na assembleia fóssil do Holoceno médio e tardio, separadamente.

\subsection{RESUltados E DisCUSSÃO}

\subsubsection{PROCESSAMENTO DE LENHOS FÓSSEIS}

Foram analisadas 125 amostras de lenho fóssil, das quais 66 escavadas em estratos sedimentares datados do Holoceno médio e 59 amostras escavadas em estrato referente ao Holoceno tardio. Cabe aqui salientar que nem todas as amostras foram processadas, por apresentarem condições muito ruins, que somaram 12 amostras do Holoceno médio e 5 amostras do Holoceno tardio. Em ambos os fácies, a principal dificuldade encontrada foi o estado de carbonificação mais avançado de algumas amostras, o que não permitiu o corte histológico, sendo necessária uma metodologia antracológica, não realizada neste trabalho. Por fim, foram estudadas 108 amostras, das quais 54 do Holoceno médio e 54 do Holoceno tardio.

\subsubsection{DESCRIÇÃO ANATÔMICA:}

Por se tratar de fósseis, ou seja, de material soterrado, submetido a processos químicos e físicos por milhares de anos, o pesquisador deve tomar alguns cuidados na hora de interpretar, nas amostras, certas características anatômicas.

Pela dificuldade de visualizá-las, ou mesmo pela possibilidade delas terem sido degradadas no processo tafonômico, sua não observação foi frequentemente interpretada como característica "não visível”, ao invés de considerá-la "ausente".

No plano transversal, com exceção das poucas amostras bem preservadas, foi observada uma tortuosidade no parênquima radial, interpretada como consequência da pressão da coluna sedimentar que soterrou as amostras. Esta tortuosidade, 
frequentemente, causou dificuldade na descrição de características anatômicas dos planos tangencial e radial, visto que não foi possível obter cortes bem orientados.

A degradação diferencial das paredes das fibras dentro de uma mesma amostra foi outra dificuldade encontrada, principalmente para a caracterização do parênquima axial e da espessura da parede de fibra. Em alguns casos, essas características foram interpretadas a partir de pequenas áreas do corte melhor preservadas.

Nos planos radial e tangencial, as principais dificuldades encontradas foram relacionadas às fibras, como pontuações e septos, devido ao colapso e coalescência da células, e a tortuosidade do plano radial, que atrapalhou a delimitação de características como a largura do raio e o número de células da série fusiforme do parênquima axial. Nesses planos, o uso de luz polarizada auxiliou na observação de cristais. Porém, a birrefringência não foi observada propriamente nos cristais, mas na parede interna das células cristalíferas. Sendo assim, ou o cristal perdeu sua refringência durante o processo tafonômico, ou o cristal foi dissolvido, e o que se observa hoje é apenas o molde deixado por ele.

O resultado das descrições dos materiais está apresentado no APÊNDICE 2, as respectivas iconografias, no APÊNDICE 3. Devido à quantidade de material analisado, foi apresentada a descrição de apenas uma amostra de cada táxon identificado.

\subsubsection{IDENTIFICAÇÃO TAXONÔMICA}

A assembleia de fósseis estudada revelou grande diversidade, sendo identificados 27 morfotipos diferentes. Outros 10 morfotipos foram discriminados, mas não tiveram a identificação taxonômica realizada. Isso ocorreu pelo seu estado de degradação anatômica significativo ou pela falta de material de referência compatível. Dentre as identificações, dois táxons, Myroxylon peruiferum e Allophylus /Cupania sp foram identificados tanto no estrato datado do Holoceno tardio com no estrato depositado durante o Holoceno médio. Eles são apresentados na tabela 3 e 4.

\subsubsection{ANÁLISES}

A assembleia de lenhos identificada para o Holoceno tardio da região de Lagoa Santa possui alta ocorrência de táxons distribuídos atualmente em fisionomias vegetais fechadas, florestais, como Floresta Semidecídua e Mata Ciliar. Lithraea molleoides é a única espécie identificada que tem distribuição significativa em áreas de cerrado, embora seja generalista e ocorra também com significativa abundância em áreas de 
Floresta Semidecídua (Herrmann et al., 1998; Ratter et al., 1996; Rodrigues et al., 2002; Saporetti Jr et al., 2003). Astronium/Myracrodruon sp, como foi possível constatar no estudo fitossociológico atual da região (Capítulo 1, tabela 4 e 5), possui alta importância fitossociológica nas áreas de Floresta Estacional Semidecidual e de Mata Ciliar. Seguem o mesmo padrão, Celtis sp, Trichilia sp e Allophylus/Cupania sp. Já Myroxylon peruiferum, por sua vez, só foi encontrado em listagens florísticas de Floresta Semidecídua.

Quanto à assembleia identificada para o Holoceno médio da região, embora com diferentes táxons identificados, foram encontrados indícios do mesmo padrão de cobertura vegetal que o da assembleia fóssil do Holoceno Tardio. O gênero Qualea sp é um táxon típico dos cerrados, o que foi constatado no estudo fitossociológico (capítulo 1, tabela 3), onde as duas únicas espécies encontradas dentro de parcelas estavam em ambiente de cerrado stricto sensu (s.s). Diversos outros táxons tem ocorrência em áreas de cerrado s.s., embora ocorram também em fisionomias florestais, como Combretum $s p$ e Terminalia sp. Os demais táxons são indicadores de ambientes florestais.

A análise de agrupamento (figura 6) corrobora com a interpretação de grande similaridade entre as duas assembleias fósseis (em vermelho), que foram agrupadas antes de qualquer outra. A co-ocorrência dos táxons Allophylus/Cupania sp, Myroxylon peruiferum e Terminalia $s p$ propiciaram tal similaridade. Na sequência, as assembleias fósseis são agrupadas com Floresta Estacional Semidecidual de Ouro Preto e, em seguida, com uma vegetação de Mata Seca, de GO. Tal agrupamento mostra a similaridade da vegetação pretérita de Lagoa Santa com fisionomias florestais que ocorrem sob clima sazonal. Maytenus sp, Myrcia / Calyptranthes sp, Ocotea/Nectandra $s p$ e Myrsine sp contribuem para a aproximação com a floresta semidecídua, enquanto as associações dos táxons Asidosperma sp, Ficus/Sorocea sp, Maytenus sp de um lado, e Anadenanthera / Dimorphandra sp e Astronium/Myracrodruon sp do outro, indicam proximidade da mata seca com a assembleia fóssil do Holoceno médio e tardio, respectivamente. A similaridade com os cerrados da região aparece logo na sequência, envolvendo um grupo que concentra a maioria dos cerrados analisados. Tal semelhança foi obtida pela presença conjunta de táxons generalistas com táxons de expressiva ocorrência em áreas de cerrados, como Qualea sp e Lithraea molleoides. As matas ciliares e florestas ombrófilas se apresentaram mais distantes das assembleias fósseis por esta análise. 
Tabela 3: Morfotipos identificados na assembleia de lenhos fósseis datados do Holoceno médio, listando as amostras que apresentaram o mesmo padrão anatômico. *amostras tipo.

\begin{tabular}{|c|c|c|c|}
\hline $\begin{array}{c}\text { Morfo } \\
\text { tipo }\end{array}$ & Família & Gênero/Espécie & $\operatorname{Amostra}(\mathbf{s})$ \\
\hline 3 & APOCYNACEAE & Aspidosperma sp & RMT 970* \\
\hline 4 & CELASTRACEAE & Maytenus sp & $\begin{array}{l}\text { RMT 873, RMT } 1958 \text { e RMT } \\
\text { 1974* }\end{array}$ \\
\hline 6 & COMBRETACEAE & Combretum sp & RMT 881 e RMT $899 *$ \\
\hline 8 & COMBRETACEAE & Terminalia sp 2 & $\begin{array}{l}\text { RMT 2099*, RMT } 2186 \text { e RMT } \\
2200\end{array}$ \\
\hline 11 & LEGUMINOSAE & Centrolobium sp & RMT $1312 *$ \\
\hline 12 & LEGUMINOSAE & Lonchocarpus sp & RMT $2059 *$ e $2060-1$ \\
\hline 18 & MORACEAE & Ficus sp & RMT 872* e RMT 1963 \\
\hline 19 & MORACEAE & Ficus/Sorocea sp & RMT 13160 e RMT 1307-1 \\
\hline 21 & MYRTACEAE & $\begin{array}{c}\text { Myrcia sp/Calyptranthes } \\
\text { concina }\end{array}$ & RMT 1964 e RMT 2185* \\
\hline 22 & MYRTACEAE & $\begin{array}{c}\text { Myrcia sp/Psidium } \\
\text { sp/Calyptranthes concina }\end{array}$ & RMT $1962 *$ \\
\hline 23 & SAPINDACEAE & Allophylus/Cupania sp & RMT 2246 e RMT 2271 \\
\hline 24 & SAPINDACEAE & Serjania sp & $\begin{array}{l}\text { RMT 964, RMT } 1966 \text { e RMT } \\
\text { 2053* }\end{array}$ \\
\hline 25 & SAPOTACEAE & Chrysophyllum sp & RMT 2098* \\
\hline 26 & VOCHYSIACEAE & Qualea sp & RMT 962* \\
\hline 13 & LEGUMINOSAE & Myroxylon peruiferum & $\begin{array}{l}\text { RMT 879, RMT 882, RMT } 1965 \text {, } \\
\text { RMT 2054, RMT 2055, RMT } \\
2056^{*} \text { e RMT } 2252\end{array}$ \\
\hline 29 & (não identificada) & (não identificada) & RMT $1307-3$ e RMT 1307-4 \\
\hline 32 & (não identificada) & (não identificada) & $\begin{array}{l}\text { RMT 875, RMT 946, RMT } 2049 \text { e } \\
\text { RMT } 2250\end{array}$ \\
\hline 33 & (não identificada) & (não identificada) & $\begin{array}{l}\text { RMT 877, RMT 900, RMT 943, } \\
\text { RMT 947, RMT 967, RMT 1971, } \\
\text { RMT 2187, RMT } 2247 \text { e RMT } \\
2269\end{array}$ \\
\hline 36 & (não identificada) & (não identificada) & $\begin{array}{l}\text { RMT 876, RMT 942, RMT 1960- } \\
\text { 1, RMT 1967, RMT } 1968 \text { e RMT } \\
1969\end{array}$ \\
\hline $\begin{array}{l}\text { não } \\
\text { identificado }\end{array}$ & - & - & $\begin{array}{l}\text { RMT 843, RMT 1307-2, RMT } \\
\text { 1307-5, RMT 1313, RMT 1961, } \\
\text { RMT 2052, RMT 2060-2 e RMT } \\
2172\end{array}$ \\
\hline
\end{tabular}


Tabela 4: Morfotipos identificados na assembleia de lenhos fósseis datados do Holoceno tardio, listando as amostras que apresentaram o mesmo padrão anatômico. *amostras tipo.

\begin{tabular}{|c|c|c|c|}
\hline $\begin{array}{c}\text { Morfo } \\
\text { tipo }\end{array}$ & Família & Gênero/Espécie & $\operatorname{Amostra}(s)$ \\
\hline 1 & ANACARDIACEAE & Astronium/Myracrodruon sp & RMT 2157* \\
\hline 2 & ANACARDIACEAE & Lithraea molleoides & RMT 2040* \\
\hline 5 & CANNABACEAE & Celtis sp & $\begin{array}{l}\text { RMT 2154-2*, RMT 2158, RMT } \\
2163\end{array}$ \\
\hline 7 & COMBRETACEAE & Terminalia sp 1 & RMT 2125 e RMT 2170* \\
\hline 9 & LEGUMINOSAE & Acacia/Mimosa sp & RMT $1304-7 *$ \\
\hline 10 & LEGUMINOSAE & $\begin{array}{l}\text { Anadenanthera peregrina/ } \\
\text { Dimorphandra/Inga sp }\end{array}$ & RMT 2153* \\
\hline 13 & LEGUMINOSAE & Myroxylon peruiferum & $\begin{array}{l}\text { RMT 879, RMT 882, RMT } 1965 \text {, } \\
\text { RMT 2054, RMT 2055, RMT } \\
2056^{*}, \text { RMT } 2252\end{array}$ \\
\hline 14 & LAURACEAE 1 & & $\begin{array}{l}\text { RMT 2031*, RMT 2152-1 e 2156- } \\
1\end{array}$ \\
\hline 15 & LAURACEAE 2 & cf Ocotea/Nectandra sp & RMT 2204* \\
\hline 16 & MELIACEAE & Trichilia cf. claussenii & RMT 2166* \\
\hline 17 & MELIACEAE & Trichilia cf. pallida & $\begin{array}{l}\text { RMT 1318, RMT 2026, RMT } \\
2041, \text { RMT } 2154-1^{*}, \text { RMT } 2161\end{array}$ \\
\hline 20 & MYRSINACEAE & Myrsine sp & RMT 2165* e RMT 2151 \\
\hline 23 & SAPINDACEAE & Allophylus/Cupania sp & $\begin{array}{l}\text { RMT 1304-6, RMT 1306, RMT } \\
2029, \text { RMT 2030, RMT 2033, } \\
\text { RMT 2034*, RMT 2144, RMT } \\
2146, \text { RMT 2149, RMT 2150, } \\
\text { RMT 2152-2, RMT 2156-2, RMT } \\
\text { 2159, RMT 2164-1, RMT 2164-2, } \\
\text { RMT 2167, RMT 2169 }\end{array}$ \\
\hline 27 & VOCHYSIACEAE & Salvertia convallariodora & RMT 2028* \\
\hline 28 & (não identificada) & (não identificada) & $\begin{array}{l}\text { RMT 1304-2, } \\
\text { RMT2 } 155\end{array}$ \\
\hline 30 & (não identificada) & (não identificada) & RMT 2255 \\
\hline 31 & (não identificada) & (não identificada) & RMT 1304-4 \\
\hline 34 & (não identificada) & (não identificada) & RMT 1317 \\
\hline 35 & (não identificada) & (não identificada) & RMT 2035 \\
\hline 37 & (não identificada) & (não identificada) & RMT 1304-5 \\
\hline $\begin{array}{c}\text { não } \\
\text { identificado }\end{array}$ & - & - & RMT 2127 e RMT2162 \\
\hline
\end{tabular}


Os resultados da análise de agrupamentos devem levar em conta, porém, o fato de o pequeno número de identificações dos fósseis intensificar a influência do tamanho das listas florísticas sobre as similaridades estimadas. Como só existe presença para 14 táxons no Holoceno médio, a co-ocorrência de 2 deles em uma lista de 30 táxons leva à uma similaridade de 0,045. Em uma outra lista, com 98 táxons, deverá existir 5 táxons co-ocorrentes para ter a mesma similaridade.

Desta forma, localidades com maior riqueza, como as florestas semidecíduas, matas ciliares e ombrófilas podem ter o mesmo número de ocorrências que as demais listas (de cerrados, por exemplo), mas seus índices de similaridade com as assembleias fósseis tendem a ser menores quanto mais ricas essas listas forem.

Analisando apenas a ocorrência dos 11 táxons identificados para o Holoceno médio (tabela 5), verifica-se que a florística de semidecídua de Lagoa Santa, levantada no capítulo 1, possui 10 deles, o que revela uma enorme afinidade. Esta semelhança não é detectada na análise de agrupamento devido a existência de 134 táxons nesta lista, que repercute em uma similaridade de apenas 0,07 .

Portanto, além das considerações fundamentadas na análise de agrupamento, deve-se pesar melhor a maior ocorrência de táxons em florestas semidecíduas, das florestas serranas de Itaparica, PE (caatinga), da mata ciliar de Ipeúna, SP e do mosaico de vegetações do município de Prudente de Morais, poucos quilômetros ao norte da ACLS (tabela 5 e 6 ).

Para o Holoceno tardio, o resultado obtido com a análise direta dos táxons foi praticamente o mesmo para o Holoceno médio, mostrando a coerência da análise de agrupamento ao agregar as assembleias fósseis.

Dessa forma, mesmo considerando a interferência do tamanho das listas florísticas nos resultados da análise de agrupamento, todas as análises realizadas apontaram para uma grande similaridade entre as assembleias fósseis dos dois períodos considerados. 


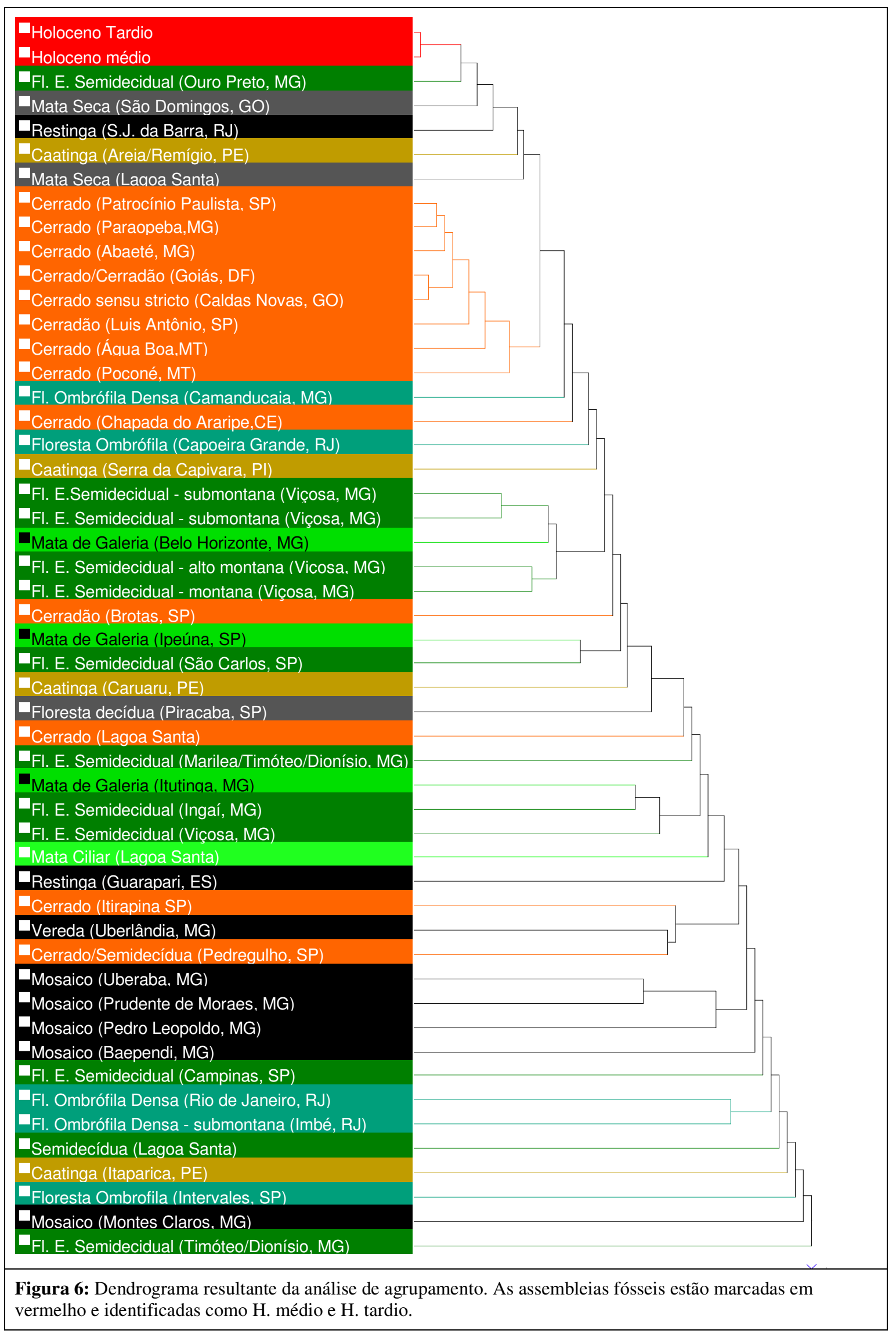


Tabela 5: Número de táxons identificados na assembleia fóssil do Holcoeno médio que co-ocorrem em outras listas florísticas. Estão apresentados apenas as listas com os mais altos valores.

\begin{tabular}{cc}
\hline Lista florística & No $^{\mathbf{0}}$ de táxons co-ocorrentes \\
\hline Semidecídua (Lagoa Santa) & 10 \\
LAGOA SANTA, MG & 10 \\
Fl. E. Semidecidual (São Carlos, SP) & 9 \\
Fl. E. Semidecidual (Campinas, SP) & 9 \\
Fl. E. Semidecidual (Ingaí, MG) & 9 \\
Mata de Galeria (Ipeúna, SP) & 8 \\
Caatinga (Itaparica, PE) & 8 \\
Mosaico (Prudente de Moraes, MG) & 8 \\
Fl. E. Semidecidual (Timóteo/Dionísio, MG) & 8 \\
Floresta decídua (Piracicaba, SP) & 7 \\
Fl. E. Semidecidual - submontana (Viçosa, MG) & 7 \\
Fl. E. Semidecidual - montana (Viçosa, MG) & 7 \\
Cerrado (Lagoa Santa) & 7 \\
Fl. Ombrófila Densa - submontana (Imbé, RJ) & 7 \\
Fl. E. Semidecidual (Viçosa, MG) & 7 \\
\hline
\end{tabular}

Tabela 6: Número de táxons identificados na assembleia fóssil do Holoceno tardio que co-ocorrem em outras listas florísticas. Estão apresentados apenas as listas com os mais altos valores.

\begin{tabular}{cc}
\hline Lista florística & N$^{\circ}$ de táxons co-ocorrentes \\
\hline Semidecídua (Lagoa Santa) & 10 \\
LAGOA SANTA, MG & 10 \\
Fl. E. Semidecidual (São Carlos, SP) & 9 \\
Fl. E. Semidecidual (Campinas, SP) & 9 \\
Fl. E. Semidecidual (Ingaí, MG) & 9 \\
Mata de Galeria (Ipeúna, SP) & 8 \\
Caatinga (Itaparica, PE) & 8 \\
Mosaico (Prudente de Moraes, MG) & 8 \\
Fl. E. Semidecidual (Timóteo/Dionísio, MG) & 8 \\
Floresta decídua (Piracicaba, SP) & 7 \\
Fl. E. Semidecidual - submontana (Viçosa, MG) & 7 \\
Fl. E. Semidecidual - montana (Viçosa, MG) & 7 \\
Cerrado (Lagoa Santa) & 7 \\
Fl. Ombrófila Densa - submontana (Imbé, RJ) & 7 \\
Fl. E. Semidecidual (Viçosa, MG) & 7 \\
\hline
\end{tabular}

$\mathrm{Na}$ análise de agrupamento, foi revelada a similaridade com cerrados do Brasil central e matas decíduas, não descartando a semelhança com algumas poucas florestas semideciduais. Por outro lado, estas últimas mostraram fortes relações por meio da comparação direta com a ocorrência dos táxons fósseis, com a qual se pode notar a 
semelhança com a atual florística da floresta semidecídua da região, levantada no capítulo 1. Ainda, o compartilhamento de 8 táxons com a floresta serrana de Itaparica, PE, dentro do bioma da caatinga e clima semiárido nos indica a influência de Floresta Tropicais Sazonalmente Decíduas que, no bioma do cerrado recebem o nome de mata seca, e ocorrem em manchas isoladas do carste sobre afloramentos calcários muito drenados.

Assim, tendo-se mostrado a grande semelhança entre as assembleias fósseis dos dois períodos pretéritos considerados e suas relações com o mosaico de fitofisionomias que atualmente ocorrem na região de Lagoa Santa, MG, fica claro nesta abordagem paleoclimática a presença e manutenção das florísticas que existem atualmente da região desde o Holoceno médio, onde a datação mais antiga chegou em 5130+-40 anos A.P. (5940 a 5750 anos A.P. Cal.).

Recentemente os resultados palinológicos de Raczka (2009), para a mesma localidade, também sugerem o estabelecimento do mosaico cerrado/florestas para este período. Porém, verificou certa instabilidade climática por volta dos 6.000 anos. A abordagem aqui apresentada, contudo, não permite considerações climáticas mais detalhadas como a abordagem palinológica. A menor quantidade de amostras e a impossibilidade de tratar quantitativamente as assembleias de madeiras, na qual as espécies se fragmentam de maneira particular, são as principais restrições para tal interpretação. Também, a sensibilidade climática de uma vegetação ou mesmo de determinadas espécies dentre de um ecossitstema costumam não ser alta suficientemente para interpretações climáticas mais detalhadas. Pesquisas envolvendo outros indicadores, principalmente os químicos e físicos, como isótopos de espeleotemas, podem trazer mais detalhamento paleoclimático.

Sob o ponto de vista tafonômico, os resultados respondem várias dúvidas e críticas existentes no início do trabalho. Por se tratar de um afloramento paleontológico de sedimento aluvionar, um ponto criticado foi a alta possibilidade do afloramento Ribeirão da Mata (RMT) apresentar apenas espécies típicas da mata de galeria de seu entorno, e assim, não forneceria material com potencial interpretativo para uma reconstrução ambiental. Respondendo tal crítica, as relações taxonômicas apresentadas aqui mostram maiores afinidades com florestas estacionais semideciduais (destaque para Myroxylon peruiferum, Combretum sp e Serjania sp), que geralmente se distribuem mais afastadas dos corpos aquosos, que as matas ciliares ou de galerias. O gênero Qualea sp,ainda, é típico de ambientes de cerrado, que não costumam se estabelecer no 
leito de rios ou córregos. Foi constatado, então, um deslocamento de fragmentos de lenho maior do que o esperado inicialmente, revelando que afloramentos aluviais de lenhos fósseis podem trazer informações de outras fisionomias vegetais que não só ocorrem no leito dos rios, mas sim mais afastadas. A figura 5, que mostra a bacia de drenagem do ribeirão da Mata à montante do afloramento RMT revela a área distância máxima de origem dos fragmentos de lenho analisados.

\subsection{CONCLUSÕES}

Por meio da abordagem florística das assembleias fósseis do afloramento RMT concluiu-se que:

- O Holoceno médio e tardio apresentam florísticas similares, que não indicam alterações climáticas na região durante os períodos

- As assembleias fósseis identificadas corroboram com os resultados de Raczka (2009), que mostram o estabelecimento da vegetação atual de Lagoa Santa durante o Holoceno médio

- O afloramento RMT apresenta madeiras fósseis que sofreram deslocamento considerável, provenientes de outras fisionomias vegetais, que não matas de galerias, revelando o potencial para interpretações menos locais do que se esperava no início dos trabalhos.

\subsection{REFERÊNCIAS BIBLIOGRÁFICAS}

ABSY, M. L. et al. 1991. Occurrence of 4 Episodes of Rain-Forest Regression in Southeastern Amazonia during the Last 60,000 Yrs - 1st Comparison with Other Tropical Regions. Comptes Rendus De L Academie Des Sciences Serie Ii, v.312, n.6, p.673-678.

AGRITEMPO. 2003. Agritempo: Sistema de monitoramento agrometeorológico. Disponível em: http://www.agritempo.gov.br. Acessado em 10-10-2010.

ARAUJO, A. G. M. et al. 2005. Holocene dryness and human occupation in Brazil during the "Archaic Gap". Quaternary Research, v.64, n.3, Nov, p.298-307.

BAKER, P. A. et al. 2001. The history of South American tropical precipitation for the past 25,000 years. Science, v.291, n.5504, Jan 26, p.640-643.

BARBOSA, A. C. F. et al. 2010. A New Method to Obtain Good Anatomical Slides of Heterogeneous Plant Parts. IAWA Journal, v.31, n.4, p.373-383. 
BEHLING, H. 1995a. A High-Resolution Holocene Pollen Record from Lago Do Pires, Se Brazil - Vegetation, Climate and Fire History. Journal of Paleolimnology, v.14, n.3, p.253-268.

BEHLING, H. 1995b. Investigations into the Late Pleistocene and Holocene History of Vegetation and Climate in Santa-Catarina (S Brazil). Vegetation History and Archaeobotany, v.4, n.3, Sep, p.127-152.

BEHLING, H. 1997. Late Quaternary vegetation, climate and fire history of the Araucaria forest and campos region from Serra Campos Gerais, Parana State (South Brazil). Review of Palaeobotany and Palynology, v.97, n.1-2, Jul, p.109-121.

BEHLING, H. 2002. South and southeast Brazilian grasslands during Late Quaternary times: a synthesis. Palaeogeography Palaeoclimatology Palaeoecology, v.177, n.12, Jan 5, p.19-27.

BEHLING, H. 2003. Late glacial and Holocene vegetation, climate and fire history inferred from Lagoa Nova in the southeastern Brazilian lowland. Vegetation History and Archaeobotany, v.12, n.4, Dec, p.263-270.

BEHLING, H. et al. 2004. Late Quaternary Araucaria forest, grassland (Campos),fire and climate dynamics, studied by high-resolution pollen, charcoal and multivariate analysis of the Cambara do Sul core in southern Brazil. Palaeogeography Palaeoclimatology Palaeoecology, v.203, n.3-4, Feb 15, p.277-297.

BRUNNER, M.;L. J. KUCERA \& E. ZÜRCHER. 1994. Major timber trees of Guyana - A lens key. Wageningen: Tropenbos foundation (Tropenbos series 10).

CECCANTINI, G. C. T. 2000. O uso da anatomia da madeira na arqueologia. In: T. B. CAVALCANTI e B. M. T. WALTER (Ed.). Tópicos atuais em Botânica. Brasília: Embrapa Recursos Genéticose Biotecnologia/ Sociedade Botânica do Brasil. p.p.383-389.

CECCANTINI, G. C. T. 2002. Madeiras arqueológicas do anbrigo rupestre de Santa Elina, MT. Tese de Doutorado. Depto. Botânica, Instituto de Biociências, Universidade de São Paulo, São Paulo,

CECCANTINI, G. C. T. \& M. H. FERNANDEZ. 2005. Anatomia das estacas arqueológicas do abrigo rupestre: considerações tecnológicas e paleoambientais. In: Á. V. VIALOU. (Org.). Pré-História do Mato Grosso. São Paulo: EDUSP. p.189200.

COLINVAUX, P. A. et al. 1996. A long pollen record from lowland Amazonia: Forest and cooling in glacial times. Science, v.274, n.5284, Oct 4, p.85-88.

DE OLIVEIRA, P. E.; A. M. F. BARRETO \& K. SUGUIO. 1999. Late Pleistocene/Holocene climatic and vegetational history of the Brazilian caatinga: the fossil dunes of the middle Sao Francisco River. Palaeogeography Palaeoclimatology Palaeoecology, v.152, n.3-4, Sep 1, p.319-337.

DE OLIVEIRA, P. E. et al. 2005. Paleovegetação e Paleoclimas do Quaternário do Brasil. In: C. R. G. SOUZA et al (Ed.). Quaternário do Brasil. Ribeirão Preto: Holos Editora.

DÉTIENNE, P. \& P. JACQUET. 1983. Atlas d'identifi cation des bois de l'Amazonie et des régions voisines. Norgent-sur-Marne: Centre Téchnique Forestier Tropical

EVANS, J. A.;P. E. GASSON \& G. P. LEWIS. 2006. Wood anatomy of the Mimosoideae (Leguminosae) - Introduction. IAWA Journal, p.5-+ supplement. 
FEDALTO, L. C.;I. C. A. MENDES \& V. R. CORADIN. 1989. Madeiras da Amazônia: descrição do lenho de 40 espécies ocorrentes na Floresta Nacional do Tapajós. Brasília: IBAMA.

FREIRE, G. Q. \& G. C. T. CECCANTINI. 2004. Identificação de Lenhos Sub Fósseis do Holoceno Médio Brasileiro. Livro de Resumos do XV Congresso da Sociedade Botânica de São Paulo. Ubatuba.

GROSJEAN, M. et al. 2001. A 22,000 C-14 year BP sediment and pollen record of climate change from Laguna Miscanti (23 degrees S), northern Chile. Global and Planetary Change, v.28, n.1-4, Feb, p.35-51.

HERRMANN, G. et al. 1998. Estudo do meio biótico da APA Carste de Lagoa Santa. Belo Horizonte: Ibama, Companhia de Pesquisa de Recursos Minerais: 92 p.

IAWA-COMMITTEE. 1989. List of microscopic features for hardwood identification. IAWA Bulletin, v.10, p.220-332.

INSIDEWOOD. 2004-onwards. Published on the Internet. http://insidewood.lib.ncsu.edu/search Acessado em 10/10/2010.

KLAASESEN, R. 1999. Wood anatomy of the Sapindaceae. IAWA Journal, supplement 2.

KOHLER, H. C. 1989. Geomorfologia Cárstica na Região de Lagoa Santa, MG. Tese de Doutorado. Universidade of São Paulo, São Paulo, 113 p.

KRAUS, J. E. \& M. ARDUIN. 1997. Manual Básico de Métodos em Morfologia Vegetal. Seropédia, RJ, Brasil: EDUR.

LEDRU, M. P. 1992. Vegetation Changes in Central Brazil between the Late Glacial and the Present Interglacial. Comptes Rendus De L Academie Des Sciences Serie Ii, v.314, n.1, Jan 2, p.117-123.

LEDRU, M. P. 1993. Late Quaternary Environmental and Climatic Changes in Central Brazil. Quaternary Research, v.39, n.1, Jan, p.90-98.

LEDRU, M. P. et al. 2006. Millenial-scale climatic and vegetation changes in a northern Cerrado (Northeast, Brazil) since the Last Glacial Maximum. Quaternary Science Reviews, v.25, n.9-10, May, p.1110-1126.

LEDRU, M. P.;M. L. SALGADO-LABOURIAU \& M. L. LORSCHEITTER. 1998. Vegetation dynamics in southern and central Brazil during the last 10,000 yr BP. Review of Palaeobotany and Palynology, v.99, n.2, Jan, p.131-142.

MAINIERI, C. \& J. P. CHIMELO. 1989. Ficha de características das Madeiras Brasileiras. São Paulo: Instituto de Pesquisas Tecnológicas.

MARTIN, L. et al. 1997. Astronomical forcing of contrasting rainfall changes in tropical South America between 12,400 and 8800 cal yr BP. Quaternary Research, v.47, n.1, Jan, p.117-122.

MELO, M. S. et al. 1987. Datações 14C em sedimentos da Grande São Paulo. Anais do $1^{\circ}$ Congresso da Associação Brasileira de Estudos do Quaternário. Porto Alegre: ABEQUA.

NEVES, W. A. \& H. M. PUCCIARELLI. 1991. Morphological Affinities of the 1st Americans - an Exploratory Analysis Based on Early South-American Human Remains. Journal of Human Evolution, v.21, n.4, Oct, p.261-273. 
PARIZZI, M. G.;M. L. SALGADO-LABOURIAU \& H. C. KOHLER. 1998. Genesis and environmental history of Lagoa Santa, southeastern Brazil. Holocene, v.8, n.3, p.311-321.

PATRUS, M. L. R. A. 1998. Estudos hidrológicos e qualidade das águas de superfície. In: APA Carste de Lagoa Santa - Meio Físico. Belo Horizonte: CPRM/IBAMA. p.58.

PILÓ, L. B. 1998. Morfologia Cárstica e Materiais Constituintes: dinâmica e evolução da depressão poligonal Macacos-Baú - Carste de Lagoa Santa, MG. Tese de Doutorado. Depto. Geografia da Faculdade de Ciências, Filosofia e Letras, Universidade de São Paulo, São Paulo, 276 p.

POOLE, I. 2000. Fossil angiosperm wood: its role in the reconstruction of biodiversity and palaeoenvironment. Botanical Journal of the Linnean Society, v.134, n.1-2, p.361-381.

RACZKA, M. F. 2009. Mudanças paleoambientais quaternárias na região de agoa Santa, MG, Brasil: a palinologia como subsídio para o entendimento do padrão de ocupação humana. Dissertação de Mestrado. Análise Geoambiental, Universidade de Guarulhos, Guarulhos, 109 p.

RATTER, J. A. et al. 1996. Analysis of the floristic composition of the Brazilian cerrado vegetation II: Comparison of the woody vegetation of 98 areas. Edinburgh Journal of Botany, v.53, n.02, p.153-180.

RECORD, S. J. \& R. W. HESS. 1943. Timbers of the New World. New Haven: Yale University Press.

RODRIGUES, S. et al. 2002. Evidence for lake formation as a response to an inferred Holocene climatic transition in Brazil. Quaternary Research, v.57, n.1, Jan, p.131137.

SAPORETTI JR, A. W.;J. A. A. MEIRA NETO \& R. D. P. ALMADO. 2003. Fitossociologia de cerrado sensu stricto no município de Abaeté-MG. Revista Árvore, v.27, p.413-419.

SARTORI, A. L. B. 2000. Revisão taxonômica de Myrocarpus Allemão, Myroxylon L.f. e Myrospermum Jacq. (Leguminosae Papilionoideae Sophorae). Tese de doutorado. Depto. Biologia Vegetal, Universidade Estadual de Campinas, Campinas, $162 \mathrm{p}$.

SCHEEL-YBERT, R. 2000. Vegetation stability in the Southeastern Brazilian coastal area from 5500 to $1400 \mathrm{C}-14 \mathrm{yr}$ BP deduced from charcoal analysis. Review of Palaeobotany and Palynology, v.110, n.1-2, Jun, p.111-138.

SCHEEL-YBERT, R. et al. 2003. Holocene palaeoenvironmental evolution in the Sao Paulo State (Brazil), based on anthracology and soil delta C-13 analysis. Holocene, v.13, n.1, p.73-81.

SIFEDDINE, A. et al. 2003. A 21000 cal years paleoclimatic record from Caco Lake, northern Brazil: evidence from sedimentary and pollen analyses. Palaeogeography Palaeoclimatology Palaeoecology, v.189, n.1-2, Jan 1, p.25-34.

SIFEDDINE, A. et al. 1994. Lacustrine Sedimentation Indicator of Paleoenvironments Changes during the Last $30 \mathrm{Ka} \mathrm{Bp}$ (Carajas, Amazonia, Brazil). Comptes Rendus De L Academie Des Sciences Serie Ii, v.318, n.12, Jun 16, p.1645-1652. 
SUGUIO, K. 1971. Estudo dos troncos de árvores linhitificados dos aluviões antigos do Rio Pinheiros (SP): significados geocronológico e possivelmente paleoclimático. Anais do 25 Congresso Brasileiro de Geologia. São Paulo Sociedade Brasileira de Geologia.

SUGUIO, K. \& A. M. COIMBRA. 1972. Madeira fóssil silicificada na Formação Botucatu. Ciência e Cultura, v.24, n.11, p.1049-1055.

SUGUIO, K. \& D. MUSSA. 1978. Madeiras fósseis dos aluviões antigos do Rio Tietê, São Paulo. Boletim IGc-USP, v.9, p.25-45.

WHEELER, E. A. \& P. BAAS. 1993. The Potentials and Limitations of Dicotyledonous Wood Anatomy for Climatic Reconstructions. Paleobiology, v.19, n.4, Fal, p.487498.

WHEELER, E. A. et al. 1986. Computer-aided wood identification. The North Carolina Agricultural Research Service Bulletin, v.474, p.1-107 + supplement. 


\section{Capítulo 4}

\section{ANATOMIA ECOLÓGICA DE MYROXYLON PERUIFERUM (FABACEAE) APLICADA À INTERPRETAÇÃO PALEOBOTÂNICA}





\subsection{RESUMO}

O clima do Brasil central ao longo do Holoceno ainda permanece controverso, com alguns autores sugerindo umidade constante e outros sugerindo eventos de seca no intercurso. Concomitantemente, no campo da Arqueologia, trabalhos demonstrando uma drástica redução de sepultamentos humanos neste período (Hiato do Arcaico) na região de Lagoa Santa, MG, motivam mais pesquisas em reconstrução climática da área, ao hipotetizar que tal redução poderia refletir deslocamentos populacionais causados pelo estabelecimento de condições climáticas mais severas. O presente trabalho traz uma nova metodologia de investigação paleoclimática, que utiliza correlações entre clima e anatomia da madeira para inferir condições climáticas pretéritas por meio da anatomia de lenhos fósseis. Desse modo, padrões anatômicos de fósseis de Myroxylon peruiferum L.f., datados do Holoceno médio (cerca de 5.000 anos A.P.) e tardio (cerca de 2.500 anos A.P.), são comparados com padrões anatômicos encontrados em indivíduos viventes em três localidades sob regimes climáticos diferentes: semiárido, tropical com estação seca e subtropical úmido. Diversas características anatômicas se correlacionaram com variáveis climáticas, sendo que maiores correlações foram observadas entre o diâmetro de vaso e índice de sazonalidade hídrica e entre esse diâmetro e a temperatura média anual. Em outra abordagem, diversas características anatômicas foram utilizadas conjuntamente para verificar a proximidade do padrão anatômico dos fósseis com os padrões observados nos indivíduos viventes sob os diferentes climas. Os resultados obtidos não indicam grandes mudanças climáticas no Holoceno médio, mas alguns indícios sugerem uma sazonalidade ligeiramente maior. Durante o Holoceno tardio, a anatomia dos fósseis se assemelha à anatomia de espécimes sob ambientes mais úmidos, indicando um período climático próximo ao atual, corroborando com alguns dos trabalhos da literatura. 


\subsection{ABSTRACT}

The climate of central Brazil during the mid Holocene is still controversial, with some authors suggesting constant humidity, while others suggesting dry periods. In addition, in the archeology field, studies demonstrate a drastic reduction of human burial in this period (Archaic Gap) in the region of Lagoa Santa, motivating more researches in the climate reconstruction of the region, to clarify the hypothesis that this reduction is due to population migrations caused by severe climate conditions. The present study brings a new methodology to paleoclimate investigations, making use of correlations between the climate and the wood anatomy to infer the past climate conditions throughout wood fossil anatomy. Anatomic patterns of wood fossils of Myroxylon peruiferum L.f., dated from the Mid (5,000 B.P.) and Late Holocene (2,500 B.P.) where compared to the anatomy of extant specimens from three regions under different climates conditions (semiarid, tropical and humid subtropical). As a result, many anatomic characteristics were correlated to climate variables, with the most significant associations appearing between the vessel's diameter and the hydric seasonality index, and also between vessel's diameter and the annual average temperature. In another approach, several anatomic characteristics were altogether used to verify the similarity of the fossil's anatomy with the anatomy of extant specimens under different climates. The results show no great climate changes in the mid Holocene, but suggest a slightly higher seasonality slightly higher. During the late Holocene, the anatomy of the fossils resembles the anatomy of species under humid environments, indicating a climate period very similar to the present one. These data is in agreement with other studies conducted on this region. 


\subsection{INTRODUÇÃO}

Trabalhos que relacionam a variação das características anatômicas da madeira com características ambientais vêm sendo realizados desde meados da década de 60, quando Carlquist (1966) organizou a diversidade anatômica do lenho das Compositae e a discutiu em termos evolutivos, baseando-se nas características ambientais em que se encontravam os diferentes padrões anatômicos. Na ocasião, o autor levou em conta a disponibilidade hídrica, latitude, habitat, hábito entre outros. A partir de então, diversos estudos começaram a procurar quais aspectos ecológicos influenciam na estrutura da madeira, e como o fazem. Estes estudos podem ser conduzidos em diferentes níveis taxonômicos, seja entre indivíduos de uma única espécie (Ceccantini, 1996; Jono, 2009; Luchi, A. E., 2004; Marcati et al., 2001; Melo Jr, 2003; Noshiro \& Baas, 2000), entre espécies de um mesmo gênero (Alves, 1995; Baas, 1973; Noshiro \& Baas, 2000; Van Den Oever et al., 1981), gêneros de uma mesma família (Baas et al., 1988; Dickison \& Phend, 1985) ou mesmo de toda uma flora (Alves \& Angyalossy, 2000, 2002; BarajasMorales, 1985; Carlquist, S., 1977).

Em (1981), Van den Oever e colaboradores utilizaram o gênero Symplocos em uma metodologia de amostragem e análise bem consistente, e encontraram correlações significativas de diversas características anatômicas com a latitude e a altitude. Para um grupo de indivíduos, os autores encontraram forte correlação da anatomia com a altitude. Segundo seus resultados, corroborados mais tarde por Noshiro \& Baas (1998; 2000), Baas (1973), Van der Graaff \& Baas (1974), tanto a altitude como a latitude influenciam inversamente no diâmetro do vaso e diretamente na sua frequência.

Desde então, diversos trabalhos incluíram a latitude e altitude como parâmetros a serem investigados. Muitos deles encontraram correlações significativas não só para o diâmetro e frequência de vasos como também para muitas outras características anatômicas. A literatura mostra que, para determinadas espécies, quanto maior a latitude: maior a frequência de camadas de crescimento (Alves \& Angyalossy, 2000), menor quantidade de parênquima (Alves \& Angyalossy, 2002; Baas, 1973, 1982; Baas \& Schweingruber, 1987; Baas \& Zhang, 1986), menor espessura de parede e comprimento de fibra (Alves \& Angyalossy, 2002; Noshiro \& Baas, 1998, 2000; Van Den Oever et al., 1981) e menor altura de raio (Van Den Oever et al., 1981). No caso do agrupamento de vasos, embora diversos artigos tenham observado uma correlação positiva com a latitude, (Alves \& Angyalossy, 2002; Carlquist, 1966; Van Den Graaff 
\& Baas, 1974), outros encontraram correlação negativa (Noshiro \& Baas, 2000; Zhang et al., 1988).

Esta clara importância da latitude sobre a anatomia da madeira levou a uma série de questionamentos acerca do motivo de tal influência. De forma geral, as pesquisas associam as baixas latitudes com maior pluviosidade, maior temperatura anual e menor sazonalidade. O inverso para latitudes altas. Essa associação tem se mostrado coerente com diversos trabalhos que utilizam habitats mais úmidos e mais secos para estabelecer correlações com a anatomia. No Brasil é comum esta abordagem: Mina-Rodrigues (1986), Chimelo \& Mattos (1988), Ceccantini (1996) e Marcati et al. (2001) são exemplos de trabalhos que estudaram plantas em ambiente de Cerrado/Caatinga e as compararam com indivíduos de floresta.

De forma geral, os estudos apontam para a tendência de indivíduos em ambientes com maior disponibilidade hídrica, menor estação seca e menor latitude apresentarem vasos menos frequentes e de maior calibre que os indivíduos de ambientes sujeitos a déficit hídrico, sazonalidade ou latitude mais elevada.

Tais relações são frequentemente discutidas no âmbito de seu significado adaptativo-funcional. Carlquist, em (1977), dizia que a organização dos tecidos condutores das plantas resultaria do equilíbrio entre a segurança e a eficiência no transporte de água. Neste tema, o embolismo têm sido apontado como grande problema enfrentado pelo tecido xilemático no exercício de sua função de condução (Baas et al., 2004; Maherali et al., 2004). Vasos curtos e estreitos teoricamente resistiriam a maiores tensões na coluna de água, e a redução de área de condução de cada vaso seria compensada pelo aumento da sua frequência (Carlquist, S., 1977).

Zimmerman \& Brown (1971), adicionaram à esta discussão conceitos físicos de hidráulica, resgatando a equação de Hagen-Poiseuille que deduz que a eficiência hidráulica de um duto é proporcional à $4^{\mathrm{a}}$ potência de seu raio e tentando adaptá-la ao transporte xilemático. Desta forma, se o calibre do vaso sofre uma redução pela metade, serão necessários 16 vezes mais vasos para ter a mesma eficiência em condução, mostrando a crucial importância desta medida para o transporte hídrico e, consequentemente, para o metabolismo vegetal (Zimmerman \& Brown, 1971). Quanto à resistência aos embolismos, Zimmerman (1983) destaca que um maior grau de agrupamento dos vasos, características das pontoações, maior frequência e menor calibre de vasos também aumentariam a segurança na condução da seiva xilemática, reduzindo a incidência e propagação de embolismos. 
Assim, pelo balanço sugerido inicialmente por Carlquist (1977) e adotado mais tarde por diversos autores (Baas, 1982; Ceccantini, 1996; Luchi, A. E., 2004; Marcati et al., 2001; Noshiro \& Baas, 2000; Roig, 1986), os indivíduos de ambientes sujeitos a stress hídrico tendem a apresentar vasos de menor calibre para evitar os embolismos, compensando (não totalmente) a drástica queda de eficiência hidráulica com um aumento na frequência dos vasos. Por outro lado, indivíduos sujeitos a constante disponibilidade hídrica, em geral, podem investir em maior eficiência hidráulica pois necessitam menos de segurança contra embolismos.

A influência do ambiente externo sobre a anatomia da madeira parece estar bem consolidada, porém, como percebe February (1994), númerosos estudos têm examinado a anatomia da madeira e o clima, mas nenhum estabelece a relação de características específicas de vasos com pluviosidade anual média. Pouquíssimos são os trabalhos que procuram detalhar, afinal, quais são os parâmetros climáticos que influenciam e como o fazem na anatomia da madeira, restringindo-se a correlacionar características anatômicas com ambientes mais xéricos/menos xéricos, mais quentes/menos quentes, ambiente mais sazonais/menos sazonais, sem analisar parâmetros climáticos objetivos.

Um dos poucos exemplos é o trabalho de Noshiro \& Baas (2000). Nele, foram estudadas três espécies do gênero Cornus $s p$ e foram encontradas correlações não só com a altitude e latitude, mas também com precipitação anual, amplitude térmica anual e índice de calor.

Em outro trabalho, February (1994) encontrou correlações significativas no diâmetro e frequência de vasos (só analisou estes caracteres) de lenho carbonizado de Protea rupoelliae em diferentes regimes pluviométricos na África do Sul. Mas o interesse do autor em prospectar parâmetros climáticos correlacionados com a anatomia da madeira não foi um interesse meramente botânico. $\mathrm{O}$ maior mérito do autor foi a originalidade em olhar para a correlação climático-anatômica encontrada visando interpretar o regime climático na África do Sul em tempos pretéritos, utilizando para isso, carvões de fogueiras arqueológicas identificados como da mesma espécie.

Como resultado, o autor encontrou correlações da ordem de $74 \%$ entre o diâmetro de vasos de carvões atuais de $P$. rupoelliae e a média anual de pluviosidade. Utilizando o diâmetro de vaso de carvões arqueológicos da mesma espécie e a correlação obtida, o autor estimou a pluviosidade anual média para o período da ocupação arqueológica (2400 anos A.P.). Os resultados não só corroboraram com trabalhos geológicos que evidenciavam um clima mais úmido nos últimos 3000 anos na 
região, como adicionaram dados mais precisos sobre o provável incremento da precipitação anual média para o período.

O presente trabalho tem a mesma concepção de February (1994), pretendendo entender a influência de parâmetros climáticos na anatomia de Myroxylon peruiferum L.f. viventes hoje, e utilizar as correlações e padrões anatômicos obtidos para estimar dados climáticos mais precisos para a região arqueológica de Lagoa Santa, MG, no período de 5000 e 3000 anos A.P., por meio de lenhos fósseis da espécie.

\section{4 ÁREA DE ESTUDO}

A área de estudo (figura 1) compreende quatro localidades climáticas diferentes do país, onde foram coletados os indivíduos de Myroxylon peruiferum L. f.: Cidade Universitária, SP; Ribeirão Preto, SP; Reserva Natural Vale, ES; RPPN Stoessel de Britto, RN. Elas são descritas individualmente a seguir:

\subsection{1 ÁREA 01}

A Reserva do Particular do Patrimônio Natural Stoessel de Britto $\left(6^{\circ} 12\right.$ 's de latitude, de 160 a 286m de altitude) é uma unidade de conservação do bioma Caatinga, no semiárido sertão do Rio Grande do Norte, a $256 \mathrm{Km}$ para oeste da capital, região do Seridó. O clima é o mais seco dentre as localidades estudadas, classificado como semiárido quente e seco, ou Bshw, na classificação de Köppen (Roque et al., 2009). A estação chuvosa, no verão, dura apenas os meses de Março, Abril e Maio, onde cai praticamente toda a chuva do ano, que varia de 500 a $800 \mathrm{~mm}$ apenas. No inverno, todos os córregos secam, com exceção dos grandes corpos d'água que reduzem sua vazão significativamente. A temperatura é elevada, com média anual de $28^{\circ} \mathrm{C}$.

A vegetação local pertence ao bioma da Caatinga, e se enquadra no tipo SavanaEstépica-arborizada, caracterizada como uma "vegetação estacional decidual, tipicamente campestre, em geral com espécies espinhosas entremeadas de plantas suculentas, sobretudo cactáceas que crescem sobre um solo, em geral, raso e quase sempre pedregoso. Árvores são baixas, raquíticas, com troncos finos e esgalhamento profuso" (IBGE, 2004). Algumas poucas espécies conseguem se manter verdes no inverno. M. peruiferum é uma delas.

Incomum na Caatinga, Myroxylon peruiferum L.f. possui ali uma população disjunta das populações que, no sudeste, que ocorrem em florestas estacionais do bioma Mata Atlântica. Esta população habita a vertente da serra, em pequenos bolsões de mata 
cercados por grandes blocos de pedra. Quase inexiste solo nestes bolsões, que aparentam ser mais rasos que no sopé da serra, onde os espécimes RN1 e RN2 foram coletados. Os três restantes foram coletados na vertente. Todos os exemplares estavam bastante danificados pela extração do "bálsamo de tolú" pela população local, e apresentavam mais de um tronco principal rebrotado.

\subsection{2 ÁREA 02}

A Reserva Natural Vale (19 $07^{\prime} \mathrm{S}$ de latitude, $70 \mathrm{~m}$. de altitude), localizada ao norte do Espírito Santo, municípios de Linhares, é propriedade da mineradora Vale do Rio Doce que mantem 22 mil hectares de Floresta de Tabuleiro, bioma da Mata Atlântica.

Por situar-se na planície litorânea, a Floresta de Tabuleiro cresce em solo de horizonte superior (até $50 \mathrm{~cm}$ ) muito arenoso, tornando-se amarelado e mais argiloso (Rizzini, 1979). Ele se enquadra no tipo podzólico vermelho-amarelo distrófico (Peixoto \& Gentry, 1990), pobre em nutrientes e fortemente ácido. A abundante serrapilheira deve ter papel imprescindível no provimento de nutrientes (Oliveira, 1972).

O clima local possui certa peculiaridade. Embora esteja no litoral, a região sofre de déficit hídrico significativo (figura 1), ainda mais intenso que em Ribeirão Preto, área 3. Recebe, então, a mesma denominação: "Tropical com estação seca no inverno", ou Aw (Köppen, 1948). A pluviosidade anual é consideravelmente baixa para formações vegetais densas e de grande porte (dossel a 25-30 m. de altura) como a mata de Tabuleiro. Chove em média 1200mm/ano, concentrados no verão. No inverno, a região chega a suportar uma estação seca pronunciada de Maio a Agosto (4 meses), podendo se estender, como em anos de El-Niño (Rolim et al., 2005). Tal sazonalidade faz a vegetação apresentar uma fisionomia de Floresta Estacional Semidecidual (Engel, 2000). No tocante à temperatura, a proximidade com o mar implica em baixa sazonalidade e a localização ao norte das outras duas áreas amostradas faz com que a temperatura se mantenha mais elevada. A temperatura média anual fica em $24^{\circ} \mathrm{C}$ e a amplitude térmica, pela média mensal, costuma ficar em $5^{\circ} \mathrm{C}$.

Nesta reserva, os indivíduos de $M$. peruiferum coletados foram os que apresentaram maior porte dentre todas as áreas coletadas (tabela 1) e o corpo d'água mais próximo do local de coleta distava ao menos 400 metros. 


\subsection{3 ÁREA 03}

A região de Ribeirão Preto $\left(21^{\circ} \mathrm{S}\right.$ de latitude, 550m de altitude), SP, está situada na zona de tensão ecológica entre os biomas da Mata Atlântica e do Cerrado, ocorrendo tanto remanescentes de Floresta Estacional Semidecidual, quanto de Cerradão.

O clima é denominado "Tropical com estação seca", ou Aw, segundo Köppen (IPT, 2000). A estação seca chega a durar 6 meses, enquanto os meses chuvosos contribuem majoritariamente com a média anual de 1467,9 mm. Já a temperatura média mensal pode variar de $6,2^{\circ} \mathrm{C}$, em Junho, a $25^{\circ} \mathrm{C}$, em Fevereiro, ficando a média anual em torno dos $22,6^{\circ} \mathrm{C}$. (dados retirados da média histórica entre 1981 e 2002, publicados em Kotchetkoff, (2003).

As coletas de $M$. peruiferum nesta área foram feitas em diferentes remanescentes de floresta semidecídua, não observando a ocorrência da espécie em remanescentes de Cerradão. Estes remanescentes se localizam no entorno da região metropolitana de Ribeirão Preto e, assim, os indivíduos foram amostrados de forma mais esparsa que nas outras áreas.

Segundo Kotchetkoff o solo de todos os remanescentes de Floresta Estacional Semidecidual na região é do tipo latossolo roxo, caracterizado como argiloso, bastante poroso e profundo. Sua fertilidade pode variar, porém, sempre com altos teores de manganês e óxido de ferro (Lepsch, 1972).

Os fragmentos de mata amostrados variaram de tamanho, grau de preservação e distância de corpos d'água. Enquanto dois espécimes (GQF 340 e 341) foram coletados às margens de um córrego, afluente do Ribeirão das Onças, outros distavam ao menos 100 metros de qualquer corpo aquoso superficial. Enquanto a amostra GQF 344 foi coletada em fragmento pequeno, de 16,29 ha., as amostras GQF 345, 346 e 347 foram coletadas na Estação Ecológica de Ribeirão Preto, com 180,78 ha.

\subsection{4 ÁREA 04}

As amostras obtidas no município de São Paulo se localizam no "Campus Universitário Armando Salles Oliveira" (CUASO) da Universidade de São Paulo (233' S de latitude, $730 \mathrm{~m}$ altitude). Os indivíduos amostrados estão dispersos ao longo do canteiro central da Av. Prof. Luciano Gualberto.

Estes espécimes estão sob um clima denominado Temperado úmido, ou Cwa (Köppen, 1948). Tal clima não possui uma estação de seca definida. Chove em média 
$1400 \mathrm{~mm}$ anuais concentrados no verão e o inverno não chega a apresentar déficit hídrico. Quando apresenta, o faz no mês de Agosto (Figura 1). A temperatura é amena, com média anual em torno dos $20^{\circ} \mathrm{C}$ e médias mensais que variam de $25^{\circ} \mathrm{C}$ (Fevereiro) a $17^{\circ} \mathrm{C}$ (Julho) (Gomes, 1992).

Os indivíduos coletados não estavam em área de vegetação preservada, mas a vegetação original do campus, segundo Aragaki \& Mantovani (1998) se assemelha mais com Floresta Estacional Semidecidual.

Segundo Mantovani (1993), o solo encontrado no planalto paulistano é Latossolo Vermelho-Amarelo distrófico, que pode estar associado a outros tipos. Setzer (1956) e Varanda (1977) caracterizam os solos de São Paulo e da reserva CUASO como pobres em matéria orgânica, ácidos com alto teor de alumínio, com alta capacidade de retenção de água, baixa porosidade, com os horizontes mais comuns e espessos sendo argilosos. 


\section{ÁREAS DE COLETA}

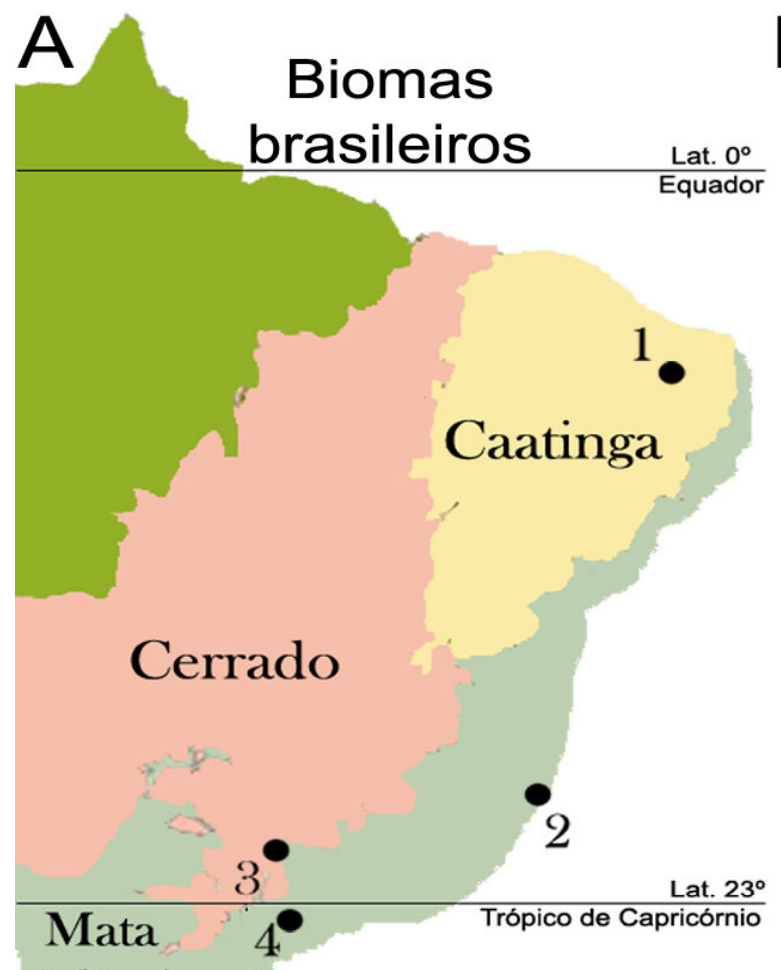

\section{Atlântica}

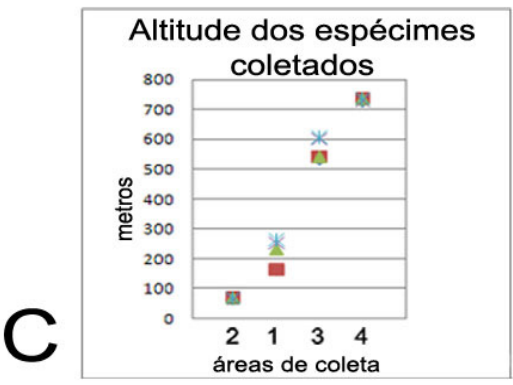

$\mathrm{D}$

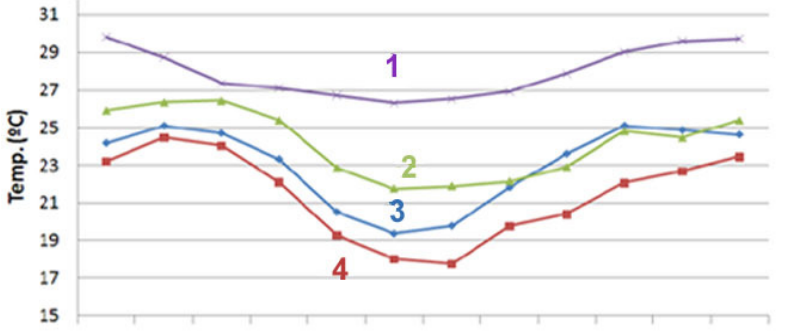

Jan Fev Mar Abr Mai Jun Jul Ago Set Out Nov Dez

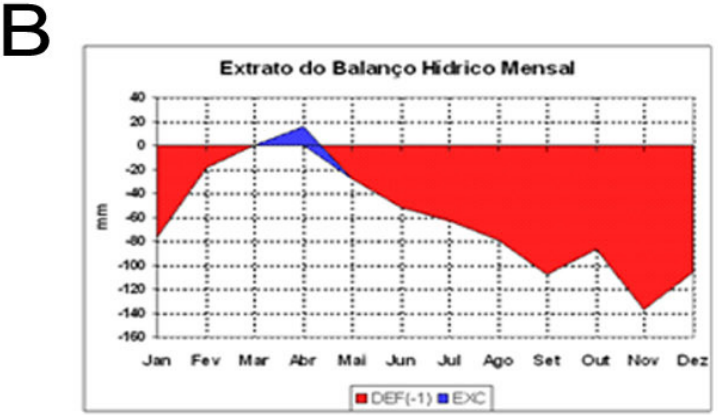

\section{Jucurutú, RN}

(estação em Florânia)

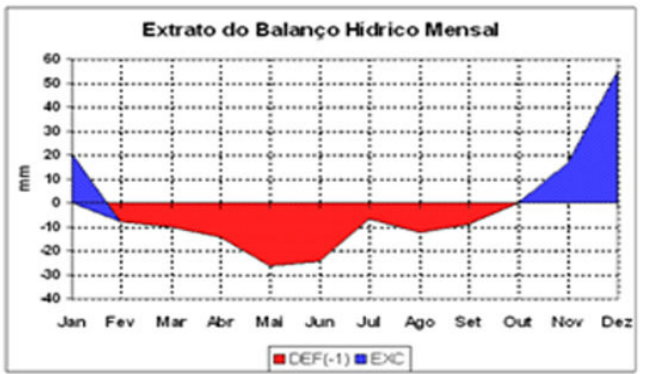

\section{Linhares, ES}

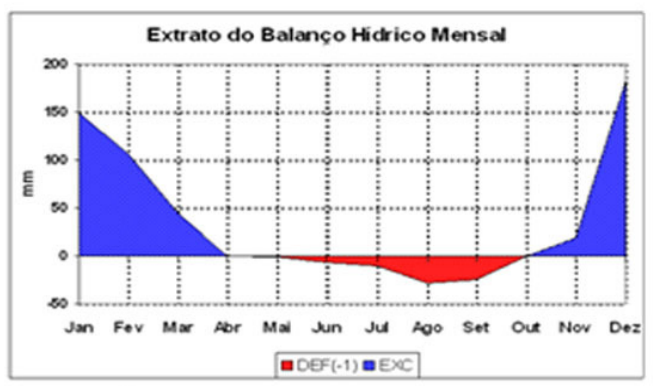

\section{Ribeirão Preto, RP}

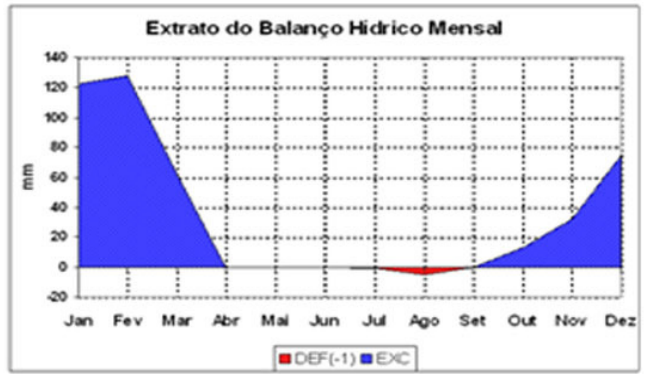

4. São Paulo, SP

Figura 1: Localização e clima das áreas amostradas. A. Locais de coleta; B. Balanços hídricos (fonte: 1. DAEE; 2. IAC; 3 e 4. INMET); C. Altitude; D. Temperatura média mensal das localidades (fonte: INMET). 


\subsection{MATERIAIS E MÉTODOS}

A espécie Myroxylon peruiferum L.f. foi escolhida para este estudo por se tratar do único táxon identificado no registro fóssil do afloramento paleontológico Ribeirão da Mata, MG, que preenche três pré-requisitos essenciais para pesquisas em anatomia ecológica: 1. Ter identificação taxonômica precisa; 2. Apresentar anatomia íntegra; 3. Ocorrer em diferentes ambientes climáticos.

Para facilitar a organização dos materiais e métodos envolvidos neste estudo, optou-se por dividi-los em duas partes: estudos preliminares ("Maturidade do lenho" e "Diferenças na anatomia de galho e tronco") e "Análise anatômico-climática".

\subsubsection{MATURIDADE DO LENHO (JUVENIL X MADURO)}

Este estudo teve por objetivo garantir que as amostras de lenho utilizadas nas análises pertencessem ao lenho maduro dos indivíduos.

Isso é necessário pois o xilema secundário juvenil, produzido no início do crescimento secundário de uma planta, apresenta características e dimensões celulares muito influenciadas pelo estágio inicial de crescimento, influência esta que deve ser evitada porque impede a comparação anatômica com outros indivíduos, de diferentes portes. Foi preciso, então, verificar a partir de qual espessura de xilema secundário a anatomia do lenho não recebe mais influência das fases iniciais de desenvolvimento. Nesta trabalho, as características anatômicas utilizadas para identificar a presença desta influência foram: o comprimento da fibra (Van Den Oever et al., 1981), e o diâmetro tangencial e frequência dos vasos.

Para tanto, foi utilizada uma secção de galho com $10 \mathrm{~cm}$ de diâmetro do indivíduo SP4 (tabela 1). Desta secção, foram retiradas duas amostras radiais, com a orientação medula-câmbio preservada. Em uma delas, o lenho foi amostrado a cada 0,2 cm de distância da medula, dissociado por meio da técnica de maceração (Franklin, 1946) e montado em lâminas histológicas para a medida do comprimento das fibras. Com a outra amostra, foram feitas lâminas histológicas do plano transversal, para a medida do diâmetro e frequência de vaso a cada $1 \mathrm{~mm}$ de distância da medula.

Todas as medidas foram realizadas utilizando mesa digitalizadora (Mousepen 8X6 Genius) e o software de domínio público ImageJ v1.4 (Rasband, 1997). Para a frequência de vasos, foi utilizado uma rede de grade de $1 \mathrm{~mm}^{2}$. A presença do lenho 
maduro foi interpretada a partir da estabilização das curvas de regressão das três variáveis consideradas.

\subsubsection{DIFERENÇA NA ANATOMIA DE GALHO E DE TRONCO}

Embora todas as amostras utilizadas para o estudo anatômico-ecológico de $M$. peruiferum foram coletadas de troncos, a origem dos fósseis com os quais se pretende inferir condições climáticas durante o Holoceno de Lagoa Santa, MG, não é certa. Apenas para a amostra RMT- 1310 há a certeza de ser proveniente de tronco. As demais amostras podem vir de galhos e, desta forma, é importante entender as diferenças anatômicas entre troncos e galhos de M. peruiferum.

Neste estudo, utilizou-se apenas o diâmetro tangencial de vaso do lenho maduro de amostras de galho e do tronco do mesmo indivíduo de $M$. peruiferum. Na análise dos dados, utilizou-se o teste $T$-student para verificar se as médias de tronco e galho do mesmo indivíduo são diferentes e, em caso positivo, quais tendências são observadas.

\subsubsection{ESTUDO ANATÔMICO-ECOLÓGICO}

\subsubsection{COLETA E PROCESSAMENTO DOS MATERIAIS}

Para as análises dos padrões anatômicos e também das correlações climáticoanatômicas, procurou-se amostrar indivíduos de $M$. peruiferum L.f. em diferentes ambientes climáticos. As quatro áreas amostradas foram descritas no tópico "área de estudo" e propiciaram um gradiente latitudinal, altitudinal, térmico e pluviométrico (figura 1).

Foram então coletadas amostras de lenho do tronco de 5 indivíduos de $M$. peruiferum em cada localidade (tabela 1$)$. Elas foram coletadas à altura do peito $(1,3 \mathrm{~m}$ do solo) utilizando a metodologia não destrutiva, com o uso de trado motorizado, higienização com sulfato de cobre e óxido de cálcio (calda bordalesa) e oclusão do orifício com rolha de cortiça. As amostras foram deixadas secar à sombra com a orientação câmbio-medula preservada e as exsicatas dos indivíduos foram identificadas pela especialista Dra. Ângela Lúcia Bagnatori Sartori e depositadas no herbário SPF.

A região do lenho utilizada para as análises foi a mais próxima da zona cambial, e, consequentemente, mais afastada da medula, com tamanho de 2 a $3 \mathrm{~cm}$ de comprimento radial. Dos corpos de prova confeccionados foram obtidos o corte transversal, radial, e tangencial, utilizando a metodologia convencional para cortes 
histológicos de madeira (Kraus \& Arduin, 1997) e posterior montagem de lâminas permanentes. A dupla coloração usada foi azul de astra e safranina. As lâminas, então, foram fotografadas ao microscópio de luz e as imagens obtidas foram montadas em pranchas com escalas micrométricas para a mensuração das variáveis anatômicas.

Tabela 1: Relação das amostras de Myroxylon peruiferum L.f. coletadas para estudo de anatomia ecológica. DAP: diâmetro a altura 1,3 m do solo. H: altura.

\begin{tabular}{ccccc|ccccc}
\hline COD & $\begin{array}{c}\text { DAP } \\
(\mathbf{c m})\end{array}$ & $\begin{array}{c}\text { H } \\
(\mathbf{m})\end{array}$ & LOCALIDADE & $\mathbf{N}^{\circ}$ COL. & COD & $\begin{array}{c}\text { DAP } \\
(\mathbf{c m})\end{array}$ & $\begin{array}{c}\text { H } \\
(\mathbf{m})\end{array}$ & LOCALIDADE & $\mathbf{N}^{\circ}$ COL. \\
\hline SP1 & 52 & 10 & Área 4 (SP) & GQF 332B & ES1 & 108 & 23 & Área 2(ES) & GQF 367 \\
SP2 & 83 & 8,5 & Área 4 (SP) & GQF 333B & ES2 & 110 & 25 & Área 2(ES) & GQF 368 \\
SP3 & 126 & 10 & Área 4 (SP) & GQF 334B1 & ES3 & 81 & 27 & Área 2(ES) & GQF 369 \\
SP4 & 57 & 9 & Área 4 (SP) & GQF 335B & ES4 & 68 & 27 & Área 2(ES) & GQF 370 \\
SP5 & 99 & 11 & Área 4 (SP) & GQF 382 & ES5 & 56 & 15 & Área 2(ES) & GQF 372 \\
RP1 & 114 & 10 & Área 3 (RP) & GQF 340 & RN1 & 41 & 12 & Área 1(RN) & GQF 348 \\
RP2 & 88 & 16 & Área 3 (RP) & GQF 341 & RN2 & 50 & 10 & Área 1(RN) & GQF 349 \\
RP3 & 169 & 61 & Área 3 (RP) & GQF 344 & RN3 & 39 & 9 & Área 1(RN) & GQF 350 \\
RP4 & 146 & 18 & Área 3 (RP) & GQF 345 & RN4 & 61 & 7 & Área 1(RN) & GQF 351 \\
RP5 & 45 & 9 & Área 3 (RP) & GQF 347 & RN5 & 43 & 7 & Área 1(RN) & GQF 356 \\
\hline
\end{tabular}

Para a interpretação climática do Holoceno médio e tardio de Lagoa Santa, MG, foram utilizadas seis amostras de lenho fóssil de $M$. peruiferum, sendo três de cada período (tabela 2, figura 2). Os dois períodos foram estipulados de acordo com cronoestratigrafia realizada no afloramento paleontológico Ribeirão da Mata, em Pedro Leopoldo, MG. Desta forma, o Holoceno médio corresponde ao período entre 4.980 e 5.920 anos A.P. Cal., enquanto o Holoceno tardio compreende de 2.740 a 1.560 anos A.P. Cal. 
A

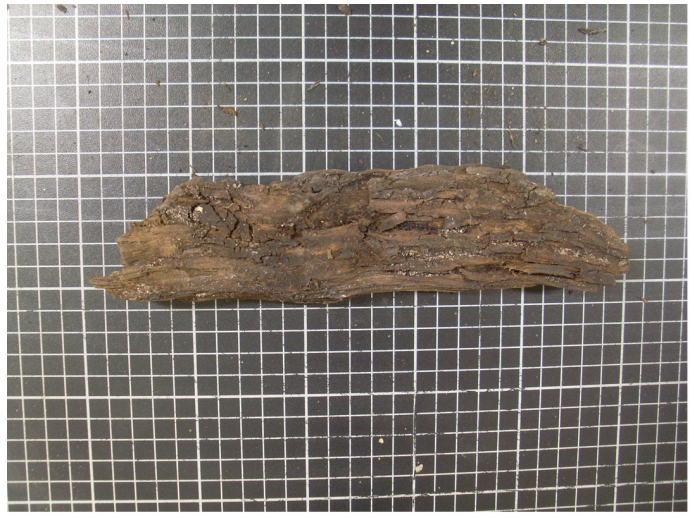

RMT 938 - Holoceno tardio

C

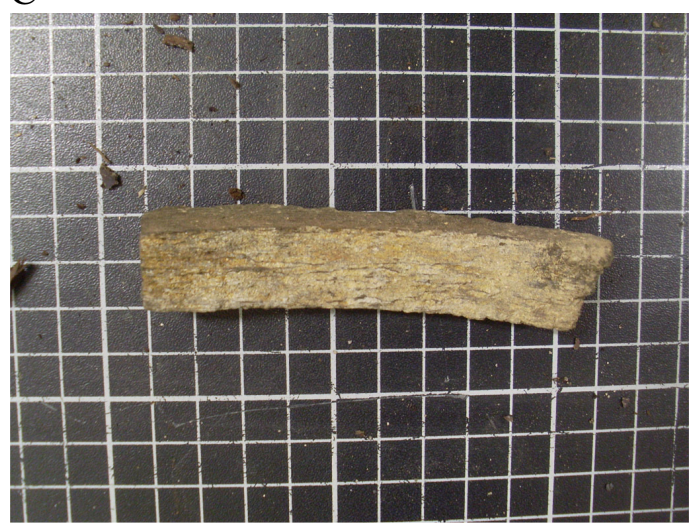

RMT 1310 - Holoceno tardio

E

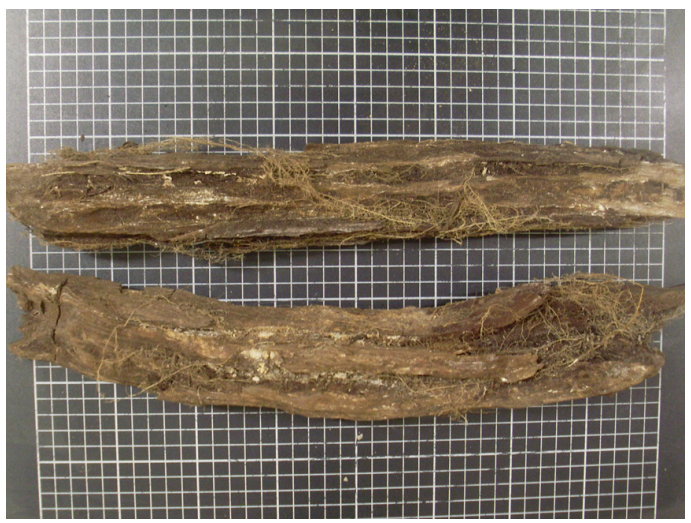

RMT 2039 - Holoceno tardio
B

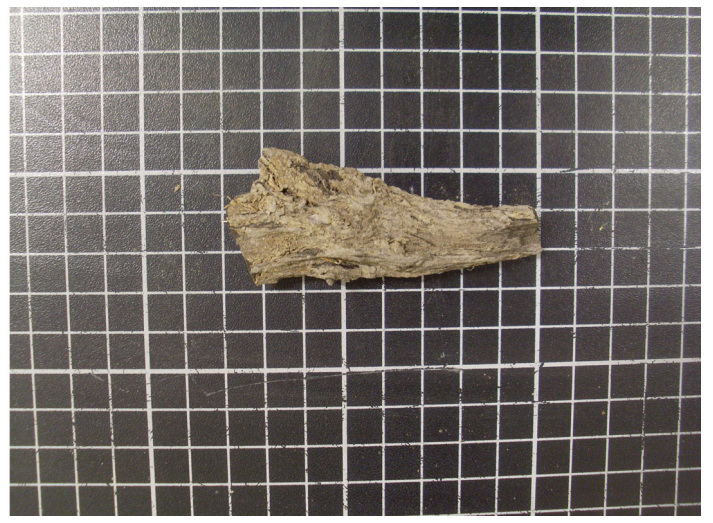

RMT 879 - Holoceno médio

D

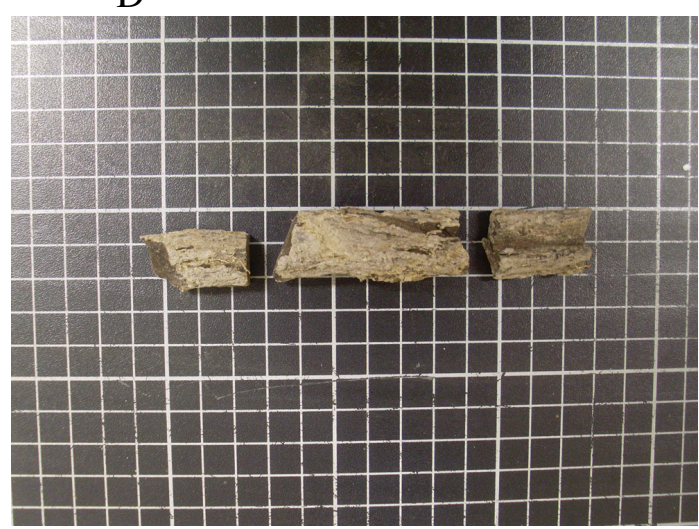

RMT 882 - Holoceno médio

F

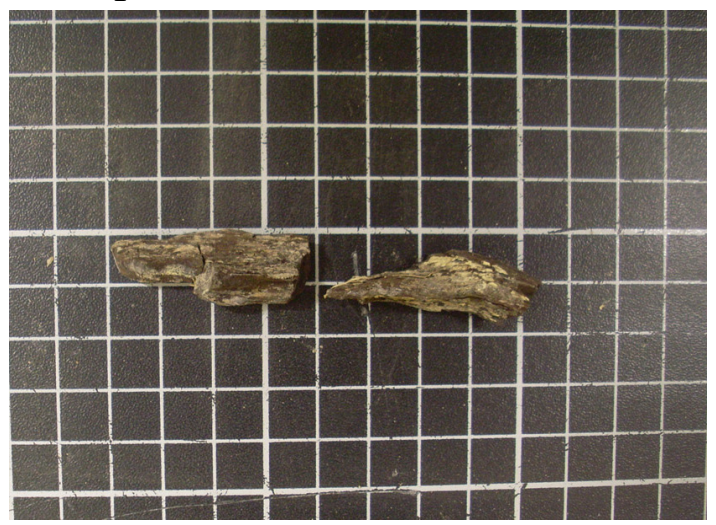

RMT 1965 - Holoceno médio

Figura 2: Algumas das fósseis utilizadas. A, C e E: Holoceno tardio; B, D e F: Holoceno médio. Rede de $1 \mathrm{~cm}$ de aresta. 


\subsubsection{VARIÁVEIS ANATÔMICAS}

Foram mensuradas as seguintes variáveis anatômicas: diâmetro tangencial de vasos (Dv), frequência de vasos (Fv), proporção de vasos solitários, (Pvsol), agrupados em 2 ou 3 (Pv2-3), agrupados em 4 ou 5 (Pv4-5), agrupados em 6 ou 7 (Pv6-7), frequência de raios $(\mathrm{Fr})$, altura de raios $(\mathrm{Ar})$, largura de raios $(\mathrm{Lr})$. O protocolo para cada medida é apresentado no (ANEXO B).

O número de medidas utilizado variou para as diferentes amostras e características anatômicas, pois foi realizado o cálculo de $\mathrm{N}$ amostral (Costa Neto, 1977) para estimar o número de medidas necessário para se ter uma acuracidade de $95 \%$ da média real dos dados. Apenas para a variável "proporção de vasos agrupados" o cálculo não foi utilizado por não ser adequado.

Para cada variável foi utilizada a média e seu desvio padrão nas análises anatômico-ecológicas. Por razões práticas, quando utilizado o desvio padrão de uma variável, sua abreviatura será precedida de “dp” (ex: dpFv), que indica variação.

Nas amostras fósseis, nem todas as variáveis anatômicas puderam se mensuradas devido ao estado de degradação e/ou alteração pós soterramento. As variáveis mensuradas para cada amostra estão relacionadas na tabela 2.

Tabela 2: Relação das amostras fósseis utilizadas, o período datado e as variáveis preservadas que foram mensuradas.

\begin{tabular}{llllllll}
\hline Amostra & Período datado & Dv & Fv & Pv & Fr & Ar & Lr \\
\hline RMT-879 & Holoceno médio & X & - & - & - & - & - \\
RMT-882 & Holoceno médio & X & X & - & - & $X$ & $X$ \\
RMT-1310 & Holoceno tardio & X & X & X & X & X & X \\
RMT-1965 & Holoceno médio & X & X & - & - & - & - \\
RMT-2039 & Holoceno tardio & X & X & X & $X$ & $X$ & $X$ \\
RMT-938 & Holoceno tardio & - & - & - & $X$ & $X$ & $X$ \\
\hline
\end{tabular}

\subsubsection{VARIÁVEIS CLIMÁTICAS}

As variáveis climáticas, utilizadas na correlacão com os padrões anatômicos encontrados, foram obtidas por meio do banco de dados on-line do portal Agritempo (Agritempo, 2002-2009), utilizando dados de estações metereológicas localizadas nos 
mesmos municípios amostrados. Para o município de Jucurutú, RN, foi utilizada a estação metereológica do município vizinho, Florânia. Optou-se por utilizar as médias referentes ao período de Janeiro/2005 a Dezembro/2009, exceto para Florânia, onde não há dados para o ano de 2006. Para variáveis geográficas, foram utilizados dados de latitude, longitude e altitude obtidos por receptor GPS (eTrex Gramin). Todas as variáveis são apresentadas na tabela 3 .

Tabela 3: Variáveis geoclimáticas analisadas, as abreviaturas utilizadas e suas descrições.

\begin{tabular}{|c|c|}
\hline Variáveis & Descrição \\
\hline Latitude (lat) & - \\
\hline Longitude (long) & - \\
\hline Altitude (alt) & - \\
\hline média pluviométrica anual (PA) & - \\
\hline média pluviométrica mensal mínima (Pmin) & $\begin{array}{l}\text { média da pluviosidade do mês mais seco de } \\
\text { cada ano } \\
\text { média da pluviosidade do mês mais chuvoso }\end{array}$ \\
\hline média pluviométrica mensal máxima (Pmax) & $\begin{array}{l}\text { de cada ano } \\
\text { Média da diferença de pluviosidade entre o }\end{array}$ \\
\hline média de amplitude pluviométrica anual (APa) & $\begin{array}{l}\text { mês mais chuvoso e o mais seco de cada ano } \\
\text { Média da somatória da precipitação nos }\end{array}$ \\
\hline $\begin{array}{l}\text { média anual da precipitação acumulada na } \\
\text { estação de crescimento (PAEC) }\end{array}$ & $\begin{array}{l}\text { meses em que chove mais de } 50 \mathrm{~mm} \text { de cada } \\
\text { ano }\end{array}$ \\
\hline $\begin{array}{l}\text { número médio de meses da estação de } \\
\text { crescimento (NMEC) }\end{array}$ & $\begin{array}{l}\text { Média do } \mathrm{n}^{\circ} \text { de meses que chove mais de } \\
50 \mathrm{~mm} \text { de cada ano }\end{array}$ \\
\hline índice de sazonalidade hídrica (ISH) & $\begin{array}{l}\text { Média da porcentagem da precipitação anual } \\
\text { que chove nos três meses mais chuvosos } \\
\text { Média da divisão entre a somatória da } \\
\text { temperatura nos três meses mais quentes e a } \\
\text { somatória das temperaturas mensais de cada } \\
\text { ano }\end{array}$ \\
\hline média de temperatura mensal mínima (Tmin) & $\begin{array}{l}\text { Média da temperatura no mês mais frio de } \\
\text { cada ano }\end{array}$ \\
\hline média de temperatura mensal máxima (Tmax) & $\begin{array}{l}\text { Média da temperatura no mês mais quente } \\
\text { de cada ano }\end{array}$ \\
\hline média anual de temperatura $(\mathbf{T A})$ & - \\
\hline $\begin{array}{l}\text { média de amplitude térmica anual (ATa) } \\
\text { média de número de meses com temperatura } \\
\text { abaixo da média anual (MTA) }\end{array}$ & $\begin{array}{l}\text { Média da diferença entre o mês mais quente } \\
\text { e o mais frio de cada ano }\end{array}$ \\
\hline índice de calor (IC) & Adaptado de (Noshiro \& Baas, 2000) \\
\hline
\end{tabular}




\subsubsection{ANÁLISES}

A primeira análise das relações climático-anatômicas foi realizada por meio da prospecção das variáveis anatômicas e climáticas estatisticamente correlacionadas, para $\alpha=5 \%$. Encontradas tais correlações, foram analisadas as curvas de regressão para avaliar o potencial das correlações para predições climáticas utilizando a anatomia dos fósseis.

Em um segundo momento, as variáveis foram analisadas conjuntamente por meio das técnicas de análise multivariada: Análise de Agrupamento e Análise Discriminante (DA). O software utilizado foi JMP 5.0.1 (SAS, 1999).

Análise de Agrupamento - Esta análise tem por objetivo dividir os elementos amostrais (indivíduos coletados) em grupos de acordo com a similaridade ou dissimilaridade das variáveis que neles foram medidas (Mingot, 2005). A interpretação dos resultados é feita utilizando o gráfico do tipo dendrograma, que mostra os agrupamentos formados e o nível de similaridade obtido na formação de cada grupo. Para tanto, foi escolhido o índice de distância euclidiana e o algoritmo de aglomeração Ward.

Análise Discriminante (DA) - Nesta análise, os grupos são estabelecidos a priori e é construída uma regra discriminante que utiliza as variáveis anatômicas para classificar as amostras de acordo com os grupos preestabelecidos. Esta análise atribui pesos às variáveis anatômicas de forma a minimizar as variações internas de cada grupo e maximizar a variação entre os grupos (Mingot, 2005). Uma vez criada a regra discriminante, as amostras fósseis são classificadas de acordo com seu padrão anatômico dentro das localidades climáticas pré-estabelecidas.

\subsection{RESUlTADOS E DisCUSSÃO}

\subsubsection{MATURIDADE DO LENHO (JUVENIL X MADURO)}

Os resultados do estudo da maturação do lenho de Myroxylon peruiferum L.f. mostram que o diâmetro dos vasos e sua frequência e o comprimento das fibras se estabilizam já nos primeiros $1,5 \mathrm{~cm}$ de distância da medula (figura 3). Tais resultados sugerem que a maturidade do lenho é atingida nos primeiros $1,5 \mathrm{~cm}$ de crescimento secundário, apontando que galhos com mais de $3 \mathrm{~cm}$ já apresentam estabilização das 
dimensões de suas células xilemáticas. Van den Oever (1981) encontrou resultados parecidos, indicando estabilização das fibras em $2 \mathrm{~cm}$ da medula em Symplocos $s p$.

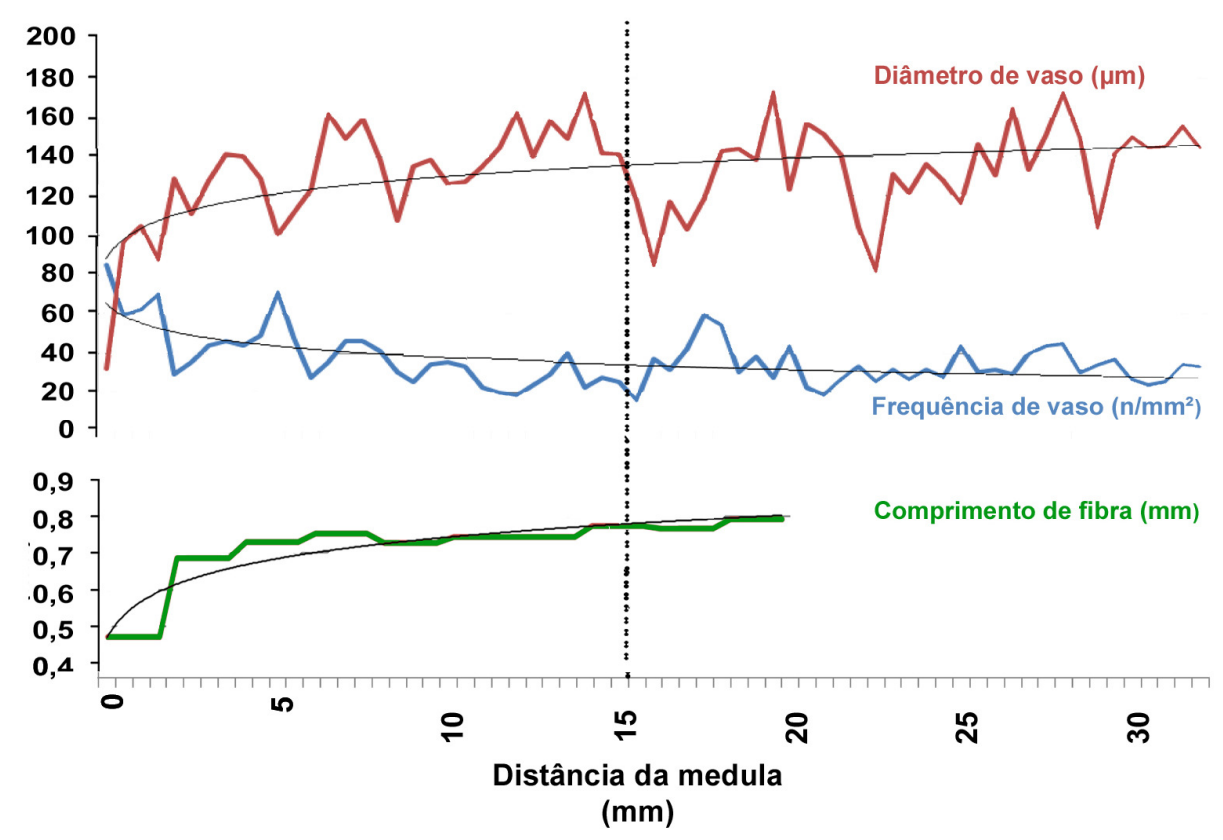

Figura 3: Gráficos elaborados para verificar a distância da medula na qual as variáveis diâmetro tangencial de vaso (A) e frequência (B) de vasos e comprimento de fibras (C) se estabilizam.

Para as 20 amostras de Myroxylon peruiferum L.f. utilizadas nos estudo de anatomia ecológica, entretanto, o diâmetro tangencial de vaso mostrou correlação estatisticamente significativa com o DAP dos indivíduos coletados, revelando uma condição onde, segundo Baas (comunicação pessoal), a espessura do tronco dos indivíduos influenciaria a anatomia das amostras, mostrando que, mesmo com troncos de grande diâmetro, ainda se tem influência do estágio de crescimento nas características anatômicas e, assim, impossibilitando a comparação entre indivíduos.

Contudo, esta correlação é influenciada principalmente pelos indivíduos coletados em RN, que se apresentavam muito injuriados pela a extração de "bálsamo de tolú” e, frequentemente, com mais de um tronco principal. Essa excepcionalidade local acabou por tornar significativa a correlação de Dv com o DAP e, quando se exclui as amostras de RN, a significância estatística se desfaz (figura 4). 


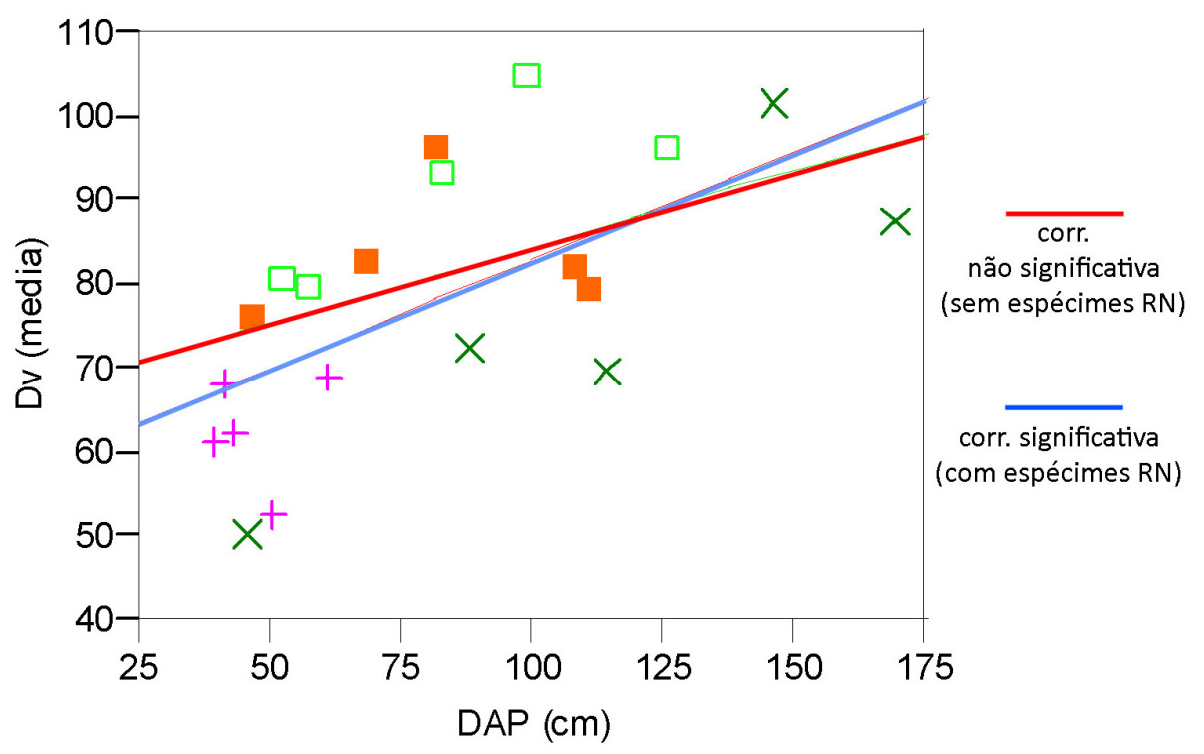

Figura 4: Correlação de Dv e DAP $(\alpha=0,05)$. Legenda: + -RN; $X$-RP; $\square$-ES; $\square$-SP.

Para complementar os indícios de independência das variáveis DAP e DV, foi analisado o diâmetro dos vasos de cada uma das 20 amostras de Myroxylon peruiferum L.f. ao longo do eixo radial. O resultado obtido revelou a ausência de correlação estatística em 19 amostras (95\%), sustentando ainda mais que a variável anatômica é independente do DAP e sua correlação com Dv é, possivelmente, influenciada por variáveis climáticas que, além de restringirem o DAP, restringem também o calibre dos vasos em ambientes com muito déficit hídrico ou mesmo pelo acaso. A correlação significativa da variável climática PA tanto com o Dv quanto com o DAP exemplifica e sustenta a interpretação das duas variáveis anatômicas serem dependentes de variáveis climáticas e suas correlações podem ocorrer mesmo que sejam independentes entre si.

Deste modo, a prerrogativa de que as amostras utilizadas para o estudo anatômico-ecológico não são influenciadas pelo DAP foi aceita, permitindo o trabalho com os 20 indivíduos de Myroxylon peruiferum L.f. amostrados nos quais o DAP variou entre 39 e $169 \mathrm{~cm}$ (tabela 1$)$.

\subsubsection{DiFERENÇA NA ANATOMIA DE GALHO E DE TRONCO}

Os galhos e troncos dos indivíduos SP1, SP2, SP4 foram amostrados na região mais próxima ao câmbio, consideradas lenho maduro pelo estudo anterior. Os resultados são apresentados na tabela 4 e não mostram uma conformidade nas relações entre a anatomia do lenho maduro de galho e tronco. Eles mostram que, para o espécime SP1, o galho apresentou um Dv médio maior em $21 \%$ do que no tronco. Para o espécie SP4, o 
galho apresentou um Dv médio menor do que no tronco, em 42\%. Por fim, o indivíduo SP2 não apresentou diferenças significativas.

Estes resultados mostram que a anatomia do galho, mesmo que maduro, pode apresentar diferenças do lenho do tronco do mesmo indivíduo. Contudo, as relações entre a anatomia das duas estruturas do xilema secundário não mostraram uma tendência muito contundente de redução no diâmetro do vaso nos galhos, mesmo que bem desenvolvidos. Em vista destes resultados, a interpretação paleoclimática, utilizando Dv de lenhos fósseis dos quais não se sabe a estrutura de origem, deve ser inferida com cautela pois, mesmo não encontrando tendência anatômica, em duas amostras foram obtidas médias estatisticamente diferentes.

Tabela 4: média de diâmetro tangencial de vaso mensurado no lenho maduro de galho e tronco do mesmo indivíduo e o resultado do teste $\mathrm{T}(*=$ diferença significativa; $\mathrm{ns}=$ não significativa $)$

\begin{tabular}{cccc}
\hline Amostra & Dv - Galho $(\boldsymbol{\mu m})$ & Dv -Tronco $(\boldsymbol{\mu m})$ & teste $\mathbf{T}(\boldsymbol{\alpha}=\mathbf{0 , 0 5})$ \\
\hline SP1 & 63,43 & 80,59 & $*$ \\
SP2 & 92,16 & 92,98 & $\mathrm{~ns}$ \\
SP4 & 137,62 & 79,36 & $*$ \\
\hline
\end{tabular}

\subsubsection{ANÁLISE ANATÔMICO CLIMÁTICA}

\subsubsection{ANÁLISES BIVARIADAS}

A matriz de correlação (tabela 5) apresenta as variáveis climáticas e anatômicas que se correlacionam com significância estatística. DAP, Dv, Fr e $\mathrm{Pv}_{2-3}$, são as variáveis anatômicas que se correlacionam com o maior número de variáveis climáticas enquanto latitude (lat), índice de sazonalidade hídrica (ISH) e número de meses com temperatura abaixo da média anual (MTA) foram as variáveis climáticas mais correlacionadas. Os maiores coeficientes de correlação foram encontrados entre Dv e Pmin, Dv e lat, e $\mathrm{Pv}_{2-3}$ e Tmin (figura 5).

Entretanto, ao analisar as curvas de regressão, os valores de $\mathrm{r}^{2}$ são todos baixos, inferiores a 0,4 , consequência de um alto grau de dispersão dos dados internamente a cada grupo, e revelam que os pontos obtidos não se ajustam suficientemente à curva de regressão para que se possa ter uma razoável predição climática com os dados anatômicos dos fósseis. 

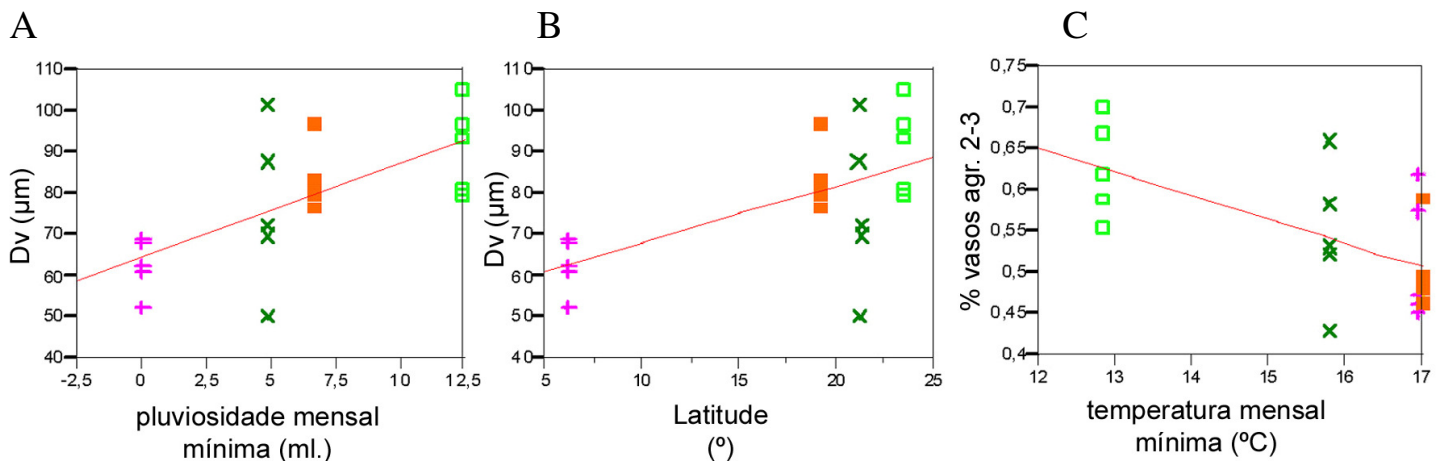

Figura 5: Correlações significativas $(\alpha=0,05)$ entre variáveis anatômicas e geoclimáticas, com as curvas de regressões lineares. Nos três gráficos se observa a grande variação anatômica das amostras provenientes de Ribeirão Preto.Legenda: + -RN; X-RP; _-ES; $\square$-SP.

Um dos fatores que influenciam estes baixos $\mathrm{r}^{2}$ é a grande variação anatômica dos espécimes de Ribeirão Preto (RP), que, deste modo, parecem não responder muito aos parâmetros climáticos regionais utilizados e devem receber influência de outras variáveis ambientais. Diferentemente das demais localidades, os espécimes de RP foram coletados em diversos ambientes na região metropolitana e rural do município. A variação anatômica encontrada pode refletir estes diferentes micro-habitats, não sendo possível extrair um padrão anatômico em nenhuma das variáveis mensuradas.

Quando as amostras de RP são desconsideradas da análise por não expressarem condições climáticas mais gerais do município, as correlações tornam-se mais fortes, com o $\mathrm{r}^{2}$ chegando a 0,7 em alguns casos. As relações mais nítidas observadas são entre Dv e Ata (Figura 7A) e entre Dv e ISH (figura 7B).

Cinco são as amostras fósseis que possuem medidas para Dv. As amostras datadas do Holoceno tardio, possuem Dv maiores, de 92 e $78 \mu \mathrm{m}$ respectivamente, enquanto as do Holoceno médio possuem entre 54 e $58 \mu \mathrm{m}$. Esta grande diferença de valores e, principalmente, os baixos valores para o Holoceno médio, trazem à discussão uma possível presença de lenho juvenil no material. Dentre as amostras fósseis, sabe-se apenas a procedência de RMT 1310, vinda de uma região muito distante da medula de tronco de um indivíduo de grande porte (DAP $>60 \mathrm{~cm}$ ) As outras amostras, contudo, vieram de fragmentos menores (figura 2), podendo ter vindo de galhos e, ainda, com presença de lenho juvenil. Importante notar que em nenhuma amostra foi encontrada medula. Assim, foram analisados os Dvs medidos no eixo radial das amostras e foi constatado que as medidas dos dois primeiros milímetros da amostra RMT 882 apresentavam valores ligeiramente abaixo dos milímetros subsequentes, que se apresentam mais estáveis (figura 6A). Esta região, portanto, foi desconsiderada da análise, utilizando-se apenas os valores subsequentes que indicam uma maior 
estabilidade. Com a amostra RMT 879, verificou-se também um ligeiro aumento de Dv ao longo dos 8 milímetros em direção radial mensurados (figura 6B). No último milímetro, os vasos tiveram valores médio maiores que os mm restantes. Deste modo, resolveu-se utilizar os dados do último mm da amostra RMT 879.

A

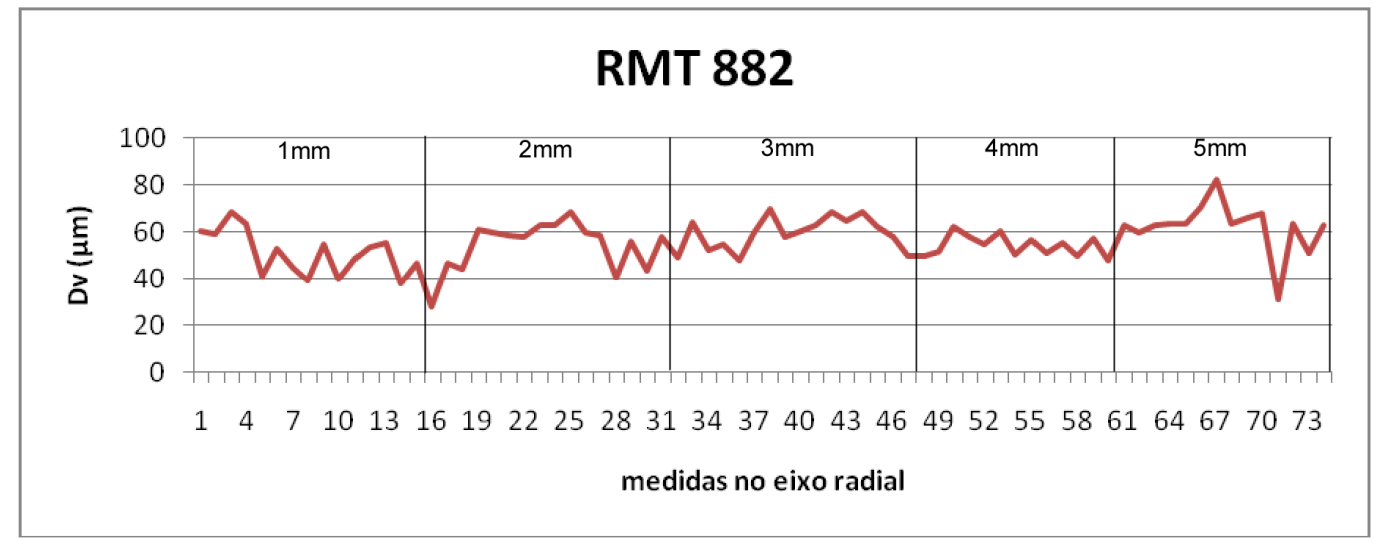

B

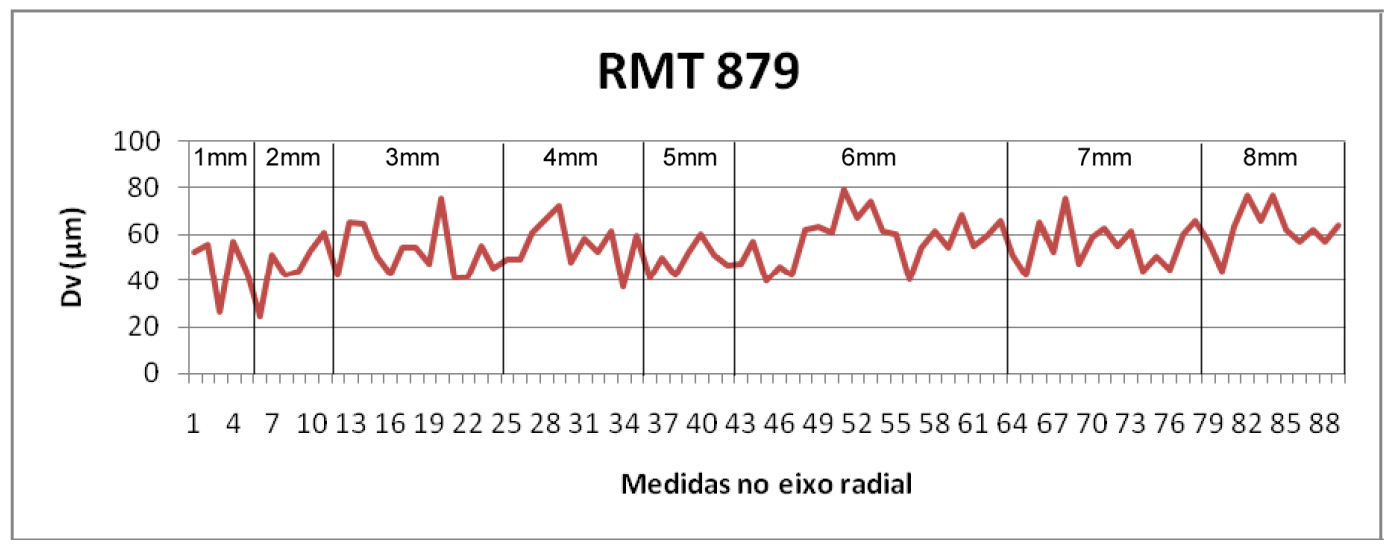

Figura 6: Diâmetro tangencial dos vasos das amostras ao longo do eixo radial. A. amostra RMT 882 mostra valores ligeiramente menores no $1^{\circ}$ e começo do $2^{\circ} \mathrm{mm}$. B. amostra RMT 879 mostrando valores ligeiramente menores nos primeiros $7 \mathrm{~mm}$.

Uma vez que foram obtidas correlações significativas entre a variável anatômica Dv e as climáticas ATA e ISH (tabela 5), os dados de Dv das amostras fósseis foram plotados, conjuntamente com as amostras atuais, em gráficos de Dv x ATA (figura 7a) e Dv ISH (figura 7b). Como resultado, foram observados dois regimes climáticos distintos para a região de Lagoa Santa durante o Holoceno: um Holoceno médio com amplitude térmica anual (ATA) entre 25,8 e $26,2^{\circ} \mathrm{C}$ e com $75 \%$ a $84 \%$ da chuva anual caída nos 3 meses mais úmidos do ano (ISH); e um Holoceno tardio com amplitude térmica anual entre 26,5 e $27,1^{\circ} \mathrm{C}$ e com 52 a $65 \%$ da chuva anual caída nos 3 meses mais úmidos do ano. 
A amplitude térmica anual atual da região de Lagoa Santa é $27^{\circ} \mathrm{C}$ e seu índice de sazonalidade hídrica é de $61 \%$. Portanto, as amostras fósseis indicam um Holoceno tardio com os parâmetros climáticos similares ao que temos atualmente na região, enquanto que os resultados para o Holoceno médio sugerem um clima com menor amplitude térmica e sazonalidade hídrica mais acentuada.

A

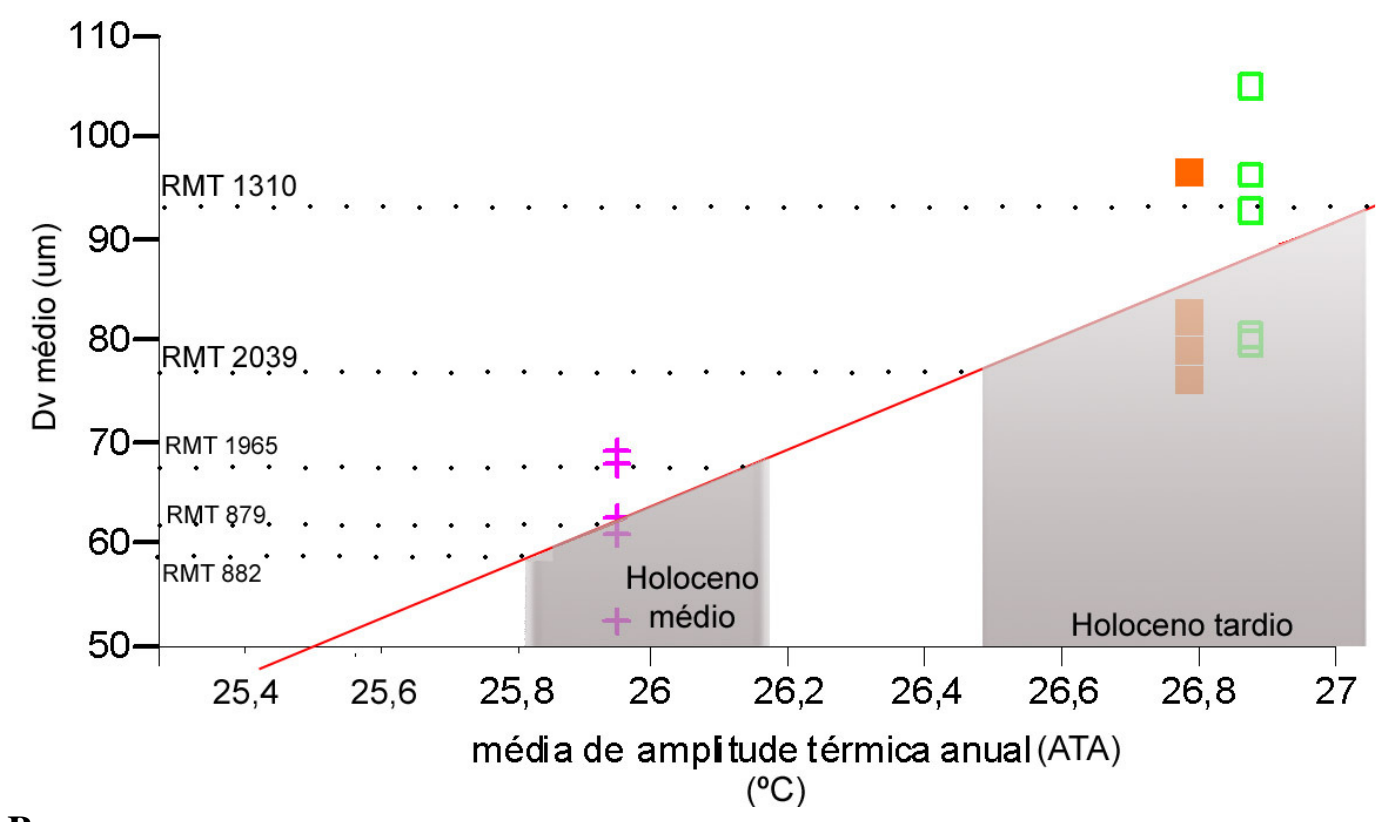

B

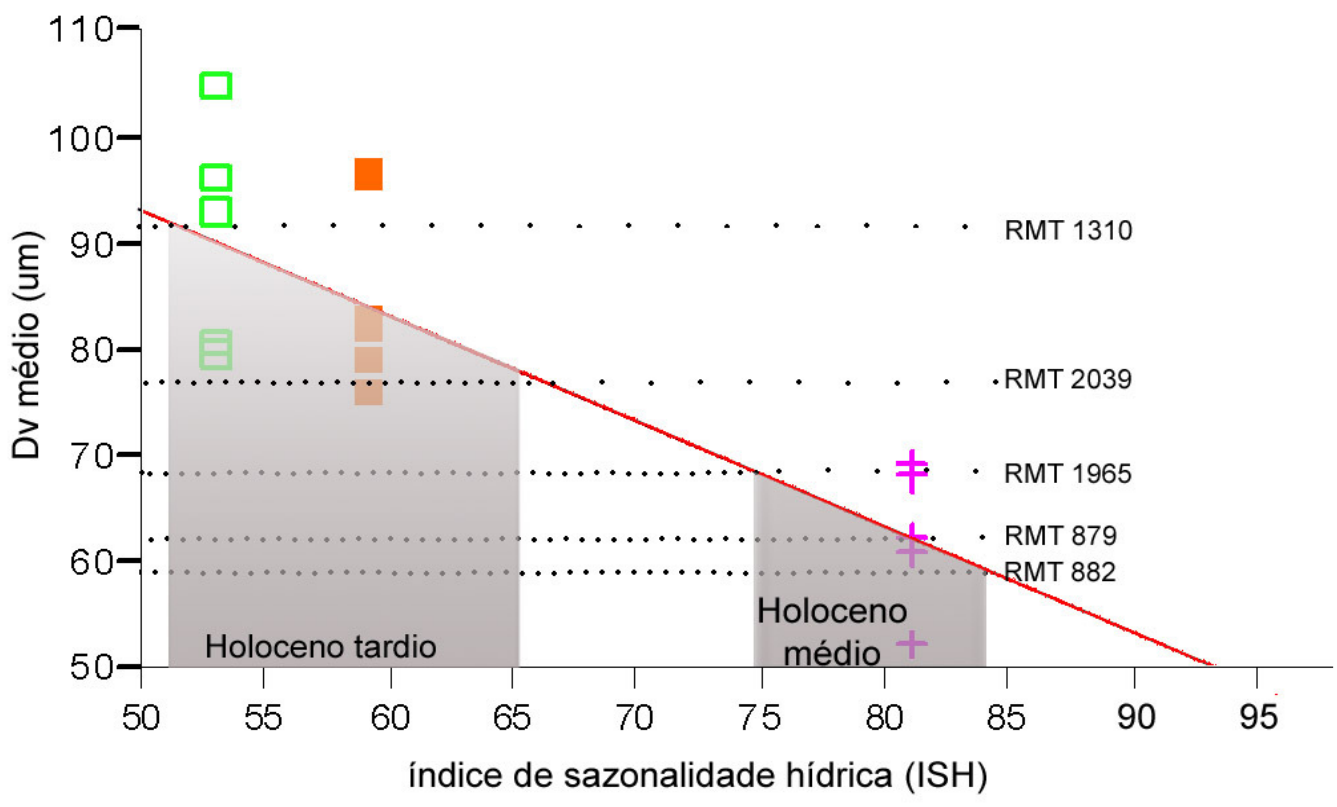

Figura 7: Predição de parâmetros climáticos para Lagoa Santa por meio dos valores Dv dos fós projetados na curva de regressão obtida com anatomia de espécimes viventes sob diferentes localida climáticas. A. Predição de amplitude térmica anual B. Predição de índice de sazonalidade hídrica. Leger +-RN; $\square$-ES; $\square$-SP. 


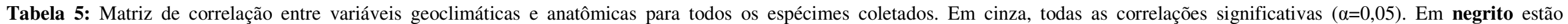
correlações significativas quando todos os espécimes foram inclusos. Com “*” estão as correlações significativas quando se exclui os espécimes de Ribeirão Preto.

\begin{tabular}{|c|c|c|c|c|c|c|c|c|c|c|c|c|c|c|c|c|c|}
\hline $\begin{array}{c}\text { Variáveis } \\
\text { anatômicas }\end{array}$ & Lat & Long & Alt & PA & Pmin & Pmax & $\mathrm{APa}$ & PAEC & NMEC & ISH & IST & Tmin & Tmax & TA & ATa & MTA & IC \\
\hline DAP & $0,53^{*}$ & 0,54 & 0,28 & 0,46 & $0,28 *$ & 0,02 & $-0,02$ & 0,46 & $0,52 *$ & $-0,53^{*}$ & 0,14 & $-0,18$ & 0,25 & 0,01 & $0,58^{*}$ & 0,52 & 0,00 \\
\hline Dv & $0,62^{*}$ & $0,42^{*}$ & 0,32 & $0,58 *$ & $0,67 *$ & 0,30 & 0,24 & $0,57^{*}$ & $0,61 *$ & $-0,62 *$ & $0,49 *$ & $-0,48^{*}$ & $-0,14$ & $-0,37$ & $0,11^{*}$ & 0,27 & $-0,39$ \\
\hline dpDv & 0,21 & 0,03 & 0,03 & 0,16 & 0,29 & 0,06 & 0,03 & 0,15 & 0,19 & $-0,21$ & 0,16 & $-0,14$ & $-0,05$ & $-0,12$ & $-0,11$ & 0,09 & $-0,13$ \\
\hline Fv & $-0,46 *$ & $-0,16$ & 0,20 & $-0,25$ & $-0,35$ & 0,26 & 0,31 & $-0,23$ & $-0,40$ & $0,48 *$ & 0,02 & $-0,03$ & $-0,39$ & $-0,18$ & $-0,17^{*}$ & $-0,58 *$ & $-0,16$ \\
\hline dpFv & $-0,51^{*}$ & $-0,25$ & 0,07 & $-0,34$ & $-0,40$ & 0,14 & 0,20 & $-0,32$ & $-0,46^{*}$ & $0,52 *$ & $-0,08$ & 0,08 & $-0,30$ & $-0,08$ & $-0,22^{*}$ & $-0,54^{*}$ & $-0,05$ \\
\hline $\mathrm{Fr}$ & $-0,31$ & $-0,32 *$ & $-0,45^{*}$ & $-0,4201^{*}$ & $-0,44$ & $-0,49 *$ & $-0,47^{*}$ & $-0,42^{*}$ & $-0,35$ & 0,29 & $-0,52 *$ & $0,52 *$ & 0,41 & $0,50 *$ & $-0,01$ & 0,13 & $0,51 *$ \\
\hline $\mathrm{dpFr}$ & $-0,37$ & $-0,29$ & $-0,20$ & $-0,33$ & $-0,31$ & $-0,09$ & $-0,06$ & $-0,32$ & $-0,36$ & 0,37 & $-0,20$ & 0,20 & $-0,04$ & 0,11 & $-0,21$ & $-0,26$ & 0,12 \\
\hline $\mathrm{Ar}$ & $0,48 *$ & $0,35^{*}$ & 0,31 & $0,45^{*}$ & $0,49 *$ & 0,20 & 0,16 & $0,44^{*}$ & $0,48^{*}$ & $-0,48^{*}$ & 0,35 & $-0,34$ & $-0,05$ & $-0,24$ & $0,15^{*}$ & 0,25 & $-0,26$ \\
\hline dpAr & $-0,58^{*}$ & $-0,44$ & $-0,19$ & $-0,48$ & $-0,45^{*}$ & $-0,05$ & 0,00 & $-0,47$ & $-0,56 *$ & $0,58 *$ & $-0,23$ & 0,24 & $-0,17$ & 0,08 & $-0,36^{*}$ & $-0,48$ & 0,10 \\
\hline Lr & 0,13 & 0,36 & 0,50 & 0,30 & 0,13 & 0,42 & $0,42^{*}$ & 0,31 & 0,19 & $-0,12$ & $0,34^{*}$ & $-0,37$ & $-0,31 *$ & $-0,35$ & 0,23 & $-0,15$ & $-0,34 *$ \\
\hline$d p L r$ & 0,18 & 0,46 & $0,57^{*}$ & 0,37 & 0,17 & $0,49 *$ & $0,51 *$ & 0,39 & 0,25 & $-0,16$ & 0,41 & $-0,44^{*}$ & $-0,35^{*}$ & $-0,42$ & 0,31 & $-0,16$ & $-0,41 *$ \\
\hline $\mathrm{Pv}_{\text {sol }}$ & 0,08 & $-0,15$ & $-0,48 *$ & $-0,14$ & $-0,06$ & $-0,50 *$ & $-0,53^{*}$ & $-0,15$ & 0,01 & $-0,10$ & $-0,37$ & 0,37 & $0,51 *$ & $0,45^{*}$ & 0,05 & $0,44^{*}$ & 0,44 \\
\hline $\mathrm{Pv}_{2-3}$ & 0,35 & $0,42 *$ & $0,56 *$ & $0,50 *$ & $0,48 *$ & $0,60 *$ & $0,59 *$ & $0,51 *$ & 0,40 & $-0,33$ & $0,61 *$ & $-0,62^{*}$ & $-0,49 *$ & $-0,60 *$ & 0,07 & $-0,17$ & $-0,60 *$ \\
\hline $\mathbf{P v}_{4-5}$ & $-0,18$ & 0,02 & 0,24 & $-0,05$ & $-0,14$ & 0,21 & 0,24 & $-0,04$ & $-0,14$ & 0,19 & 0,08 & $-0,09$ & $-0,24$ & $-0,15$ & $-0,01$ & $-0,29$ & $-0,14$ \\
\hline $\mathrm{Pv}_{6-7}$ & $-0,45$ & $-0,26$ & 0,01 & $-0,33$ & $-0,37$ & 0,06 & 0,11 & $-0,32$ & $-0,42$ & 0,46 & $-0,12$ & 0,12 & $-0,20$ & $-0,01$ & $-0,21$ & $-0,43$ & 0,01 \\
\hline$d p P v_{\text {sol }}$ & 0,04 & $-0,01$ & $-0,18$ & $-0,07$ & $-0,12$ & $-0,31$ & $-0,32$ & $-0,08$ & 0,01 & $-0,05$ & $-0,26$ & 0,25 & 0,36 & 0,32 & 0,19 & 0,30 & 0,32 \\
\hline$d p P v_{2-3}$ & $-0,18$ & $-0,02$ & 0,19 & $-0,06$ & $-0,11$ & 0,20 & 0,23 & $-0,05$ & $-0,14$ & 0,19 & 0,09 & $-0,09$ & $-0,25$ & $-0,16$ & $-0,07$ & $-0,30$ & $-0,15$ \\
\hline$d p P v_{4-5}$ & $-0,27$ & $-0,06$ & 0,25 & $-0,09$ & $-0,13$ & 0,31 & 0,34 & $-0,08$ & $-0,22$ & 0,28 & 0,15 & $-0,15$ & $-0,39$ & $-0,26$ & $-0,17$ & $-0,46 *$ & $-0,25$ \\
\hline $\mathrm{dpPv}_{6-7}$ & $-0,45$ & $-0,23$ & 0,06 & $-0,30$ & $-0,36$ & 0,10 & 0,15 & $-0,29$ & $-0,41$ & 0,45 & $-0,09$ & 0,09 & $-0,23$ & $-0,04$ & $-0,18$ & $-0,45^{*}$ & $-0,02$ \\
\hline
\end{tabular}

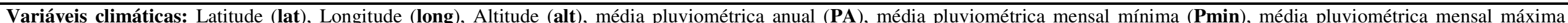

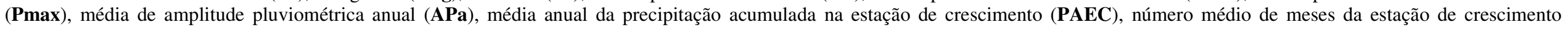

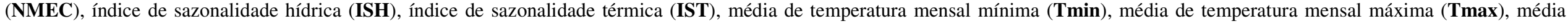

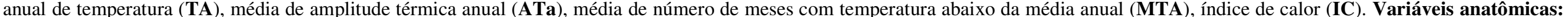

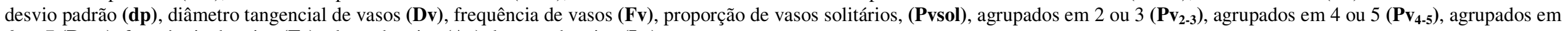
6 ou $7\left(\mathbf{P v}_{6-7}\right)$, frequência de raios $(\mathbf{F r})$, altura de raios $(\mathbf{A r})$, largura de raios $(\mathbf{L r})$. 


\subsubsection{ANÁLISES MULTIVARIADAS}

Inicialmente, para se trabalhar com muitas variáveis, é importante escolher quais serão utilizadas. Como o objetivo deste trabalho é entender as relações entre clima e anatomia da madeira, variáveis anatômicas que pouco se relacionam com o clima acabam confundindo as interpretações. Desta forma, optou-se por utilizar apenas variáveis que contribuem para a separação anatômica por localidades climáticas.

\subsection{ANÁLISE DE AGRUPAMENTO}

Para a análise de agrupamento, foram escolhidas as variáveis anatômicas mais correlacionadas com variáveis climáticas e consideradas independentes entre si: Dv, Fv, dpFv, Fr, dpAr, dpLr, $\mathrm{Pv}_{\text {sol }}, \mathrm{Pv}_{2-3}$. Os resultados estão apresentados na figura 8.

Como foi possível perceber já nas regressões simples, os espécimes de Ribeirão Preto apresentaram, entre si, muita variação anatômica e foram agrupados com espécimes de todas as localidades climáticas (Figura 8A). Estes espécimes, porém, não alteraram significativamente a hierarquização dos grandes agrupamentos, obtendo sucesso ao aglomerar os padrões anatômicos dos espécimes pelas localidades climáticas SP, ES e RN.

A única inconsistência encontrada foi o espécime RN1, agrupado com o indivíduo ES2 (figura 8A e B). Uma explicação possível para esta semelhança é que RN1 foi coletado do sopé da Serra do Estreito, onde possivelmente há maior disponibilidade de água e o solo é aparentemente mais profundo do que na vertente da serra. O indivíduos RN2, também coletado no sopé da serra, embora tenha sido agrupado junto com os outros representantes de sua localidade, apresentou a menor similaridade entre eles. Tal interpretação nos leva a considerar uma grande sensibilidade anatômico-adaptativa de uma mesma população em climas extremos, onde pequenas diferenças ambientais refletem diferenças anatômicas. 
A.
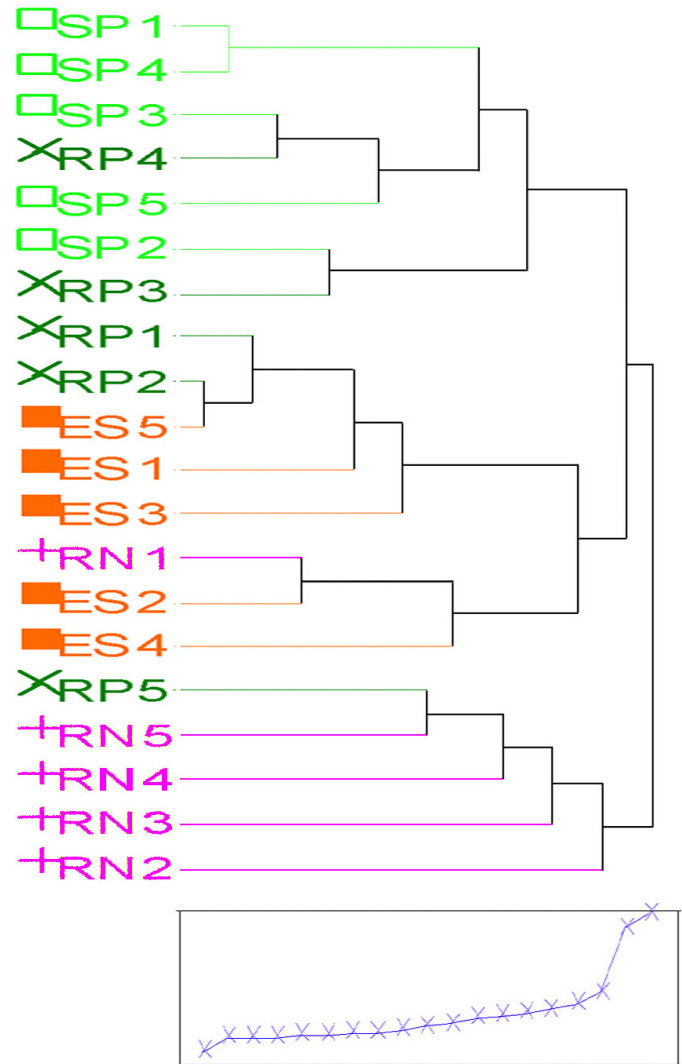

B.

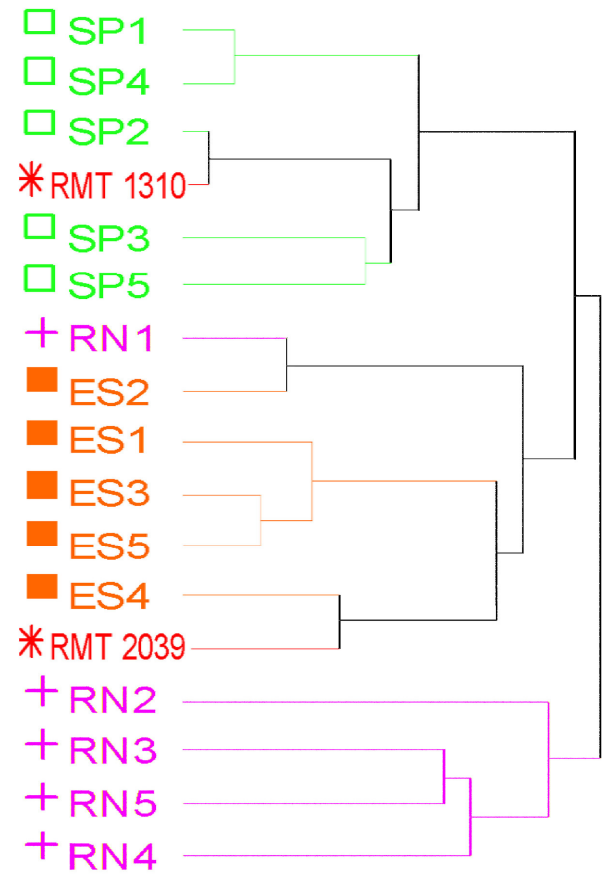

Figura 8: Dendrogramas obtidos utilizando variáveis anatômicas independentes (Dv, Fv, dpFv, Fr, dpAr, dpLr, $\mathrm{Pv}_{\mathrm{sol}}, \mathrm{Pv}_{2-3}$ ), algoritmo de ligação completa e distância euclidiana. A. Sem amostras fósseis. B. Com amostras fosseis e sem amostras de RP, para facilitar a visualização dos grupos formados. Legenda: + . RN; X-RP; $\square$-ES; $\square$-SP; 米-fóssil Holoceno tardio.

As únicas amostras fósseis com medidas para todas as variáveis anatômicas utilizadas nesta análise foram as RMT1310 e RMT 2039, datadas do Holoceno tardio e plotadas na figura $8 \mathrm{~B}$, onde os indivíduos de $\mathrm{RP}$ foram retirados para melhorar a visualização dos grupos. A amostra RMT 1310 mostrou-se mais similar às amostras de SP e a RMT-2039 mostrou maior similaridade com ES.

Esta análise, então, revela que a maior abrangência nos valores de ATa e ISH estimados para o Holoceno tardio de Lagoa Santa na análise bivariada tem sua explicação na razoável diferença anatômica das duas amostras fósseis do Holoceno tardio.

Analisando todos os resultados já obtidos, a amostra RMT 1310 se aproxima de padrões anatômicos de ambientes mais úmidos enquanto que a amostra RMT2039 se assemelha com ambientes mais sazonais, como de Linhares, ES ou mesmo com o clima atual de Lagoa Santa, MG. 
Tal resultado não era esperado, visto que duas amostras da mesma localidade e período deveriam ter padrões anatômicos similares que as agrupassem, ao menos, no mesmo grande grupo. Mas como se viu na figura 7, na análise bivariada, a amostra RMT 2039 já apresentava valores diferentes para Dv em comparação com RMT 1310. Na análise de agrupamento, contudo, esta diferença se mostrou não só para Dv, mas também para outras variáveis consideradas.

A diferença anatômica das duas amostras pode ser explicada por uma diferença local de onde viveram. A amostra RMT1310 pertence a um espécime de grandes dimensões (12 de altura e CAP $>1,5 \mathrm{~m}$ ) soterrado no lado direito do afloramento. Tais dimensões sugerem que o exemplar foi soterrado in-situ e, uma vez inferido que tal soterramento se deu por processos aluviais de sedimentação, é muito provável que o exemplar viveu próximo, senão à beira, do Ribeirão da Mata, tendo em sua anatomia influência de um solo com umidade sempre presente. A maior similaridade de sua anatomia com os espécimes de São Paulo, sob clima mais úmido e de déficit hídrico quase ausente, pode ter significativa influência deste aspecto edáfico. Por outro lado, a amostra RMT 2039, retirada de um fragmento de menor dimensão que RMT 1310, e que poderia ter se deslocado consideravelmente até o local onde foi sedimentado, mostrou uma anatomia similar a espécimes de clima mais sazonal (ES), o que seria esperado se fossem encontrados indivíduos de $M$. peruiferum viventes atualmente em Pedro Leopoldo, MG, em solos em que a umidade refletisse a sazonalidade climática.

\subsection{ANÁLISE DISCRIMINANTE (AD)}

\subsection{HOLOCENO TARDIO}

As variáveis anatômicas utilizadas nesta análise foram: $\mathrm{Pv}_{2-3}, \mathrm{Pv}_{6-7}, \mathrm{dpPv}_{\mathrm{sol}}, \mathrm{dpPv}_{2-3}$, dpFv, Ar, dpAr e Fr. Elas foram escolhidas utilizando o método Stepwise (Mingot, 2005) e também por meio de combinações feitas manualmente.

Com esta combinação de variáveis, a função de discriminação obtida classificou corretamente a localidade climática de 19 amostras coletadas, sendo o único erro, a amostra SP2, classificada como proveniente de RP. Este dado já era previsto, uma vez que as amostras de RP possuem grande variabilidade anatômica e se aproximam de amostras de praticamente todas as localidades climáticas amostradas (figura 8). Mesmo assim, a análise mostrou uma precisão de $95 \%$, revelando um elevado poder de discriminação que 
propicia resultados confiáveis. Quando colocadas as amostras fósseis RMT 1310 e RMT 2039 na análise, as únicas que possuem todas as variáveis mensuradas, elas são classificadas como pertencentes ao padrão da localidade do ES (figura 9).

Entretanto, pode-se notar um considerável distanciamento dos fósseis com as demais amostras, mesmo as de ES. Analisando os vetores da figura 9, nota-se grande participação da variável Ar, que é a principal força que distancia as amostras fósseis no eixo 1. Esta variável recebe bastante peso na regra discriminante por facilitar a delimitação do grupo RP, mas acaba distanciando muito as amostras fósseis dos outros padrões, ficando o padrão ES o menos distante. Quando excluídos os espécimes de RP e a variável Ar da análise, a predição correta entre as 15 amostras não fósseis fica em $100 \%$ e as amostras fósseis são classificadas como SP (figura 10). Enquanto a confiabilidade da classificação de RMT 1310 é 100\% a da RMT2039 é de 80\%. Com é possível ver, as amostras fósseis, segundo tais características anatômicas, se localizam dentro da variação encontrada em SP.

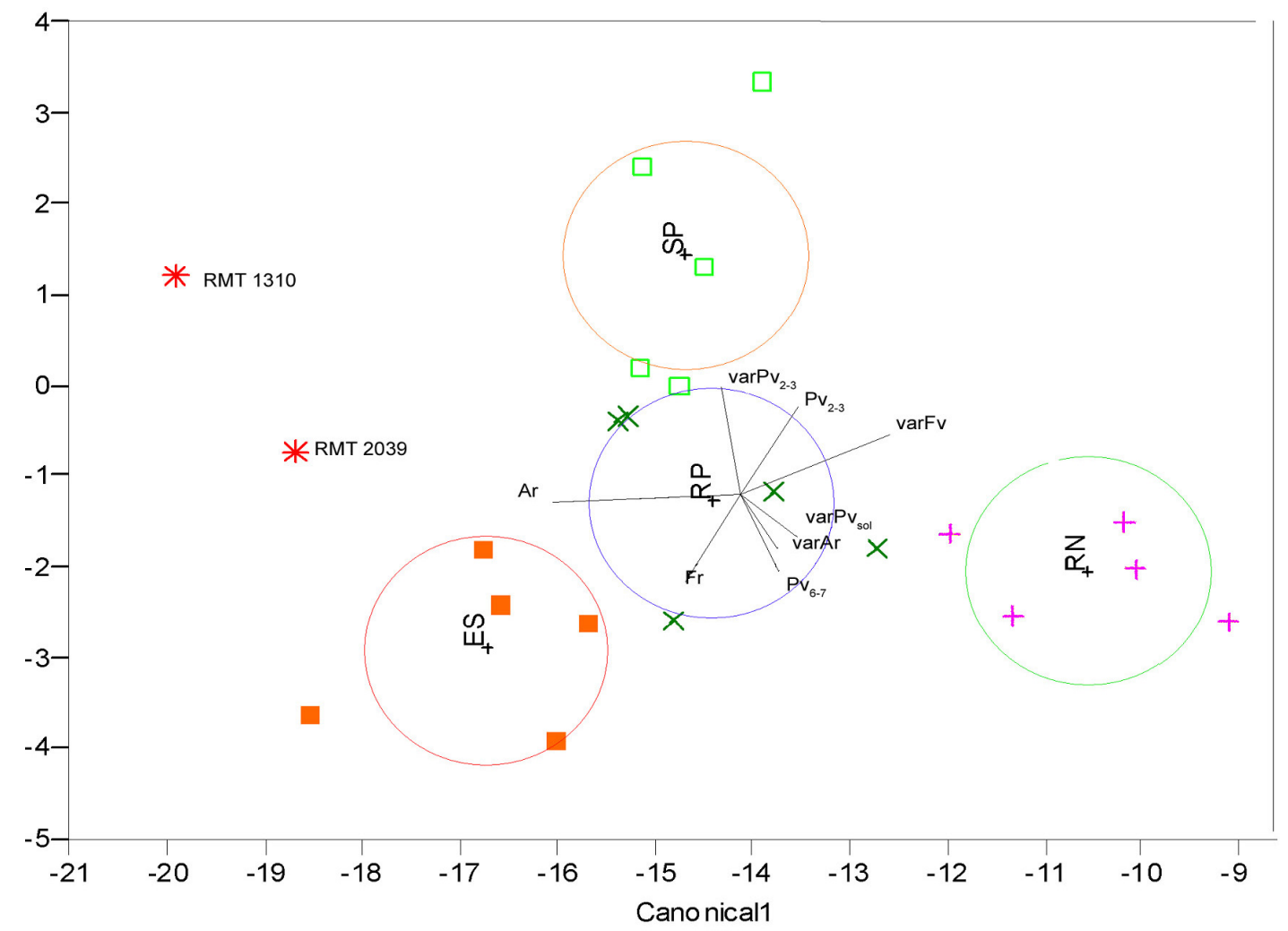

Figura 9: Análise discriminante com predição correta para 95\% das 20 amostras, incluindo as amostras de Ribeirão Preto, SP. A grande influência da variável Ar ocasiona o deslocamento das amostras fósseis para menores valores do eixo canônico 1, distanciando-os dos padrões das amostras atuais. Fósseis classificados como ES. Legenda: vetores indicam a influência de cada variável anatômica utilizada; † -RN; $X$-RP; ES; $\square$-SP; * *-fóssil Holoceno tardio. 


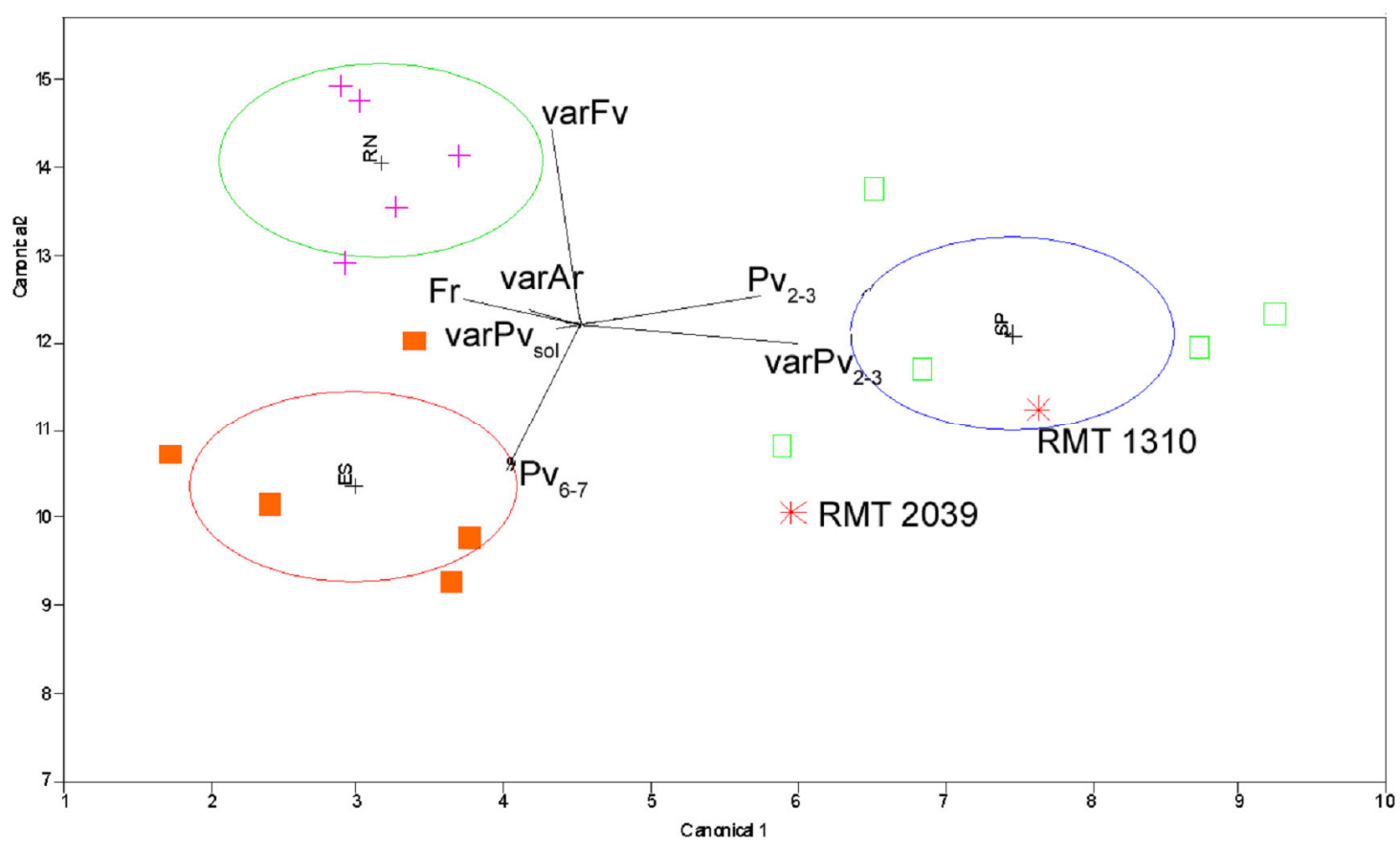

Figura 10: Análise discriminante sem amostras de Ribeirão Preto e a variável Ar. Predição correta para 100\% das 15 amostras atuais. Fósseis classificados como SP. Legenda: vetores indicam a influência de cada variável anatômica utilizada; + -RN; $\square$-ES; $\square$-SP; * *-fóssil Holoceno tardio.

Utilizando as variáveis que foram mensuradas para RMT 938, também datada do Holoceno tardio, as duas melhores funções discriminantes, com $85 \%$ de classificações corretas, classificaram a amostra como pertencente ao grupo RP (figura 11). Entretanto, principalmente os padrões anatômicos de SP e RP, com estas variáveis anatômicas, ficam muito interseccionados, não propiciando um resultado muito sustentado. Mesmo o padrão ES intersecciona com SP e RP. Deste modo, a classificação da discriminante dá 59\% de probabilidade de ser RP, 32\% SP e 15\% ES. Desta forma, é mais prudente considerar a amostra RMT938 com um padrão relacionado às localidades climáticas do sudeste brasileiro ligeiramente mais próximo de climas com déficit hídrico menos acentuado, como São Paulo e Ribeirão Preto. O resultado para esta amostra é importante, por se tratar de um lenho de tamanho similar à amostra RMT 2039, porém com anatomia ligeiramente diferente.

Desta forma, as amostras fósseis do Holoceno tardio de Lagoa Santa apresentaram um padrão anatômico coerente que as associa ao padrão anatômico de indivíduos atualmente viventes sob climas mais úmidos ou, ao menos, com déficit hídrico meno 
intenso como em São Paulo e Ribeirão Preto, embora tenham sido percebidas semelhanças pontuais com a anatomia de espécimes de Linhares, ES.

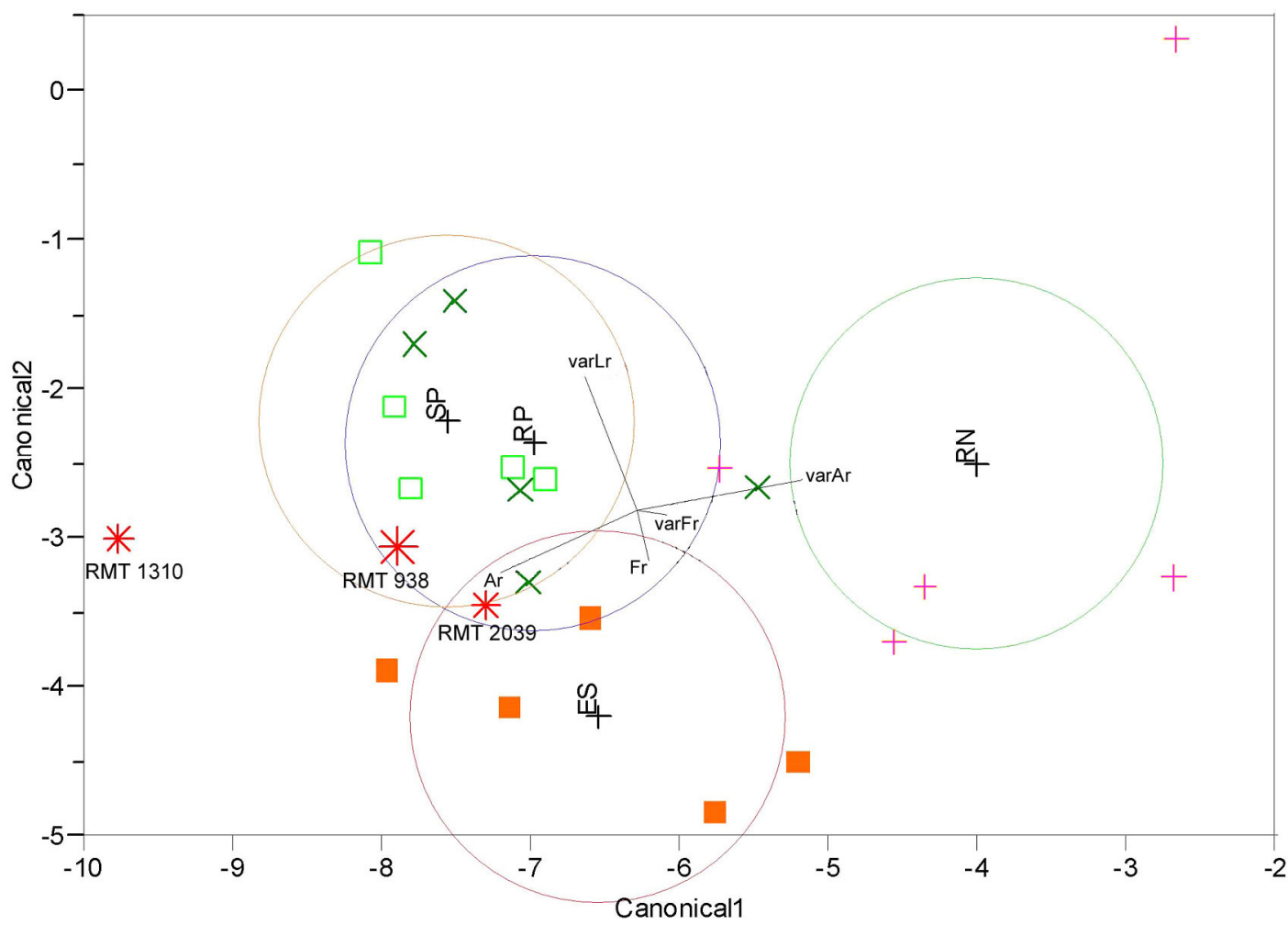

Figura 11: Análise discriminante com $85 \%$ de predições corretas realizada para classificar a amostra RMT 938, datada do Holoceno tardio. Os vetores indicam a influência de cada variável anatômica utilizada. Legenda: + -RN; X-RP; $\square$-ES; $\square$-SP; * *-fóssil Holoceno tardio;

\subsection{HOLOCENO MÉDIO}

As amostras fósseis datadas do Holoceno médio apresentaram ainda maior degradação anatômica e, sendo assim, o menor número de variáveis mensuradas (tabela 2), o que causou menores potenciais preditivos nas análises discriminantes. A amostra que teve maior confiabilidade na análise foi a amostra RMT 882, com 85\% de predição correta, levando-se em conta as variáveis Dv, Fv, dpFv, Ar, dpAr e dpLr (figura 12). Nesta análise, os círculos de ES e RN ficaram nitidamente delimitados, não havendo nenhum erro de classificação entre seus espécimes. A fragilidade da análise está na classificação das localidades SP e RP, que ficaram muito interseccionadas. Neste contexto, a amostra foi classificada como pertencente ao grupo ES, com $97 \%$ de confiança. Este resultado é muito 
consistente, visto que o grupo ES está bem delimitado e a amostra fóssil está representada próxima aos demais espécimes do grupo.

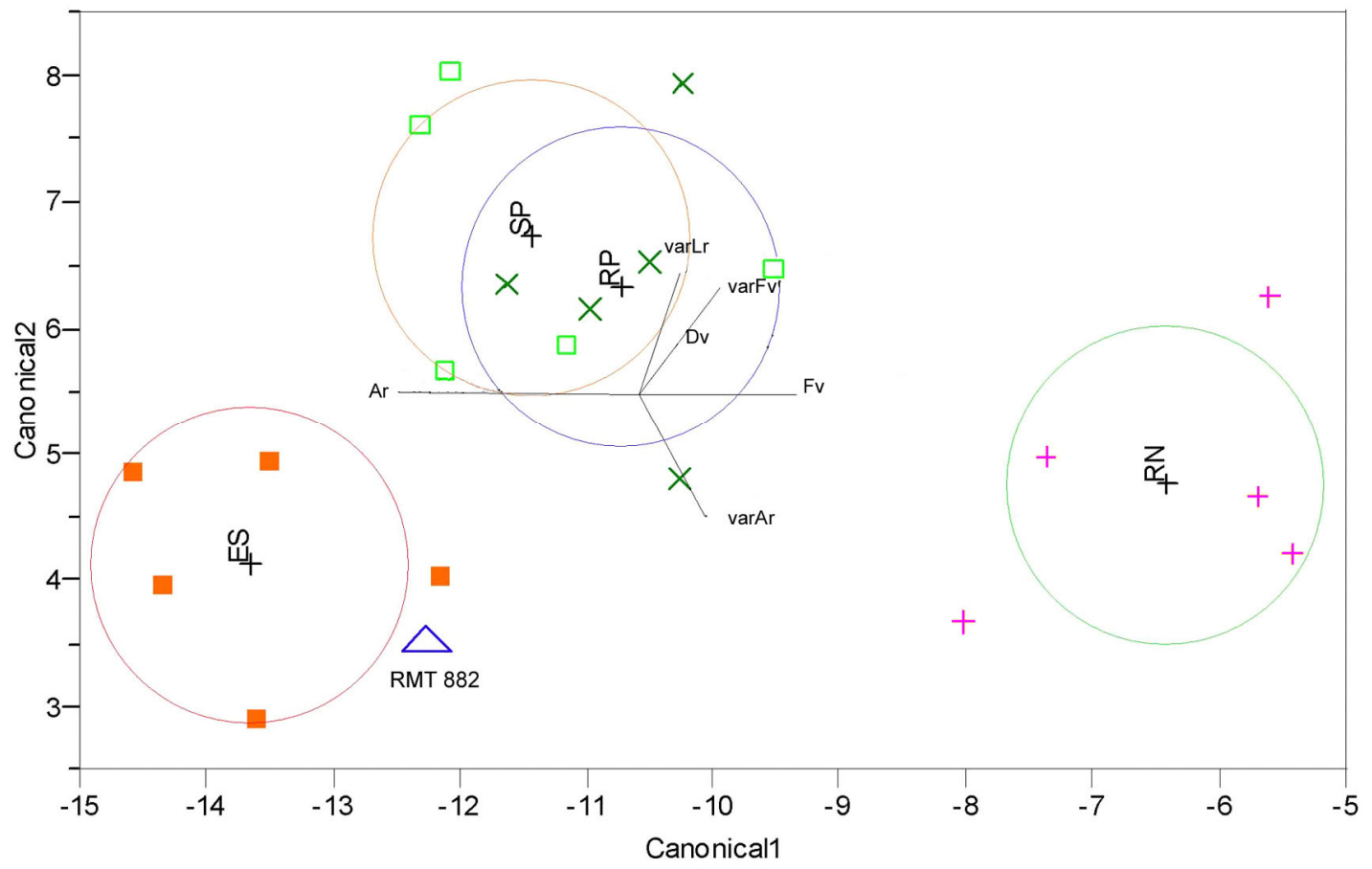

Figura 12: Análise discriminante com $70 \%$ de predições corretas realizada para classificar a amostra RMT 882, datada do Holoceno médio. Os vetores indicam a influência de cada variável anatômica utilizada. Legenda: + -RN; X-RP; $\square$-ES; $\square$-SP; $*$-fóssil Holoceno tardio; $\triangle$-fóssil Holoceno médio.

O poder de predição das demais amostras (RMT 1965 e RMT 879) foi muito prejudicado pelo ainda mais baixo número de variáveis possíveis (tabela 2). A predição de RMT 1965 obteve 70\% de acertos, mas nenhuma localidade climática foi bem delimitada, havendo muita intersecção de seus padrões anatômicos. Foram utilizadas apenas as variáveis Fv e Dv. Como resultado, a amostra foi classificada como RN assim como RMT 882, outrora classificada como ES em análise muito mais confiável. Esta análise, portanto, fica bastante prejudicada, pois as poucas variáveis não foram utilizadas nas outras análises por não delimitarem bem as localidades climáticas. Para a amostra RMT 879, o poder discriminante foi ainda menor, de forma que os resultados também não podem ser considerados. 


\subsection{CONSIDERAÇÕES FINAIS}

A anatomia do lenho de Myroxylon peruiferum L.f. mostrou um padrão bastante complexo, principalmente na localidade de Ribeirão Preto, SP, onde a enorme variação das características anatômicas foi interpretada como influência de outros fatores externos, que não as condições climáticas regionais de cada município. Mesmo considerando esta variação interna em Ribeirão Preto, muitas foram as variáveis anatômicas e climáticas correlacionadas estatisticamente. Entretanto, foi necessário excluir estas amostras para que as correlações apresentassem uma aproximação à curva de regressão suficiente para poder se fazer predições climáticas com a anatomia das amostras fósseis. As correlações de diâmetro de vaso com amplitude térmica anual e com índice de sazonalidade hídrica indicaram diferenças climáticas significativas para Lagoa Santa, MG, durante os últimos 5000 anos A.P. Um Holoceno médio bastante estacional em termos pluviométricos, e um Holoceno tardio de "muito úmido" a "pequeno déficit hídrico", como ocorre atualmente na região. Enquanto para o Holoceno tardio os resultados parecem corroborar com os trabalhos publicados na literatura (Behling, 2003; Ledru, 1993; Parizzi et al., 1998; Raczka, 2009), os resultados para o Holoceno médio corroboram com Ledru (1993), que encontrou evidências sedimentares e palinológicas de um intenso evento árido de curta duração em Salitre, MG.

Por outro lado, as análises multivariadas conseguiram encontrar padrões anatômicos coerentes entre os espécimes de cada localidade. Foram formados grupos anatômicos coesos para cada localidade climática (exceto para os espécimes de Ribeirão Preto), revelando assim diferenças anatômicas possivelmente influenciadas pelas condições climáticas regionais.

Tais análises não revelaram uma diferença tão pronunciada no clima do Holoceno médio e tardio como a análise baseada apenas na variável diâmetro de vaso. Tampouco revelaram uma aproximação dos fósseis do Holoceno médio com a anatomia de espécimes do semiárido potiguar. A única amostra fóssil do primeiro período passível de ser analisada se assemelha fortemente com o padrão anatômico dos espécimes sob clima de Linhares, ES. No caso das amostras do Holoceno tardio, as análises multivariadas mostraram um padrão mais semelhante com o encontrado em espécimes de São Paulo e Ribeirão Preto mas também com similaridades pontuais com Linhares, ES, resultado este que seria 
esperado para amostras atuais de $M$. peruiferum da região de Lagoa Santa, MG, se tivessem sido amostrados.

Sendo assim, o conjunto dos resultados obtidos não sugere uma mudança significativa no regime climático em Lagoa Santa nos últimos 5000 anos A.P., mas indícios de uma sazonalidade ligeiramente maior durante o Holoceno médio foram encontrados, mostrando que o evento de seca apontado por Ledru (1993) pode ter ocorrido, embora não tenha-se mostrado tão intenso quanto os resultados da autora.

\subsection{REFERÊNCIAS BIBLIOGRÁFICAS}

AGRITEMPO. 2002-2009. Agritempo: Sistema de Monitoramento Agrometereológico. E. I. E. AGROPECUÁRIA: <http://www.agritempo.gov.br/>. Acessado em 05/05/2009.

ALVES, E. S. 1995. The effects of pollution in wood of Cecropia glazioui (Cecropiaceae). IAWA Journal, v.16, p.69-80.

ALVES, E. S. \& V. ANGYALOSSY. 2000. Ecological trends in the wood anatomy of some Brazilian species. 1. Growth rings and vessels. IAWA Journal, v.21, n.1, p.3-30.

ALVES, E. S. \& V. ANGYALOSSY. 2002. Ecological trends in the wood anatomy of some Brazilian species. 2. Axial parenchyma, rays and fibres. IAWA Journal, v.23, n.4, p.391-418.

ARAGAKI, S. \& W. MANTOVANI. 1998. Caracterização do clima e da vegetação de remanescente florestal no Planalto Paulistano (SP). In: WATANABE, S. (Coord.). Anais do IV Simpósio sobre Ecossistemas Brasileiros. São Paulo: Aciesp. p.25-36.

BAAS, P. 1973. Structural Variation in Secondary Xylem of 70 Species of Genus Ilex. Acta Botanica Neerlandica, v.22, n.3, p.248-248.

BAAS, P. 1982. Systematic, Phylogenetic and Ecological Wood Anatomy - History and Perspectives. Acta Botanica Neerlandica, v.31, n.5-6, p.501-501.

BAAS, P. et al. 1988. Wood Anatomy of the Oleaceae. IAWA Bulletin, v.9, n.2, p.103-182.

BAAS, P. et al. 2004. Evolution of xylem physiology. In: A. R. HEMSLEY \& I. POOLE (Ed.). The evolution of plant physiology: Elsevier Ltd. p.273-295.

BAAS, P. \& F. H. SCHWEINGRUBER. 1987. Ecological Trends in the Wood Anatomy of Trees, Shrubs and Climbers from Europe. IAWA Bulletin, v.8, n.3, p.245-274.

BAAS, P. \& X. Y. ZHANG. 1986. Wood Anatomy of Trees and Shrubs from China .1. Oleaceae. IAWA Bulletin, v.7, n.3, p.195-220.

BARAJAS-MORALES, J. 1985. Wood structural differences between trees of two tropical forests in Mexico. IAWA Bulletin, v.6, n.4, p.355-364. 
BEHLING, H. 2003. Late glacial and Holocene vegetation, climate and fire history inferred from Lagoa Nova in the southeastern Brazilian lowland. Vegetation History and Archaeobotany, v.12, n.4, Dec, p.263-270.

CARLQUIST, S. 1966. Wood anatomy os compositae: a summary, with comments on factor controlling wood evolution. Aliso, v.6, p.25-44.

CARLQUIST, S. 1977. Ecological factors in wood evolution: a floristic approach. American Journal of Botany, v.64, p.887-896.

CECCANTINI, G. 1996. Anatomia ecológica do lenho de cerrado e mata: Casearia silvetris Sw. e Machaerium villosum Vog. . Depto. Botânica, Universidade de São Paulo, São Paulo,

CHIMELO, J. P. \& A. MATTOS-FILHO. 1988. Preliminary wood structure observation of five hard-woos species from diferent sites in Brazil. In: Annals of $5^{\circ}$ Conference International Union of Forestry Research Organization. São Paulo. p.100.

COSTA NETO, P. L. O. 1977. Estatística. São Paulo: Edgar Blücher

DICKISON, W. C. \& K. D. PHEND. 1985. Wood Anatomy of the Styracaceae Evolutionary and Ecological Considerations. IAWA Bulletin, v.6, n.1, p.3-22.

ENGEL, V. L. 2000. Estudo fenológio de espécies arbóreas de uma floresta tropical em Linhares - ES. Tese de Doutorado. Universidade de Campinas, Campinas,

FEBRUARY, E. C. 1994. Rainfall Reconstruction Using Wood Charcoal from 2 Archaeological Sites in South-Africa. Quaternary Research, v.42, n.1, Jul, p.100-107.

FRANKLIN, G. L. 1946. A rapid method of softering wood for microtome sectioning. Tropical Woods, v.88, n.35.

GOMES, E. P. C. 1992. Fitossociologia do componente arbóreo de um trecho de mata em São Paulo, SP. Dissertação de Mestrado. Universidade de São Paulo, São Paulo,

IBGE. 2004. Mapa de biomas do Brasil. Escala 1:5.000.000. Rio de Janeiro: IBGE. 20010: Disponível em: <http://mapas.IBGE.gov.br/biomas2/> p.

IPT. 2000. Diagnóstico da situação atual dos Recursos Hídricos e estabelecimento de diretrizes técnicas para elaboração do Plano da Bacia Hidrográfica do rio Pardo Relatório Zero. Instituto de Pesquisas Tecnológicas. São Paulo, SP. 2000

JONO, V. Y. 2009. Anatomia ecológica do lenho e atividade cambial do lenho de Roupala rhombifolia (Proteaceae) na Serra do Cipó (MG). Dissertação de Mestrado. Depto. Botânica, Universidade de São Paulo, São Paulo, 75 p.

KÖPPEN, W. 1948. Climatologia: con un estudio de los climas de la tierra. México: Fondo de Cultura Econômica. 479p p.

KOTCHETKOFF, H. O. 2003. Caracterização da Vegetação Natural de Ribeirão Preto, SP: Bases para Conservação. Tese de doutorado. Universidade de São Paulo, Ribeirão Preto,

KRAUS, J. E. \& M. ARDUIN. 1997. Manual Básico de Métodos em Morfologia Vegetal. Seropédia, RJ, Brasil: EDUR

LEDRU, M. P. 1993. Late Quaternary Environmental and Climatic Changes in Central Brazil. Quaternary Research, v.39, n.1, Jan, p.90-98. 
LEPSCH, I. F. 1972. Classificação e mapeamento dos solos de São Paulo. In: A. C. MONIZ (Ed.). Elementos de pedologia. São Paulo: Polígono. p.377-390.

LUCHI, A. E. 2004. Anatomia do lenho de Croton urucurana Baill. (Euphorbiaceae) de solos com diferentes níveis de umidade. Revista Brasileira de Botânica, v.27, n.2, p.271-280.

MAHERALI, H.;W. T. POCKMAN \& R. B. JACKSON. 2004. Adaptive variation in the vulnerability of woody plants to xylem cavitation. Ecology, v.85, n.8, Aug, p.21842199.

MANTOVANI, W. 1993. Estrutura e dinâmica da floresta atlântica na Juréia, Iguape-SP. Tese de Livre-Docência. Universidade de São Paulo, São Paulo.

MARCATI, C. R.;V. ANGYALOSSY \& L. BENETATI. 2001. Anatomia comparada do lenho de Copaifera langsdorffii Desf. (Leguminosae-Caesalpinoideae) de floresta e cerradão. Revista Brasileira de Botânica, v.24, p.311-320.

MELO JR, J. C. F. 2003. Anatomia ecológica da folha e do leho de Copaifera Langsdorffii Desf. (Leguminosae) do Parque Estadual do Cerrado, Jaguariaíva - PR. Tese de Mestrado. Depto. Botânica, Universidade Federal do Paraná, Curitiba, 73 p.

MINA-RODRIGUES, E. M. C. 1986. Estudo morfo-anatômico dos órgãos vegetativos de Pera glabrata Baill. (Euphorbiaceae), em material procedente de mata mesófila semidecídua e de cerrado. Dissertação de Mestrado. Universidade Estadual Paulista, São Paulo,

MINGOTI, S. A. 2005. Análise de dados através de métodos de estatística multivariada: uma abordagem aplicada. Belo Horizonte: Editora UFMG: 297 p.

NOSHIRO, S. \& P. BAAS. 1998. Systematic wood anatomy of cornaceae and allies. IAWA Journal, v.19, n.1, p.43-97.

NOSHIRO, S. \& P. BAAS. 2000. Latitudinal trends in wood anatomy within species and genera: Case study in Cornus SL (Cornaceae). American Journal of Botany, v.87, n.10, Oct, p.1495-1506.

OLIVEIRA, J. B. 1972. Princípios básicos para classificação e sinopse dos principais grandes grupos de solos do mundo. In: A. M. MONIZ (Ed.). Elementos de Pedologia. São Paulo: Editora Poligono. p.357-362.

PARIZZI, M. G.;M. L. SALGADO-LABOURIAU \& H. C. KOHLER. 1998. Genesis and environmental history of Lagoa Santa, southeastern Brazil. Holocene, v.8, n.3, May, p.311-321.

PEIXOTO, A. L. \& A. GENTRY. 1990. Diversidade e composição florística da mata de tabuleiro na Reserva Florestal de Linhares (Espírito Santo, Brasil). Revista Brasileira de Botânica, v.13, p.19-25.

RACZKA, M. F. 2009. Mudanças paleoambientais quaternárias na região de Lagoa Santa, MG, Brasil: a palinologia como subsídio para o entendimento do padrão de ocupação humana. Dissertação de Mestrado. Análise Geoambiental, Universidade de Guarulhos, Guarulhos, 109 p.

RASBAND, W. S. 1997. ImageJ. Bethesda, Maryland, USA: U.S. National Institute of Health: http://rsb.info.nih.gov/ij/ p.

RIZZINI, C. T. 1979. Tratado de fitogeografia do Brasil. São Paulo: Hucitec/Edusp, 
ROIG, F. A. 1986. The Wood of Adesmia-Horrida and Its Modifications by Climatic Conditions. IAWA Bulletin, v.7, n.2, p.129-135.

ROLIM, S. G. et al. 2005. Biomass change in an Atlantic tropical moist forest: the ENSO effect in permanent sample plots over a 22-year period. Oecologia, v.142, n.2, Jan, p.238-246.

ROQUE, A. A.;R. T. QUEIROZ \& M. I. B. LOIOLA. 2009. Diversidade florística do Seridó. In: E. M. X. FREIRE (Ed.). Recursos naturais das Caatingas: uma visão multidisciplinar. Natal: EDUFRN. p.240.

SAS. 1999. JMP: Statistics made visual. Versión 3.2.6. Cary, NC: SAS Institute Inc.

SETZER, J. 1956. Os solos do município de São Paulo (segunda parte). Boletim Paulista de Geografia, v.22, p.26-54.

VAN DEN OEVER, L.;P. BAAS \& M. ZANDEE. 1981. Comparative Wood Anatomy of Symplocos and Latitude and Altitude of Provenance. IAWA Bulletin, v.2, n.1, p.3-24.

VARANDA, E. M. 1977. Balanço hídrico de espécies da Mata do Butantã, São Paulo $S P$. Dissertação de Mastrado. Universidade de São Paulo, São Paulo.,

ZHANG, X. Y.;L. DENG \& P. BAAS. 1988. The Ecological Wood Anatomy of the Lilacs (Syringa-Oblata Var Giraldii) on Mount Taibei in Northwestern China. IAWA Bulletin, v.9, n.1, p.24-30.

ZIMMERMAN, M. H. 1983. Xylem structureand ascent sap. Berlin: Springer Verlag

ZIMMERMAN, M. H. \& C. L. BROWN. 1971. Trees. Structure and function. Berlin: Springer Verlag 


\section{CONSIDERAÇÕES FINAIS}

O presente trabalho listou 347 espécies lenhosas para a região arqueológica de Lagoa Santa, MG e caracterizou suas diferentes fitofisionomias segundo parâmetros fitossociológicos que, além de contribuírem para o conhecimento da riqueza e diversidade da região, proveram subsídios para a a identificação e interpretação de lenhos fósseis ali depositados durante do Holoceno médio e tardio.

O levantamento florístico revelou uma alta riqueza de plantas lenhosas na região, mesmo se considerada a grande perda observada nos últimos 150 anos, como foi possível perceber ao comparar com a listagem de Warming (1908). Tal riqueza de espécies lenhosas não chega a ser encontrada em parques reconhecidos como patrimônio natural da humanidade pela UNESCO, como o Parque Nacional de Emas, GO (Neri et al., 2007), evidenciando a importância da área como abrigo da biodiversidade vegetal. Tal riqueza é aqui atribuída ao mosaico de vegetações típico da região, onde o bioma da Mata Atlântica divide espaço com o do Cerrado, modulados pelo embasamento cárstico, resultando na presença de diversas fitofisionomias diferentes e muito próximas.

De fato, por meio do estudo fitossociológico das principais fitofisionomias deste mosaico (mata ciliar, floresta semidecídua/cerradão e cerrado stricto sensu) foi possível identificar preferências ecológicas diferentes para muitas espécies, que acabam por promover a grande riqueza de espécies lenhosas encontradas na região.

Uma vez caracterizada a vegetação atual da região de Lagoa Santa, a identificação taxonômica dos lenhos fósseis do afloramento Ribeirão da Mata (RMT) revelou florísticas similares para o período do Holoceno médio (ca. 5.000 anos A.P.) e para o Holoceno tardio (ca.2.500 anos A.P.), não provendo indícios de uma mudança significativa na cobertura vegetal a ponto de ser verificada nos registros paleobotânicos do RMT.

As informações fitossociológicas obtidas auxiliaram significativamente na interpretação sobre a ocorrência de Allophylus sp, Astronium/Myracrodruon sp, Qualea $s p$ $e$ Trichilia $s p$, dando maior fundamentação às interpretações paleobotânicas relativas às assembléias existentes no passado, o que foi confirmado pela análise de agrupamento e comparações diretas com listagens florísticas da região Centro Oeste e Sudeste brasileira.

Esses resultados mostraram que a florística das assembleias fósseis se relacionam muito com a florística de florestas semidecíduas e também com matas secas, de galeria e 
cerrados, indicando claramente que este mosaico que caracteriza a região atualmente já havia se estabelecido no local durante o Holoceno médio. Apoiando essa consideração, Nakamura (2011) encontrou resultados similares por meio da identificação taxonômica de folhas fósseis do Holoceno médio. No mesmo afloramento RMT, Raczka (2009), trabalhando com todo o Holoceno da região, evidenciou a expansão dos cerrados e matas de clima mais quente no ínício do Holoceno médio, com o gradual desaparecimento de espécies indicadoras de matas sob temperatura mais amenas, resquícios do Holoceno inicial que ainda sofria influência térmica do último período glacial, que teve sua maior intensidade 8.000 anos antes (ca. 18.000 anos A.P.).

Por outro lado, os resultados da abordagem que utilizou a anatomia ecológica do lenho de Myroxylon peruiferum L.f. (Capítulo 4) para interpretar condições climáticas pretéritas, sugerem uma aproximação do padrão anatômico das amostras do Holoceno médio com o padrão de espécimes viventes sob clima mais sazonal. Já as amostras do Holoceno tardio, nitidamente se aparentaram mais com espécimes viventes sob clima de São Paulo, SP, com estação seca reduzida. Quando utilizada apenas a característica "diâmetro de vaso", esta diferença se torna muito mais acentuada, estimando um regime climático com maior estiagem e alta temperatura durante o Holoceno médio. De acordo com tal interpretação, Raczka (2009) observa o desaparecimento de espécies de clima montano ou subtropical, como Podocarpus sp e Araucaria angustifolia nos registros palinológicos da transição Holoceno inicial/médio. Contudo, a ausência dessas espécies não indica uma temperatura acima da atual para a região, como sugere a análise anatômico-ecológica. Os resultados de tal análise são aqui discutidos com cautela devido à possibilidade, embora não comprovada, das amostras fósseis serem proveniente de galhos, que influenciariam com menores valores de diâmetro de vaso e estimariam climas mais quentes e secos. Existem, portanto, apenas indícios de maior sazonalidade durante o Holoceno médio, confirmados pelas análises discriminantes e pela análise anatômicoecológica de $M$. peruiferum.

Desta forma, é possível sintetizar que os resultados obtidos na presente tese apresentam indícios de uma maior sazonalidade e temperatura durante o Holoceno médio, porém, insuficientes para causar alterações florísticas no mosaico vegetacional da região de Lagoa Santa, que já estava presente na região, ao menos, desde o Holoceno médio, a 5.000 anos A.P., e se manteve até os dias de hoje. 
Essa dinâmica climática interpretada pelos lenhos fósseis do RMT é condizente com diversos outros estudos, que mostram uma instabilidade climática no Brasil central por volta dos 6.000 anos A.P., no início do Holoceno médio. Nesse período, Raczka (2009) observou o crescimento da representatividade de Caryocar brasiliense, típico do cerrado, concomitantemente a uma instabilidade climática, indicada principalmente por uma ampla flutuação polínica de Zygnema, alga indicadora de áreas paludosas, como brejo ou pântano entre outros táxons. A redução da taxa de sedimentação na lagoa Olhos D’Água, que fora constante entre 18.000 até 5.500 anos A.P., também indica maior sazonalidade.

Outros trabalhos palinológicos, como os de Behling (1995; 2003), mostram oscilações nos diagramas polínicos para localidades mineiras no período entre o Holoceno inicial e médio, se estabilizando a partir de 5.530 anos A.P. Os resultados de Ledru (1993) parecem ser os mais expressivos, ao indicar um evento seco no Holoceno médio, entre 5.560 a 4.350 anos A.P., mas a falta de tal intensidade observada em outras publicações sugere que os resultados da autora possam representar alterações mais locais da região de Serra do Salitre (Triângulo Mineiro - Patrocínio - MG). Em outro trabalho, Parizzi et al (1998), concluíram que o retorno da umidade na região por volta de 5.300 anos A.P., data de formação da Lagoa Santa, concomitantemente com o evento seco estimado por Ledru (1993).

Os registros animais, embora menos sensíveis aos ambientes que o das plantas, podem trazer informações independentes interessantes. Perez (2009), estudando vestígios ósseos de animais depositados em sítios paleontológicos na região de Lagoa Santa, encontrou indícios de alterações ambientais apenas a partir de 3.000 anos A.P., quando a redução de ossadas de certos animais e o aparecimento de outros indicam uma expansão das matas. Embora não revele grandes períodos secos, os indícios de um ambiente mais úmido, no Holoceno tardio, podem ser interpretados como uma menor umidade durante o Holoceno inicial e médio.

Em contraposição a esse cenário, Ferraz-Vicentini \& Salgado-Labouriau (1996) bem como Barberi et. al., (2000), em perfis palinológicos próximos à Brasília (DF), observaram o aumento de umidade na região a partir de 7.000 anos A.P. Esses estudos, porém, carecem de uma cronologia bem estabelecida por datações radiocarbônicas durante o Holoceno médio, e estimam o início do aumento de umidade por meio da extrapolação de datações, que utiliza, como premissa, uma deposição sedimentar constante entre duas datações obtidas, o que raramente é verdadeiro. Essa peculiaridade pode causar 
significativas imprecisões cronológicas, uma vez que, entre milhares de anos, a taxa de sedimentação pode variar significativamente.

Uma outra alternativa para a ocorrência de cenários climáticos diferentes no Brasil central, próximo ao Distrito Federal e nas regiões mineiras, é a de o clima no Brasil central durante o Holoceno médio não seguir o mesmo padrão para todas as suas localidades. De fato, embora a hipótese do "Ótimo Climático" seja bem sustentada no Hemisfério Norte, mostrando um aumento de umidade em diversas áreas do globo durante o Holoceno médio, no Hemisfério Sul as alterações climáticas foram mais amenas e, aparentemente, mais complexas (Wanner et al., 2008).

Como apontam Kousky et. al. (1984), o sistema climático brasileiro sofre grande influência do fenômeno "El Niño", que ocasiona uma assimetria climática entre as regiões Sul/Sudeste e Norte/Nordeste. Uma vez que a região central brasileira se encontra na linha divisória desta assimetria climática, é possível que uma alta frequência desse fenômeno possa ter ocasionado diferenças climáticas nas localidades do Brasil central, repercutindo em flutuações climáticas em Lagoa Santa, como observou Raczka (2009) na Lagoa Olhos d'Água.

Desse modo, adicionando os resultados apresentados nesta tese ao estado do saber sobre o paleoambiente do Brasil central, fica clara a instabilidade e complexidade climática que se estabeleceu durante o Holoceno médio da região. Contudo, especificamente para a região arqueológica de Lagoa Santa, fica bem sustentada, por diversos indicadores biológicos e sedimentares, a manutenção do mosaico atual de vegetações durante o Holoceno médio. Assim, a hipótese do "Hiato do Arcaico" não se sustenta sobre alterações nas composições de espécies ou em grandes modificações da paisagem vegetal. Como os povos pré-históricos que ali habitavam utilizavam como base de sua dieta o alimento vegetal tanto das matas (ex: Syagrus coronata Mart. Becc., e Psidium sp) como do cerrado (ex. Annona crassiflora Mart., Caryocar brasiliense Cambess. e Eugenia dysenterica DC.) (Neves \& Pilo, 2008; Prous \& Rodet, 2009), é difícil apoiar a idéia de falta de recursos alimentares na região durante o Holoceno médio. É possível que a causa de tal hiato resida em questões relacionadas à instabilidade climática na transição Holoceno inicial/médio, que pode ter repercutido em outros recursos que não os vegetais ou animais. Quem sabe recursos hídricos em pequena escala, como posição de nascentes, ou sazonalidade de regatos. Possivelmente outros indicadores, físicos e químicos, de maior sensibilidade 
climática que os biológicos aqui apresentados possam trazer mais detalhamento plaeoclimático.

No campo da arqurologia, também são necessárias maiores investigações acerca desse período para sustentar ainda com mais força a ausência de sepultamentos na região. Neste âmbito, é fundamental aguardar as pesquisas em outros sítios, com por exemplo, as que vêm sendo desenvolvidas no sítio arqueológico Caixa d'Água, em Buritizeiro, MG. Esse sítio, ainda pouco pesquisado, tem grande potencial científico para auxiliar estas discussões, uma vez que dista $500 \mathrm{Km}$ ao Norte da região de Lagoa Santa, e resguarda um cemitério humano datado em cerca de 6.100 a 5.000 anos A. P. 
CONCLUSÕES 


\section{CONCLUSÕES}

Por este trabalho foi verificada a importância da APA - Carste de Lagoa Santa (ACLS), MG, como guarida de grande riqueza de espécies lenhosas, mesmo levando-se em consideração a drástica perda de espécies nos últimos 150 anos. A proximidade da região com a capital do Estado de Minas Gerais, e o processo de conurbação da região metropolitana aumentam a pressão sobre os remanescentes naturais da ACLS, que merece a atenção das políticas públicas para a conservação do patrimônio natural, para continuar abrigando as centenas de espécies que aqui foram listadas. Caso contrário, a perda de espécies verificada desde o tempo de Warming, em 1860, deverá continuar em taxas cada vez maiores.

A fitossociologia da ACLS revelou as diferenças entre uma área de mata ciliar, cerrado s.s. e floresta semidecídua que, somados à listagem florística e o acervo histológico e iconográfico realizado, auxiliaram de forma expressiva tanto na identificação taxonômica dos lenhos fósseis como nas interpretações paleoambientais realizadas.

Por meio do estudo anatômico ecológico de Myroxylon peruiferum L.f., foram verificadas correlações significativas entre diversas variáveis climáticas e anatômicas, sendo que a principal característica anatômica correlacionada foi o diâmetro de vaso, que não só se correlacionou com variáveis de precipitação mas também com variáveis relacionadas à temperatura. No entanto, deve-se investigar mais a falta de padrão anatômico da espécie no município de Ribeirão Preto, para que se tenha maiores informações sobre outros aspectos que podem influenciar a anatomia do lenho desta espécie

Por fim, as diferentes abordagens utilizadas para interpretação paleoambiental da região por meio de lenhos fósseis mostraram resultados complementares, que indicam um período sensivelmente mais sazonal no Holoceno médio, porém insuficiente para propiciar alterações florísticas no mosaico vegetacional que existia na época e caracteriza hoje a região. Esses resultados, portanto, não apóiam a hipótese de alterações intensas nem na flora e nem na presença das vegetações que ali existiam e forneciam a base da alimentação dos povos pré-históricos. 


\section{REFERÊNCIAS BIBLIOGRÁFICAS}

BARBERI, M.;M. L. SALGADO-LABOURIAU \& K. SUGUIO. 2000. Paleovegetation and paleoclimate of "Vereda de Aguas Emendadas", central Brazil. Journal of South American Earth Sciences, v.13, n.3, Jul, p.241-254.

BEHLING, H. 1995a. A High-Resolution Holocene Pollen Record from Lago Do Pires, Se Brazil - Vegetation, Climate and Fire History. Journal of Paleolimnology, v.14, n.3, Nov, p.253-268.

BEHLING, H. 2003. Late glacial and Holocene vegetation, climate and fire history inferred from Lagoa Nova in the southeastern Brazilian lowland. Vegetation History and Archaeobotany, v.12, n.4, Dec, p.263-270.

FERRAZVICENTINI, K. R. \& M. L. SALGADOLABOURIAU. 1996. Palynological analysis of a palm swamp in Central Brazil. Journal of South American Earth Sciences, v.9, n.3-4, May-Jul, p.207-219.

KOUSKY, V. E.;M. T. KAGANO \& I. F. A. CAVALCANTI. 1984. A Review of the Southern Oscillation - Oceanic-Atmospheric Circulation Changes and Related Rainfall Anomalies. Tellus Series a-Dynamic Meteorology and Oceanography, v.36, n.5, p.490504.

LEDRU, M. P. 1993. Late Quaternary Environmental and Climatic Changes in Central Brazil. Quaternary Research, v.39, n.1, Jan, p.90-98.

NAKAMURA, C. 2011. Folhas fósseis do Ribeirão da Mata: uma abordagem florística e anatômica para caracterização do paleoambiente do Holoceno Médio de Lagoa Santa, MG.Dissertação de mestrado. Universidade de São Paulo, São Paulo.

NERI, A. V. et al. 2007. Composição florísitca de uma área de cerrado sensu stricto no município de Senador Modestino Gonçalves, Vale do Jequitinhonha (MG) e análise de similaridade florística de algumas áreas de cerrado em Minas Gerais. Revista Árrvore, v.31, p.1109-1119.

NEVES, W. A. \& L. B. PILO. 2008. O povo de Luzia: em busca dos primeiros americanos. São Paulo: Globo. 334 p.

PARIZZI, M. G.;M. L. SALGADO-LABOURIAU \& H. C. KOHLER. 1998. Genesis and environmental history of Lagoa Santa, southeastern Brazil. Holocene, v.8, n.3, May, p.311-321.

PEREZ, C. P. 2009. Paleoecologia de mamíferos viventes como ferramenta na caracterização do ambiente holocênico de Lagoa Santa. Ecologia, Universidade de São Paulo, São Paulo,

PROUS, A. \& M. J. RODET. 2009. Os vivos e seus mortos no Brasil tropical e sub-tropical pré-histórico (11.000/500 BP). In: W. F. MORALES e P. O. MOI (Ed.). Cenários Regionais em Arqueologia Brasileira. Porto Seguro: Annablume

RACZKA, M. F. 2009. Mudanças paleoambientais quaternárias na região de Lagoa Santa, Mg, Brasil: a palinologia como subsídeo para o entendimento do padrão de ocupação humana. Dissertação de mestrado. Universidade de Guarulhos, Guarulhos, 119 p.

WANNER, H. et al. 2008. Mid- to Late Holocene climate change: an overview. Quaternary Science Reviews, v.27, n.19-20, Oct, p.1791-1828.

WARMING, E. 1908. Lagoa Santa, contribuição para a geographia phytobiológica. Belo Horizonte: Imprensa Oficial do Estado de Minas Gerais. II+282p. 


\section{ANEXo A}

\section{PARÂMETROS FITOSSOCIOLÓGICOS UTILIZADOS}



Frequência absoluta (FA)

$\mathrm{FAi}=100(\mathrm{Ui} / \mathrm{UT})$

Frequência relativa (FR)

$\mathrm{FRi}=100\left(\mathrm{FAi} / \sum \mathrm{ij}=1 \mathrm{FAj}\right)$

Densidade absoluta (DA)

$\mathrm{DAi}=\mathrm{ni} / \mathrm{A}$

Densidade Relativa (DR)

$\mathrm{DRi}=100(\mathrm{ni} / \mathrm{N})$

Dominância absoluta (DoA)

$\mathrm{DoAi}=\mathrm{ABi} / \mathrm{A}$

Dominância Relativa (DoR)

DoRi=100(ABi/ABT)

Diversidade de Shannon-Wiener

$$
\begin{gathered}
\mathrm{H}^{\prime}=-\sum \text { pi.Lnpi } \\
\mathrm{Pi}=\mathrm{ni} / \mathrm{N}
\end{gathered}
$$

Dominância de Simpson (D)

$$
\mathrm{D}=1-\sum(\mathrm{ni}(\mathrm{ni}-1) / \mathrm{N}(\mathrm{N}-1))
$$

Índice de valor de importância (IVI)

$$
\text { IVIi=DRi+FRi+DoRi }
$$

\section{Equitabilidade de Pielou (J) \\ $\mathrm{J}=\mathrm{H}^{\prime} / \mathrm{LnS}$}

\section{Onde:}

$\mathrm{N}=\mathrm{n}^{\mathrm{o}}$ total de indivíduos

$\mathrm{A}=$ área amostrada

ni $=n^{\circ}$ de indivíduos da espécie "i”"

$\mathrm{ABi}$ = área basal da espécie "i”

$\mathrm{Ui}=\mathrm{n}^{\circ}$ de parcelas com ocorrência da espécie "i”"

$\mathrm{UT}=\mathrm{n}^{\mathrm{o}}$ total de parcelas na amostra

$\mathrm{S}=\mathrm{n}^{\mathrm{o}}$ total de espécies

$\mathrm{N}=\mathrm{n}^{\mathrm{o}}$ total de indivíduos 



\section{ANEXO B}

\section{PROTOCOLO DE MENSURAÇÕES DAS CARACTERÍSTICAS ANATÔMICAS DE $M$. PERUIFERUM L.F. UTILIZADAS NO CAPÍTULO 4}





\section{ANEXO B: Variáveis anatômicas mensuradas no capítulo 4 e o protocolo utilizado para tais mensurações.}

Característica anatômica

\section{Protocolo}

Foi mensurado o diâmetro tangencial apenas dos vasos íntegros, excluindo os vasos oblíquos, de

Diâmetro tangencial de vasos

(Dv)

parede colapsada, em transição de elementos de vaso

ou agrupados em cachos. No caso dos outros

agrupamentos, mediu-se apenas o vaso de maior

diâmetro.

Frequência de vasos

(Fv)

Utilizou-se grids de $1 \mathrm{~mm}^{2}$ ao longo do eixo radial.

Todos os vasos foram contabilizados, incluindo vasos

nos que continha mais de $50 \%$ de área dentro do grid

Proporção de vasos solitários,

$$
\left(\mathbf{P v}_{\text {sol }}\right)
$$

agrupados em 2 ou 3 ,

(Pv2-3)

agrupados em 4 ou 5 ,

(Pv 4-5)

agrupados em 6 ou 7 ,

(Pv6-7)

Frequência de raios $(\mathbf{F r})$

Altura de raios (Ar)

Largura de raios (Lr)
Foram mensuradas utilizando uma rede de grade de 1 $\mathrm{mm}^{2}$ e considerado o $\mathrm{n}^{\mathrm{o}}$ de vasos solitários, geminados, múltiplos de 3, de 4, 5, 6 e 7 ou mais. Os vasos geminados, quando aparentavam refletir a mudança de elementos de vaso foram considerados solitários. Foi calculada a porcentagem de vasos em cada tipo de agrupamento.

Seguiu estritamente as orientações da IAWA, por meio da contagem do número de raios em linhas horizontais de $1 \mathrm{~mm}$. Como os raios são estratificados a linha passou no meio da estratificação e, em caso da estratificação estar inclinada, inclinouse também a linha. Evitou-se, quando possível, a presença de vaso no meio do transecto.

Foram tomadas apenas nos raios envolvidos por fibras. Raios imersos ou próximos de parênquima axial e vasos foram evitados.

Mesmo procedimento utilizado para "altura de raios" 



\section{APÊNDICE 1}

\section{LISTA DE ESPÉCIES LENHOSAS DA}

\section{APA - CARSTE DE LAgOA SANTA, MG}


Apêndice 1: Espécies lenhosas encontradas na ACLS Carste de Lagoa Santa com seu respectivo hábito (arv = árvore; arb = arbusto; lia = liana). As espécies encontradas por Warming (War.), o número de registro das amostras de lenho depositadas no herbário SPFw e o no de coletor também são computadas. Ordenados por família e espécie. Prov= provável.

\begin{tabular}{|c|c|c|c|c|c|c|c|}
\hline Família & Espécie & Arv & Arb & Lia & War. & SPFw & $\mathrm{col} / \mathrm{n}^{\circ}$ \\
\hline Acanthaceae & Ruellia brevifolia (Pohl) C. Ezcurra & & $\mathrm{x}$ & & $\operatorname{sim}$ & 2383 & G.C.T.Ceccantini, 2872 \\
\hline Acanthaceae & Thunbergia convolvulifolia & & & $\mathrm{x}$ & não & - & G.C.T.Ceccantini, 2782 \\
\hline Anacardiaceae & Astronium graveolens Jacq. & $\mathrm{x}$ & & & $\operatorname{sim}$ & 2407 & G.C.T.Ceccantini, 2902 \\
\hline Anacardiaceae & Lithraea molleoides (Vell.) Engl. & $\mathrm{x}$ & $\mathrm{x}$ & & $\operatorname{sim}$ & 2586 & G.C.T.Ceccantini, 2979 \\
\hline Anacardiaceae & Myracrodruon urundeuva Allemão & $\mathrm{x}$ & & & não & 2863 & G.C.T.Ceccantini, 3162 \\
\hline Anacardiaceae & Tapirira guianensis Aubl. & $\mathrm{x}$ & & & $\operatorname{sim}$ & 2663 & G.Q.Freire, 220 \\
\hline Annonaceae & Annona crassiflora Mart. & $\mathrm{x}$ & & & $\operatorname{sim}$ & 2720 & J.C.F.Melo Jr., 639 \\
\hline Annonaceae & Annona dolabripetala Raddi & $\mathrm{x}$ & & & não & 2602 & G.C.T.Ceccantini, 2997 \\
\hline Annonaceae & Annona sylvatica A.St.-Hil. & $\mathrm{x}$ & & & $\operatorname{sim}$ & 2654 & G.Q.Freire, 210 \\
\hline Annonaceae & Guatteria villosissima A.St.-Hil. & $\mathrm{x}$ & & & $\operatorname{sim}$ & 2591 & G.C.T.Ceccantini, 2984 \\
\hline Annonaceae & Xylopia aromatica (Lam.) Mart. & $\mathrm{x}$ & & & $\operatorname{sim}$ & 2881 & G.C.T.Ceccantini, 3204 \\
\hline Annonaceae & Xylopia brasiliensis Spreng. & $\mathrm{x}$ & & & $\operatorname{sim}$ & - & J.C.F.Melo Jr., P31-43 \\
\hline Annonaceae & Xylopia sericea A. St.-Hil. & $\mathrm{x}$ & & & $\operatorname{sim}$ & 2483 & J.C.F.Melo Jr., 522 \\
\hline Apocynaceae & Aspidosperma tomentosum Mart. & $\mathrm{x}$ & & & $\operatorname{sim}$ & 2756 & G.Q.Freire, 292 \\
\hline Apocynaceae & Forsteronia cf. thyrsoidea (Vell.) Müll.Arg. & & & $\mathrm{x}$ & $\operatorname{sim}$ & 2726 & G.Q.Freire, 257 \\
\hline Apocynaceae & Hancornia sp & & $\mathrm{x}$ & & prov. & 2859 & G.C.T.Ceccantini, 3146 \\
\hline Apocynaceae & Himatanthus sucuuba (Spruce ex Müll.Arg.) Woodson & $\mathrm{x}$ & & & não & 2673 & G.Q.Freire, 230 \\
\hline Apocynaceae & Schubertia grandiflora Mart. & & & $\mathrm{x}$ & não & - & G.C.T.Ceccantini, 2883 \\
\hline Apocynaceae & Tabernaemontana catharinensis A.DC. & $\mathrm{x}$ & & & não & 2503 & J.C.F.Melo Jr., 544 \\
\hline Araliaceae & Dendropanax cuneatus (DC.) Decne. \& Planch. & $\mathrm{x}$ & & & $\operatorname{sim}$ & 2358 & G.C.T.Ceccantini, 2841 \\
\hline Araliaceae & Schefflera macrocarpa (Cham. \& Schltdl.) Frodin & $\mathrm{x}$ & & & $\operatorname{sim}$ & 2749 & G.Q.Freire, 285 \\
\hline Araliaceae & Schefflera morototoni (Aubl.) Maguire et al. & $\mathrm{x}$ & & & prov. & 2239 & G.C.T.Ceccantini, 2778 \\
\hline Araliaceae & Schefflera vinosa (Cham. \& Schltdl.) Frodin \& Fiaschi & $\mathrm{x}$ & & & prov. & - & J.C.F.Melo Jr., P26-16 \\
\hline Arecaceae & Acrocomia aculeata (Jacq.) Lodd. ex Mart. & $\mathrm{x}$ & & & $\operatorname{sim}$ & 2865 & G.C.T.Ceccantini, 3136 \\
\hline Asteraceae & Baccharis crispa Spreng. & & $\mathrm{x}$ & & não & 2306 & G.C.T.Ceccantini, 2739 \\
\hline Asteraceae & Baccharis dracunculifolia DC. & & $\mathrm{x}$ & & $\operatorname{sim}$ & - & J.C.F.Melo Jr., P30-28 \\
\hline Asteraceae & Chromolaena laevigata (Lam.) R.M.King \& H.Rob. & $\mathrm{x}$ & & & $\operatorname{sim}$ & 2334 & G.C.T.Ceccantini, 2809 \\
\hline Asteraceae & Cosmos sulphureus Cav. & & $\mathrm{x}$ & & não & 2691 & J.C.F.Melo Jr., 607 \\
\hline Asteraceae & Dasyphyllum brasiliense (Spreng.) Cabrera & & & $\mathrm{x}$ & não & 2409 & G.C.T.Ceccantini, 2904 \\
\hline Asteraceae & Eremanthus erythropappus (DC.) MacLeish & $\mathrm{x}$ & & & não & 2286 & G.C.T.Ceccantini, 2718 \\
\hline Asteraceae & Eremanthus glomeratus Less. & & $\mathrm{x}$ & & $\operatorname{sim}$ & 2299 & G.C.T.Ceccantini, 2731 \\
\hline
\end{tabular}


APÊNDICE 1

Apêndice 1: Espécies lenhosas encontradas na ACLS Carste de Lagoa Santa com seu respectivo hábito (arv = árvore; arb = arbusto; lia = liana). As espécies encontradas por Warming (War.), o número de registro das amostras de lenho depositadas no herbário SPFw e o nº de coletor também são computadas. Ordenados por família e espécie. Prov= provável.

\begin{tabular}{|c|c|c|c|c|c|c|c|}
\hline Família & Espécie & Arv & Arb & Lia & War. & SPFw & $\mathrm{col} / \mathrm{n}^{\mathrm{o}}$ \\
\hline Asteraceae & Gochnatia paniculata (Less.) Cabrera & & $\mathrm{x}$ & & $\operatorname{sim}$ & 2493 & J.C.F.Melo Jr., 532 \\
\hline Asteraceae & Lessingianthus obtusatus (Less.) H. Rob. & & $\mathrm{x}$ & & $\operatorname{sim}$ & - & D.G. Rodrigues-Silva \& J.D. Rosário, 343 \\
\hline Asteraceae & Mikania sp & & & $\mathrm{x}$ & prov. & - & D.G. Rodrigues-Silva \& J.D. Rosário, 416 \\
\hline Asteraceae & Piptocarpha rotundifolia (Less.) Baker & $\mathrm{X}$ & & & $\operatorname{sim}$ & 2662 & G.Q.Freire, 219 \\
\hline Asteraceae & Vernonanthura membranacea (Gardner) H. Rob. & & $\mathrm{x}$ & & $\operatorname{sim}$ & 2335 & G.C.T.Ceccantini, 2810 \\
\hline Asteraceae & Vernonanthura phosphorica (Vell.) H. Rob. & $\mathrm{x}$ & & & $\operatorname{sim}$ & 2298 & G.C.T.Ceccantini, 2730 \\
\hline Asteraceae & Vernonia $s p$ & $\mathrm{x}$ & & & não & - & G.C.T.Ceccantini, 2889 \\
\hline Bignoniaceae & Amphilophium crucigerum (L.) L. G. Lohmann & & & $\mathrm{x}$ & não & 2621 & G.C.T.Ceccantini, 3030 \\
\hline Bignoniaceae & Amphilophium elongatum (Vahl) L. G. Lohmann & & & $\mathrm{x}$ & não & 2316 & G.C.T.Ceccantini, 2788 \\
\hline Bignoniaceae & Amphilophium paniculatum (L.) Kunth & & & $\mathrm{x}$ & não & 2450 & G.Q.Freire, 181 \\
\hline Bignoniaceae & Cuspidaria pulchra (Cham.) L. Lohmann & & & $\mathrm{x}$ & $\operatorname{sim}$ & 2373 & G.C.T.Ceccantini, 2861 \\
\hline Bignoniaceae & Cybistax antisyphilitica (Mart.) Mart & $\mathrm{x}$ & & & $\operatorname{sim}$ & 2555 & J.C.F.Melo Jr., 597 \\
\hline Bignoniaceae & Dolichandra unguis-cati (L.) L. Lohmann & & & $\mathrm{x}$ & $\operatorname{sim}$ & 2645 & G.Q.Freire, 201 \\
\hline Bignoniaceae & Fridericia chica (Bonpl.) L.G.Lohmann & & & $\mathrm{x}$ & não & 2568 & G.C.T.Ceccantini, 2954 \\
\hline Bignoniaceae & Fridericia craterophora (DC.) L. Lohmann & & & $\mathrm{x}$ & $\operatorname{sim}$ & 2259 & G.C.T.Ceccantini, 2689 \\
\hline Bignoniaceae & Fridericia florida (A. DC.) L. Lohmann & & & $\mathrm{x}$ & não & 2347 & G.C.T.Ceccantini, 2823 \\
\hline Bignoniaceae & Handroanthus heptaphyllus Mattos & $\mathrm{X}$ & & & não & 2734 & G.Q.Freire, 266 \\
\hline Bignoniaceae & Handroanthus impetiginosus Mattos & $\mathrm{x}$ & & & $\operatorname{sim}$ & 2478 & J.C.F.Melo Jr., 517 \\
\hline Bignoniaceae & Handroanthus serratifolius (A.H.Gentry) S.Grose & $\mathrm{x}$ & & & não & 2773 & G.Q.Freire, 314 \\
\hline Bignoniaceae & Lundia obliqua Sond. & & & $\mathrm{x}$ & $\operatorname{sim}$ & 2644 & G.Q.Freire, 200 \\
\hline Bignoniaceae & Pyrostegia venusta (Ker Gawl.) Miers & & & $\mathrm{x}$ & $\operatorname{sim}$ & 2398 & G.C.T.Ceccantini, 2892 \\
\hline Bignoniaceae & Stizophyllum riparium (Kunth) Sandwith & & & $\mathrm{x}$ & não & - & G.C.T.Ceccantini, 3144 \\
\hline Bignoniaceae & Zeyheria montana Mart. & $\mathrm{x}$ & & & $\operatorname{sim}$ & 2302 & G.C.T.Ceccantini, 2734 \\
\hline Bignoniaceae & Zeyheria tuberculosa (Vell.) Bureau ex Verl. & $\mathrm{x}$ & & & $\operatorname{sim}$ & 2587 & G.C.T.Ceccantini, 2980 \\
\hline Bixaceae & Bixa orellana $L$ & & $\mathrm{x}$ & & $\operatorname{sim}$ & 2739 & G.Q.Freire, 271 \\
\hline Boraginaceae & Cordia trichotoma (Vell.) Arráb. ex Steud. & $\mathrm{x}$ & & & $\operatorname{sim}$ & 2785 & G.Q.Freire, 326 \\
\hline Boraginaceae & Tournefortia paniculata Cham. & & $\mathrm{x}$ & & não & 2648 & G.Q.Freire, 204 \\
\hline Boraginaceae & Varronia curassavica Jacq. & & $\mathrm{x}$ & & $\operatorname{sim}$ & 2690 & G.Q.Freire, 249 \\
\hline Burseraceae & Protium heptaphyllum (Aubl.) Marchand & $\mathrm{x}$ & & & $\operatorname{sim}$ & - & G.Q.Freire, 175 \\
\hline Cannabaceae & Celtis iguanaea (Jacq.) Sarg. & $\mathrm{x}$ & & & não & - & G.Q.Freire, 237 \\
\hline Cannabaceae & Celtis pubescens (Kunth) Spreng. & $\mathrm{x}$ & & & $\operatorname{sim}$ & 2585 & G.C.T.Ceccantini, 2977 \\
\hline
\end{tabular}


APÊNDICE 1

Apêndice 1: Espécies lenhosas encontradas na ACLS Carste de Lagoa Santa com seu respectivo hábito (arv = árvore; arb = arbusto; lia = liana). As espécies encontradas por Warming (War.), o número de registro das amostras de lenho depositadas no herbário SPFw e o nº de coletor também são computadas. Ordenados por família e espécie. Prov= provável.

\begin{tabular}{|c|c|c|c|c|c|c|c|}
\hline Família & Espécie & Arv & Arb & Lia & War. & SPFw & $\mathrm{col} / \mathrm{n}^{\circ}$ \\
\hline Cannabaceae & Trema micrantha (L.) Blume & $\mathrm{X}$ & & & $\operatorname{sim}$ & 2617 & G.C.T.Ceccantini, 3025 \\
\hline Capparaceae & Cleome viridiflora Schreb. & & $\mathrm{x}$ & & $\operatorname{sim}$ & 2333 & G.C.T.Ceccantini, 2808 \\
\hline Caryocaraceae & Caryocar brasiliense Cambess. & $\mathrm{x}$ & & & $\operatorname{sim}$ & 2350 & G.C.T.Ceccantini, 2829 \\
\hline Celastraceae & Cheiloclinium cognatum (Miers) A.C. Sm. & $\mathrm{x}$ & & & $\operatorname{sim}$ & 2682 & G.Q.Freire, 241 \\
\hline Celastraceae & Hippocratea volubilis $L$ & & & $\mathrm{x}$ & $\operatorname{sim}$ & - & D.G. Rodrigues-Silva \& J.D. Rosário, 204 \\
\hline Celastraceae & Maytenus floribunda Reissek & & $\mathrm{x}$ & & $\operatorname{sim}$ & 2787 & G.Q.Freire, 328 \\
\hline Celastraceae & Maytenus ilicifolia * Mart. ex Reissek & $\mathrm{x}$ & & & não & - & J.C.F.Melo Jr., P14-10 \\
\hline Celastraceae & Maytenus robusta Reissek & $\mathrm{x}$ & & & não & - & G.C.T.Ceccantini, 3158 \\
\hline Celastraceae & Peritassa campestris (Cambess.) A.C. Sm. & & $\mathrm{x}$ & & $\operatorname{sim}$ & 2419 & G.C.T.Ceccantini, 2914 \\
\hline Celastraceae & Plenckia populnea Reissek & $\mathrm{x}$ & & & $\operatorname{sim}$ & - & J.C.F.Melo Jr., P27-23 \\
\hline Chrysobalanaceae & Couepia grandiflora (Mart. \& Zucc.) Benth. & $\mathrm{x}$ & & & $\operatorname{sim}$ & 2434 & G.Q.Freire, 163 \\
\hline Combretaceae & Terminalia argentea Mart. & $\mathrm{x}$ & & & $\operatorname{sim}$ & 2415 & G.C.T.Ceccantini, 2910 \\
\hline Combretaceae & Terminalia glabrescens Mart. & $\mathrm{x}$ & & & $\operatorname{sim}$ & 2470 & J.C.F.Melo Jr., 507 \\
\hline Connaraceae & Connarus sp & & $\mathrm{x}$ & & prov. & - & G.C.T.Ceccantini, 3132 \\
\hline Connaraceae & Rourea pseudospadicea G.Schellenb. & & $\mathrm{x}$ & & não & 2476 & J.C.F.Melo Jr., 514 \\
\hline Convolvulaceae & Ipomoea tubata Nees & & & $\mathrm{x}$ & $\operatorname{sim}$ & 2737 & G.Q.Freire, 269 \\
\hline Convolvulaceae & Merremia macrocalyx (Ruiz \& Pav.) O’Donell & & & $\mathrm{x}$ & $\operatorname{sim}$ & - & G.C.T.Ceccantini, 2774 \\
\hline Dilleniaceae & Doliocarpus dentatus (Aubl.) Standl. & & & $\mathrm{x}$ & não & 2744 & G.Q.Freire, 279 \\
\hline Ebenaceae & Diospyros hispida A. DC. & $\mathrm{x}$ & & & $\operatorname{sim}$ & 2675 & G.Q.Freire, 232 \\
\hline Ebenaceae & Diospyros inconstans Jacq. & $\mathrm{x}$ & & & $\operatorname{sim}$ & - & D.G. Rodrigues-Silva \& J.D. Rosário, 258 \\
\hline Erythroxylaceae & Erythroxylum campestre A. St.-Hil. & & $\mathrm{x}$ & & $\operatorname{sim}$ & 2558 & J.C.F.Melo Jr., 600 \\
\hline Erythroxylaceae & Erythroxylum cuneifolium (Mart.) O.E. Schulz & $\mathrm{x}$ & & & prov. & 2625 & G.C.T.Ceccantini, 3034 \\
\hline Erythroxylaceae & Erythroxylum suberosum A. St.-Hil. & $\mathrm{x}$ & & & $\operatorname{sim}$ & 2604 & G.C.T.Ceccantini, 2999 \\
\hline Erythroxylaceae & Erythroxylum subrotundum A. St.-Hil. & & $\mathrm{x}$ & & $\operatorname{sim}$ & 2584 & G.C.T.Ceccantini, 2976 \\
\hline Erythroxylaceae & Erythroxylum tortuosum Mart. & $\mathrm{X}$ & & & $\operatorname{sim}$ & 2753 & G.Q.Freire, 289 \\
\hline Euphorbiaceae & Acalypha communis Müll.Arg. & & $\mathrm{x}$ & & $\operatorname{sim}$ & 2655 & G.Q.Freire, 211 \\
\hline Euphorbiaceae & Alchornea glandulosa Poepp. \& Endl. & $\mathrm{X}$ & & & $\operatorname{sim}$ & 2367 & G.C.T.Ceccantini, 2853 \\
\hline Euphorbiaceae & Astraea lobata (L.) Klotzsch & $\mathrm{x}$ & & & $\operatorname{sim}$ & 2521 & J.C.F.Melo Jr., 563 \\
\hline Euphorbiaceae & Croton gracilipes Baill. & $\mathrm{x}$ & & & $\operatorname{sim}$ & 2592 & G.C.T.Ceccantini, 2985 \\
\hline Euphorbiaceae & Croton urucurana Baill. & $\mathrm{x}$ & & & $\operatorname{sim}$ & 2649 & G.Q.Freire, 205 \\
\hline Euphorbiaceae & Dalechampia stipulacea Müll.Arg. & & & $\mathrm{x}$ & $\operatorname{sim}$ & 2381 & G.C.T.Ceccantini, 2870 \\
\hline
\end{tabular}


APÊNDICE 1

Apêndice 1: Espécies lenhosas encontradas na ACLS Carste de Lagoa Santa com seu respectivo hábito (arv = árvore; arb = arbusto; lia = liana). As espécies encontradas por Warming (War.), o número de registro das amostras de lenho depositadas no herbário SPFw e o nº de coletor também são computadas. Ordenados por família e espécie. Prov= provável.

\begin{tabular}{|c|c|c|c|c|c|c|c|}
\hline Família & Espécie & Arv & Arb & Lia & War. & SPFw & $\mathrm{col} / \mathrm{n}^{\mathbf{o}}$ \\
\hline Euphorbiaceae & Euphorbia heterophylla L. & & $\mathrm{x}$ & & não & - & D.G. Rodrigues-Silva \& J.D. Rosário, 399 \\
\hline Euphorbiaceae & Mabea fistulifera Mart. & $\mathrm{x}$ & & & $\operatorname{sim}$ & 2729 & G.Q.Freire, 261 \\
\hline Euphorbiaceae & Manihot anomala Pohl & $\mathrm{x}$ & & & $\operatorname{sim}$ & 2708 & J.C.F.Melo Jr., 625 \\
\hline Euphorbiaceae & Manihot janiphoides Müll.Arg. & & $\mathrm{x}$ & & $\operatorname{sim}$ & 2736 & G.Q.Freire, 268 \\
\hline Euphorbiaceae & Manihot tripartita (Spreng.) Müll.Arg. & & $\mathrm{x}$ & & $\operatorname{sim}$ & 2553 & J.C.F.Melo Jr., 595 \\
\hline Euphorbiaceae & Maprounea guianensis Aubl. & & $\mathrm{x}$ & & não & 2751 & G.Q.Freire, 287 \\
\hline Euphorbiaceae & Pera glabrata (Schott) Poepp. ex Baill. & $\mathrm{x}$ & & & $\operatorname{sim}$ & 2766 & G.Q.Freire, 307 \\
\hline Euphorbiaceae & Sapium glandulosum (L.) Morong & $\mathrm{x}$ & & & $\operatorname{sim}$ & 2783 & G.Q.Freire, 324 \\
\hline Euphorbiaceae & Sebastiania brasiliensis Spreng. & $\mathrm{x}$ & & & $\operatorname{sim}$ & 2650 & G.Q.Freire, 206 \\
\hline Euphorbiaceae & Sebastiania klotzschiana (Müll.Arg.) Müll.Arg. & $\mathrm{x}$ & & & $\operatorname{sim}$ & 2733 & G.Q.Freire, 265 \\
\hline Lamiaceae & Aegiphila integrifolia (Jacq.) Moldenke & $\mathrm{x}$ & & & $\operatorname{sim}$ & 2237 & G.C.T.Ceccantini, 2776 \\
\hline Lamiaceae & Aegiphila verticillata Vell. & $\mathrm{x}$ & & & $\operatorname{sim}$ & 2549 & J.C.F.Melo Jr., 591 \\
\hline Lamiaceae & Aegiphila vitelliniflora Walp. & & $\mathrm{x}$ & $\mathrm{x}$ & $\operatorname{sim}$ & - & D.G. Rodrigues-Silva \& J.D. Rosário, 307 \\
\hline Lamiaceae & Hyptidendron canum (Pohl ex Benth.) Harley & $\mathrm{x}$ & & & $\operatorname{sim}$ & 2537 & J.C.F.Melo Jr., 579 \\
\hline Lamiaceae & Vitex polygama Cham. & $\mathrm{x}$ & & & $\operatorname{sim}$ & 2631 & G.C.T.Ceccantini, 3040 \\
\hline Lauraceae & Nectandra cf. cissiflora Nees & $\mathrm{x}$ & & & $\operatorname{sim}$ & - & J.C.F.Melo Jr., P6-10 \\
\hline Lauraceae & Nectandra lanceolata Nees & $\mathrm{x}$ & & & $\operatorname{sim}$ & 2446 & G.Q.Freire, 177 \\
\hline Lauraceae & Nectandra psammophila Nees & $\mathrm{x}$ & & & não & 2402 & G.C.T.Ceccantini, 2896 \\
\hline Lauraceae & Ocotea corymbosa (Meisn.) Mez. & $\mathrm{x}$ & & & $\operatorname{sim}$ & 2772 & G.Q.Freire, 313 \\
\hline Lauraceae & Ocotea velutina (Nees) Rohwer & $\mathrm{x}$ & & & $\operatorname{sim}$ & 2786 & G.Q.Freire, 327 \\
\hline Lecythidaceae & Cariniana estrellensis (Raddi) Kuntze & $\mathrm{x}$ & & & $\operatorname{sim}$ & 2747 & G.Q.Freire, 282 \\
\hline Lecythidaceae & Cariniana legalis (Mart.) Kuntze & $\mathrm{x}$ & & & $\operatorname{sim}$ & 2511 & J.C.F.Melo Jr., 552 \\
\hline Leguminosae & Anadenanthera peregrina (Benth.) Altschul & $\mathrm{x}$ & & & não & - & G.C.T.Ceccantini, 2744 \\
\hline Leguminosae & Bauhinia longifolia (Bong.) Steud. & $\mathrm{x}$ & & & $\operatorname{sim}$ & 2390 & G.C.T.Ceccantini, 2882 \\
\hline Leguminosae & Bauhinia ungulata $L$. & $\mathrm{x}$ & & & não & 2542 & J.C.F.Melo Jr., 584 \\
\hline Leguminosae & Bowdichia virgilioides Kunth & $\mathrm{x}$ & & & $\operatorname{sim}$ & 2867 & G.C.T.Ceccantini, 3175 \\
\hline Leguminosae & Cassia ferruginea (Schrad.) Schrad. ex DC. & $\mathrm{x}$ & & & $\operatorname{sim}$ & 2743 & G.Q.Freire, 278 \\
\hline Leguminosae & Chamaecrista apoucouita (Aubl.) H.S. Irwin \& Barneby & $\mathrm{x}$ & & & $\operatorname{sim}$ & 2647 & G.Q.Freire, 203 \\
\hline Leguminosae & Chamaecrista ensiformis (Vell.) H.S. Irwin \& Barneby & $\mathrm{x}$ & & & não & - & J.C.F.Melo Jr., P2-1 \\
\hline Leguminosae & Chamaecrista flexuosa (L.) Greene & $\mathrm{x}$ & & & não & - & D.G. Rodrigues-Silva \& J.D. Rosário, 407 \\
\hline Leguminosae & Clitoria fairchildiana R.A. Howard & $\mathrm{x}$ & & & não & 2746 & G.Q.Freire, 281 \\
\hline
\end{tabular}


APÊNDICE 1

Apêndice 1: Espécies lenhosas encontradas na ACLS Carste de Lagoa Santa com seu respectivo hábito (arv = árvore; arb = arbusto; lia = liana). As espécies encontradas por Warming (War.), o número de registro das amostras de lenho depositadas no herbário SPFw e o nº de coletor também são computadas. Ordenados por família e espécie. Prov= provável.

\begin{tabular}{|c|c|c|c|c|c|c|c|}
\hline Família & Espécie & Arv & Arb & Lia & War. & SPFw & $\mathrm{col} / \mathbf{n}^{\mathbf{o}}$ \\
\hline Leguminosae & Copaifera langsdorffii Desf. & $\mathrm{X}$ & & & $\operatorname{sim}$ & 2771 & G.Q.Freire, 312 \\
\hline Leguminosae & Dalbergia miscolobium Benth. & $\mathrm{x}$ & & & $\operatorname{sim}$ & 2752 & G.Q.Freire, 288 \\
\hline Leguminosae & Dimorphandra mollis Benth. & $\mathrm{x}$ & & & $\operatorname{sim}$ & 2750 & G.Q.Freire, 286 \\
\hline Leguminosae & Enterolobium contortisiliquum (Vell.) Morong & $\mathrm{x}$ & & & $\operatorname{sim}$ & 2404 & G.C.T.Ceccantini, 2899 \\
\hline Leguminosae & Erythrina falcata Benth. & $\mathrm{x}$ & & & $\operatorname{sim}$ & 2790 & G.Q.Freire, 331 \\
\hline Leguminosae & Harpalyce brasiliana Benth. & & $\mathrm{x}$ & & $\operatorname{sim}$ & 2723 & J.C.F.Melo Jr., 642 \\
\hline Leguminosae & Hymenaea courbaril $L$. & $\mathrm{X}$ & & & $\operatorname{sim}$ & 2974 & G.Q.Freire, 336 \\
\hline Leguminosae & Hymenaea stigonocarpa Mart. ex Hayne & $\mathrm{x}$ & & & $\operatorname{sim}$ & 2877 & G.C.T.Ceccantini, 3195 \\
\hline Leguminosae & Indigofera suffruticosa Mill. & & $\mathrm{x}$ & & $\operatorname{sim}$ & - & D.G. Rodrigues-Silva \& J.D. Rosário, 275 \\
\hline Leguminosae & Inga vera Willd. & $\mathrm{x}$ & & & $\operatorname{sim}$ & 2680 & G.Q.Freire, 239 \\
\hline Leguminosae & Leptolobium dasycarpum Vogel & $\mathrm{x}$ & & & $\operatorname{sim}$ & 2278 & G.C.T.Ceccantini, 2710 \\
\hline Leguminosae & Lonchocarpus muehlbergianus Hassl. & $\mathrm{x}$ & & & não & - & J.C.F.Melo Jr., P14-12 \\
\hline Leguminosae & Lonchocarpus sericeus (Poir.) DC. & $\mathrm{x}$ & & & $\operatorname{sim}$ & 2681 & G.Q.Freire, 240 \\
\hline Leguminosae & Machaerium acutifolium Vogel & $\mathrm{x}$ & & & não & - & J.C.F.Melo Jr., P30-41 \\
\hline Leguminosae & Machaerium hirtum (Vell.) Stellfeld & $\mathrm{x}$ & & & $\operatorname{sim}$ & 2730 & G.Q.Freire, 262 \\
\hline Leguminosae & Machaerium opacum Vogel & $\mathrm{x}$ & & & $\operatorname{sim}$ & 2548 & J.C.F.Melo Jr., 590 \\
\hline Leguminosae & Mimosa debilis Humb. \& Bonpl. ex Willd. & & $\mathrm{x}$ & & não & 2709 & J.C.F.Melo Jr., 627 \\
\hline Leguminosae & Mimosa laticifera Rizzini \& A. Mattos & $\mathrm{x}$ & & & $\operatorname{sim}$ & 2703 & J.C.F.Melo Jr., 620 \\
\hline Leguminosae & Mucuna pruriens (L.) DC & & & $x$ & não & 2677 & G.Q.Freire, 235 \\
\hline Leguminosae & Peltophorum dubium (Spreng.) Taub. & $\mathrm{X}$ & & & $\operatorname{sim}$ & 2597 & G.C.T.Ceccantini, 2992 \\
\hline Leguminosae & Plathymenia reticulata Benth. & $\mathrm{x}$ & & & $\operatorname{sim}$ & 2861 & G.C.T.Ceccantini, 3160 \\
\hline Leguminosae & Platymiscium pubescens Micheli & $\mathrm{x}$ & & & $\operatorname{sim}$ & 2800 & J.C.F.Melo Jr., 809 \\
\hline Leguminosae & Platypodium elegans Vogel & $\mathrm{x}$ & & & $\operatorname{sim}$ & 2748 & G.Q.Freire, 284 \\
\hline Leguminosae & Poiretia punctata (Willd.) Desv. & & & $\mathrm{x}$ & $\operatorname{sim}$ & 2878 & G.C.T.Ceccantini, 3196 \\
\hline Leguminosae & Senegalia martiusiana (Steud.) Seigler \& Ebinger & & $\mathrm{x}$ & & não & 2580 & G.C.T.Ceccantini, 2972 \\
\hline Leguminosae & Senegalia polyphylla (DC.) Britton \& Rose & $\mathrm{x}$ & & & $\operatorname{sim}$ & 2705 & J.C.F.Melo Jr., 622 \\
\hline Leguminosae & Senna macranthera (DC. ex Collad.) H.S. Irwin \& Barneby & $\mathrm{x}$ & & & $\operatorname{sim}$ & 2364 & G.C.T.Ceccantini, 2848 \\
\hline Leguminosae & Senna multijuga (Rich.) H.S. Irwin \& Barneby & $\mathrm{x}$ & & & $\operatorname{sim}$ & 2233 & G.C.T.Ceccantini, 2662 \\
\hline Leguminosae & Senna pendula (Humb. \& Bonpl. ex Willd.) H.S. Irwin \& Barneby & & $\mathrm{x}$ & & $\operatorname{sim}$ & 2341 & G.C.T.Ceccantini, 2817 \\
\hline Leguminosae & Senna silvestris (Vell.) H.S.Irwin \& Barneby & $\mathrm{X}$ & & & $\operatorname{sim}$ & 2329 & G.C.T.Ceccantini, 2804 \\
\hline Leguminosae & Stryphnodendron adstringens (Mart.) Coville & $\mathrm{x}$ & & & $\operatorname{sim}$ & 2659 & G.Q.Freire, 216 \\
\hline
\end{tabular}


APÊNDICE 1

Apêndice 1: Espécies lenhosas encontradas na ACLS Carste de Lagoa Santa com seu respectivo hábito (arv = árvore; arb = arbusto; lia = liana). As espécies encontradas por Warming (War.), o número de registro das amostras de lenho depositadas no herbário SPFw e o nº de coletor também são computadas. Ordenados por família e espécie. Prov= provável.

\begin{tabular}{|c|c|c|c|c|c|c|c|}
\hline Família & Espécie & Arv & Arb & Lia & War. & SPFw & $\mathrm{col} / \mathbf{n}^{\mathbf{0}}$ \\
\hline Leguminosae & Swartzia macrostachya Benth. & $\mathrm{x}$ & & & $\operatorname{sim}$ & 2507 & J.C.F.Melo Jr., 548 \\
\hline Leguminosae & Tachigali aurea Tul. & $\mathrm{x}$ & & & $\operatorname{sim}$ & - & J.C.F.Melo Jr., P25-27 \\
\hline Leguminosae & Zollernia ilicifolia (Brongn.) Vogel & $\mathrm{x}$ & $\mathrm{X}$ & & $\operatorname{sim}$ & 2879 & G.C.T.Ceccantini, 3197 \\
\hline Loganiaceae & Strychnos trinervis (Vell.) Mart. & & & $\mathrm{x}$ & $\operatorname{sim}$ & 2386 & G.C.T.Ceccantini, 2877 \\
\hline Lythraceae & Cuphea warmingii Koehne & & $\mathrm{x}$ & & $\operatorname{sim}$ & 2614 & G.C.T.Ceccantini, 3020 \\
\hline Malpighiaceae & Banisteriopsis argyrophylla (A. Juss.) B. Gates & & & $\mathrm{X}$ & $\operatorname{sim}$ & 2248 & G.C.T.Ceccantini, 2678 \\
\hline Malpighiaceae & Banisteriopsis laevifolia (A. Juss.) B. Gates & & $\mathrm{x}$ & & $\operatorname{sim}$ & - & D.G. Rodrigues-Silva \& J.D. Rosário, 482 \\
\hline Malpighiaceae & Banisteriopsis malifolia (Nees \& Mart.) B. Gates & & & $\mathrm{x}$ & $\operatorname{sim}$ & 2240 & G.C.T.Ceccantini, 2670 \\
\hline Malpighiaceae & Banisteriopsis megaphylla (A. Juss.) B. Gates & & $\mathrm{x}$ & & $\operatorname{sim}$ & 2412 & G.C.T.Ceccantini, 2907 \\
\hline Malpighiaceae & Banisteriopsis muricata (Cav.) Cuatrec. & & & $\mathrm{x}$ & $\operatorname{sim}$ & 2235 & G.C.T.Ceccantini, 2665 \\
\hline Malpighiaceae & Bunchosia maritima (Vell.) J.F. Macbr. & $\mathrm{x}$ & & & não & 2784 & G.Q.Freire, 325 \\
\hline Malpighiaceae & Byrsonima cf. crassifolia (L.) Kunth & & $\mathrm{x}$ & & $\operatorname{sim}$ & - & G.C.T.Ceccantini, 3183 \\
\hline Malpighiaceae & Byrsonima coccolobifolia Kunth & $\mathrm{x}$ & & & $\operatorname{sim}$ & 2671 & G.Q.Freire, 228 \\
\hline Malpighiaceae & Byrsonima cydoniifolia A. Juss. & $\mathrm{x}$ & & & não & 2668 & G.Q.Freire, 225 \\
\hline Malpighiaceae & Byrsonima intermedia A. Juss. & & $\mathrm{x}$ & & $\operatorname{sim}$ & 2562 & J.C.F.Melo Jr., 604 \\
\hline Malpighiaceae & Byrsonima ligustrifolia A. Juss. & $\mathrm{x}$ & & & não & 2338 & G.C.T.Ceccantini, 2813 \\
\hline Malpighiaceae & Byrsonima verbascifolia (L.) DC. & $\mathrm{x}$ & & & $\operatorname{sim}$ & 2669 & G.Q.Freire, 226 \\
\hline Malpighiaceae & Dicella bracteosa (A. Juss.) Griseb. & & & $\mathrm{x}$ & $\operatorname{sim}$ & 2727 & G.Q.Freire, 258 \\
\hline Malpighiaceae & Diplopterys pubipetala (A. Juss.) W.R. Anderson \& C.C. Davis & & $\mathrm{x}$ & & $\operatorname{sim}$ & 2430 & G.Q.Freire, 157 \\
\hline Malpighiaceae & Heteropterys byrsonimifolia A. Juss. & $\mathrm{x}$ & & & não & 2600 & G.C.T.Ceccantini, 2995 \\
\hline Malpighiaceae & Heteropterys campestris A. Juss. & & $\mathrm{x}$ & & $\operatorname{sim}$ & 2254 & G.C.T.Ceccantini, 2684 \\
\hline Malpighiaceae & Mascagnia sp & & & $\mathrm{X}$ & prov. & - & D.G. Rodrigues-Silva \& J.D. Rosário, 335 \\
\hline Malpighiaceae & Pterandra pyroidea A. Juss. & & $\mathrm{x}$ & & $\operatorname{sim}$ & 2492 & J.C.F.Melo Jr., 531 \\
\hline Malpighiaceae & Thryallis latifolia Mart. & & & $\mathrm{X}$ & $\operatorname{sim}$ & - & D.G. Rodrigues-Silva \& J.D. Rosário, 254 \\
\hline Malvaceae & Apeiba tibourbou Aubl. & $\mathrm{x}$ & & & $\operatorname{sim}$ & 2695 & J.C.F.Melo Jr., 611 \\
\hline Malvaceae & Guazuma ulmifolia Lam. & $\mathrm{x}$ & & & $\operatorname{sim}$ & 2646 & G.Q.Freire, 202 \\
\hline Malvaceae & Helicteres brevispira A. St.-Hil. & & $\mathrm{x}$ & & $\operatorname{sim}$ & 2687 & G.Q.Freire, 246 \\
\hline Malvaceae & Hibiscus $s p$ & & $\mathrm{x}$ & & não & - & G.C.T.Ceccantini, 3237 \\
\hline Malvaceae & Luehea divaricata Mart. \& Zucc. & $\mathrm{x}$ & & & $\operatorname{sim}$ & 2728 & G.Q.Freire, 259 \\
\hline Malvaceae & Luehea grandiflora Mart. \& Zucc. & $\mathrm{x}$ & & & não & 2757 & G.Q.Freire, 298 \\
\hline Malvaceae & Melochia pyramidata $L$. & & $\mathrm{x}$ & & $\operatorname{sim}$ & - & D.G. Rodrigues-Silva \& J.D. Rosário, 337 \\
\hline
\end{tabular}


APÊNDICE 1

Apêndice 1: Espécies lenhosas encontradas na ACLS Carste de Lagoa Santa com seu respectivo hábito (arv = árvore; arb = arbusto; lia = liana). As espécies encontradas por Warming (War.), o número de registro das amostras de lenho depositadas no herbário SPFw e o nº de coletor também são computadas. Ordenados por família e espécie. Prov= provável.

\begin{tabular}{|c|c|c|c|c|c|c|c|}
\hline Família & Espécie & Arv & Arb & Lia & War. & SPFw & $\mathrm{col} / \mathbf{n}^{\mathbf{o}}$ \\
\hline Malvaceae & Pseudobombax campestre (Mart. \& Zucc.) A. Robyns & $\mathrm{x}$ & & & não & - & D.G. Rodrigues-Silva \& J.D. Rosário, 128 \\
\hline Malvaceae & Pseudobombax grandiflorum (Cav.) A. Robyns & $\mathrm{x}$ & & & $\operatorname{sim}$ & 2735 & G.Q.Freire, 267 \\
\hline Malvaceae & Pseudobombax tomentosum (Mart. \& Zucc.) Robyns & $\mathrm{x}$ & & & $\operatorname{sim}$ & 2372 & G.C.T.Ceccantini, 2858 \\
\hline Malvaceae & Sterculia striata A. St.-Hil. \& Naudin & $\mathrm{x}$ & & & $\operatorname{sim}$ & - & D.G. Rodrigues-Silva \& J.D. Rosário, 192 \\
\hline Malvaceae & Triumfetta semitriloba Jacq. & & $\mathrm{x}$ & & $\operatorname{sim}$ & 2452 & G.Q.Freire, 183 \\
\hline Melastomataceae & Leandra sp & & $\mathrm{x}$ & & prov. & - & D.G. Rodrigues-Silva \& J.D. Rosário, 440 \\
\hline Melastomataceae & Miconia albicans (Sw.) Steud. & $\mathrm{x}$ & & & $\operatorname{sim}$ & 2465 & J.C.F.Melo Jr., 502 \\
\hline Melastomataceae & Miconia burchellii (Sw.) Triana & $\mathrm{x}$ & & & não & 2722 & J.C.F.Melo Jr., 641 \\
\hline Melastomataceae & Miconia calvescens DC. & $\mathrm{x}$ & $\mathrm{x}$ & & $\operatorname{sim}$ & 2715 & J.C.F.Melo Jr., 634 \\
\hline Melastomataceae & Miconia ferruginata $D C$ & $\mathrm{x}$ & & & $\operatorname{sim}$ & 2765 & G.Q.Freire, 306 \\
\hline Melastomataceae & Miconia ibaguensis (Bonpl.) Triana & & $\mathrm{x}$ & & $\operatorname{sim}$ & 2593 & G.C.T.Ceccantini, 2988 \\
\hline Melastomataceae & Miconia latecrenata (DC.) Naudin & & $\mathrm{x}$ & & não & 2633 & G.C.T.Ceccantini, 3042 - B \\
\hline Melastomataceae & Miconia ligustroides (DC.) Naudin & & $\mathrm{x}$ & & $\operatorname{sim}$ & 2656 & G.Q.Freire, 213 \\
\hline Melastomataceae & Miconia macrothyrsa Benth. & & $\mathrm{x}$ & & $\operatorname{sim}$ & 2664 & G.Q.Freire, 221 \\
\hline Melastomataceae & Miconia pepericarpa $D C$ & $\mathrm{x}$ & $\mathrm{x}$ & & $\operatorname{sim}$ & 2693 & J.C.F.Melo Jr., 609 \\
\hline Melastomataceae & Miconia rubiginosa (Bonpl.) DC. & $\mathrm{x}$ & $\mathrm{x}$ & & $\operatorname{sim}$ & 2308 & G.C.T.Ceccantini, 2741 \\
\hline Melastomataceae & Miconia stenostachya DC. & & $\mathrm{x}$ & & $\operatorname{sim}$ & 2307 & G.C.T.Ceccantini, 2740 \\
\hline Melastomataceae & Tibouchina stenocarpa (Schrank \& Mart. ex DC.) Cogn. & $\mathrm{x}$ & $\mathrm{x}$ & & $\operatorname{sim}$ & 2425 & G.C.T.Ceccantini, 2920 \\
\hline Meliaceae & Cabralea canjerana (Vell.) Mart. & $\mathrm{x}$ & & & $\operatorname{sim}$ & - & D.G. Rodrigues-Silva \& J.D. Rosário, 292 \\
\hline Meliaceae & Guarea guidonia (L.) Sleumer & $\mathrm{x}$ & & & $\operatorname{sim}$ & 2566 & G.C.T.Ceccantini, 2951 \\
\hline Meliaceae & Guarea macrophylla Vahl & $\mathrm{x}$ & & & $\operatorname{sim}$ & 2323 & G.C.T.Ceccantini, 2796 \\
\hline Meliaceae & Trichilia catigua A. Juss. & $\mathrm{x}$ & & & $\operatorname{sim}$ & - & J.C.F.Melo Jr., P4-12 \\
\hline Meliaceae & Trichilia clausseni C. DC. & $\mathrm{x}$ & & & $\operatorname{sim}$ & 2565 & G.C.T.Ceccantini, 2950 \\
\hline Meliaceae & Trichilia elegans A. Juss. & $\mathrm{x}$ & & & $\operatorname{sim}$ & - & G.C.T.Ceccantini, 3152 \\
\hline Meliaceae & Trichilia hirta $L$. & $\mathrm{x}$ & & & não & 2616 & G.C.T.Ceccantini, 3024 \\
\hline Meliaceae & Trichilia pallida $S w$ & $\mathrm{x}$ & & & $\operatorname{sim}$ & 2641 & G.Q.Freire, 197 \\
\hline Menispermaceae & Cissampelos glaberrima A. St.-Hil. & & & $\mathrm{x}$ & $\operatorname{sim}$ & - & G.C.T.Ceccantini, 2967 \\
\hline Menispermaceae & Odontocarya acuparata Miers & & & $\mathrm{x}$ & não & - & D.G. Rodrigues-Silva \& J.D. Rosário, 374 \\
\hline Moraceae & Brosimum gaudichaudii Trécul & & $\mathrm{x}$ & & $\operatorname{sim}$ & 2636 & G.C.T.Ceccantini, 3046 \\
\hline Moraceae & Ficus calyptroceras (Miq.) Miq. & $\mathrm{x}$ & & & $\operatorname{sim}$ & - & D.G. Rodrigues-Silva \& J.D. Rosário, 171 \\
\hline Moraceae & Ficus obtusifolia Kunth & $\mathrm{x}$ & & & $\operatorname{sim}$ & 2479 & J.C.F.Melo Jr., 518 \\
\hline
\end{tabular}


APÊNDICE 1

Apêndice 1: Espécies lenhosas encontradas na ACLS Carste de Lagoa Santa com seu respectivo hábito (arv = árvore; arb = arbusto; lia = liana). As espécies encontradas por Warming (War.), o número de registro das amostras de lenho depositadas no herbário SPFw e o nº de coletor também são computadas. Ordenados por família e espécie. Prov= provável.

\begin{tabular}{|c|c|c|c|c|c|c|}
\hline Família & Espécie & Arv & Arb Lia & War. & SPFw & $\mathrm{col} / \mathrm{n}^{0}$ \\
\hline Moraceae & Maclura tinctoria (L.) D.Don ex Steud. & $\mathrm{X}$ & & $\operatorname{sim}$ & 2504 & J.C.F.Melo Jr., 545 \\
\hline Myrsinaceae & Geissanthus ambiguus (Mart.) G.Agostini & $\mathrm{x}$ & $\mathrm{x}$ & $\operatorname{sim}$ & 2354 & G.C.T.Ceccantini, 2836 \\
\hline Myrsinaceae & Myrsine coriacea (Sw.) R. Br. ex Roem. \& Schult. & $\mathrm{x}$ & & $\operatorname{sim}$ & 2408 & G.C.T.Ceccantini, 2903 \\
\hline Myrsinaceae & Myrsine guianensis (Aubl.) Kuntze & $\mathrm{x}$ & & $\operatorname{sim}$ & - & J.C.F.Melo Jr., 619 \\
\hline Myrsinaceae & Myrsine umbellata Mart. & $\mathrm{x}$ & & $\operatorname{sim}$ & - & J.C.F.Melo Jr., P26-30 \\
\hline Myrtaceae & Calyptranthes concinna DC. & $\mathrm{x}$ & & não & 2567 & G.C.T.Ceccantini, 2952 \\
\hline Myrtaceae & Campomanesia adamantium (Cambess.) O.Berg & & $\mathrm{x}$ & $\operatorname{sim}$ & 2564 & J.C.F.Melo Jr., 606 \\
\hline Myrtaceae & Campomanesia guaviroba (DC.) Kiaersk. & $\mathrm{x}$ & & prov. & 2596 & G.C.T.Ceccantini, 2991 \\
\hline Myrtaceae & Campomanesia guazumifolia (Cambess.) O.Berg & & $\mathrm{x}$ & $\operatorname{sim}$ & 2628 & G.C.T.Ceccantini, 3037 \\
\hline Myrtaceae & Eugenia aurata O.Berg & $\mathrm{x}$ & & $\operatorname{sim}$ & 2710 & J.C.F.Melo Jr., 629 \\
\hline Myraceae & Eugenia acutata Miq. & $\mathrm{x}$ & & & & J.C.F.Melo Jr., 560 \\
\hline Myrtaceae & Eugenia bimarginata $D C$. & & $\mathrm{x}$ & $\operatorname{sim}$ & 2560 & J.C.F.Melo Jr., 602 \\
\hline Myrtaceae & Eugenia dysenterica DC. & $\mathrm{x}$ & & $\operatorname{sim}$ & 2791 & G.Q.Freire, 154 \\
\hline Myrtaceae & Eugenia florida $D C$. & $\mathrm{x}$ & & $\operatorname{sim}$ & - & J.C.F.Melo Jr., P13-10 \\
\hline Myrtaceae & Eugenia hiemalis Cambess. & $\mathrm{x}$ & & não & - & D.G. Rodrigues-Silva \& J.D. Rosário, 423 \\
\hline Myrtaceae & Eugenia involucrata DC. & & $\mathrm{x}$ & $\operatorname{sim}$ & 2508 & J.C.F.Melo Jr., 549 \\
\hline Myrtaceae & Eugenia punicifolia (Kunth) DC. & $\mathrm{x}$ & & $\operatorname{sim}$ & 2413 & G.C.T.Ceccantini, 2908 \\
\hline Myrtaceae & Eugenia subterminalis DC. & & $\mathrm{x}$ & não & 2725 & G.Q.Freire, 256 \\
\hline Myrtaceae & Eugenia theodorae Kiaersk. & & $\mathrm{x}$ & $\operatorname{sim}$ & 2543 & J.C.F.Melo Jr., 585 \\
\hline Myrtaceae & Myrcia hebepetala DC. & $\mathrm{x}$ & & $\operatorname{sim}$ & - & J.C.F.Melo Jr., P30-2 \\
\hline Myrtaceae & Myrcia multiflora (Lam.) DC. & & $\mathrm{x}$ & $\operatorname{sim}$ & 2632 & G.C.T.Ceccantini, 3041 \\
\hline Myrtaceae & Myrcia rufipes $D C$. & $\mathrm{x}$ & & $\operatorname{sim}$ & 2590 & G.C.T.Ceccantini, 2983 \\
\hline Myrtaceae & Myrcia splendens (Sw.) DC. & $\mathrm{x}$ & & $\operatorname{sim}$ & 2490 & J.C.F.Melo Jr., 529 \\
\hline Myrtaceae & Myrcia tomentosa (Aubl.) DC. & $\mathrm{x}$ & & $\operatorname{sim}$ & 2523 & J.C.F.Melo Jr., 565 \\
\hline Myrtaceae & Myrcia variabilis Mart. ex DC. & $\mathrm{x}$ & & $\operatorname{sim}$ & 2496 & J.C.F.Melo Jr., 535 \\
\hline Myrtaceae & Plinia cauliflora (Mart.) Kausel & $\mathrm{x}$ & & $\operatorname{sim}$ & 2468 & J.C.F.Melo Jr., 505 \\
\hline Myrtaceae & Psidium firmum O.Berg & & $\mathrm{x}$ & $\operatorname{sim}$ & - & G.Q.Freire, 159 \\
\hline Myrtaceae & Psidium guineense $S w$. & & $\mathrm{x}$ & $\operatorname{sim}$ & 2689 & G.Q.Freire, 248 \\
\hline Myrtaceae & Siphoneugena cf. densiflora O.Berg & $\mathrm{x}$ & & $\operatorname{sim}$ & - & J.C.F.Melo Jr., P18-24 \\
\hline Nyctaginaceae & Guapira noxia (Netto) Lundell & $\mathrm{x}$ & & $\operatorname{sim}$ & - & J.C.F.Melo Jr., P27-13 \\
\hline Nyctaginaceae & Guapira opposita (Vell.) Reitz & $\mathrm{x}$ & & não & - & J.C.F.Melo Jr., P23-4 \\
\hline
\end{tabular}


APÊNDICE 1

Apêndice 1: Espécies lenhosas encontradas na ACLS Carste de Lagoa Santa com seu respectivo hábito (arv = árvore; arb = arbusto; lia = liana). As espécies encontradas por Warming (War.), o número de registro das amostras de lenho depositadas no herbário SPFw e o nº de coletor também são computadas. Ordenados por família e espécie. Prov= provável.

\begin{tabular}{|c|c|c|c|c|c|c|c|}
\hline Família & Espécie & Arv & Arb & Lia & War. & SPFw & $\mathrm{col} / \mathrm{n}^{\circ}$ \\
\hline Nyctaginaceae & Neea $(c f)$ & $\mathrm{x}$ & & & prov. & 2498 & J.C.F.Melo Jr., 537 \\
\hline Ochnaceae & Ouratea castaneifolia (DC.) Engl. & $\mathrm{x}$ & & & $\operatorname{sim}$ & 2541 & J.C.F.Melo Jr., 583 \\
\hline Phyllanthaceae & Margaritaria nobilis L.f. & $\mathrm{x}$ & & & $\operatorname{sim}$ & 2264 & G.C.T.Ceccantini, 2694 \\
\hline Phyllanthaceae & Phyllanthus acuminatus Vahl & $\mathrm{x}$ & & & $\operatorname{sim}$ & 2627 & G.C.T.Ceccantini, 3036 \\
\hline Picramniaceae & Picramnia sellowii Planch. & $\mathrm{x}$ & & & $\operatorname{sim}$ & 2378 & G.C.T.Ceccantini, 2866 \\
\hline Piperaceae & Piper amalago $L$. & $\mathrm{x}$ & & & $\operatorname{sim}$ & 2714 & J.C.F.Melo Jr., 633 \\
\hline Polygalaceae & Bredemeyera floribunda Willd. & $\mathrm{x}$ & & & $\operatorname{sim}$ & 2698 & J.C.F.Melo Jr., 614 \\
\hline Proteaceae & Roupala montana Aubl. & $\mathrm{x}$ & & & $\operatorname{sim}$ & 2880 & G.C.T.Ceccantini, 3198 \\
\hline Rhamnaceae & Gouania virgata Reissek & & & $\mathrm{x}$ & $\operatorname{sim}$ & 2788 & G.Q.Freire, 329 \\
\hline Rosaceae & Prunus myrtifolia (L.) Urb. & $\mathrm{x}$ & & & $\operatorname{sim}$ & - & D.G. Rodrigues-Silva \& J.D. Rosário, 435 \\
\hline Rubiaceae & Amaioua intermedia Mart. ex Schult. \& Schult.f. & $\mathrm{x}$ & & & $\operatorname{sim}$ & - & D.G. Rodrigues-Silva \& J.D. Rosário, 377 \\
\hline Rubiaceae & Chiococca alba (L.) Hitchc. & & $\mathrm{x}$ & & $\operatorname{sim}$ & 2620 & G.C.T.Ceccantini, 3029 \\
\hline Rubiaceae & Chomelia obtusa Cham. \& Schltdl. & $\mathrm{x}$ & $\mathrm{x}$ & & $\operatorname{sim}$ & - & D.G. Rodrigues-Silva \& J.D. Rosário, 297 \\
\hline Rubiaceae & Chomelia ribesioides Benth. ex A.Gray & $\mathrm{x}$ & $\mathrm{x}$ & & $\operatorname{sim}$ & - & D.G. Rodrigues-Silva \& J.D. Rosário, 146 \\
\hline Rubiaceae & Cordiera concolor (Cham.) Kuntze & $\mathrm{x}$ & & & não & - & J.C.F.Melo Jr., P31-21 \\
\hline Rubiaceae & Cordiera macrophylla (K.Schum.) Kuntze & $\mathrm{x}$ & & & não & - & J.C.F.Melo Jr., P28-41 \\
\hline Rubiaceae & Coussarea hydrangeifolia (Benth.) Müll.Arg. & $\mathrm{x}$ & & & $\operatorname{sim}$ & - & G.C.T.Ceccantini, 2880 \\
\hline Rubiaceae & Faramea $(c f)$ & $\mathrm{x}$ & & & prov. & 2820 & G.C.T.Ceccantini, 3159 \\
\hline Rubiaceae & Genipa americana $L$ & $\mathrm{x}$ & & & $\operatorname{sim}$ & 2376 & G.C.T.Ceccantini, 2864 \\
\hline Rubiaceae & Guettarda viburnoides Cham. \& Schltdl. & $\mathrm{x}$ & $\mathrm{x}$ & & $\operatorname{sim}$ & 2571 & G.C.T.Ceccantini, 2961 \\
\hline Rubiaceae & Hamelia patens Jacq. & $\mathrm{x}$ & $\mathrm{x}$ & & $\operatorname{sim}$ & 2692 & J.C.F.Melo Jr., 608 \\
\hline Rubiaceae & Ixora brevifolia Benth. & $\mathrm{x}$ & & & $\operatorname{sim}$ & 2711 & J.C.F.Melo Jr., 630 \\
\hline Rubiaceae & Palicourea rigida Kunth & $\mathrm{x}$ & $\mathrm{x}$ & & $\operatorname{sim}$ & 2486 & J.C.F.Melo Jr., 525 \\
\hline Rubiaceae & Psychotria capitata Ruiz \& Pav. & & $\mathrm{x}$ & & $\operatorname{sim}$ & 2667 & G.Q.Freire, 224 \\
\hline Rubiaceae & Psychotria carthagenensis Jacq. & & $\mathrm{x}$ & & $\operatorname{sim}$ & 2606 & G.C.T.Ceccantini, 3001 \\
\hline Rubiaceae & Psychotria vellosiana Benth. & $\mathrm{x}$ & & & não & 2716 & J.C.F.Melo Jr., 635 \\
\hline Rubiaceae & Psychotria warmingii Müll.Arg. & & $\mathrm{x}$ & & $\operatorname{sim}$ & - & D.G. Rodrigues-Silva \& J.D. Rosário, 375 \\
\hline Rubiaceae & Randia armata $(S w) D C$. & $\mathrm{x}$ & & & $\operatorname{sim}$ & 2731 & G.Q.Freire, 263 \\
\hline Rubiaceae & Rudgea corymbulosa Benth. & $\mathrm{x}$ & & & não & - & G.C.T.Ceccantini, 2978 \\
\hline Rubiaceae & Rudgea viburnoides (Cham.) Benth. & $\mathrm{x}$ & & & $\operatorname{sim}$ & 2480 & J.C.F.Melo Jr., 519 \\
\hline Rubiaceae & Tocoyena formosa (Cham. \& Schltdl.) K.Schum. & $\mathrm{x}$ & & & $\operatorname{sim}$ & 2767 & G.Q.Freire, 308 \\
\hline
\end{tabular}


APÊNDICE 1

Apêndice 1: Espécies lenhosas encontradas na ACLS Carste de Lagoa Santa com seu respectivo hábito (arv = árvore; arb = arbusto; lia = liana). As espécies encontradas por Warming (War.), o número de registro das amostras de lenho depositadas no herbário SPFw e o nº de coletor também são computadas. Ordenados por família e espécie. Prov= provável.

\begin{tabular}{|c|c|c|c|c|c|c|c|}
\hline Família & Espécie & Arv & Arb & Lia & War. & SPFw & $\mathrm{col} / \mathrm{n}^{\mathbf{0}}$ \\
\hline Rutaceae & Conchocarpus pentandrus (A. St.-Hil.) Kallunki \& Pirani & $\mathrm{x}$ & & & não & - & D.G. Rodrigues-Silva \& J.D. Rosário, 76 \\
\hline Rutaceae & Dictyoloma vandellianum A.H.L. Juss. & $\mathrm{x}$ & & & $\operatorname{sim}$ & 2635 & G.C.T.Ceccantini, 3044 \\
\hline Rutaceae & Galipea jasminiflora (A. St.-Hil.) Engl. & $\mathrm{x}$ & $\mathrm{x}$ & & $\operatorname{sim}$ & 2713 & J.C.F.Melo Jr., 632 \\
\hline Rutaceae & Zanthoxylum rhoifolium Lam. & $\mathrm{x}$ & & & $\operatorname{sim}$ & 2874 & G.C.T.Ceccantini, 3192 \\
\hline Rutaceae & Zanthoxylum riedelianum Engl. & $\mathrm{x}$ & & & $\operatorname{sim}$ & 2869 & G.C.T.Ceccantini, 3177 \\
\hline Salicaceae & Azara sp & $\mathrm{x}$ & & & não & - & D.G. Rodrigues-Silva \& J.D. Rosário, 139 \\
\hline Salicaceae & Casearia arborea (Rich.) Urb. & $\mathrm{x}$ & $\mathrm{X}$ & & $\operatorname{sim}$ & 2538 & J.C.F.Melo Jr., 580 \\
\hline Salicaceae & Casearia sylvestris $S w$ & $\mathrm{x}$ & & & $\operatorname{sim}$ & 2438 & G.Q.Freire, 167 \\
\hline Salicaceae & Prockia crucis $P$. Browne ex $L$. & $\mathrm{x}$ & & & $\operatorname{sim}$ & 2579 & G.C.T.Ceccantini, 2971 \\
\hline Sapindaceae & Allophylus sericeus (Cambess.) Radlk. & $\mathrm{x}$ & & & $\operatorname{sim}$ & 2510 & J.C.F.Melo Jr., 551 \\
\hline Sapindaceae & Cupania oblongifolia Mart. & $\mathrm{x}$ & & & não & - & J.C.F.Melo Jr., P6-16 \\
\hline Sapindaceae & Cupania vernalis Cambess. & $\mathrm{x}$ & & & $\operatorname{sim}$ & 2613 & G.C.T.Ceccantini, 3008 \\
\hline Sapindaceae & Cupania zanthoxyloides Radlk. & $\mathrm{x}$ & & & não & 2520 & J.C.F.Melo Jr., 562 \\
\hline Sapindaceae & Dilodendron bipinnatum Radlk. & $\mathrm{x}$ & & & $\operatorname{sim}$ & 2392 & G.C.T.Ceccantini, 2885 \\
\hline Sapindaceae & Magonia pubescens A. St.-Hil. & $\mathrm{x}$ & & & $\operatorname{sim}$ & 2253 & G.C.T.Ceccantini, 2683 \\
\hline Sapindaceae & Matayba elaeagnoides Radlk. & $\mathrm{x}$ & & & não & 2500 & J.C.F.Melo Jr., 541 \\
\hline Sapindaceae & Matayba guianensis Aubl. & $\mathrm{x}$ & & & $\operatorname{sim}$ & 2594 & G.C.T.Ceccantini, 2989 \\
\hline Sapindaceae & Paullinia elegans Cambess. & & & $\mathrm{x}$ & $\operatorname{sim}$ & - & D.G. Rodrigues-Silva \& J.D. Rosário, 205 \\
\hline Sapindaceae & Paullinia meliifolia Juss. & & & $\mathrm{x}$ & prov. & 2516 & J.C.F.Melo Jr., 558 \\
\hline Sapindaceae & Paullinia trigonia Vell. & & & $\mathrm{x}$ & não & 2374 & G.C.T.Ceccantini, 2862 \\
\hline Sapindaceae & Serjania laruotteana Cambess. & & & $\mathrm{x}$ & não & 2406 & G.C.T.Ceccantini, 2901 \\
\hline Sapindaceae & Serjania lethalis A.St.-Hil. & & & $\mathrm{x}$ & não & 2792 & G.Q.Freire, 155 \\
\hline Sapindaceae & Serjania multiflora Cambess. & & & $\mathrm{x}$ & não & 2619 & G.C.T.Ceccantini, 3028 \\
\hline Sapindaceae & Serjania reticulata Cambess. & & & $\mathrm{x}$ & não & 2741 & G.Q.Freire, 274 \\
\hline Sapindaceae & Serjania tristis Radlk. & & & $\mathrm{x}$ & não & 2724 & G.Q.Freire, 255 \\
\hline Sapotaceae & Chrysophyllum gonocarpum (Mart. \& Eichler ex Miq.) Engl. & $\mathrm{x}$ & & & $\operatorname{sim}$ & - & D.G. Rodrigues-Silva \& J.D. Rosário, 54 \\
\hline Sapotaceae & Chrysophyllum marginatum (Hook. \& Arn.) Radlk. & $\mathrm{x}$ & & & $\operatorname{sim}$ & 2672 & G.Q.Freire, 229 \\
\hline Sapotaceae & Pouteria cf. ramiflora (Mart.) Radlk. & $\mathrm{x}$ & & & $\operatorname{sim}$ & - & G.C.T.Ceccantini, 3196 \\
\hline Sapotaceae & Pouteria torta (Mart.) Radlk. & $\mathrm{x}$ & & & $\operatorname{sim}$ & 2424 & G.C.T.Ceccantini, 2919 \\
\hline Scrophulariaceae & Buddleja stachyoides Cham. \& Schltdl. & & $\mathrm{X}$ & & $\operatorname{sim}$ & - & D.G. Rodrigues-Silva \& J.D. Rosário, 483 \\
\hline Simaroubaceae & Simarouba sp & $\mathrm{x}$ & & & não & - & D.G. Rodrigues-Silva \& J.D. Rosário, 235 \\
\hline
\end{tabular}


APÊNDICE 1

Apêndice 1: Espécies lenhosas encontradas na ACLS Carste de Lagoa Santa com seu respectivo hábito (arv = árvore; arb = arbusto; lia = liana). As espécies encontradas por Warming (War.), o número de registro das amostras de lenho depositadas no herbário SPFw e o nº de coletor também são computadas. Ordenados por família e espécie. Prov= provável.

\begin{tabular}{|c|c|c|c|c|c|c|c|}
\hline Família & Espécie & Arv & Arb & Lia & War. & SPFw & $\mathrm{col} / \mathrm{n}^{\mathrm{o}}$ \\
\hline Siparunaceae & Siparuna guianensis Aubl. & $\mathrm{x}$ & & & $\operatorname{sim}$ & 2577 & G.C.T.Ceccantini, 2968 \\
\hline Smilacaceae & Smilax $(c f)$ & & & $\mathrm{x}$ & prov. & 2533 & J.C.F.Melo Jr., 575 \\
\hline Solanaceae & Brunfelsia uniflora (Pohl) D. Don & & $\mathrm{X}$ & & não & 2528 & J.C.F.Melo Jr., 570 \\
\hline Solanaceae & Capsicum flexuosum Sendtn. & & $\mathrm{x}$ & & não & - & D.G. Rodrigues-Silva \& J.D. Rosário, 331 \\
\hline Solanaceae & Cestrum axillare Vell. & $\mathrm{x}$ & $\mathrm{x}$ & & $\operatorname{sim}$ & 2467 & J.C.F.Melo Jr., 504 \\
\hline Solanaceae & Cestrum schlechtendalii G. Don & $\mathrm{x}$ & & & $\operatorname{sim}$ & 2363 & G.C.T.Ceccantini, 2847 \\
\hline Solanaceae & Cestrum strigilatum Ruiz \& Pav. & & $\mathrm{x}$ & & $\operatorname{sim}$ & 2451 & G.Q.Freire, 182 \\
\hline Solanaceae & Cestrum velutinum Hiern & & $\mathrm{x}$ & & $\operatorname{sim}$ & - & G.Q.Freire, 238 \\
\hline Solanaceae & Solanum alternatopinnatum Steud. & & & $\mathrm{x}$ & $\operatorname{sim}$ & - & G.C.T.Ceccantini, 2873 \\
\hline Solanaceae & Solanum decompositiflorum Sendtn. & & $\mathrm{x}$ & & não & 2230 & G.C.T.Ceccantini, 2659 \\
\hline Solanaceae & Solanum granulosoleprosum Dunal & $\mathrm{x}$ & & & não & - & D.G. Rodrigues-Silva \& J.D. Rosário, 390 \\
\hline Solanaceae & Solanum lycocarpum A. St.-Hil. & $\mathrm{x}$ & & & $\operatorname{sim}$ & 2670 & G.Q.Freire, 227 \\
\hline Solanaceae & Solanum paniculatum L. & $\mathrm{x}$ & $\mathrm{x}$ & & $\operatorname{sim}$ & 2678 & G.Q.Freire, 236 \\
\hline Solanaceae & Solanum scuticum M.Nee & $\mathrm{x}$ & & & $\operatorname{sim}$ & 2449 & G.Q.Freire, 180 \\
\hline Solanaceae & Solanum sublentum Hieron. & & $\mathrm{x}$ & & $\operatorname{sim}$ & 2337 & G.C.T.Ceccantini, 2812 \\
\hline Solanaceae & Solanum variabile Mart. & $\mathrm{x}$ & & & não & 2573 & G.C.T.Ceccantini, 2963 \\
\hline Solanaceae & Solanum viarum Dunal Schrank & & $\mathrm{x}$ & & não & - & D.G. Rodrigues-Silva \& J.D. Rosário, 35 \\
\hline Styracaceae & Styrax camporum Pohl & $\mathrm{x}$ & $\mathrm{x}$ & & $\operatorname{sim}$ & 2661 & G.Q.Freire, 218 \\
\hline Styracaceae & Styrax ferrugineus Nees \& Mart. & $\mathrm{x}$ & & & $\operatorname{sim}$ & 2764 & G.Q.Freire, 305 \\
\hline Symplocaceae & Symplocos nitens (Pohl) Benth. & $\mathrm{x}$ & & & não & 2494 & J.C.F.Melo Jr., 533 \\
\hline Urticaceae & Boehmeria caudata $S w$. & $\mathrm{x}$ & $\mathrm{x}$ & & $\operatorname{sim}$ & 2226 & G.C.T.Ceccantini, 2655 \\
\hline Urticaceae & Cecropia pachystachya Trécul & $\mathrm{x}$ & & & prov. & 2506 & J.C.F.Melo Jr., 547 \\
\hline Urticaceae & Urera baccifera (L.) Gaudich. ex Wedd. & $\mathrm{x}$ & $\mathrm{x}$ & & $\operatorname{sim}$ & 2622 & G.C.T.Ceccantini, 3031 \\
\hline Verbenaceae & Lantana camara $L$. & & $\mathrm{x}$ & & $\operatorname{sim}$ & 2260 & G.C.T.Ceccantini, 2690 \\
\hline Verbenaceae & Lantana trifolia $L$ & & $\mathrm{x}$ & & $\operatorname{sim}$ & - & D.G. Rodrigues-Silva \& J.D. Rosário, 268 \\
\hline Verbenaceae & Lippia martiana Schauer & & $\mathrm{x}$ & & $\operatorname{sim}$ & 2651 & G.Q.Freire, 207 \\
\hline Verbenaceae & Lippia velutina Schauer & $\mathrm{x}$ & & & não & 2345 & G.C.T.Ceccantini, 2821 \\
\hline Violaceae & Hybanthus atropurpureus (A. St.-Hil.) Taub. & & $\mathrm{x}$ & & $\operatorname{sim}$ & 2505 & J.C.F.Melo Jr., 546 \\
\hline Vitaceae & Cissus sulcicaulis (Baker) Planch. & & & $\mathrm{X}$ & não & 2707 & J.C.F.Melo Jr., 624 \\
\hline Vochysiaceae & Callisthene major Mart. \& Zucc. & $\mathrm{x}$ & & & não & 2796 & J.C.F.Melo Jr., 814 \\
\hline Vochysiaceae & Qualea cordata (Mart.) Spreng. & $\mathrm{x}$ & & & $\operatorname{sim}$ & - & D.G. Rodrigues-Silva \& J.D. Rosário, 281 \\
\hline
\end{tabular}


APÊNDICE 1

Apêndice 1: Espécies lenhosas encontradas na ACLS Carste de Lagoa Santa com seu respectivo hábito (arv = árvore; arb = arbusto; lia = liana). As espécies encontradas por Warming (War.), o número de registro das amostras de lenho depositadas no herbário SPFw e o no de coletor também são computadas. Ordenados por família e espécie. Prov= provável.

\begin{tabular}{|c|c|c|c|c|c|c|}
\hline Família & Espécie & Arv & Arb Lia & War. & SPFw & $\mathrm{col} / \mathbf{n}^{\circ}$ \\
\hline Vochysiaceae & Qualea grandiflora Mart. & $\mathrm{x}$ & & $\operatorname{sim}$ & 2854 & J.C.F.Melo Jr., 816 \\
\hline Vochysiaceae & Qualea multiflora Mart. & $\mathrm{x}$ & & $\operatorname{sim}$ & 2768 & G.Q.Freire, 309 \\
\hline Vochysiaceae & Qualea parviflora Mart. & $\mathrm{x}$ & & $\operatorname{sim}$ & 2760 & G.Q.Freire, 301 \\
\hline Vochysiaceae & Salvertia convallariodora A. St.-Hil. & $\mathrm{x}$ & & $\operatorname{sim}$ & 2759 & G.Q.Freire, 300 \\
\hline Vochysiaceae & Vochysia rufa Mart. & $\mathrm{x}$ & & $\operatorname{sim}$ & 2701 & J.C.F.Melo Jr., 618 \\
\hline Vochysiaceae & Vochysia tucanorum Mart. & $\mathrm{x}$ & & $\operatorname{sim}$ & 2742 & G.Q.Freire, 277 \\
\hline
\end{tabular}




\section{APÊNDICE 2}

\section{DESCRIÇÃO MICROSCÓPICA DA ANATOMIA DOS MORFOTIPOS FÓSSEIS IDENTIFICADOS NO CAPÍTULO 3}





\section{Morfotipo: 1}

\section{Identificação: Astronium / Myracrodruon sp (ANACARDIACEAE)}

\section{Amostra: RMT 2157*15}

Datação: Holoceno tardio

Descrição anatômica: camada de crescimento não visível (indistinta?); porosidade difusa(?); vasos solitários e múltiplos, de frequência média a alta; diâmetro de vaso pequeno(2 tamanhos?); obstrução por tilos; placa de perfuração simples; pontoação intervascular alterna, grande, guarnecida; pontoação radiovascular redonda a angular(?), escalariforme a vertical(?); fibra septada, ; parênquima axial não abundante (não foi possível determinar), marginal(?), difuso em agregado(?); raios baixos, de frequência mediana, com 1 a 3 (bisseriados?) células de largura, com vários tipos de composição celular, predominando 1 a 4 fileiras marginais de células eretas; canais intercelulares radiais.

\section{Morfotipo: 2}

\section{Identificação: Lithraea molleoides (ANACARDIACEAE)}

\section{Amostra: RMT 2040*}

Datação: Holoceno tardio

Descrição anatômica: camada de crescimento distinta por zona fibrosa, por parênquima marginal(?); porosidade difusa; vasos solitários e múltiplos, de frequência alta; diâmetro de vaso médio; obstrução por tilos; placa de perfuração simples; pontoação intervascular alterna, de tamanho médio, com pequena abertura; pontoação radiovascular escalariforme a vertical(?); pontoação de fibras simples à diminutamente areolada; espessura da parede das fibras mediana; fibra septada; parênquima axial apotraqueal, paratraqueal, vasicêntrico escasso, difuso em agregados(?) ou marginal descontínuo(?); série fusiforme com 3 a 4 células; raios de frequência mediana, uni(?) e bisseriados, de altura variável, com 1 a 4 fileiras marginais de células eretas.

\footnotetext{
${ }^{15}$ Asterisco indica a amostra-tipo utilizada para identificar os respectivos morfotipos
} 


\section{Morfotipo: 3}

\section{Identificação: Aspidosperma polyneuron Müll.Arg.(APOCYNACEAE)}

Amostra: RMT 970*

Datação: Holoceno médio

Descrição anatômica: camada de crescimento pouco distinta por zona fibrosa; porosidade difusa; vasos solitários e múltiplos; espessamento helicoidal não visível; contorno dos vasos solitários não visível; diâmetro de vaso pequeno a médio, de frequência muito alta; obstrução por tilos; placa de perfuração simples; pontoação intervascular alterna de tamanho médio; pontoação radiovascular com areola distinta, similar a pontoação intervascular; pontoação de fibras areolada; fibra septada ausente; espessura da parede das fibras fina a espessa; traqueíde vascular presente; parênquima axial apotraqueal, difuso, difuso em agregados; série fusiforme com 3 a 4 e 5 a 8(?) células; raios bisseriados, de altura baixa a média, com apenas células procumbentes, frequência mediana; estratificação ausente; células oleíferas não visíveis; canais intercelulares não visíveis; cristais prismáticos no parênquima axial subdividido, com 1 cristal por subdivisão.

Processo de Identificação: o gênero Aspidosperma compreende espécies arbóreas de valor econômico, popularmente conhecidas como Peroba. Assim, existe bastante material de referência tanto no laminário da xiloteca BCTw quanto no banco on-line Inside Wood (2004-onwrads ${ }^{16}$ ). Em Lagoa Santa, MG, Warming (1908) identificou 7 espécies: $A$. australe Müll.Arg., A. cylindrocarpon Müll.Arg., A. polyneuron Müll.Arg., A. spruceanum Benth. ex Müll. Arg., A. subincanum Mart., A. tomentosum Mart., A. warmingii). Apenas a última espécie não foi consultada pela ausência de material de referência. Dentre as espécies com histologia consultada, verificou-se grande similaridade com A. ramiflorum e A. polyneuron e A. spruceanum, pois a presença de raios unisseriados, camada de crescimento indistinta e vasos menos frequentes excluíram as restantes. Dentre elas, a única espécie em que foram vistos tilos, consultados no laminário BCTw e no banco de imagens Inside Wood, foi A. polyneuron. As outras duas ainda diferiram da amostra fóssil por apresentarem ou raios multisseriados com prolongamentos unisseriados significativo ou menor frequência de vasos.

\footnotetext{
${ }^{16}$ Referência consta no capítulo 3
} 


\section{Morfotipo: 4}

\section{Identificação: Maytenus sp (CELASTRACEAE)}

Amostra: RMT 873, RMT 1958, RMT 1974*

Datação: Holoceno médio

Descrição anatômica: camada de crescimento indistinta; porosidade difusa; vasos exclusivamente solitários(?), solitários e múltiplos(?); diâmetro de vaso médio a grande, de frequência alta; obstrução por substância orgânica; placa de perfuração simples; pontoação intervascular alterna pequena, diminuta(?); pontoação radiovascular com areola distinta, similar a pontoação intervascular; pontoação de fibras areolada; espessura da parede das fibras mediana a espessa; fibras septadas parecidas com parênquima axial;traqueíde vascular presente(?); parênquima axial ausente ou extremamente raro; raios de 1 a 3 células, de altura variável, com 2 a 4 fileiras marginais de células eretas/quadradas, mais de 4 fileiras marginais de células eretas/quadradas, de frequência alta; células com parede disjuntiva.

\section{Morfotipo: 5}

\section{Identificação: Celtis sp (CANNABACEAE)}

\section{Amostra: RMT 2154-2*, RMT 2158, RMT 2163}

\section{Datação: Holoceno tardio}

Descrição anatômica: camada de crescimento distinta por zona fibrosa; porosidade em anel semi-poroso(?); vasos solitários e múltiplos, cachos (raros), de frequiência média; diâmetro de vaso variável; obstrução por tilos; placa de perfuração simples; pontoação intervascular alterna, de tamanho médio; pontoação radiovascular com aréola distinta, similar a pontoação intervascular; espessura da parede das fibras mediana(?); parênquima axial paratraqueal, concêntrico(?), aliforme, confluente formando linhas/faixas; série fusiforme com duas, 3 a 4 células; raios de freqüência mediana, de 1 a 3 (comumente bi) células de largura, de altura média, com apenas células procumbentes (?); cristais prismáticos presentes(?) no parênquima axial, em células subdivididas, 1 cristal por subdivisão. 


\section{Morfotipo: 6}

\section{Identificação: Combretum sp (COMBRETACEAE)}

Amostra: RMT 881 e RMT 899*

Datação: Holoceno médio

Descrição anatômica: camada de crescimento não visível (indistinta?); porosidade difusa; vasos exclusivamente solitários (90\% ou mais); diâmetro de vaso muito grande; vasos de dois tamanhos distintos; obstrução ausente; placa de perfuração simples; pontoação intervascular alterna grande, guarnecida; pontoação radiovascular com areola distinta, similar a pontoação intervascular; parede das fibras fina a espessa; parênquima axial presente (não foi possível compreender sua distribuição); série fusiforme com 3 a 4, 5 a 8 células; raios unisseriados (localmente bi), altos, com apenas células procumbentes, de frequiência alta; células alargadas (oleíferas ou com cristais?) no raio; floema incluso difuso.

\section{Morfotipo: 7}

\section{Identificação: Terminalia spl (COMBRETACEAE)}

Amostra: RMT 2125 e RMT 2170*

Datação: Holoceno tardio (amostra RMT 2125 datada entre 2010 e 1870 anos A.P.cal.)

Descrição anatômica: camada de crescimento distinta, por espessamento de fibra(?), parênquima marginal(?); porosidade difusa(?); vasos solitários e múltiplos, de frequência alta; obstrução por substância orgânica; placa de perfuração simples(?); pontoação intervascular alterna, de tamanho médio, guarnecida; pontoação radiovascular com aréola distinta, similar a pontoação intervascular; parede das fibras espessa; parênquima axial paratraqueal, concêntrico(?), marginal, vasicêntrico, aliforme; série fusiforme com 3 a 4 células; raios de frequência mediana, unisseriados, podendo haver bisseriados, baixos a médios, com apenas células procumbentes.

\section{Morfotipo: 8}

Identificação: Terminalia sp2 (COMBRETACEAE)

Amostra: RMT 2099*, RMT 2186 e RMT 2200

Datação: Holoceno médio (amostra RMT 2200 datada entre 5600 e 5470 anos A.P.cal.) 
Descrição anatômica: camada de crescimento distinta, por parênquima marginal(?); porosidade difusa; vasos solitários e múltiplos, de frequência média; diâmetro de vaso médio a grande; obstrução por substância orgânica; placa de perfuração simples; pontoação intervascular alterna, de tamanho médio, guarnecida, de formato poligonal; pontoação radiovascular com aréola distinta, similar a pontoação intervascular; fibra septada ausente; parênquima axial paratraqueal(?), concêntrico, vasicêntrico, aliforme, marginal(?); série fusiforme com 2(?), 3 a 4 células; raios de frequência mediana, unisseriados (ocorrendo também bisseriados), de altura média a alta, com apenas células procumbentes; cristais prismáticos no parênquima axial(?), em células subdivididas, 1 cristal por subdivisão.

\section{Morfotipo: 9}

\section{Identificação: Acacia / Mimosa sp (LEGUMINOSAE)}

Amostra: RMT 1304-7*

Datação: Holoceno tardio

Descrição anatômica: camada porosidade difusa; vasos solitários e múltiplos, de frequência alta; diâmetro de vaso médio; obstrução por substância orgânica; placa de perfuração simples(?); pontoação intervascular alterna, de tamanho médio, guarnecida; pontoação radiovascular com aréola distinta, similar a pontoação intervascular; parênquima axial paratraqueal, vasicêntrico, aliforme, podendo haver linhas descontínuas; série fusiforme com duas, 3 a 4, 5 a 8 células; raios de frequência mediana, de 1 a 4 células de largura, de altura média a alta, com apenas células procumbentes?; cristais prismáticos presentes(?) no parênquima axial, 1 cristal por subdivisão; mais de 1 cristal por subdivisão.

\section{Morfotipo: 10}

\section{Identificação: Anadenanthera peregrina / Dimorphandra / Inga sp (LEGUMINOSAE)} Amostra: RMT 2153*

Datação: Holoceno tardio (amostra RMT 2153 datada entre 2730 e 2360 anos A.P.cal.)

Descrição anatômica: camada de crescimento não visível (indistinta?); vasos solitários e múltiplos, de frequência média; diâmetro de vaso médio; obstrução por substância orgânica; placa de perfuração simples; pontoação intervascular alterna, de tamanho médio; pontoação radiovascular com aréola distinta, similar a pontoação intervascular; espessura da parede das fibras mediana(?), espessa(?); parênquima axial paratraqueal, vasicêntrico, 
confluente(?); série fusiforme com 3 a 4(?) células; raios de frequência mediana a alta, de 1 a 3 células de largura, baixos a médios, com apenas células procumbentes(?), uma fileira de células eretas(?); raios agregados(?).

\section{Morfotipo: 11}

\section{Identificação: Centrolobium sp (LEGUMINOSAE)}

Amostra: RMT 1312*

Datação: Holoceno médio

Descrição anatômica: camada de crescimento distinta por parênquima marginal (às vezes descontínuo); porosidade difusa; vasos solitários e múltiplos, de frequência média; diâmetro de vaso pequeno a médio(?); obstrução ausente; placa de perfuração simples; pontoação intervascular alterna, pequena a média; pontoação radiovascular com aréola distinta, similar a pontoação intervascular (?), redonda/angular(?); pontoação de fibras simples a diminutamente areolada; espessura da parede das fibras mediana; parênquima axial concêntrico, paratraqueal, marginal, aliforme, vasicêntrico; série fusiforme com duas, 3 a 4(?) células; raios de frequência mediana, unisseriados (raramente bisseriados), baixos, com apenas células procumbentes; parênquima axial estratificado, fibra estratificada, raio estratificado, elemento de vaso estratificado(?);.

Processo de Identificação: As espécies arbóreas do gênero Machaerium sp apresentaram anatomia bastante similar, mas foram excluídas por não apresentaram concomitantemente parênquima vasicêntrico com raios unisseriados.

\section{Morfotipo:12}

\section{Identificação: Lonchocarpus sp (LEGUMINOSAE)}

Amostra: RMT 2059* e 2060-1

Datação: Holoceno médio

Descrição anatômica: porosidade difusa; vasos exclusivamente solitários(?), solitários e múltiplos(?), de frequência média; diâmetro de vaso pequeno a médio; obstrução por substância de aspecto granular; placa de perfuração simples; pontoação intervascular alterna, de tamanho médio a grande, guarnecida; pontoação radiovascular com aréola distinta, similar a pontoação intervascular; espessura da parede das fibras mediana; parênquima axial concêntrico, em faixas; série fusiforme com duas; raios de frequência 
mediana, de 1 a 3 células de largura, baixos, com apenas células procumbentes; parênquima axial estratificado, raio estratificado; cristais prismáticos no parênquima axial, em células subdivididas(?), 1 cristal por subdivisão(?).

\section{Morfotipo: 13}

Identificação: Myroxylon peruiferum L.f (LEGUMINOSAE)

Amostra: RMT 879, RMT 882, RMT 938, RMT 1305, RMT 1310, RMT 1965, RMT 2036, RMT 2039, RMT 2054, RMT 2055, RMT 2056*, RMT 2252, RMT 2296

Datação: Holoceno médio (amostras RMT 2055 e 2056, datadas entre 4980 e 5450 anos A.P.cal.)

Holoceno tardio (amostras RMT 938 e RMT 1310 datadas entre 2740 e 2050 anos A.P.cal.)

Descrição anatômica: camada de crescimento distinta por parênquima marginal (podendo ser descontínuo); porosidade difusa; vasos solitários e múltiplos; diâmetro de vaso médio, de frequência média a alta; obstrução por substância orgânica; placa de perfuração simples; pontoação intervascular alterna pequena, guarnecida; pontoação radiovascular com areola distinta, similar a pontoação intervascular; parede das fibras muito espessa; parênquima axial paratraqueal, vasicêntrico; série fusiforme 3 a 4(?), 5 a 8 células; raios bisseriados, baixos a médios(?), com uma fileira marginal de células eretas/quadradas, 2 a 4 fileiras marginais de células eretas/quadradas (raras), de frequência mediana; raio estratificado; cristais prismáticos no parênquima axial subdividido e nas células eretas do raio, 1 cristal por subdivisão.

Processo de Identificação: Muitas amostras apresentaram o mesmo padrão anatômico. A presença de pontoações intervasculares guarnecidas, reaio estratificado e parênquima vasicêntrico pouco abundante foram importantes para identificar a família e os gêneros Myroxylon/Myrocarpus sp. A presença de odor agradável ainda conservado foi sentida no momento da escavação para diversas amostras, como RMT 938 e 1310. A distinção entre os dois gêneros foi realizada por meio da distribuição dos cristais prismáticos que apenas 
em Myroxylon $s p$ foram vistos em células radiais. Segundo Sartori $\left(2000^{17}\right)$ este gênero possui três espécies que se distribuem do México ao sul brasileiro. Contudo, apenas a espécie $M$. peruiferum L.f. têm registros ao sul da floresta amazônica, ocorrendo nos biomas de Cerrado e Mata Atlântica.

\section{Morfotipo: 14}

\section{Identificação: LAURACEAE}

Amostra: RMT 2031*, RMT 2152-1 e 2156-1

Datação: Holoceno tardio

Descrição anatômica: camada de crescimento distinta por zona fibrosa(?); vasos solitários e múltiplos, de frequência média a alta; diâmetro de vaso variável; obstrução por tilos; pontoação intervascular alterna, de tamanho médio a grande; pontoação radiovascular redonda a angular; pontoação de fibras simples a diminutamente areolada(?); parede das fibras espessa(?); parênquima axial presente mas de difícil visualização (escasso, raro?); série fusiforme com 3 a 4(?), 5 a 8(?) células; raios de frequência mediana, de 1 a 3 células de largura, de altura variável, com 1 fileira marginal de células eretas.

\section{Morfotipo: 15}

\section{Identificação: cf Ocotea / Nectandra sp (LAURACEAE)}

Amostra: RMT 2204*

Datação: Holoceno tardio

Descrição anatômica: camada de crescimento distinta, por parênquima marginal, por espessamento de fibra(?); porosidade difusa; vasos solitários e múltiplos, de frequência média; diâmetro de vaso médio; obstrução por tilos; placa de perfuração simples(?); pontoação intervascular alterna, grande; pontoação radiovascular escalariforme a vertical; pontoação de fibras simples à diminutamente areolada, na parede tangencial e radial(?); parede das fibras fina; fibra septada; parênquima axial paratraqueal, concêntrico(?), marginal, vasicêntrico escasso(?); série fusiforme com 3 a 4 células; raios de frequência

17 SARTORI, A. L. B. 2000. Revisão taxonômica de Myrocarpus Allemão, Myroxylon L.f. e Myrospermum Jacq. (Leguminosae Papilionoideae Sophorae). Tese de doutorado. Depto. Biologia Vegetal, Universidade Estadual de Campinas, Campinas, $162 \mathrm{p}$ 
mediana, bisseriados, de altura média, com uma a 4 fileiras de células eretas, células eretas(?)quadradas misturadas.

\section{Morfotipo: 16}

\section{Identificação: Trichilia cf. claussenii (MELIACEAE)}

Amostra: RMT 2166*

Datação: Holoceno tardio

Descrição anatômica: camada de crescimento distinta por parênquima marginal; porosidade difusa; vasos exclusivamente solitários(?), solitários e múltiplos(?), de frequência média a alta; diâmetro de vaso médio a grande; obstrução por substância orgânica; placa de perfuração simples; pontoação intervascular alterna, pequena; pontoação radiovascular com aréola distinta, similar a pontoação intervascular; parênquima axial apotraqueal, paratraqueal, concêntrico(?), marginal, em linhas(?), aliforme formando linhas(?); raios de frequência alta, unisseriados, baixos a médios, com apenas células procumbentes; cristais prismáticos no parênquima axial, em células subdivididas, 1 cristal por subdivisão; mácula presente.

\section{Morfotipo: 17}

\section{Identificação: Trichilia cf pallida (MELIACEAE)}

Amostras: RMT 1318, RMT 2026, RMT 2041, RMT 2154-1*, RMT 2161

Datação: Holoceno tardio

Descrição anatômica: camada de crescimento distinta por parênquima marginal; porosidade difusa; vasos solitários e múltiplos; diâmetro de vaso médio; obstrução por substância orgânica; placa de perfuração simples(?); pontoação intervascular alterna, diminuta; espessura da parede das fibras mediana a espessa; parênquima axial concêntrico, marginal; raios de frequência alta, unisseriados, baixos a médios, com apenas células procumbentes; células procumbentes menores; cristais prismáticos no parênquima axial, em células subdivididas, 1 cristal por subdivisão.

\section{Morfotipo: 18}

\section{Identificação: Ficus sp (MORACEAE)}


Amostra: RMT 872* e RMT 1963

Datação: Holoceno médio

Descrição anatômica: camada porosidade difusa; vasos solitários e múltiplos, de frequência alta; obstrução por tilos; placa de perfuração simples; pontoação intervascular alterna, de tamanho médio(?), grande(?); pontoação radiovascular redonda a angular; parede das fibras fina; parênquima axial concêntrico, em faixas, aliforme podendo ter confluências; série fusiforme com 3 a 4 células; raios de frequência mediana, de 1 a 3, 4 a 10(?) células de largura, de altura variável, com 1 fileira marginal de células eretas/quadradas, 2 a 4 fileiras marginais de células eretas/quadradas.

\section{Morfotipo: 19}

\section{Identificação: Ficus / Sorocea sp (MORACEAE)}

Amostra: RMT 1316* e RMT 1307-1

Datação: Holoceno médio

Descrição anatômica: camada de crescimento distinta(?); porosidade em anel semiporoso(?); vasos solitários e múltiplos, de frequência média a alta; diâmetro de vaso médio; obstrução por tilos; pontoação intervascular alterna, de tamanho médio; pontoação radiovascular redonda a angular(?); parênquima axial concêntrico, em faixas; série fusiforme com 3 a 4 células; raios de frequência mediana, 1 a 3 células de largura, de altura variável, com 1 fileira marginal de células eretas/quadradas, 2 a 4 fileiras marginais de células eretas/quadradas; raio com 2 tamanhos de raio distintos(?); elemento de vaso estratificado(?).

\section{Morfotipo: 20}

\section{Identificação: Myrsine sp (MYRSINACEAE)}

Amostra: RMT 2165* e RMT 2151

Datação: Holoceno tardio

Descrição anatômica: camada de crescimento não visível (indistinta?); vasos solitários(?), solitários e múltiplos(?), de frequência pequena(?) a média; diâmetro de vaso médio a grande; obstrução ausente; pontoação intervascular não visível, pontoação radiovascular não visível; parênquima axial paratraqueal, presente mas sem determinação; série fusiforme não visível ; raios de frequência baixa, de 4 a 10 células de largura, muito altos, 
com células eretas/quadradas e células procumbentes misturadas(?); células oleíferas presentes no raio.

\section{Morfotipo: 21}

Identificação: Myrcia sp / Calyptranthes concina (MYRTACEAE)

Amostra: RMT 1964 e RMT 2185*

Datação: Holoceno médio (amostra RMT 2185 datada entre 5600 e 5340 anos A.P.cal.)

Descrição anatômica: camada de crescimento não visível (indistinta?); porosidade difusa; vasos exclusivamente solitários (90\% ou mais), de frequência pequena a média; diâmetro de vaso grande; obstrução por substância orgânica; pontoação intervascular alterna, pequena; pontoação radiovascular com aréola distinta, similar a pontoação intervascular; pontoação de fibras areolada; espessura da parede das fibras mediana(?); traqueíde vascular presente; parênquima axial concêntrico, em faixas descontínuas; série fusiforme com 3 a 4 células; raios de frequência mediana, com 1 a 3 células de largura, de altura média, com 2 a 4 fileiras marginais de células eretas/quadradas, células eretas/quadradas e células procumbentes misturadas; raio agregado (raro); células com parede disjuntiva; cristais prismáticos nas células eretas do raio(?), nas células procumbentes(?).

\section{Morfotipo: 22}

Identificação: Myrcia sp / Psidium sp / Calyptranthes concina (MYRTACEAE)

\section{Amostra: RMT $1962 *$}

Datação: Holoceno médio

Descrição anatômica: camada de crescimento não visível (indistinta?); porosidade difusa; vasos exclusivamente solitários (90\% ou mais), de frequência média; diâmetro de vaso médio (mas grande para Myrtaceae); obstrução por substância orgânica, tilos(?); pontoação radiovascular com aréola distinta, similar a pontoação intervascular; parênquima axial apotraqueal, concêntrico, em linhas, difuso em agregado; série fusiforme com 3 a 4 células; raios de frequência alta, bisseriados, de altura variável, com 1 fileira marginal de células eretas/quadradas, 2 a 4 fileiras marginais de células eretas/quadradas. 


\section{Morfotipo: 23}

Identificação: Allophylus / Cupania sp (SAPINDACEAE)

Amostra: RMT 1304-6, RMT 1306, RMT 2029, RMT 2030, RMT 2033, RMT 2034*, RMT 2144, RMT 2146, RMT 2149, RMT 2150, RMT 2152-2, RMT 2156-2, RMT 2159, RMT 2164-1, RMT 2164-2, RMT 2167, RMT 2169, RMT 2246, RMT 2271

Datação: Holoceno médio

Holoceno tardio (amostras RMT 2029 e RMT 2033 datadas entre 1830 e 1510 anos A.P.cal.)

Descrição anatômica: camada de crescimento distinta, por espessamento e achatamento de fibras; porosidade difusa ou em anel semi-poroso(?); vasos solitários e múltiplos, de frequência média; diâmetro de vaso pequeno a médio; obstrução por substância orgânica; pontoação intervascular alterna, pequena; pontoação radiovascular com aréola distinta, similar a pontoação intervascular; parede das fibras muito espessa(?); parênquima axial provávelmente raro, visível apenas em corte longitudinal; raios de frequência alta, unisseriados (localmente bisseriados), de altura variável, com apenas células procumbentes; cristais prismáticos no parênquima axial, em fibras, em células subdivididas, 1 cristal por subdivisão, mais de 1 cristal por subdivisão.

\section{Morfotipo: 24}

Identificação: Serjania sp (SAPINDACEAE)

Amostra: RMT 964, RMT 1966, RMT 2053*

Datação: Holoceno médio

Descrição anatômica: camada porosidade difusa; vasos solitários e múltiplos, de frequência alta; vasos de 2 diâmetros distintos; obstrução por substância orgânica; placa de perfuração simples; pontoação intervascular alterna, de tamanho médio; pontoação radiovascular com aréola distinta, similar a pontoação intervascular; pontoação de fibras simples a diminutamente areolada; traqueíde vascular presente; parênquima axial apotraqueal(?), paratraqueal(?), vasicêntrico ou vasicêntrico escasso, difuso em agregado(?); raios de frequência mediana, com 1 a 3 células, altos, com células eretas/quadradas e células procumbentes misturadas; raios agregados; com 2 tamanhos de raio distintos(?); parênquima axial estratificado(?), elemento de vaso estratificado(?); 
cristais prismáticos no parênquima axial, em células subdivididas(?), 1 cristal por subdivisão(?).

Processo de Identificação: a anatomia da amostra se mostrou muito similar tanto do o gênero Serjania sp, quanto Paullinia. Embora a amostra apresentasse algo parecido com lenho composto, típico de Serjanias, não foi possível confirmar a identificação. Contudo, optou-se pelo gênero devido a ausência de cristais em células de raio das Serjanias, em contraste com as espécies de Paullinias coletadas em Lagoa Santa.

\section{Morfotipo: 25}

Identificação: Chrysophyllum sp (SAPOTACEAE)

Amostra: RMT 2098*

Datação: Holoceno médio (amostra datada entre 5740 e 5590 anos A.P.cal.)

Descrição anatômica: camada de crescimento distinta por zona fibrosa(?); arranjo de vaso radial ou diagonal(?); vasos de frequência média, solitários e múltiplos(?), múltiplos em cadeia radial de 4 ou mais vasos; diâmetro de vaso pequeno a médio; obstrução por tilos; placa de perfuração simples(?); pontoação intervascular alterna, de tamanho médio; pontoação radiovascular redonda a angular(?); espessura da parede das fibras muito espessa; traqueíde vascular presente(?); parênquima axial apotraqueal, em linhas; série fusiforme com duas células(?); raios de frequência mediana, unisseriados e com 1 a 3 células de largura, de altura variável, com apenas células procumbentes(?), 2 a 4 fileiras marginais de células eretas/quadradas e mais de 4 fileiras marginais de células eretas/quadradas; corpos silicosos em células de raio.

\section{Morfotipo: 26}

\section{Identificação: Qualea sp (VOCHYSIACEAE)}

\section{Amostra: RMT 962*}

\section{Datação: Holoceno médio}

Descrição anatômica: camada porosidade difusa; vasos solitários e múltiplos, de frequência baixa; diâmetro de vaso médio; obstrução por substância orgânica, tilos(?); pontoação intervascular alterna, de tamanho médio, guarnecida; pontoação radiovascular com aréola distinta, similar a pontoação intervascular; parede das fibras fina; parênquima axial paratraqueal(?), vasicêntrico, confluente formando faixas; série fusiforme com duas, 
3 a 4 células; raios de frequência mediana, de 1 a 3 e raios maiores de 4 a 10(?)células de largura, de altura variável, com apenas células procumbentes; elemento de vaso estratificado(?); cristais prismáticos no parênquima axial subdividido, 1 cristal por subdivisão.

\section{Morfotipo: 27}

Identificação: Salvertia convalleriodora (VOCHYSIACEAE)

Amostra: RMT 2028*, RMT 2142

Datação: Holoceno tardio

Descrição anatômica: camada de crescimento não visível (indistinta?); porosidade difusa; vasos exclusivamente solitários(?), solitários e múltiplos(?), de frequência baixa; diâmetro de vaso pequeno; obstrução por substância orgânica; placa de perfuração simples; pontoação intervascular alterna, de tamanho médio, guarnecida; pontoação radiovascular com aréola distinta, similar a pontoação intervascular; parede das fibras muito espessa(?); parênquima axial concêntrico, em faixas; série fusiforme com duas, 3 a 4 células; raios unisseriados e com 1 a 3 células de largura, de frequência mediana, baixos a médios, com apenas células procumbentes(?); cristais prismáticos no parênquima axial, em células subdivididas(?), 1 cristal por subdivisão. 


\section{APÊNDICE 3}

\section{ICONOGRAFIA DOS MORFOTIPOS FÓSSEIS IDENTIFICADOS NO CAPÍTULO 3}



Morfotipo: 1

Família: ANACARDIACEAE

Espécie: Astronium/Myracrodruon sp

Amostra: RMT-1/ 2157
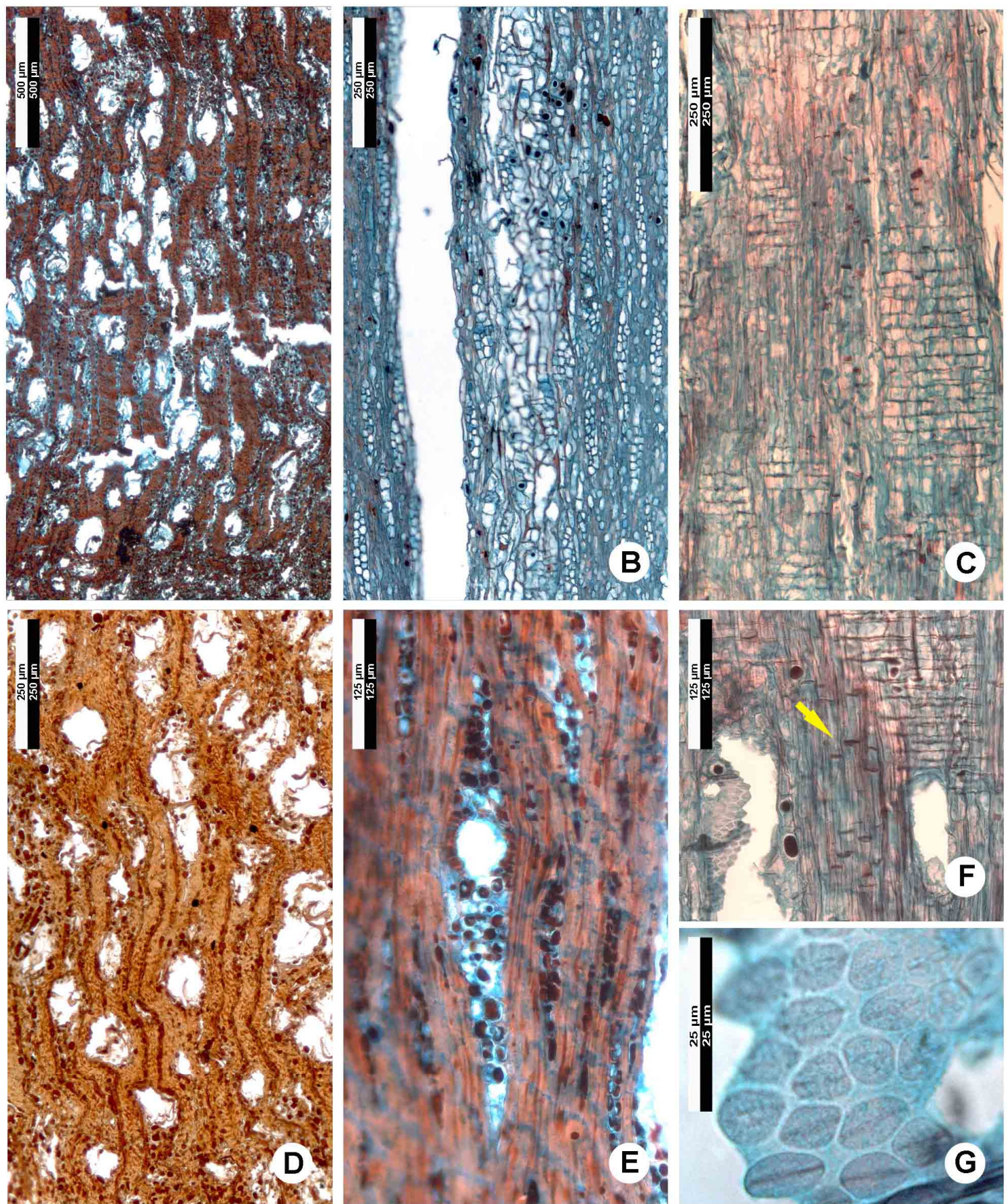

Legenda: anatomia de lenho fóssil. A e D, plano transversal; B, E e G, plano tangencial; $\mathbf{C}$ e $\mathbf{F}$, plano radial. Detalhe de canal radial $(\mathbf{E})$, fibras septadas $(\mathbf{F})$ e pontoação intervascular alterna e grande $(\mathbf{G})$. 
Morfotipo: 2

Família: ANACARDIACEAE

Espécie: Lithraea molleoides

Amostra: RMT-1/ 2040
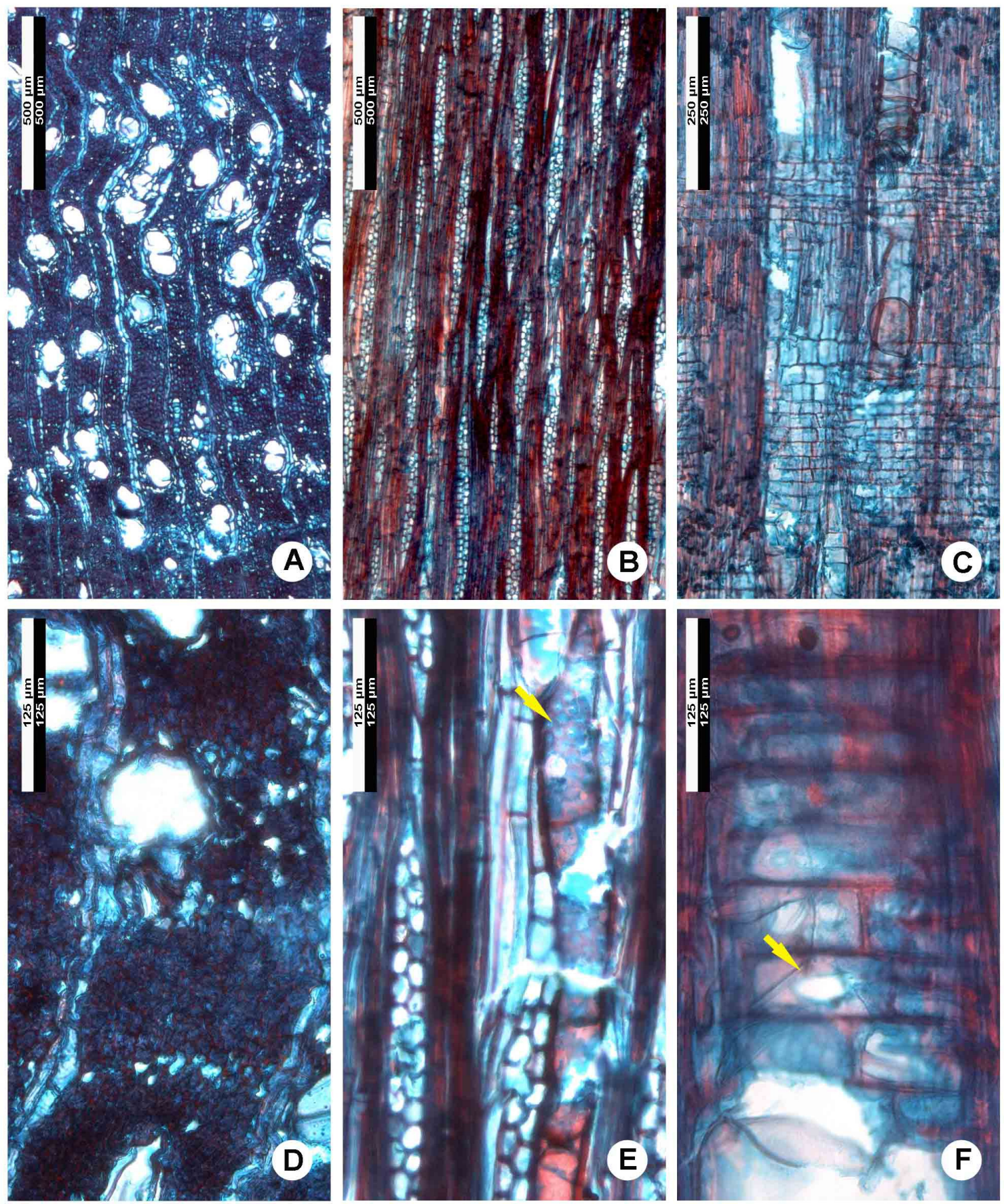

Legenda: anatomia de lenho fóssil. A e D, plano transversal; $\mathbf{B}$ e $\mathbf{E}$, plano tangencial; C e F, plano radial. Detalhe de pontoações intervasculares alternas $(E)$ e radiovasculares de verticais a escalariformes e circulares a angulares (F). 
Morfotipo: 3

Família: APOCYNACEAE

Espécie: Aspidosperma polyneuron

Amostra: RMT-1/ 970
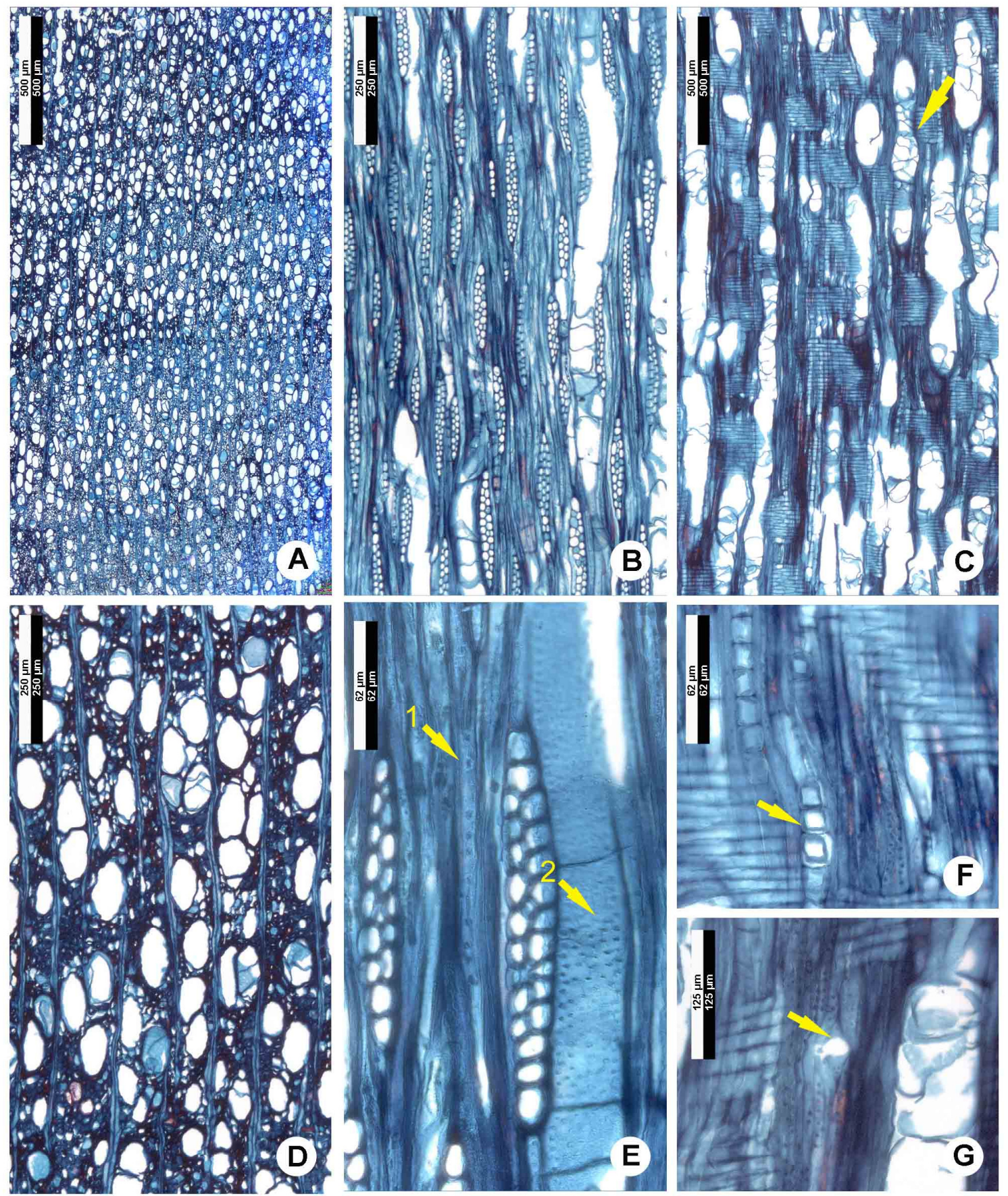

Legenda: anatomia de lenho fóssil. A e D, plano transversal; B e E, plano tangencial; $\mathbf{C}, \mathbf{F}$ e $\mathbf{G}$, plano radial. Detalhe de tilos (C), pontoação de fibras areoladas (E1) e pontoação intervascular alterna pequena (E2), cristais em células subdivididas do parenquima axial $(\mathbf{F})$, e placa de perfuração simlpes (G). 
Morfotipo: 4

Família: CELASTRACEAE

Espécie: Maytenus $s p$

Amostra: RMT-1/ 1974
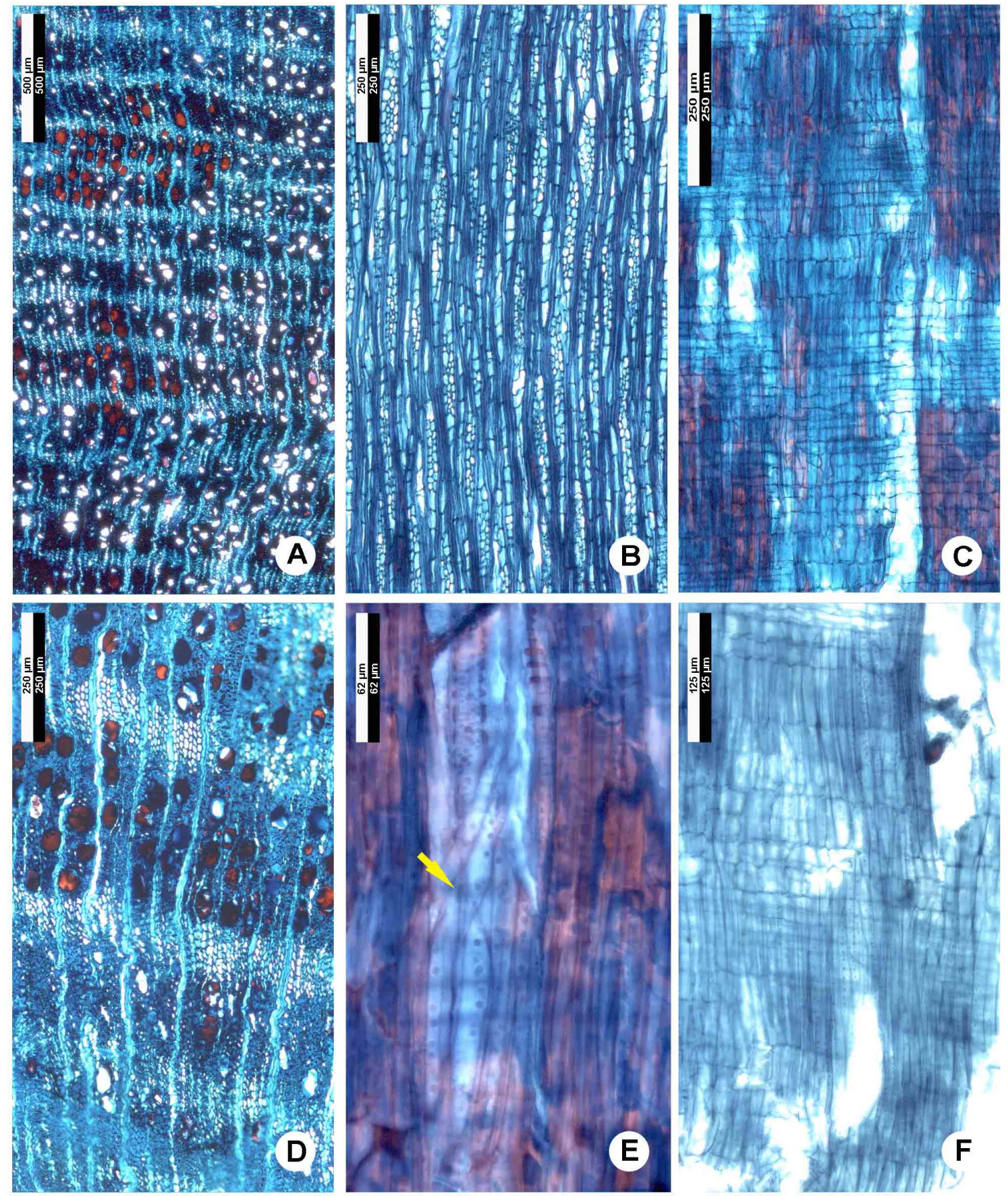

Legenda: anatomia de lenho fóssil. A e D, plano transversal; $\mathbf{B}$, plano tangencial; $\mathbf{C}$ e F, plano radial; Detalhe de traqueídes $(\mathrm{E})$. 
Morfotipo: 5

Família: CANNABACEAE

Espécie: Celtis $s p$

Amostra: RMT-1/2154-2
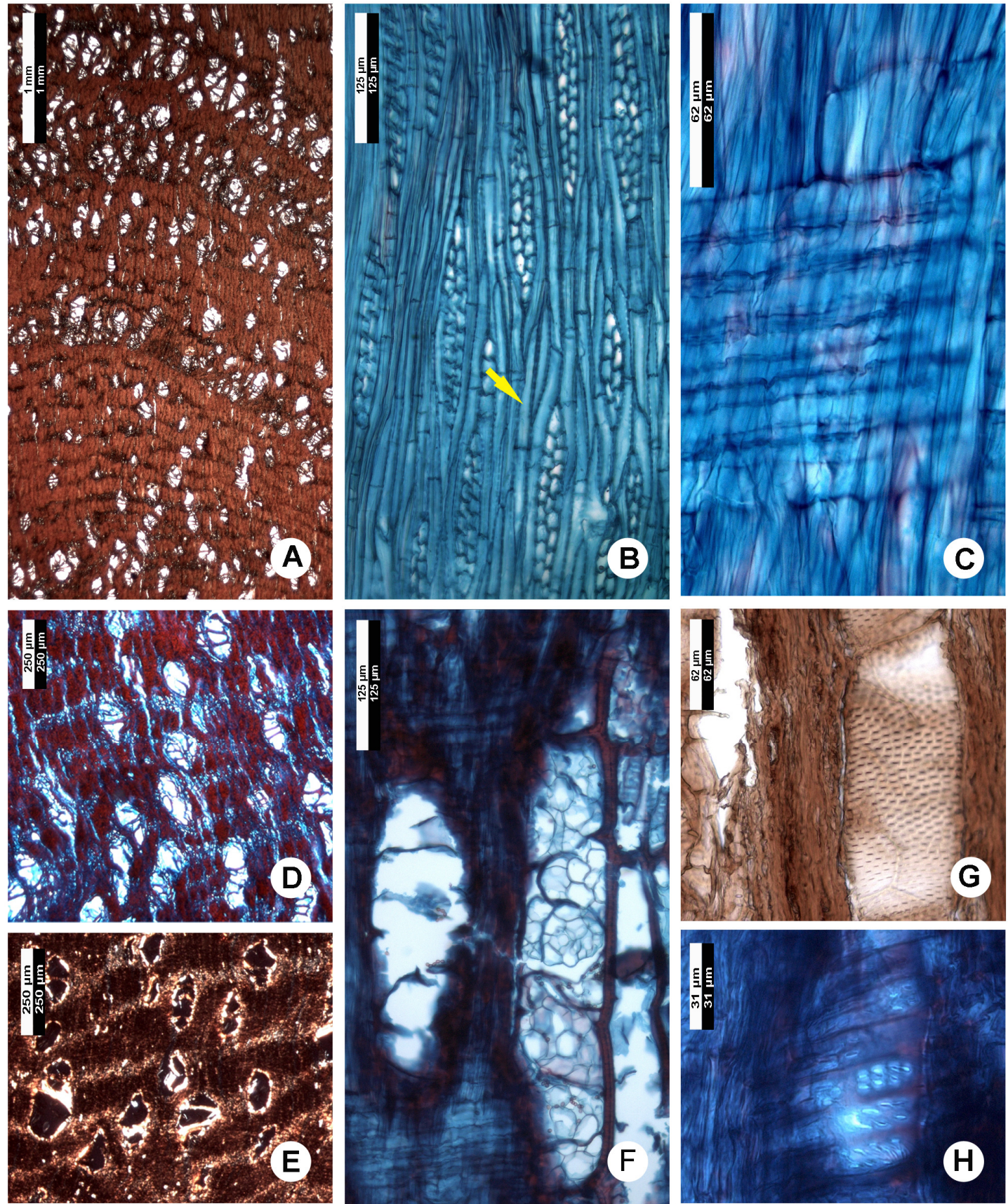

Legenda: anatomia de lenho fóssil. A, D e E, plano transversal; B e G, plano tangencial; $\mathbf{C}, \mathbf{F}$ e H, plano radial. Detalhe de série fusiforme de parênquima axial com duas células $(B)$ raio com uma fileira marginal de célula ereta/quadrada $(\mathbf{C})$, birrefringência de parênquima axial e elementos de vaso em luz polarizada $(\mathbf{E})$, tilos $(\mathbf{F})$, pontoação intervascular alterna $(\mathbf{G})$ e pontoação radiovascular areolada $(\mathbf{H})$. 
Morfotipo: 6

Família: COMBRETACEAE

Espécie: Combretum $s p$

Amostra: RMT-1/ 899
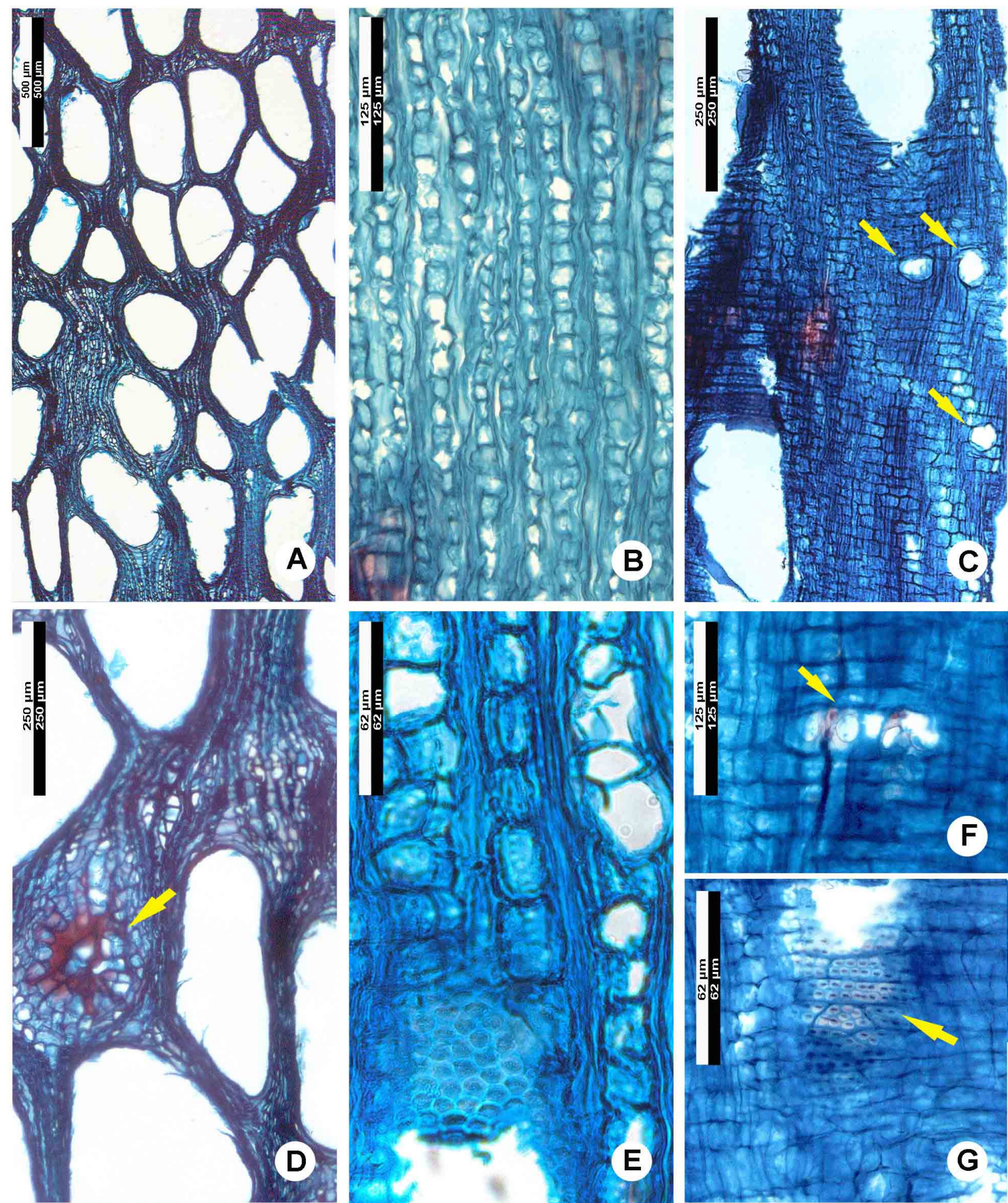

F

Legenda: anatomia de lenho fóssil. A e D, plano transversal; B e E, plano tangencial; $\mathbf{C}$ e F, plano radial. Detalhe de células alargadas no raio provavelmente por conter cristais que se perderam (C), floema incluso do tipo difuso (D), pontoações intervasculares alternas (E), celulas perfuradas de raio $(\mathbf{F})$ e pontoações radiovasculares areoladas $(\mathbf{G})$. 
Morfotipo: 7

Família: COMBRETACEAE

Espécie: Terminalia sp1

Amostra: RMT-1/ 2170
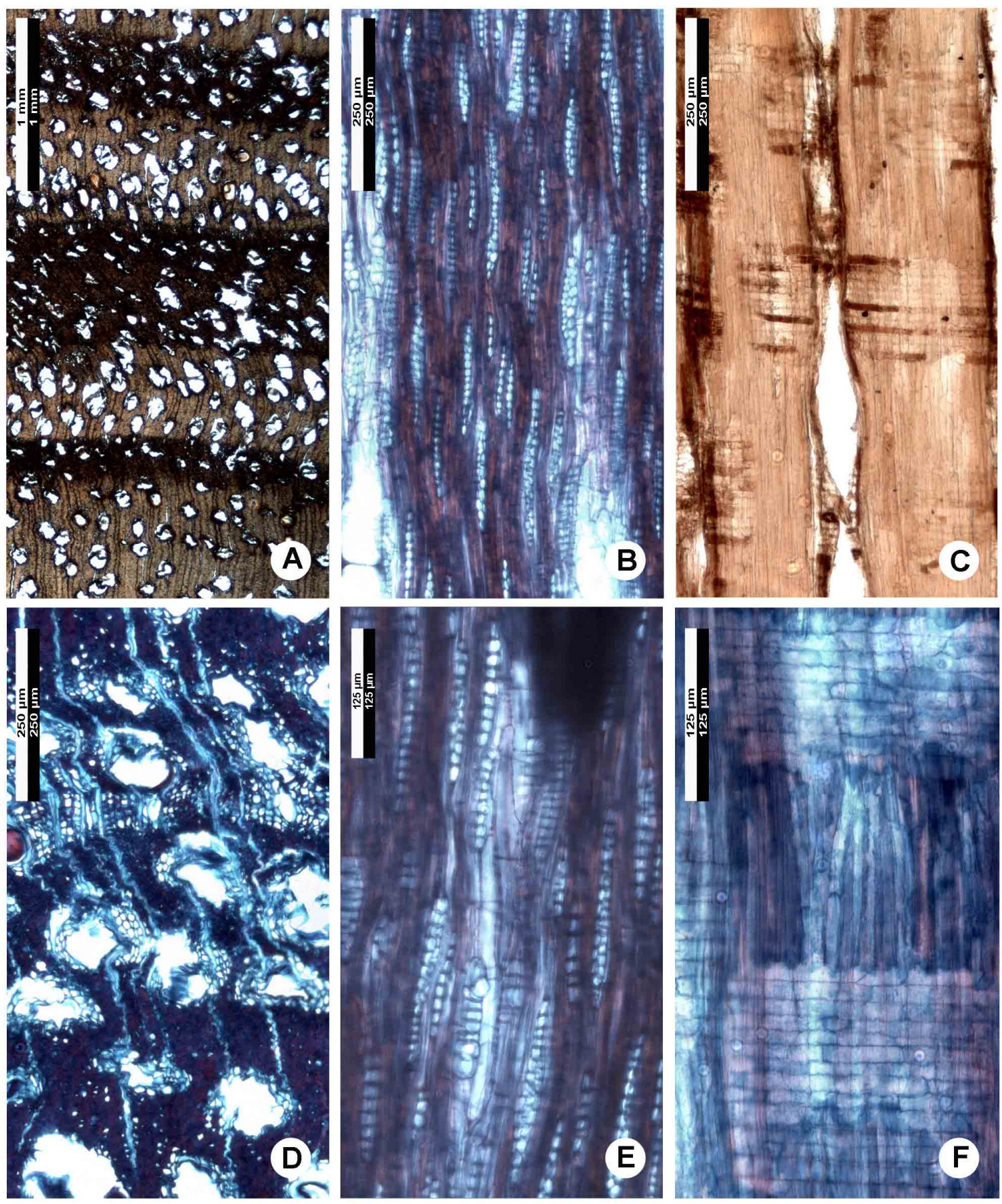

Legenda: anatomia de lenho fóssil. A e D, plano transversal; B e E, plano tangencial; $\mathbf{C}$ e $\mathbf{F}$, plano radial. 
Morfotipo: 8

Família: COMBRETACEAE

Espécie: Terminalia $s p 2$

Amostra: RMT-1/ 2099
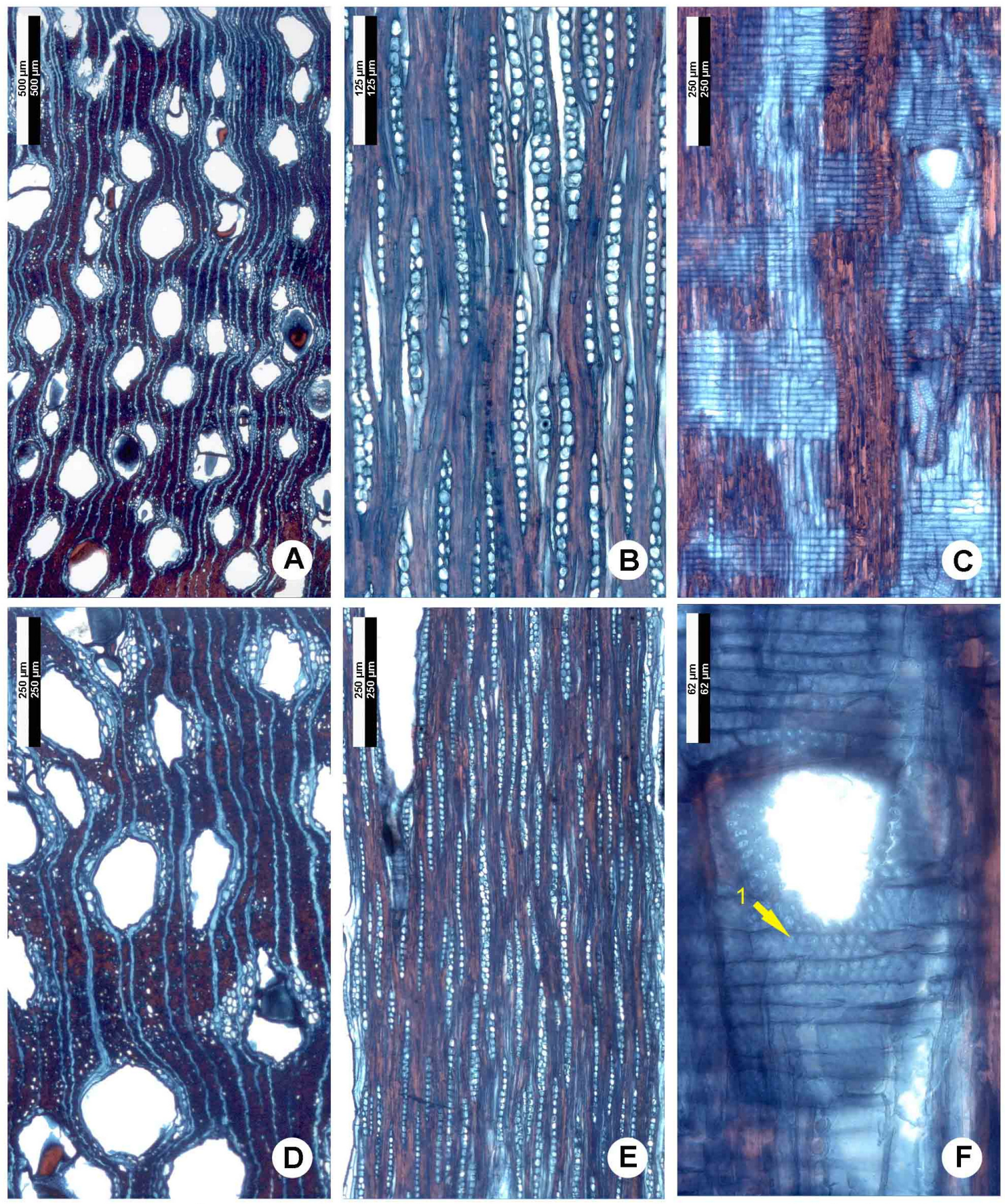

Legenda: anatomia de lenho fóssil. A e D, plano transversal; $\mathbf{B}$ e $\mathbf{E}$, plano tangencial; $\mathbf{C}$ e F, plano radial. Detalhe de pontoações radiovasculares areoladas $(\mathbf{F})$. 
Morfotipo: 9

Família: LEGUMINOSAE

Espécie: Acacia/Mimosa sp

Amostra: RMT-1/1304-7
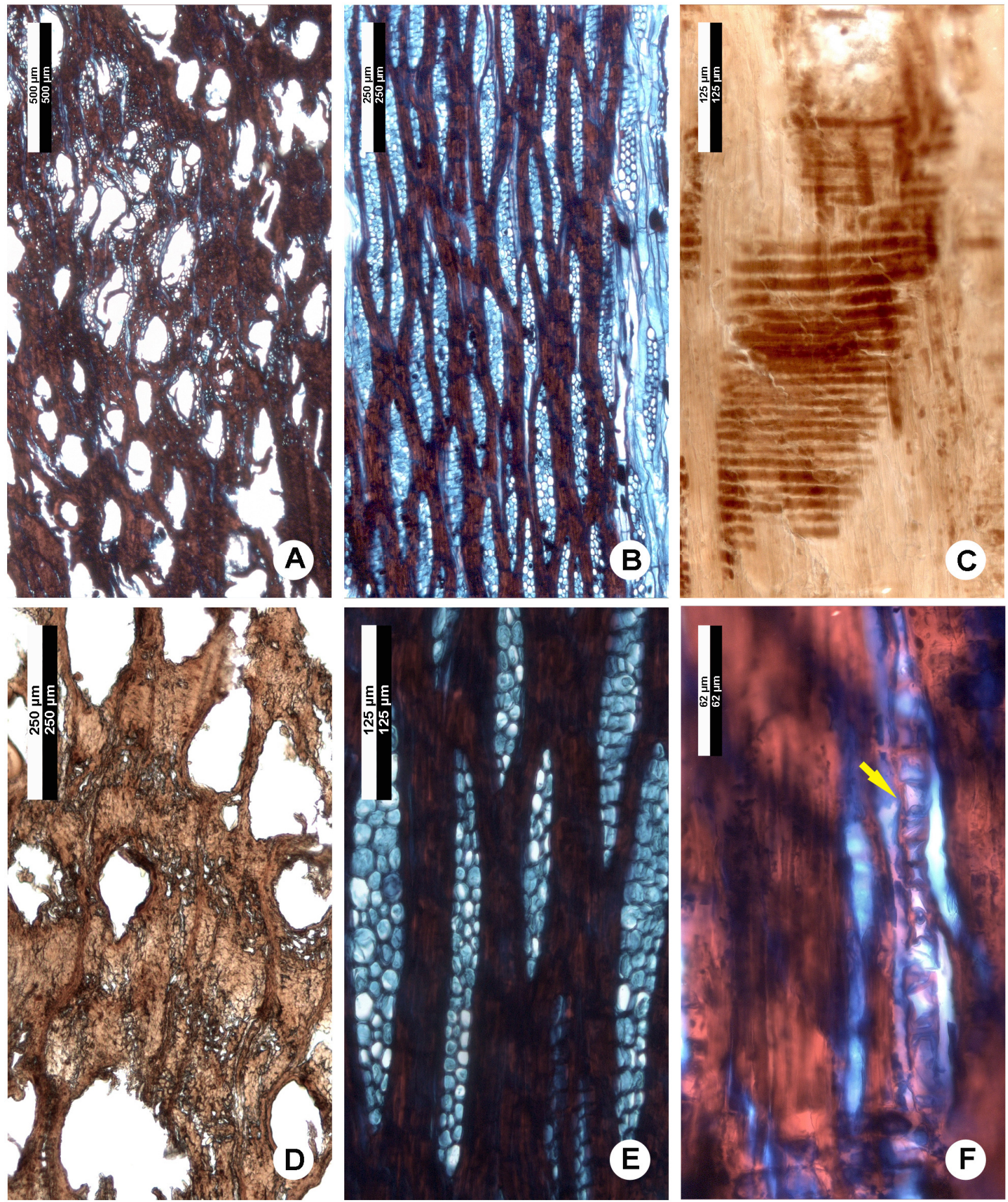

Legenda: anatomia de lenho fóssil. A e D, plano transversal; $\mathbf{B}$ e $\mathbf{E}$, plano tangencial; $\mathbf{C}$, plano radial; $\mathbf{F}$, detalhe de série cristalífera. 
Morfotipo: 10

Família: LEGUMINOSAE

Espécie: Anadenanthera peregrina/Dimorphandra sp/Inga sp

Amostra: RMT-1/ 2153
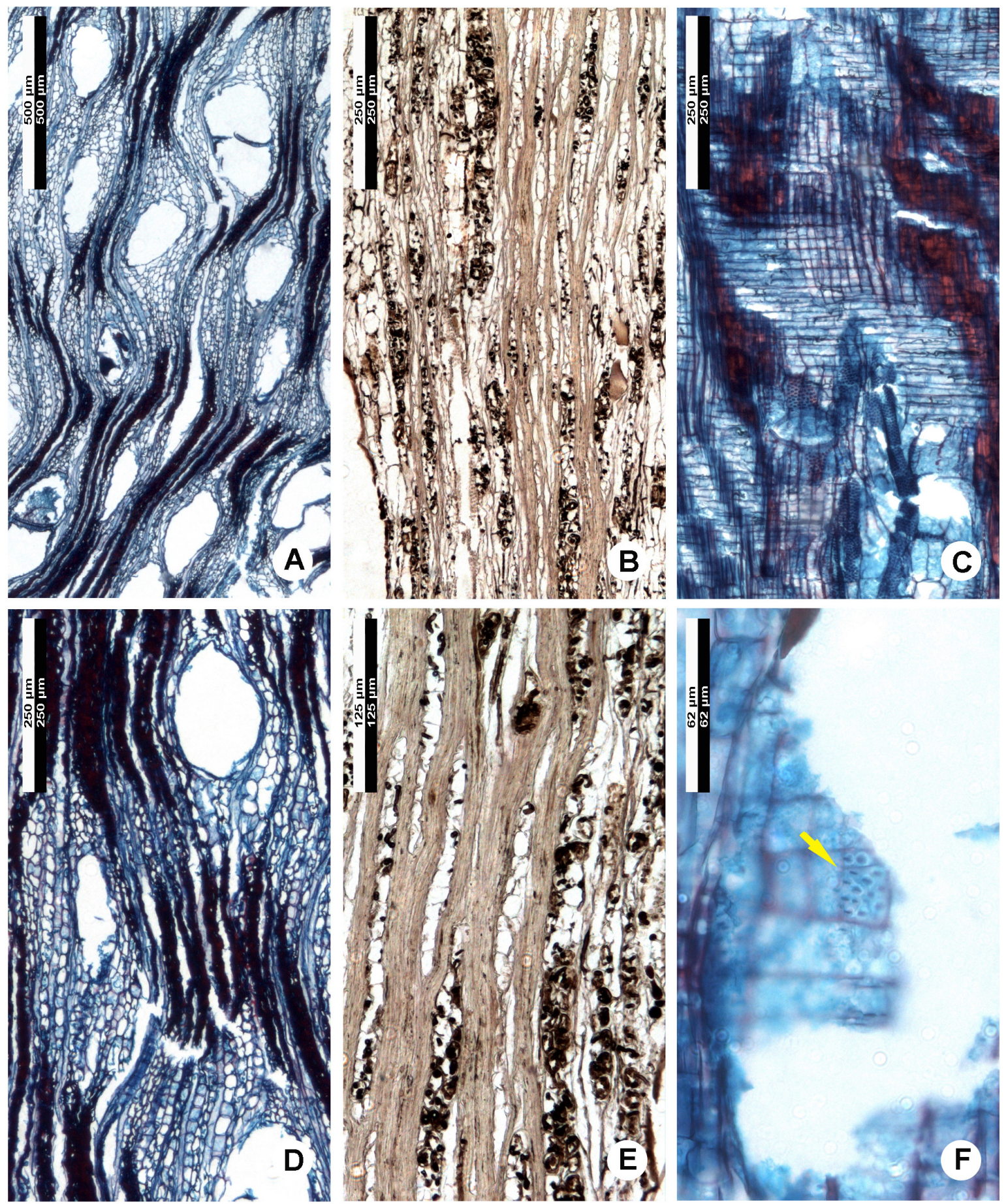

Legenda: anatomia de lenho fóssil. A e D, plano transversal; $\mathbf{B}$ e E, plano tangencial; $\mathbf{C}$ e $\mathbf{F}$, plano radial. Detalhe de pontoações radiovasculares areoladas (F). 
Morfotipo: 11

Família: LEGUMINOSAE

Espécie: Centrolobium sp

Amostra: RMT-1/ 1312
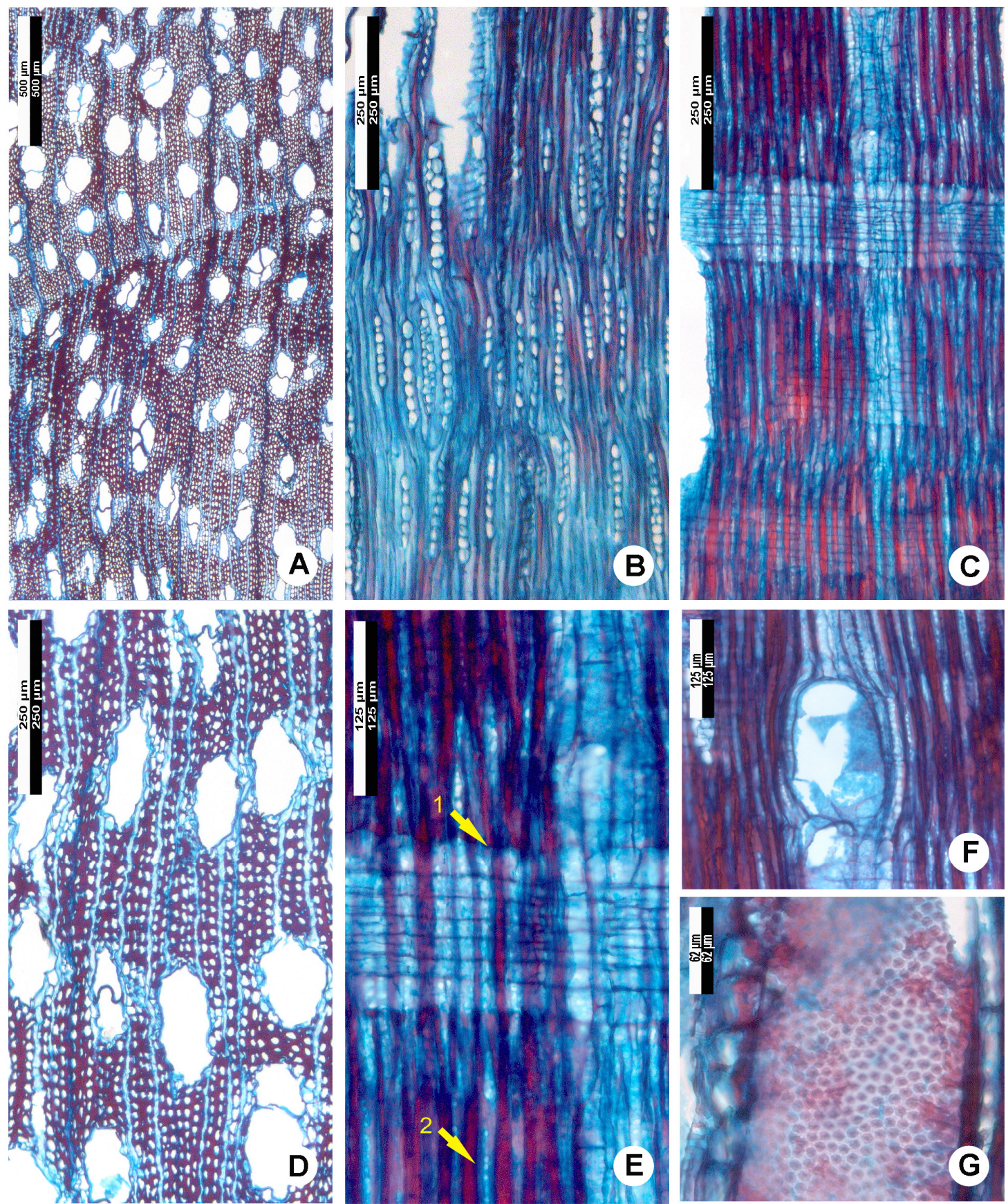

Legenda: anatomia de lenho fóssil. A e D, plano transversal; $\mathbf{B}$ e $\mathbf{G}$, plano tangencial; C, E e F, plano radial. Detalhe do raio mostrando que apesar de maiores dimensões, a fileira marginal do raio é também procumbente (E1), pontoação de fibra simples (E2), placa de perfuração simples e pontoações alternas poligonais $(G)$. 
Morfotipo: 12

Família: LEGUMINOSAE

Espécie: Lonchocarpus sp

Amostra: RMT-1/ 2060-1
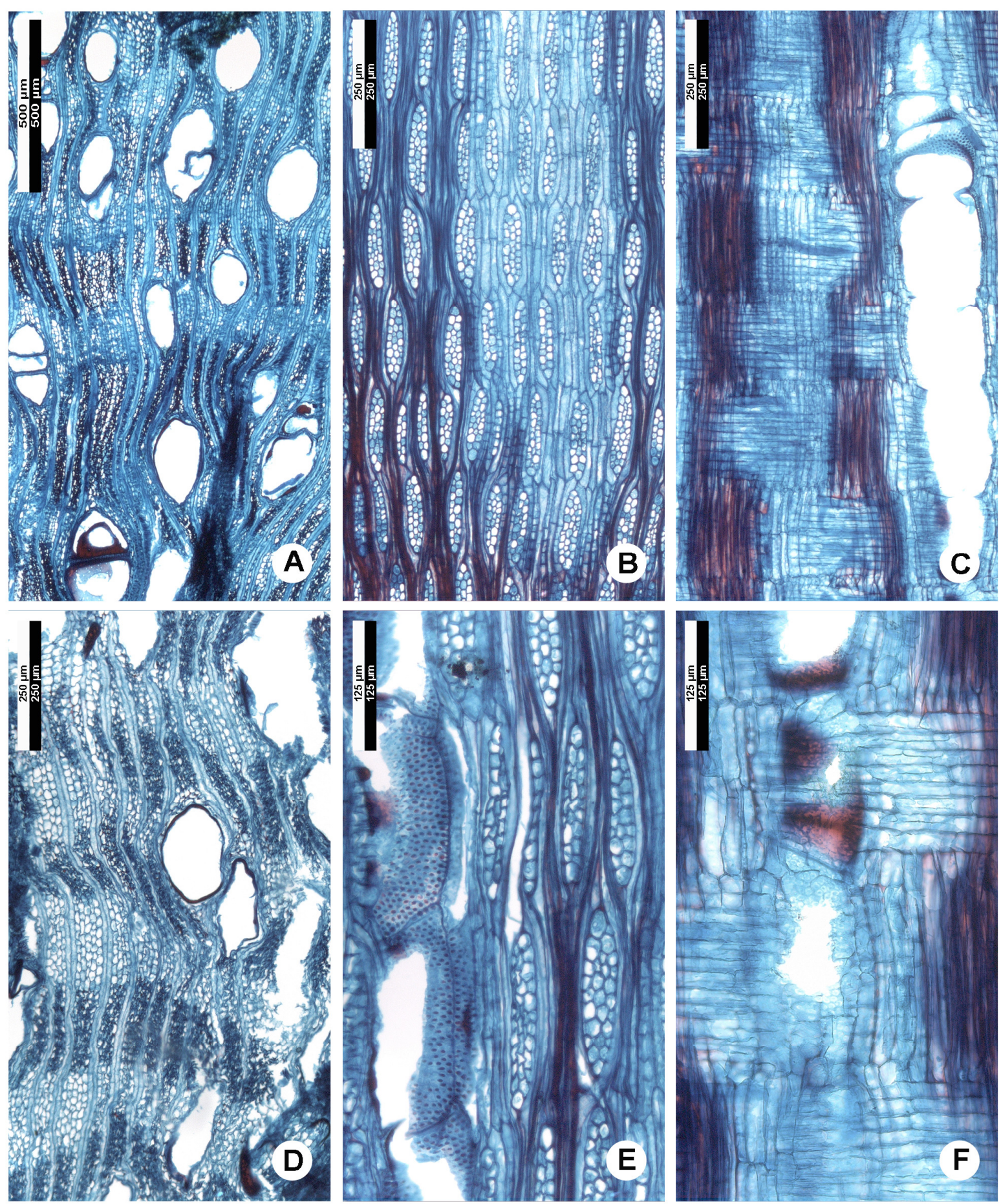

Legenda: anatomia de lenho fóssil. A e D, plano transversal; B e E, plano tangencial; $\mathbf{C}$ e $\mathbf{F}$, plano radial. 
Morfotipo: 13

Família: LEGUMINOSAE

Espécie: Myroxylon peruiferum L.f.

Amostra: RMT-1/ 2056
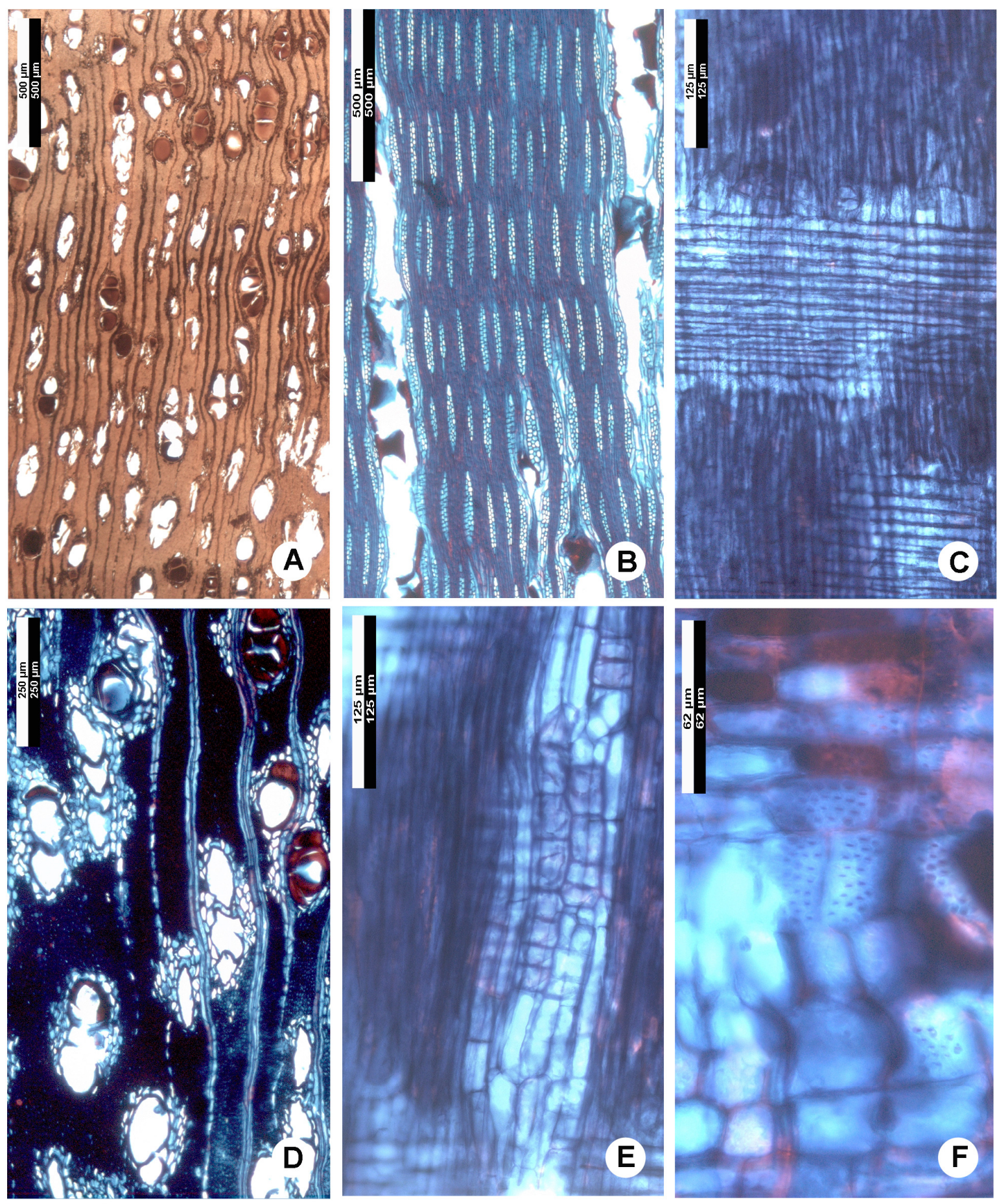

Legenda: anatomia de lenho fóssil. A e D, plano transversal; B, plano tangencial; C, E e F, plano radial. Detalhe de cristais em célula subdividida de parênquima axial $(\mathbf{E})$ e pontoações radiovasculares areoladas $(\mathbf{F})$. 
Morfotipo: 14

Família: LAURACEAE

Espécie: indeterminada

\section{Amostra: RMT-1/ 2031}
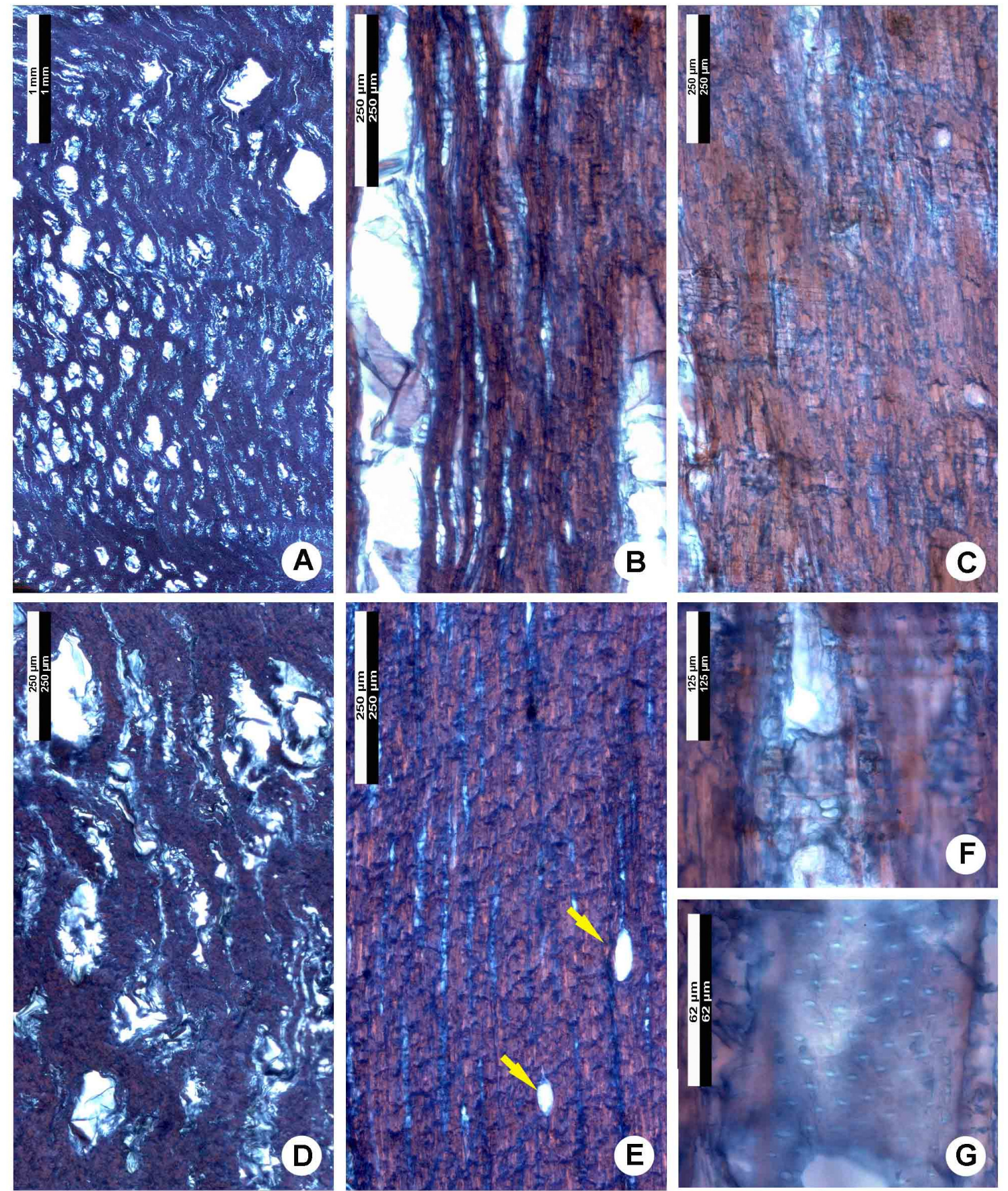

Legenda: anatomia de lenho fóssil. A e D, plano transversal; B, E e G, plano tangencial; $\mathbf{C}$ e $\mathbf{F}$, plano radial. Detalhe de cálula oleífera não colapsada no parêquima radial $(\mathbf{E})$, pontoações radiovasculares circulareas a angulares $(\mathbf{F})$ e pontoações intervasculares alternas (G). 
Morfotipo: 15

Família: lauraceae

Espécie: cf Ocotea/Nectandra sp

Amostra: RMT-1/ 2204
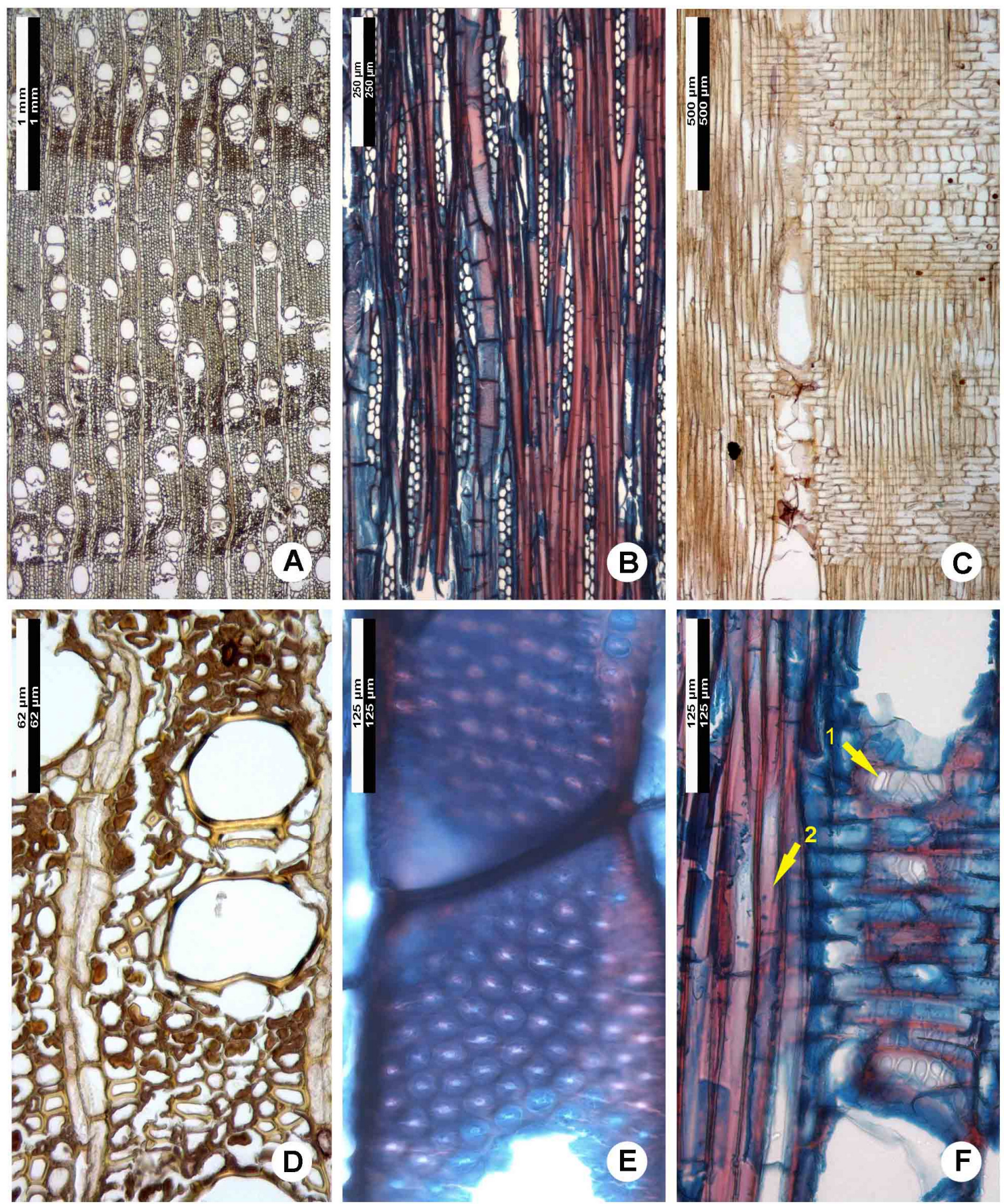

Legenda: anatomia de lenho fóssil. A e D, plano transversal; $\mathbf{B}$, plano tangencial; C, plano radial; E, pontoação intervascular;, F, detalhe de fibras septadas (1) e pontoação radiovascular verticais a escalariformes (2). 
Morfotipo: 16

Família: MELIACEAE

Espécie: Trichilia of claussenii

Amostra: RMT-1/ 2166
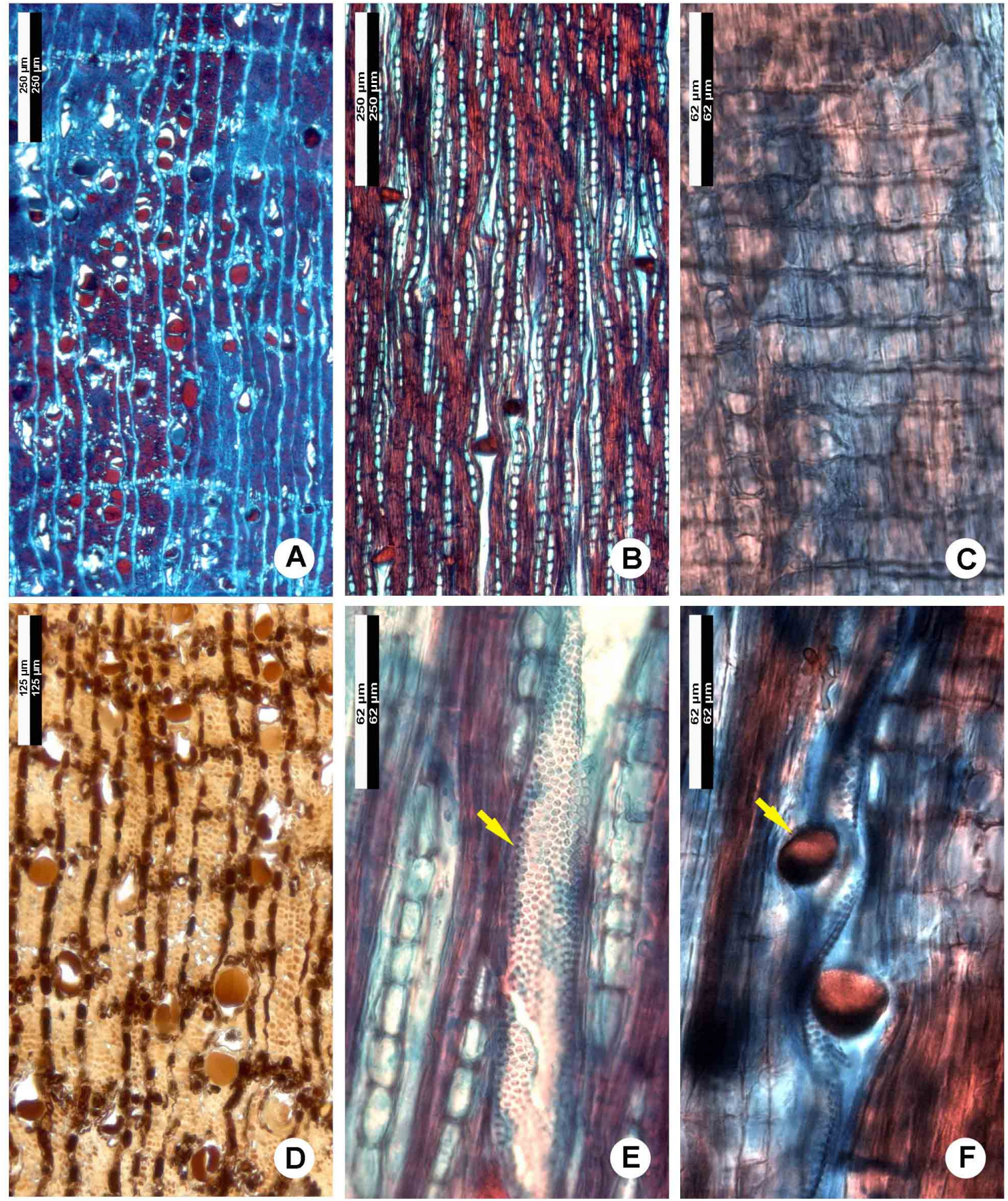

Legenda: anatomia de lenho fóssil. A e D, plano transversal; B e E, plano tangencial; C e F, plano radial. Detalhe de pontoações intervasculares alternas e diminutas (E) e placa de perfuração simples com deposição de substância orgânica $(\mathbf{F})$. 
Morfotipo: 17

Família: MELIACEAE

Espécie: Trichilia cf pallida

Amostra: RMT-1/2154-1
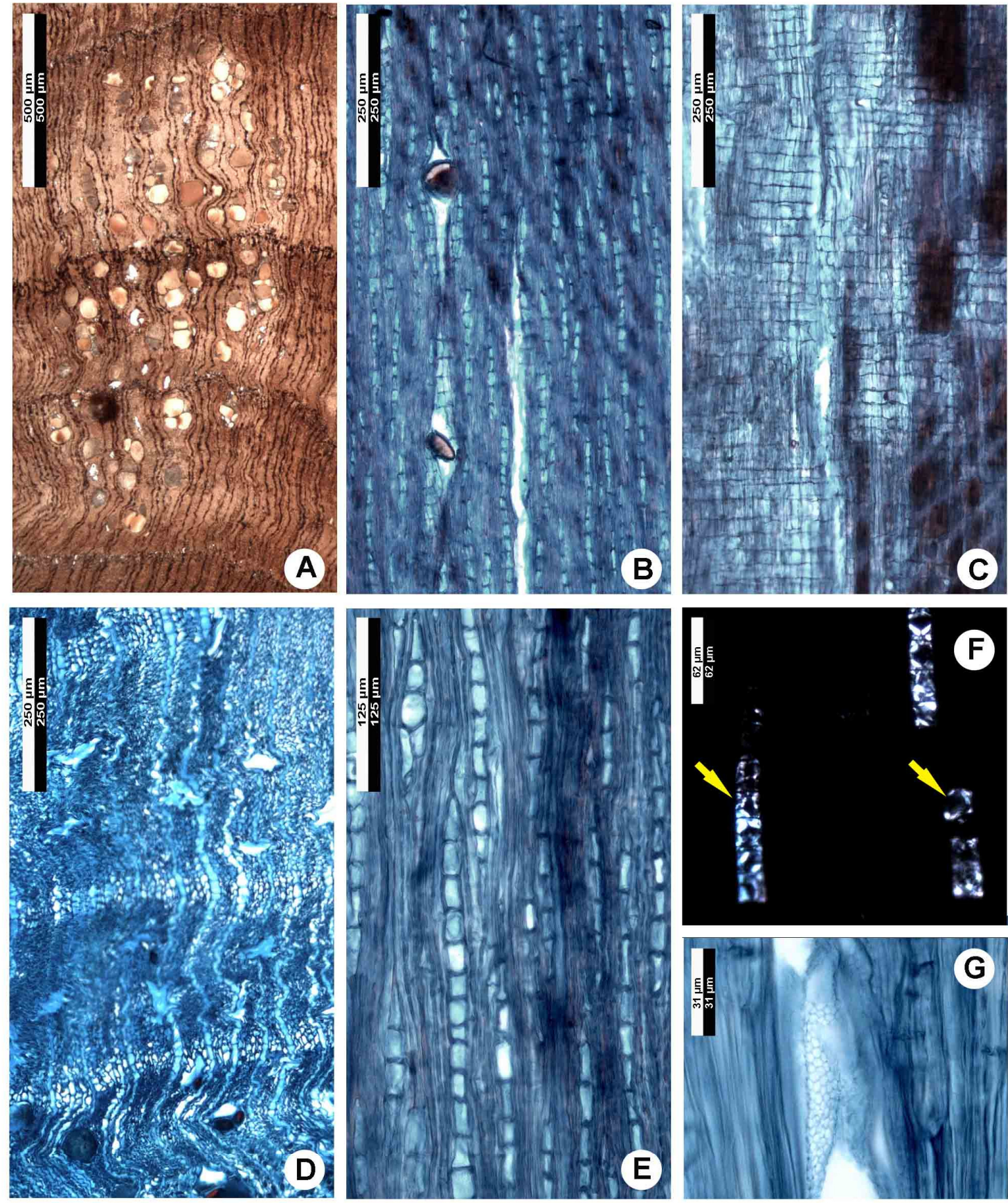

Legenda: anatomia de lenho fóssil. A e D, plano transversal; B e $\mathbf{E}$, plano tangencial; $\mathbf{C}$ e $\mathbf{F}$, plano radial. Detalhe de células cristalíferas subdivididas do parênquima axial em luz polarizada, onde só o contorno dos dos cristais presrvaram a birrefringência $(\mathbf{F})$, e pontoações intervasculares alterna com aréolas degradadas $(\mathbf{G})$. 
Morfotipo: 18

Família: MORACEAE

Espécie: Ficus $s p$

Amostra: RMT-1/ 872
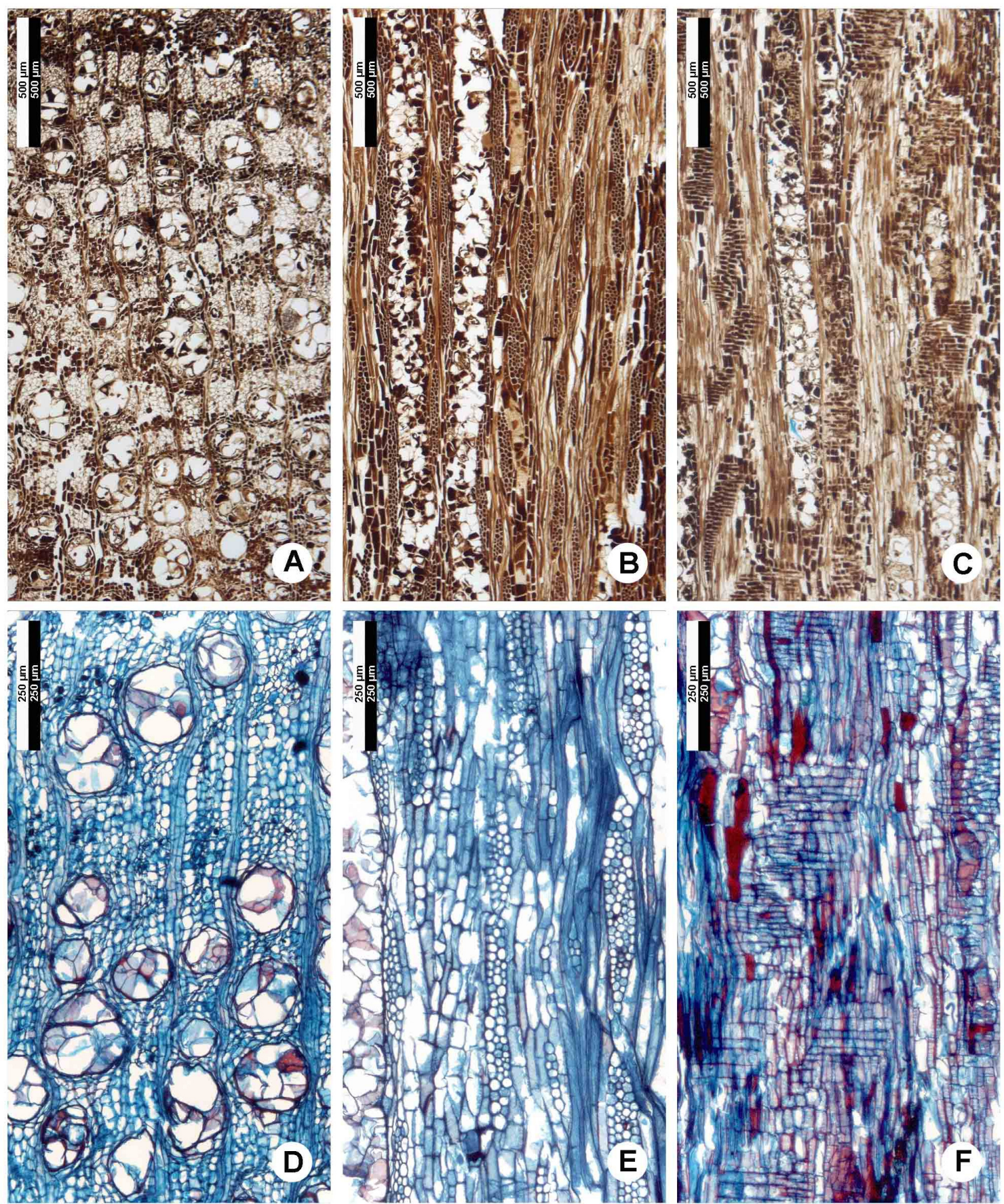

Legenda: anatomia de lenho fóssil. A e D, plano transversal; B e E, plano tangencial; C e F, plano radial. 
Apêndice 3

Morfotipo: 19

Família: MORACEAE

Espécie: Ficus / Sorocea $s p$

Amostra: RMT-1/ 1316
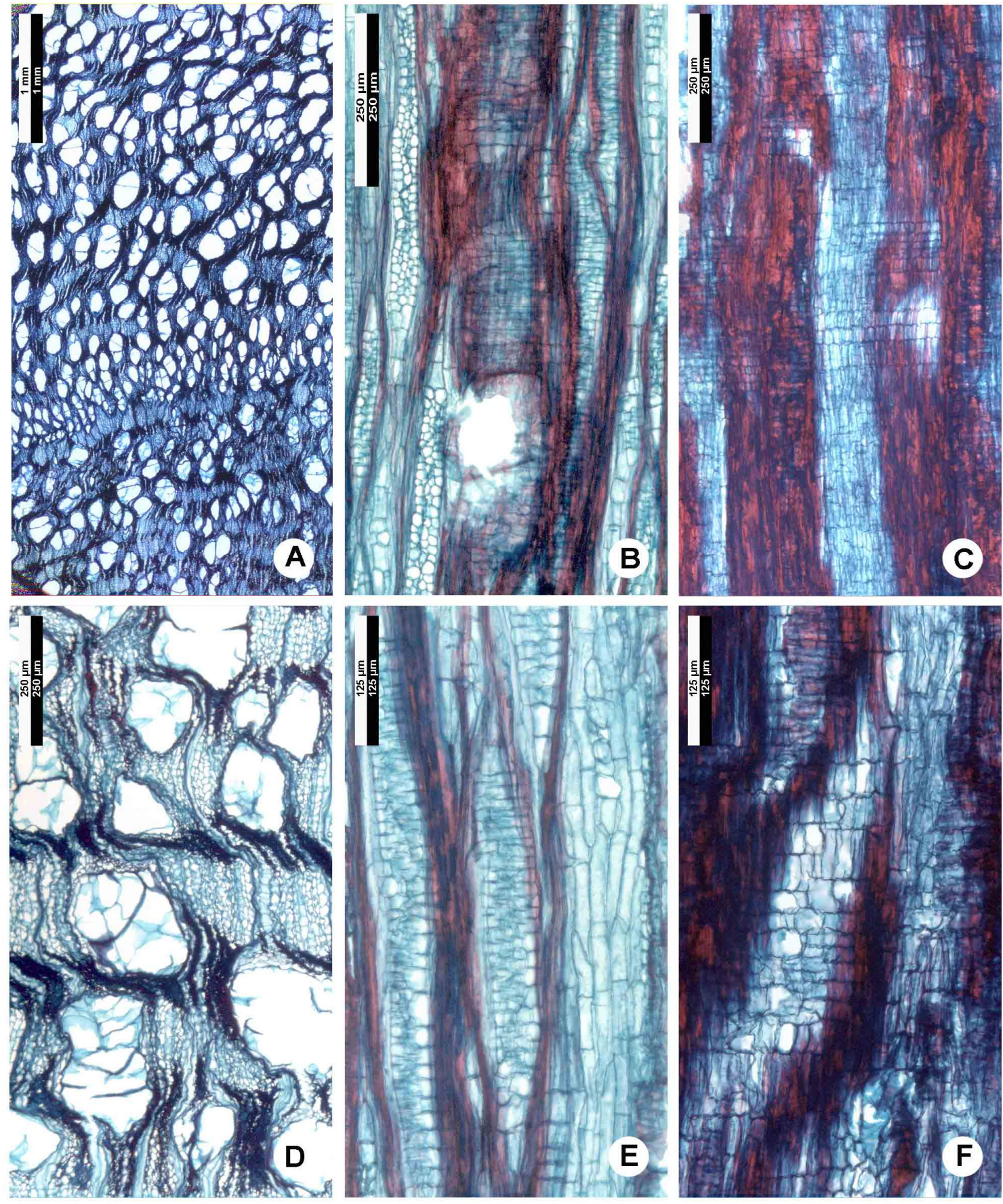

Legenda: anatomia de lenho fóssil. A e D, plano transversal; B e E, plano tangencial; $\mathbf{C}$ e $\mathbf{F}$, plano radial. 
Morfotipo: 20

Família: MYRSINACEAE

Espécie: Myrsine sp

Amostra: RMT-1/ 2165
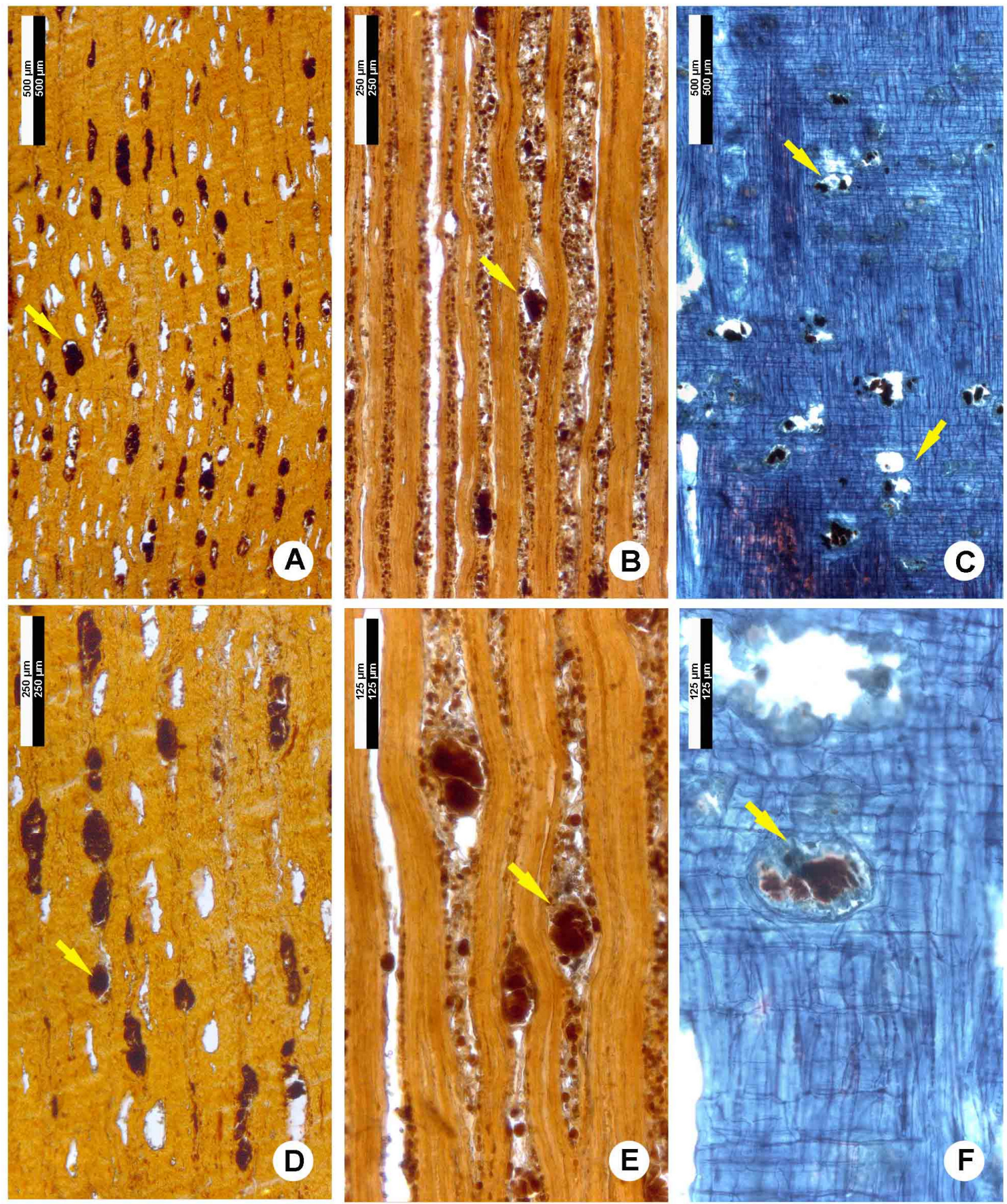

Legenda: anatomia de lenho fóssil. A e D, plano transversal; $\mathbf{B}$ e $\mathbf{E}$, plano tangencial; $\mathbf{C}$ e $\mathbf{F}$, plano radial. Detalhe da célula oleífera entre células procumbentes do corpo do raio em matriz colapsada.. 
Morfotipo: 21

Família: MYRTACEAE

Espécie: Myrcia sp / Calyptranthes concina

Amostra: RMT-1/ 2185
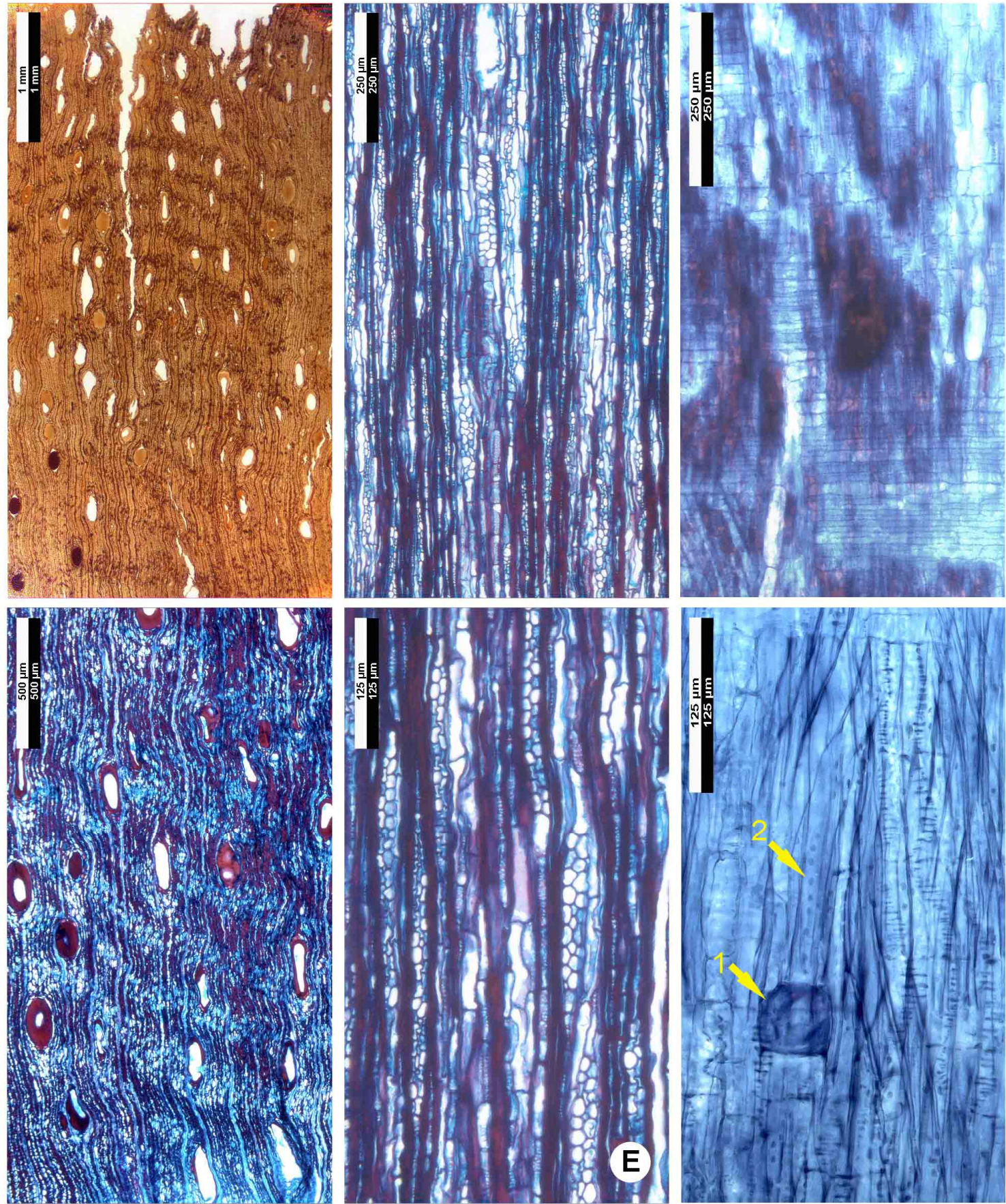

Legenda: anatomia de lenho fóssil. A e D, plano transversal; $\mathbf{B}$ e $\mathbf{E}$, plano tangencial; $\mathbf{C}$ e $\mathbf{F}$, plano radial. Detalhe de cristal grande em células subdivididas de parênquima axial (F1) entre traqueídes (F2). 
Apêndice 3

Morfotipo: 22

Família: MYRTACEAE

Espécie: Myrcia sp / Psidium sp / Calyptranthes concina

Amostra: RMT-1/1962
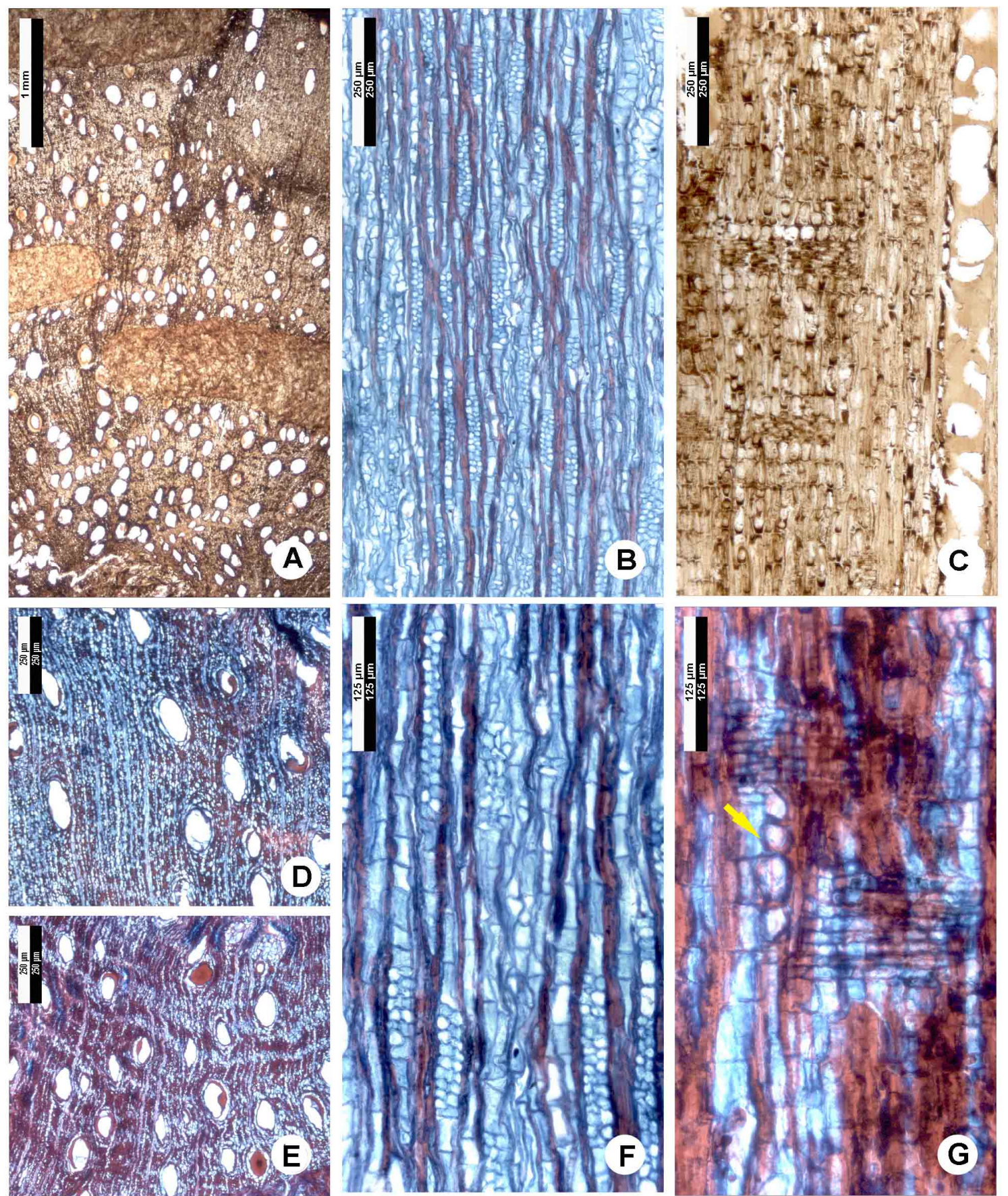

Legenda: anatomia de lenho fóssil. A, D e E, plano transversal; B e F, plano tangencial; $\mathbf{C}$ e $\mathbf{G}$, plano radial. Detalhe de células com cristais grandes $(\mathbf{G})$. 
Morfotipo: 23

Família: SAPINDACEAE

Espécie: Allophylus / Cupania sp

Amostra: RMT-1/ 2034
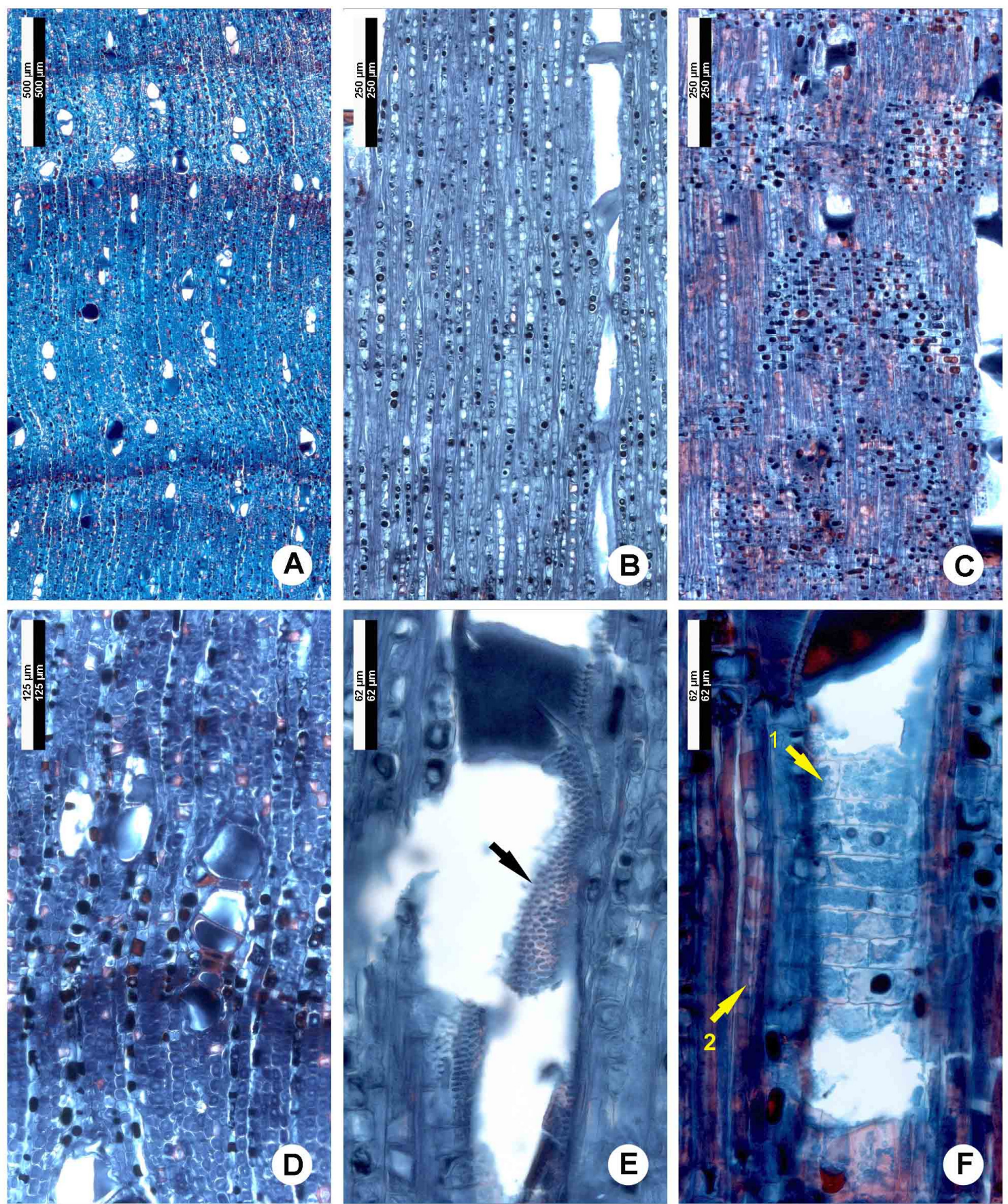

Legenda: anatomia de lenho fóssil. A e D, plano transversal; B e E, plano tangencial; $\mathbf{C}$ e $\mathbf{F}$, plano radial. Detalhe de pontoações intervasculares pequenas $(\mathbf{E})$, pontoação radiovascular areolada $(\mathbf{F} 1)$ e cristais em células subdivididas do parênquima axial (F2). 
Apêndice 3

Morfotipo: 24

Família: SAPINDACEAE

Espécie: Serjania $s p$

Amostra: RMT-1/ 2053
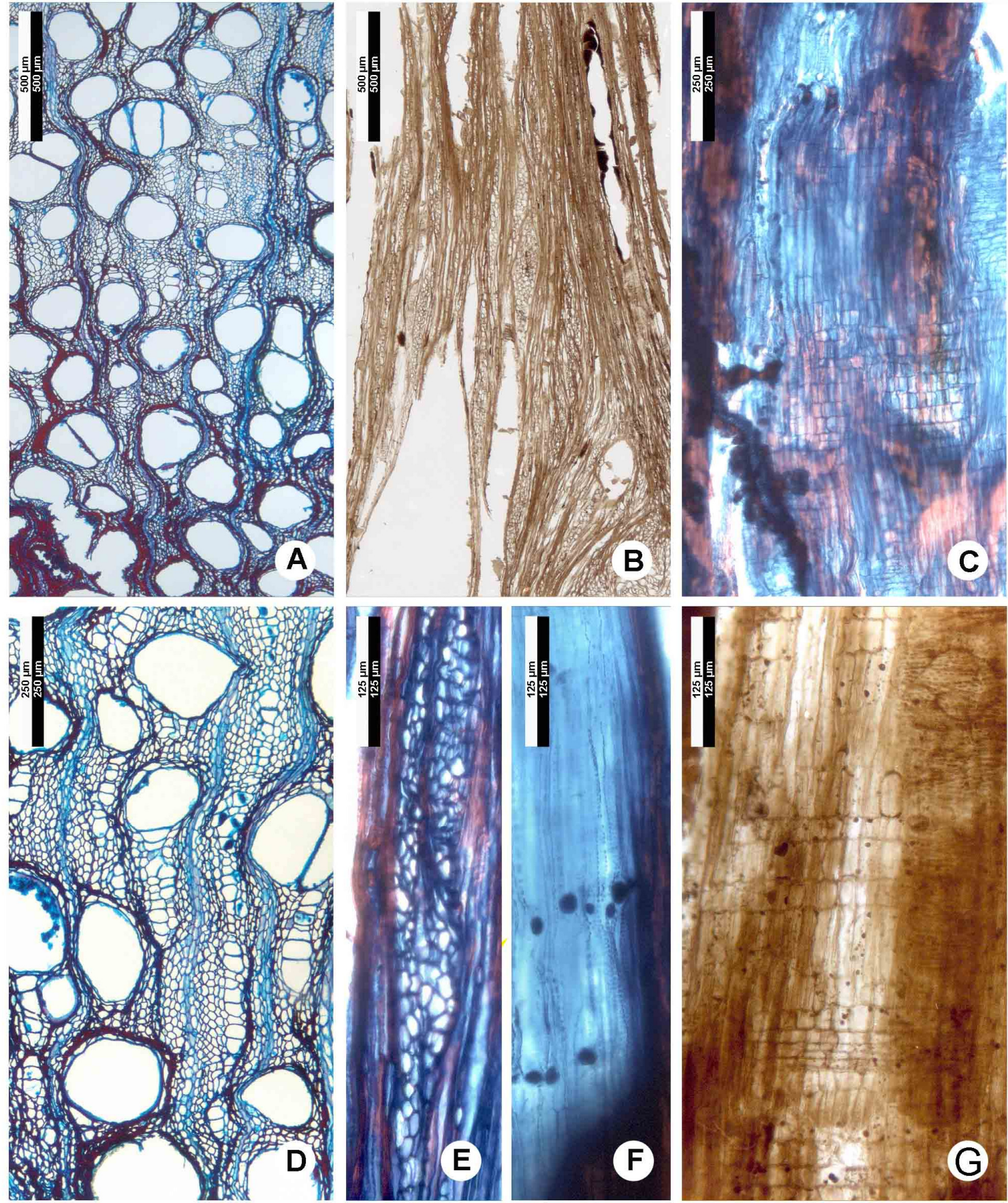

Legenda: anatomia de lenho fóssil. A e D, plano transversal; $\mathbf{B}$ e $\mathbf{E}$, plano tangencial; $\mathbf{C}, \mathbf{F}$ e $\mathbf{G}$, plano radial. Em detalhe, placas de perfuação simples $(\mathbf{F})$. 
Morfotipo: 25

Família: SAPOTACEAE

Espécie: Chrysophyllum $s p$

Amostra: RMT-1/ 2098
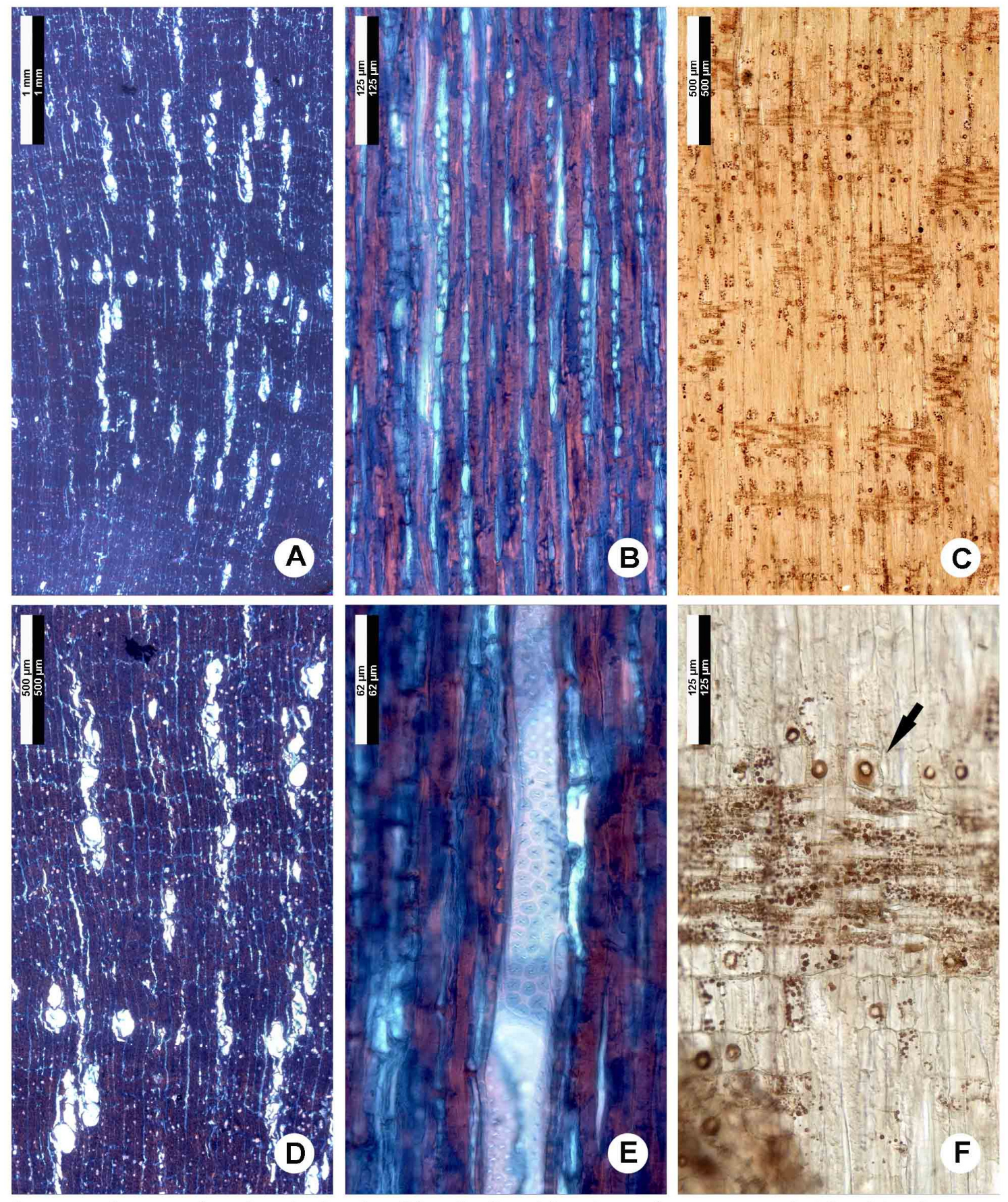

Legenda: anatomia de lenho fóssil. A e D, plano transversal; $\mathbf{B}$ e E, plano tangencial; $\mathbf{C}$ e F, plano radial. Detalhe de pontoação intervasculares alterna $(E)$ e corpos silicosos em células radiais $(\mathbf{F})$. 
Apêndice 3

Morfotipo: 26

Família: VOCHYSIACEAE

Espécie: Qualea sp

Amostra: RMT-1/ 962
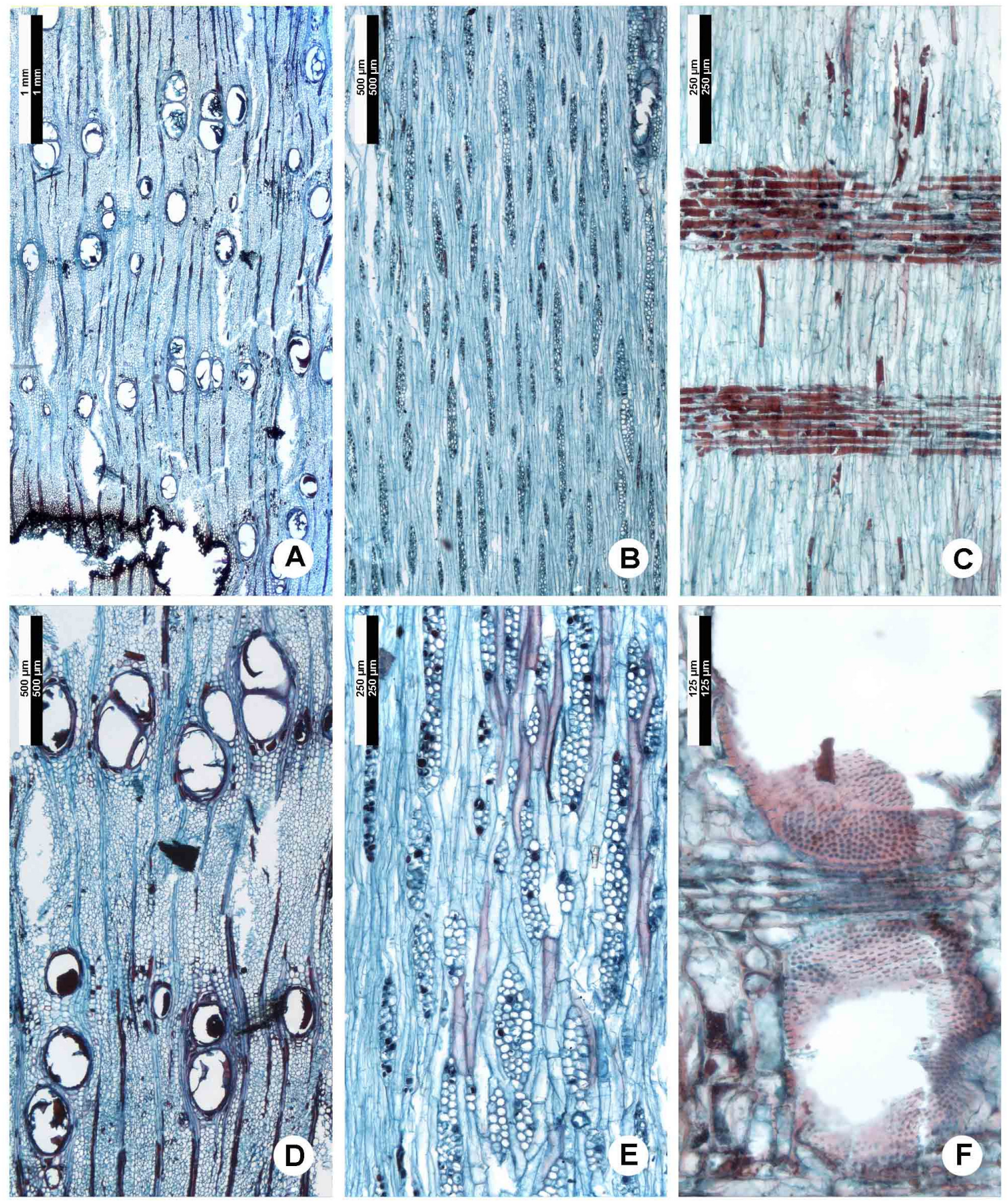

Legenda: anatomia de lenho fóssil. A e D, plano transversal; B e E, plano tangencial; $\mathbf{C}$ e $\mathbf{F}$, plano radial. 
Morfotipo: 27

Família: VOCHYSIACEAE

Espécie: Salvertia convalleriodora

Amostra: RMT-1/ 2028
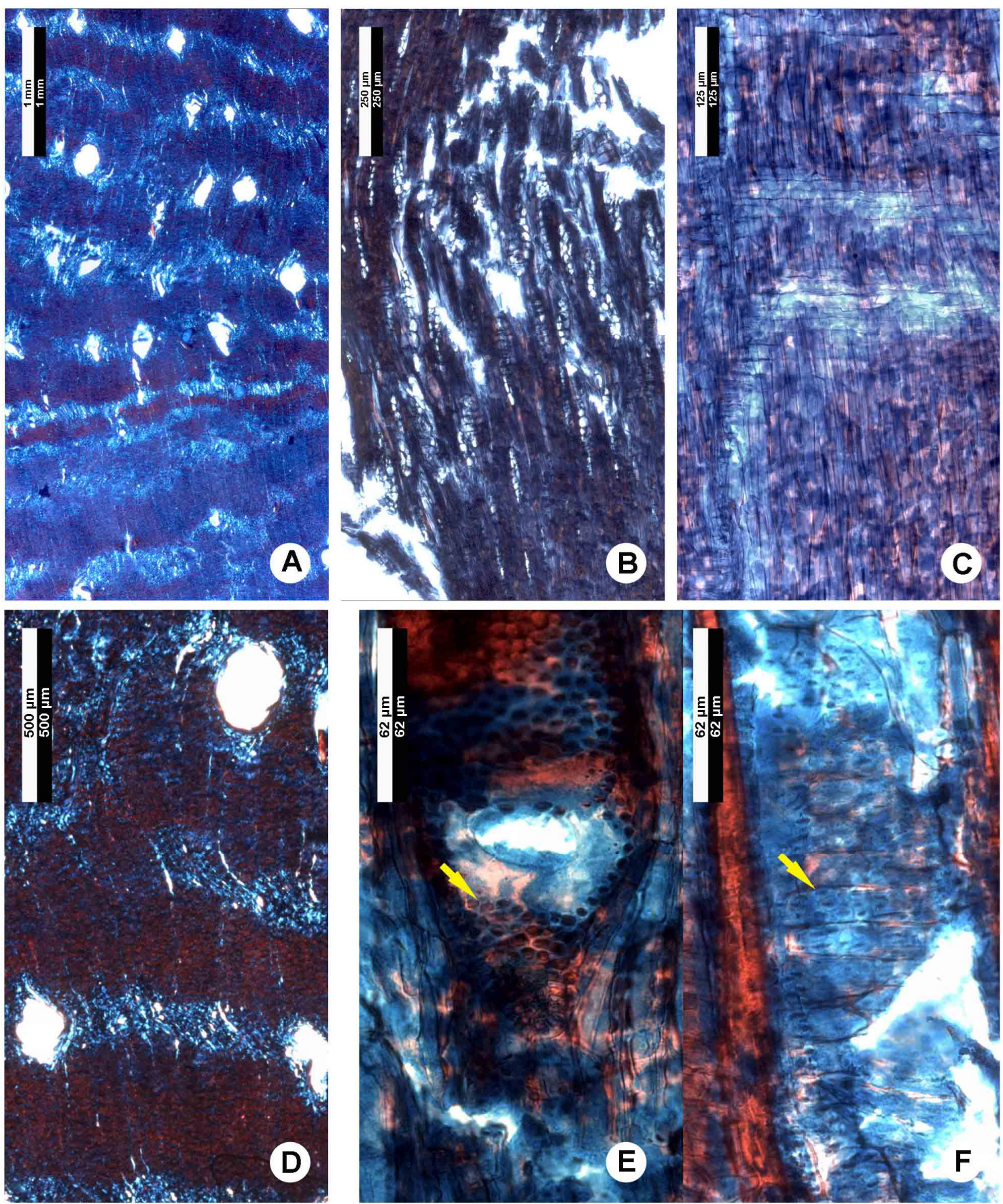

Legenda: anatomia de lenho fóssil. A e D, plano transversal; $\mathbf{B}$ e $\mathbf{E}$, plano tangencial; C e F, plano radial. Detalhe da pontoação intervascular alterna de tamanho mediano abaixo da placa de perfuração simples $(\mathbf{E})$ e da pontoação radivascular areolada(F). 